\title{
ESQUEMA DE DIAGNÓSTICO AUXILIADO POR COMPUTADOR PARA DETECÇÃO DE AGRUPAMENTOS DE MICROCALCIFICAÇÕES POR PROCESSAMENTO DE IMAGENS MAMOGRÁFICAS
}

FÁTIMA DE LOURDES DOS SANTOS NUNES

Dissertação apresentada à Escola de Engenharia de São Carlos, da Universidade de São Paulo, como parte dos requisitos para obtenção do Título de Mestre em Engenharia Elétrica.

ORIENTADOR: Prof. Dr. Homero Schiabel

São Carlos

1997 
Aos meus pais,

que me deram a vida.

Ao Luís Henrique,

que me ensinou a gostar ainda mais de viver. 


\section{AGRADECIMENTOS}

Ao Prof. Dr. Homero Schiabel, pela competente orientação, apoio e estímulo, sem os quais essa pesquisa não se realizaria.

À minha família, pelo apoio, incentivo e compreensão nos momentos de ausência.

À minha mãe, pela dedicação e disponibilidade em ajudar em todos os momentos.

Ao Luís Henrique, meu noivo, pelo estímulo e incansável paciência.

Aos amigos do Pólo Computacional da Unesp de Bauru, e, em especial ao Sr. Mitsuo Katsuki, pelo apoio e concessão de afastamento parcial das atividades profissionais.

Aos amigos Ricardo Luiz Villela e Ricardo José Ferrari, pelas árduas discussões sobre microcalcificações e processamento de imagens; e pelo apoio na preparação das imagens e confecção dos algoritmos.

Aos colegas do Laboratório de Análise e Digitalização de Imagens (LADI) do Departamento de Engenharia Elétrica, pelas discussões, amizade e companheirismo demonstrados durante a pesquisa.

Às bibliotecárias da Biblioteca Central da EESC, do ICMSC e Instituto de Física de São Carlos, pelo auxílio durante a coleta de material para a revisão bibliográfica.

À Rosane Schmidt, secretária da pós-graduação do Departamento de Engenharia Elétrica, pela simpatia e disponibilidade na resolução das tarefas burocráticas.

À amiga Kátia Lívia Zambom, pelas inúmeras demonstrações de amizade, em São Carlos e nas estradas.

Às amigas Mônica e Eloísa, pela alegria e pelo apoio na permanência em São Carlos.

Aos professores do Departamento de Computação da Unesp-Bauru, especialmente Antônio Carlos Sementille, João E. Perea M. Martins e José Remo Ferreira Brega, pelo incentivo no início do Mestrado e pelo empréstimo de materiais durante o curso.

A todas as pessoas que, mesmo sem ser citadas nominalmente, me apoiaram e incentivaram o desenvolvimento e a conclusão deste trabalho.

Finalmente, a Deus, pois sem Ele nenhuma das pessoas acima existiria. 


\section{RESUMO}

O câncer de mama é hoje uma das principais causas de mortalidade de mulheres em todo o mundo. Porém, a sua detecção no estágio inicial de desenvolvimento aumenta consideravelmente as chances de cura. Exatamente por isso estão sendo desenvolvidos vários tipos de sistemas computacionais baseados em processamento de imagens em centros de pesquisas no mundo todo, a fim de auxiliar o radiologista na precisão do seu diagnóstico. A pesquisa aqui apresentada se insere nesse contexto e consistiu no desenvolvimento de um sistema computacional para detectar uma das estruturas que podem ser indício da presença do câncer de mama: os agrupamentos ("clusters") de microcalcificações. O sistema aqui apresentado tem como fonte de dados mamogramas digitalizados, nos quais são aplicadas técnicas de processamento para extrair as regiões de interesse e detectar os possíveis "clusters" existentes. Os resultados dos testes realizados mostraram que o sistema desenvolvido apresentou uma eficiência de 94\% na identificação correta de "clusters". 


\begin{abstract}
Breast cancer is one of the main causes of women death all over the world. However, early detection of the disease increases greatly the possibility of cure. Therefore, several types of computer systems based on image processing are being developed by many research groups in order to aid the radiologist in the accuracy of the diagnosis. The work presented here is inserted in this context corresponding to the development of a computer system designed to detect microcalcifications clusters - structures which can be a strong indicative of breast cancer. This system database is digitized mammograms, to which image processing techniques are applied in order to detect regions of interest and the possible clusters. The results from the tests have shown an efficacy of $94 \%$ of the system in clusters correct identification.
\end{abstract}




\section{ÍNDICE}

ÍNDICE DE FIGURAS.................................................................. V

ÍNDICE DE TABELAS ..................................................................XIII

1 INTRODUÇÃO .................................................................... 1

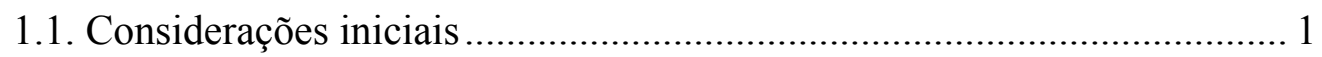

1.2. Objetivos e delineamento das etapas da pesquisa ................................. 3

1.3. Disposição do trabalho .......................................................................... 4

2 MAMOGRAFIA: BREVE HISTÓRICO E PRINCIPAIS

CARACTERÍSTICAS ................................................................ 6

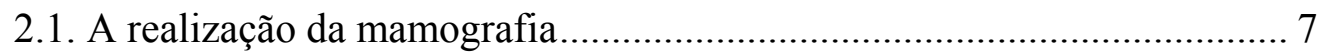

2.2. Dificuldades encontradas para a visualização de estruturas importantes.. 8

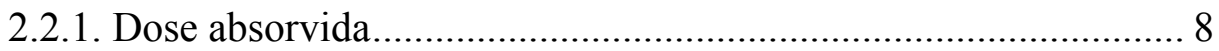

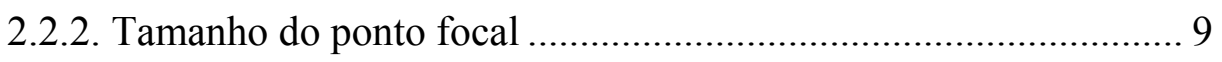

2.2.3. O efeito Heel .............................................................................. 10

2.2.4. Radiação espalhada.................................................................... 10

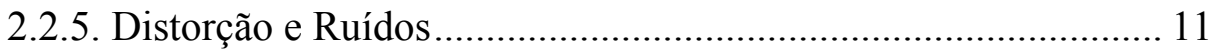

2.2.6. Sobreposição de objetos.......................................................... 12

2.2.7. Contraste e resolução da digitalização........................................ 12

2.2.8. Algumas soluções propostas .................................................... 13

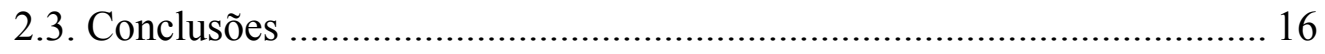

3 TÉCNICAS DE PROCESSAMENTO DE IMAGENS ............ 17

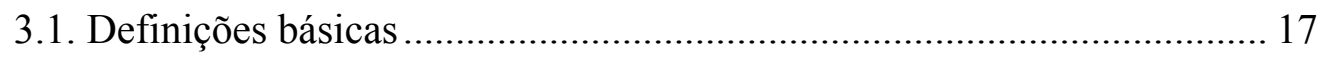

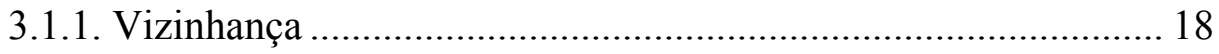

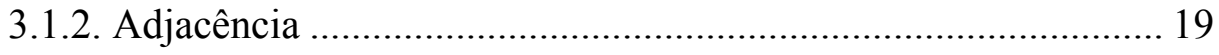

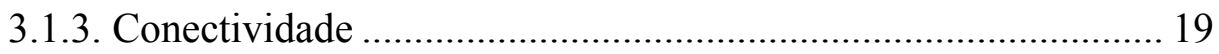

3.1.4. Distância entre pixels.............................................................. 20

3.2. Processamento de Baixo Nível........................................................... 20 


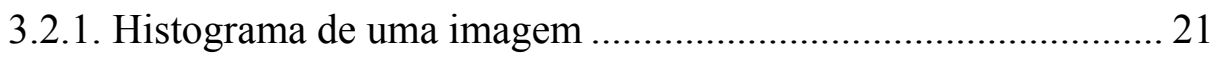

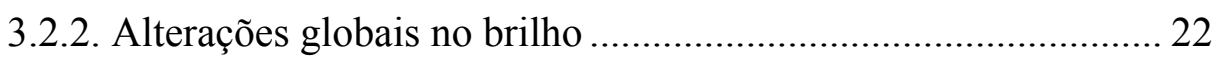

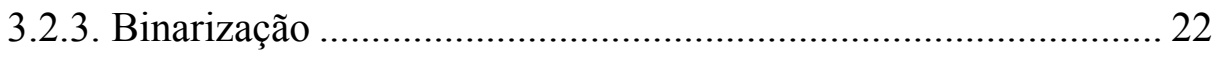

3.2.4. Quantização do Histograma ......................................................... 22

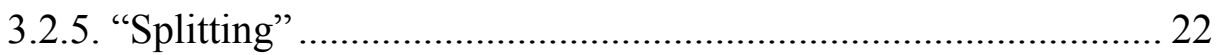

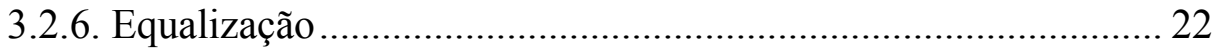

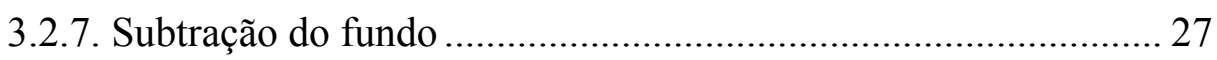

3.2.8. Suavização ........................................................................... 28

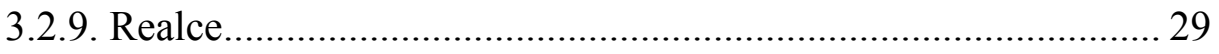

3.3. Processamento de Nível Médio - Segmentação ..................................... 30

3.3.1. Detecção de pontos isolados ...................................................... 31

3.3.2. Representação de estruturas geométricas bidimensionais .......... 35

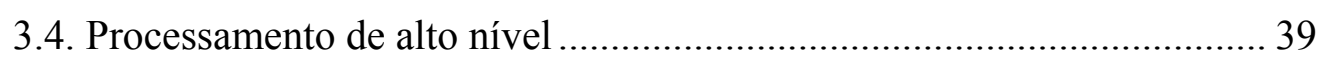

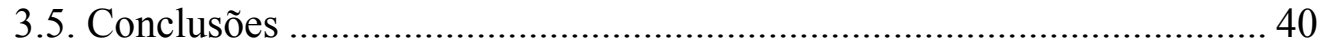

4 PROCESSAMENTO DE IMAGENS PARA DETECÇÃO DE MICROCALCIFICAÇÕES......................................................41

4.1. Dificuldades na detecção e processamento de imagens de microcalcificações mamárias............................................................ 42

4.2. Classificação de calcificações em relação aos tipos de tumores

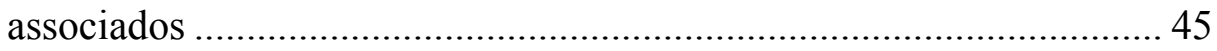

4.3. Técnicas para realce de contraste em imagens radiográficas ............... 50

4.4. Técnicas de segmentação em mamogramas para detecção de

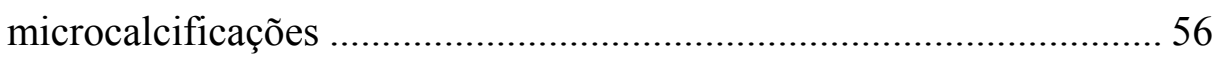

4.5. Esquemas assistidos por computador para detecção de microcalcificações mamárias 59 
5 DETECÇÃO DE AGRUPAMENTOS DE MICROCALCIFICAÇÕES EM DIAGNÓSTICO ASSISTIDO POR COMPUTADOR (CAD) ................................................61

5.1. Uma técnica de detecção de "clusters" .................................................. 62

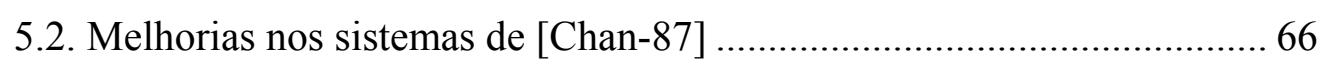

5.3. Diminuição da taxa de detecção de sinais falso-positivos ..................... 70

5.4. Esquema automatizado desenvolvido na Universidade de Chicago ....... 73

5.4.1. Transformação área-ponto recursiva ........................................ 76

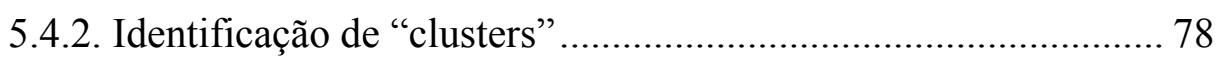

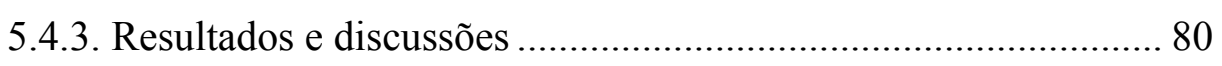

5.5. Pesquisa do MITRE Corporation - Burlington (EUA) ......................... 82

5.6. Detecção de microcalcificações baseada na análise de aspectos e na

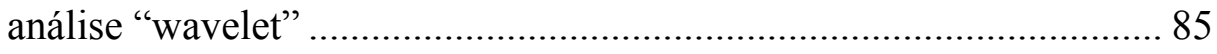

5.7. Simulação de microcalcificações agrupadas ......................................... 87

5.8. Fatores que influenciam a performance medida em um esquema de

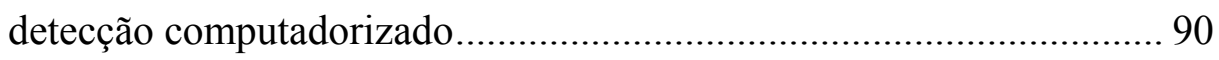

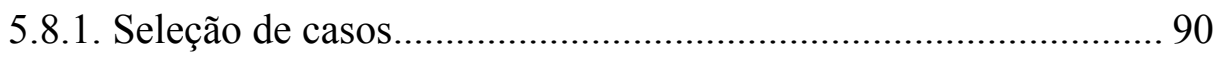

5.8.2. Método usado para quantificar os resultados............................ 90

5.8.3. Método de avaliação da performance ........................................ 91

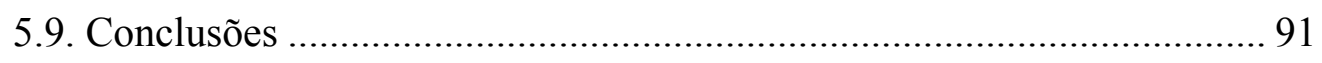

6 SISTEMA DESENVOLVIDO PARA DETECÇÃO DE

“CLUSTERS"..........................................................................93

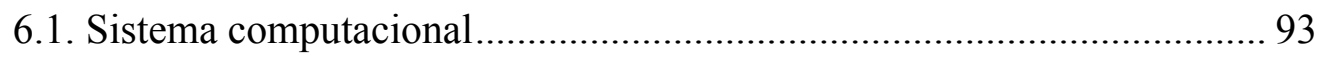

6.1.1. Detecção das regiões de interesse .............................................. 94

6.1.2. Segmentação ....................................................................... 100

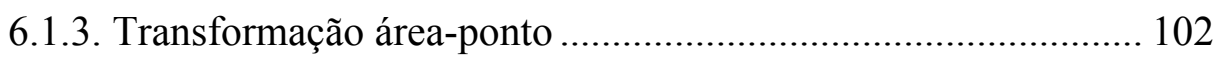

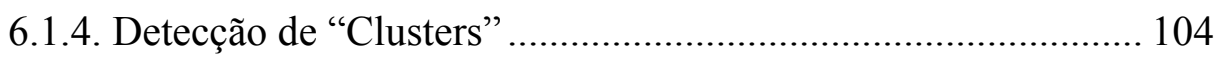

6.1.5. Visão geral do sistema computacional desenvolvido ............... 113

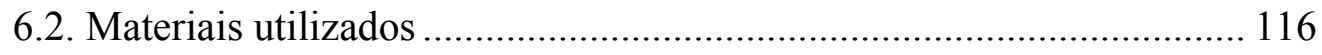


7 RESULTADOS E DISCUSSÕES............................................ 120

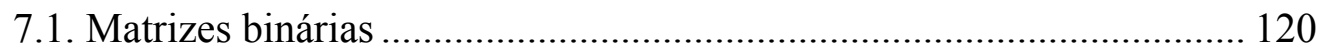

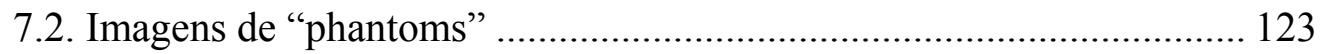

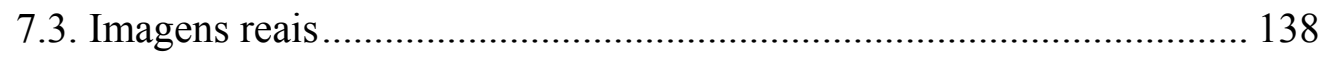

7.3.1. Primeiro conjunto de imagens .................................................. 138

7.3.2. Segundo conjunto de imagens .................................................. 173

7.4. Variação na deteç̧ão das regiões de interesse ....................................... 180

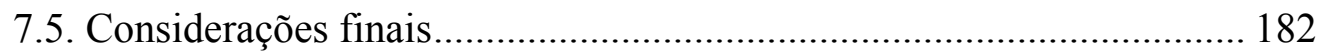

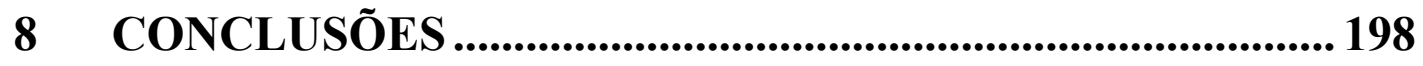

9 REFERÊNCIAS BIBLIOGRÁFICAS...................................... 203 


\section{ÍNDICE DE FIGURAS}

Figura 2-1 - Representação esquemática do sistema proposto em

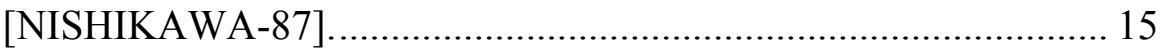

Figura 2-2 - “Scanning equalisation radiograph” (PLEWES-95)....................... 16

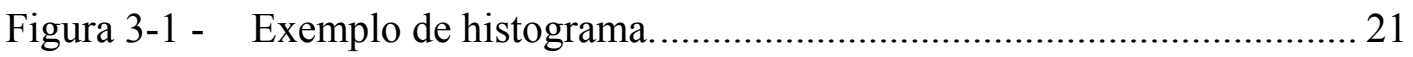

Figura 3-2 - Exemplo de alteração no brilho da imagem. a) histograma antes da alteração no brilho; b) histograma após a alteração no brilho. ........ 23

Figura 3-3 - Exemplo de binarização. a) histograma antes da binarização e b) histograma após a binarização com valor de limiar $=2$.

Figura 3-4 - Exemplo de quantização. a) histograma antes da quantização e b) histograma após a quantização. 25

Figura 3-5 - Exemplo de "splitting". a) histograma antes da técnica de "splitting" e b) histograma após aplicação da técnica de "splitting". 26

Figura 3-6 - Exemplo de equalização. a) histograma antes da equalização e b) histograma após a equalização

Figura 3-7 - Exemplo genérico de uma máscara 3 x 3 31

Figura 3-8 - Máscara que pode ser usada para detecção de pontos isolados em imagens com fundo constante. 31

Figura 3-9 - Máscaras utilizadas para a detecção de linhas. 32

Figura 3-10 - Região e máscaras para detecção de bordas através de operadores gradientes. 33

Figura 3-11 - Exemplo de aplicação da técnica de "crescimento de região". 35

Figura 3-12 - Representação da borda de uma imagem através de aproximação poligonal 36

Figura 3-13 - Exemplo de descrição de fronteira através de inscrição de polígono convexo.

Figura 3-14 - a) Código de Cadeia de 4 direções. b) Código de Cadeia de 8 direções. 37

Figura 3-15 - a) Borda com sobreposição da grade a ser utilizada. b) Resultado do "gradeamento". c) Código de Cadeia de 4 direções. d) Código de Cadeia de 8 direções. 38 
Figura 4-1 - Influência do tamanho do pixel na precisão da detecção ([CHAN-94]).

Figura 4-2 - Influência da intensidade do pixel na precisão da detecção ([CHAN-94]) 46

Figura 4-3 - Classificação de microcalcificações de acordo com suas formas ([LE GAL-84]). 48

Figura 4-4 - Conjunto básico de formas utilizadas para medidas com a finalidade de classificação ([SHEN-94]).

Figura 4-5 - Demonstração da definição de centro e região circundante ([DHAWAN-86]) 51

Figura 4-6 - Esquema de um filtro estruturado em árvore ([QIAN-94]). 55

Figura 5-1 - Esquema geral da detecção computadorizada de microcalcificações em mamogramas ([CHAN-87]). 64

Figura 5-2 - "Matched filter" usado para realce do sinal 65

Figura 5-3 - Diagrama esquematizado do processamento automatizado para identificação de microcalcificações ([CHAN-88a]). 66

Figura 5-4 - Filtros espaciais usados na aproximação da diferença de imagem ([CHAN-88b]). O "matched filter" tem um núcleo com tamanho de $3 \times 3$ pixels. O filtro "box-rim" tem a largura da área externa de 9 pixels e uma largura interna de 5 pixels. Os gráficos da coluna da esquerda mostram a forma do filtro no plano imagem. Os fatores de peso ao longo da linha no centro dos núcleos dos filtros são mostrados nos gráficos da coluna da direita. 68

Figura 5-5 - Esquema para detecção automatizada de agrupamentos de microcalcificações ([NISHIKAWA-92]) 74

Figura 5-6 - "Matched filter" usado para realce do sinal ([NISHIKAWA-92]). . 75

Figura 5-7 - Elementos estruturados usados na erosão morfológica ([NISHIKAWA-92]). 75

Figura 5-8 - Uma representação da "transformação recursiva área-ponto" ([NISHIKAWA-93a]). 77

Figura 5-9 - Uma representação da "transformação recursiva área-ponto" para um sinal em formato de "Y". 78 
Figura 5-10 - Representação do agrupamento de microcalcificações. Se três ou mais sinais estão presentes no núcleo do "cluster", que é passado sobre a imagem de entrada, então, todos os sinais são passados para a imagem de saída ([NISHIKAWA-93a])

Figura 5-11 - Efeito do tamanho do núcleo usado para o processo de agrupamento de microcalcificações no número médio de "clusters" falsos detectados por imagem ([NISHIKAWA-93a]) ............................. 80

Figura 5-12 - Esquema do sistema computadorizado ([DAVIES-90]) .................. 86

Figura 5-13 - Exemplo de uma curva FROC que pode ser utilizada para medir a performance de um esquema computadorizado de detecções ([NISHIKAWA-93b]). 92

Figura 6-1 - Esquema do sistema computacional desenvolvido para detecção de "clusters" de microcalcificações. 93

Figura 6-2 - Esquema dos passos executados para identificação das regiões de interesse. 96

Figura 6-3 - Tela inicial da identificação das regiões de interesse. 97

Figura 6-4 - Tela de gravação da região de interesse. 98

Figura 6-5 - a) Mamograma digitalizado e b) regiões de interesse identificadas e armazenadas. 99

Figura 6-6 - Esquema utilizado para segmentação das microcalcificações. 100

Figura 6-7 - Tela inicial do procedimento de segmentação 101

Figura 6-8 - Processo de segmentação. a) imagem original; b) imagem segmentada 102

Figura 6-9 - Tela inicial da transformação área-ponto. 103

Figura 6-10 - Efeito da transformação área-ponto: a) imagem segmentada; b) imagem resultante após transformação área-ponto. 103

Figura 6-11 - Tela com parâmetros iniciais para "mascaramento". 105

Figura 6-12- Tela com parâmetros iniciais para detecção de "clusters" através do método de "crescimento de região". 107

Figura 6-13 - Mamograma digitalizado. 108

Figura 6-14 - Regiões de interesse extraídas do mamograma da Figura 6-13.... 109

Figura 6-15 - Regiões de interesse após segmentação. 110 
Figura 6-16 - Regiões de interesse após transformação área-ponto.

Figura 6-17 - Regiões de interesse após a detecção de "clusters" pelo método de "mascaramento"

Figura 6-18 - Detecção de "clusters" pelo método de "crescimento de região".. 113

Figura 6-19 - Visão geral do sistema computacional desenvolvido. 114

Figura 6-20 - Disposição das simulações do primeiro "phantom” utilizado. 116

Figura 6-21 - Imagem digitalizada do primeiro "phantom": sinais de interesse estão na primeira coluna da esquerda.

Figura 6-22 - Imagem digitalizada do segundo "phantom". 118

Figura 6-23 - Exemplos de mamogramas reais utilizados nos testes. 119

Figura 7-1 - Exemplo de matriz binária utilizada nos testes. 121

Figura 7-2 - Resultados obtidos no processamento de matrizes binárias transformação área-ponto recursiva. a) Máscara 3x3, salto de linha 2, salto de coluna 2. b) Máscara 5x5, salto de linha 2, salto de coluna 2 .

Figura 7-3 - a) Imagem de "phantom"; b) regiões de interesse. 124

Figura 7-4 - Efeito do desvio padrão da segmentação nos resultados dos diagnósticos de imagens de "phantoms" processadas. 126

Figura 7-5 - Exemplo de imagem de "phantom" com variação de intensidade. 128

Figura 7-6 - Exemplos de imagem de trechos de "phantom" com contraste baixo. 129

Figura 7-7 - Influência da resolução da digitalização e da sensibilidade do sistema na eliminação de ruídos. a) imagem original; b) imagem segmentada com valor de desvio padrão 3,$0 ;$ c) imagem segmentada com valor de desvio padrão 3,5 ; d) imagem segmentada com valor de desvio padrão 4,0 . 131

Figura 7-8 - Efeito da transformação área-ponto em imagens de "phantoms" imagens originais.

Figura 7-9 - Efeito da transformação área -ponto em imagens de "phantoms" imagens segmentadas. 
Figura 7-10 - Efeito da transformação área-ponto em imagens de "phantoms imagens resultantes após transformação área-ponto. Alguns sinais resultaram em mais de um pixel

Figura 7-11 - Processamento completo de uma região de interesse de uma imagem de "phantom". a) região de interesse, b) região de interesse após segmentação, c) região de interesse após transformação área-ponto e d) região de interesse após a detecção de "clusters"

Figura 7-12 - Exemplos de imagem de mamograma com variação na distribuição de intensidade. 142

Figura 7-13 - Exemplos de imagens de mamogramas com objetos que atrapalham a identificação das regiões de interesse. a) identificação do filme na parte inferior esquerda; b) faixa branca na parte lateral direita; c) objeto na parte inferior. 144

Figura 7-14 - Relação entre tamanho da região de interesse e tempo de processamento para detecção de "clusters". 145

Figura 7-15 - Processamento de regiões de interesse com tamanhos diferentes e tempos de execução computacional dispendidos. Imagem com tamanho 250x250 - tempo de processamento: 122 . 146

Figura 7-16 - Processamento de regiões de interesse com tamanhos diferentes e tempos de execução computacional dispendidos. Imagem com tamanho 300x300 - tempo de processamento: 172. 147

Figura 7-17 - Processamento de regiões de interesse com tamanhos diferentes e tempos de execução computacional dispendidos. c) imagem com tamanho 450x450 - tempo de processamento: 287.

Figura 7-18 - Processamento de regiões de interesse com tamanhos diferentes e tempos de execução computacional dispendidos. Imagem com tamanho 500x500 -tempo de processamento: 474

Figura 7-19 - Exemplos da transformação área-ponto em regiões de interesse de mamogramas. São mostradas imagens segmentadas e as mesmas imagens após a transformação área ponto 155

Figura 7-20 - Quantidade de "clusters" detectados pelos dois métodos utilizados ... 
Figura 7-21 - Detecção de "clusters" em mamograma através dos dois métodos de agrupamento de sinais - mamograma original

Figura 7-22 - Detecção de "clusters" em mamograma através dos dois métodos de agrupamento de sinais -regiões de interesse selecionadas. 158

Figura 7-23 - Detecção de "clusters" em mamograma através dos dois métodos de agrupamento de sinais -regiões de interesse após segmentação... 159

Figura 7-24 - Detecção de "clusters" em mamograma através dos dois métodos de agrupamento de sinais - regiões de interesse após transformação área-ponto. 160

Figura 7-25 - Detecção de "clusters" em mamograma através dos dois métodos de agrupamento de sinais - regiões de interesse após detecção de "clusters" através do método de "mascaramento".

Figura 7-26 - Detecção de "clusters" em mamograma através dos dois métodos de agrupamento de sinais - regiões de interesse após detecção de "clusters" através do método de "crescimento de região". 162

Figura 7-27 - Detecção de "clusters" em mamograma através dos dois métodos de agrupamento de sinais -mamograma original.

Figura 7-28 - Detecção de "clusters" em mamograma através dos dois métodos de agrupamento de sinais -regiões de interesse selecionadas. 163

Figura 7-29 - Detecção de "clusters" em mamograma através dos dois métodos de agrupamento de sinais -regiões de interesse após segmentação.... 164

Figura 7-30 - Detecção de "clusters" em mamograma através dos dois métodos de agrupamento de sinais - regiões de interesse após transformação área-ponto. 165

Figura 7-31 - Detecção de "clusters" em mamograma através dos dois métodos de agrupamento de sinais - regiões de interesse após detecção de "clusters" através do método de "mascaramento". 165

Figura 7-32 - Detecção de "clusters" em mamograma através dos dois métodos de agrupamento de sinais - regiões de interesse após detecção de "clusters" através do método de "crescimento de região". 166

Figura 7-33 - Detecção de "clusters" em mamograma através dos dois métodos de agrupamento de sinais - mamograma original. 
Figura 7-34 - Detecção de "clusters" em mamograma através dos dois métodos de agrupamento de sinais - regiões de interesse selecionadas.

Figura 7-35 - Detecção de "clusters" em mamograma através dos dois métodos de agrupamento de sinais - regiões de interesse após segmentação... 169

Figura 7-36 - Detecção de "clusters" em mamograma através dos dois métodos de agrupamento de sinais - regiões de interesse após transformação área-ponto.

Figura 7-37 - Detecção de "clusters" em mamograma através dos dois métodos de agrupamento de sinais - regiões de interesse após detecção de "clusters" através do método de "mascaramento". 171

Figura 7-38 - Detecção de "clusters" em mamograma através dos dois métodos de agrupamento de sinais. - regiões de interesse após detecção de "clusters" através do método de "crescimento de região".

Figura 7-39 - Exemplo de processamento de um mamograma do segundo conjunto de imagens de teste - mamograma original 175

Figura 7-40 - Exemplo de processamento de um mamograma do segundo conjunto de imagens de teste - regiões de interesse selecionadas. 176

Figura 7-41 - Exemplo de processamento de um mamograma do segundo conjunto de imagens de teste - regiões de interesse após a segmentação..... 177

Figura 7-42 - Exemplo de processamento de um mamograma do segundo conjunto de imagens de teste - regiões de interesse após a transformação áreaponto 178

Figura 7-43 - Exemplo de processamento de um mamograma do segundo conjunto de imagens de teste - detecção de "clusters" através do método de "mascaramento". 179

Figura 7-44 - Imagem de mamogramas antes (1a e 2a) e após (1b e 2b) a eliminação da região em torno das fronteiras da mama. 


\section{ÍNDICE DE TABELAS}

Tabela 5-1 - Parâmetros usados nos cálculos de espessura do sinal a partir de seu

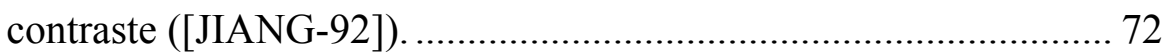

Tabela 5-2 - Performance da detecção de "clusters" em 50 mamogramas do esquema ([DAVIES-90]). A tabela indica as taxas de casos verdadeiro-positivos (TP), falso-positivos $\quad(\mathrm{FP}) \quad \mathrm{e}$ falso-negativos (FN). Os filmes foram classificados de acordo com o critério de possuírem ou não no mínimo um "cluster". 87

Tabela 6-1 - Parâmetros para a identificação das regiões de interesse.................. 97

Tabela 6-2 - Parâmetros da segmentação .......................................................... 101

Tabela 6-3 - Parâmetros da transformação área-ponto........................................ 103

Tabela 6-4 - Parâmetros da detecção de "clusters" através do método de "mascaramento". 105

Tabela 6-5 - Parâmetros da detecção de "clusters" através do método de "crescimento de região".

Tabela 6-6 - Funções do sistema computacional desenvolvido. ........................ 114

Tabela 7-1 - Parâmetros do processamento de imagens de "phantoms"........... 125

Tabela 7-2 - Resultado do processamento de imagens de "phantoms"............. 125

Tabela 7-3 - Parâmetros do processamento de imagens de mamogramas reais. 139

Tabela 7-4 - Resultado do processamento de imagens de mamogramas reais através do método de "mascaramento"

Tabela 7-5 - Resultado do processamento de imagens de mamogramas através do método de "crescimento de região". 154

Tabela 7-6 - Resultado do processamento do segundo conjunto de imagens de mamogramas reais através do método de "mascaramento". 


\section{1}

\section{INTRODUÇÃO}

\subsection{Considerações iniciais}

O câncer de mama é a doença que lidera o número de mortes em mulheres com idade entre 35 e 54 anos. No Reino Unido é o tipo mais comum de câncer entre as mulheres e na Europa Ocidental e na América do Norte, o câncer de mama apresenta a maior taxa de mortalidade entre todos os tipos de câncer, conforme afirmam D. H. Davies e D. R. Dance em [DAVIES-90]. No Canadá, estatísticas indicam que uma entre dez mulheres desenvolverão esta doença durante o seu período de vida, segundo L. Shen et al. em [SHEN-93]. De acordo com a "National Alliance of Breast Cancer Organizations", o câncer de mama também é a principal causa de morte por câncer de mulheres africanas e americanas.

Por isso, em vários países do mundo tem sido incentivada a prevenção do câncer de mama, visando à detecção no seu estágio inicial de desenvolvimento, quando ainda apresenta grandes chances de cura. Pelo fato de a doença ser assintomática nessa fase, o exame periódico é aconselhado a mulheres que, segundo as estatísticas, estão relacionadas com algum fator de risco. Geralmente, nesse exame o médico solicita a realização da mamografia, que ainda hoje é considerada a técnica mais eficaz para a detecção precoce do câncer de mama. Segundo J. Dengler, em [DENGLER-93], pesquisas realizadas nos Estados Unidos, Suécia e Holanda indicaram que a realização periódica da mamografia para prevenção do câncer de mama em mulheres acima de 40 anos pode reduzir a taxa de mortalidade em torno de $40 \%$.

No mamograma são procuradas estruturas que indicam a presença de anormalidades ou tumores. Entre esses elementos estão as microcalcificações, depósitos de cálcio de formatos e tamanhos variados, segundo R.L.Egan ([EGAN-80]). Devido ao tamanho reduzido dessas estruturas, a sua visualização em 
mamogramas exige grande experiência do examinador e, mesmo assim, muitas vezes são passadas despercebidas, visto que o sistema de raios-X pode apresentar várias limitações que prejudicam a nitidez da imagem: ruídos randômicos, variação nas características dos filmes, problemas de contraste e ponto focal com dimensões fora da especificação necessária, entre outros. A indicação de tumores malignos ou benignos a partir de microcalcificações pode ser baseada em certos fatores, tais como tamanho, forma e distribuição dessas estruturas na mama ([HAUS-78], [SICKLES-82], [OLSON-88], [CHAN-87], [FROUGE-93] e [SHEN-94]).

A dificuldade na visualização e classificação de microcalcificações e a necessidade de detecção precoce do câncer mamário levaram, e levam até hoje, pesquisadores de diversas partes do mundo a dedicarem-se ao desenvolvimento de esquemas computadorizados para auxiliar a detecção dessa doença. As características das microcalcificações têm sido objeto de estudo dos pesquisadores para a definição de alguns desses esquemas computadorizados. Segundo um levantamento realizado por F. Lefebvre et al. em [LEFEBVRE-94], há diferentes técnicas de processamento de imagens sendo utilizadas hoje para a detecção de microcalcificações: métodos de "thresholding", morfologia matemática, redes neurais, modelos estocásticos e modelos fractais.

De grande interesse ainda são os "clusters" (aglomerações) de microcalcificações, de muita importância clínica, pois são indicadores da necessidade de investigação mais aprofundada no local onde se encontram. Segundo informação do "National Cancer Institute" e do "National Institute of Health", ambos dos Estados Unidos, aproximadamente metade dos cânceres detectados através de mamografia é percebida inicialmente como uma aglomeração de microcalcificações.

A maioria dos esquemas propostos para detecção automatizada de microcalcificações utiliza o mamograma como fonte de dados: os filmes radiográficos são digitalizados, executando-se em seguida procedimentos de processamento de imagem para aumentar o contraste, reconhecer bordas, determinar o formato e a distribuição de microcalcificações, como é observado nos esquemas propostos em [WEE-75], [CHAN-84], [CHAN-87], [FAM-88], [CHAN-88a], [DAVIES-90], [CHAN-90], [NISHIKAWA-92], [SHEN-93], [NISHIKAWA-93a], [NISHIKAWA.-93b] e [DENGLER-93]. 
A aplicabilidade de esquemas automatizados em situações reais exige grande eficácia, pois erros de diagnósticos podem levar a sérias conseqüências nos diversos aspectos da vida de um paciente: psicológico, familiar, social e financeiro. Dos esquemas citados vastamente na literatura, nenhum ainda se encontra em estado adequado para utilização clínica. Geralmente os esquemas não conseguem abranger todos os aspectos relacionados ao câncer e os resultados obtidos variam imensamente de acordo com o conjunto de mamogramas testados, conforme é afirmado por R. M. Nishikawa et al. em [NISHIKAWA-93a]. Além disso, a forma de avaliação da performance por cada grupo de pesquisadores é diferente e produz resultados diferentes para um mesmo esquema avaliado.

\subsection{Objetivos e delineamento das etapas da pesquisa}

Apesar de vários esquemas estarem sendo desenvolvidos para a detecção precoce do câncer de mama, até 1988 nenhum deles ainda apresentava resultados suficientemente satisfatórios para aplicação clínica, conforme afirmam HP. Chan et al. em [CHAN-88b]. De 1988 até hoje, grandes avanços surgiram nas pesquisas em torno do assunto com o objetivo de estabelecer processamentos computacionais para detectar indícios desse tipo de câncer. Sistemas de diagnósticos auxiliados por computador $\left(\mathrm{CAD}^{1}\right)$ têm sido desenvolvidos nos últimos 10 anos, apresentando um rápido crescimento na radiologia diagnóstica e na física médica. CAD pode ser definido como um diagnóstico feito por um radiologista que leva em consideração os resultados de uma análise computacional quantitativa de imagens médicas; o radiologista, então utiliza os resultados do computador como uma "segunda opinião" ([DOI-96]). Técnicas de processamento de imagem são desenvolvidas para aumentar a qualidade das imagens dos mamogramas, realçar aspectos e torná-los mais visíveis aos radiologistas, a fim de que possam identificar sinais significantes e quantificá-los ([RANGAYYAN-96]). O objetivo da presente pesquisa é o desenvolvimento de um esquema automatizado para a detecção de “clusters" de microcalcificações que forneça uma contribuição para o desejado diagnóstico precoce dessa doença.

\footnotetext{
${ }^{1}$ Sigla resultante do termo em inglês "Computer-aided diagnosis"
} 
Para atingir essa meta, o primeiro passo consistiu na digitalização dos mamogramas, definindo-se a quantidade de níveis de cinza e a resolução do tamanho do pixel de forma a não desprezar as pequenas estruturas de interesse, ou seja, as microcalcificações. Após esse procedimento, foram aplicadas técnicas de processamento com a finalidade de preparar a imagem e extrair dela a informação correspondente às microcalcificações, quando presentes. Os métodos aplicados consistiram basicamente de filtros pré-definidos e procedimentos para a detecção de bordas. Por último, foi estudada a distribuição das microcalcificações e a formação de aglomerações ("clusters"), eliminando-se as microcalcificações isoladas.

A finalidade foi obter uma indicação da quantidade de "clusters" encontrados (e de microcalcificações dentro deles) a fim de que esses dados sirvam como subsídios para o diagnóstico médico.

\subsection{Disposição do trabalho}

O trabalho aqui descrito está divido em 9 capítulos, além desta introdução. Os capítulos 2 a 5 apresentam uma Revisão Bibliográfica sobre o assunto em pauta e o capítulo 5 descreve uma proposta de processamento computadorizado para a detecção e caracterização de "clusters" de microcalcificações. Os assuntos são abordados da seguinte forma:

Capítulo 2: mamografia; traz conceitos básicos para a compreensão do processo de registro da imagem mamográfica através de raios- $\mathrm{X}$, alguns dos problemas encontrados e influências dessas limitações na detecção computadorizada de microcalcificações, além de algumas propostas encontradas na literatura para melhorar os sistemas mamográficos.

Capítulo 3: processamento de imagens; são discutidos princípios básicos de processamento de imagens, desde a definição matemática de uma imagem digitalizada até técnicas mais avançadas de manipulação de imagens como realce, suavização e reconhecimento de bordas, entre outras.

Capítulos 4 e 5: esquemas automatizados de detecção de microcalcificações e reconhecimento de aglomerações; 
incluem-se os principais esquemas citados na literatura. Várias das técnicas descritas no capítulo 3 são aqui retomadas a fim de mostrar a sua aplicação nos esquemas citados; são também incluídos alguns aspectos de simulação de microcalcificações e as dificuldades encontradas para aferição da performance dos esquemas. desenvolvido para detecção de "clusters" e apresentação dos materiais utilizados para teste do sistema.

Capítulo 7: detalhamento dos testes realizados e apresentação dos resultados obtidos. Aqui, os resultados são discutidos em função das características das imagens. continuidade da investigação sobre o assunto.

Capítulo 9: referências bibliográficas. 


\section{MAMOGRAFIA: BREVE HISTÓRICO E PRINCIPAIS CARACTERÍSTICAS}

Desde que Röentgen, em 1895, descobriu a existência de uma radiação até então desconhecida, capaz de atravessar materiais, ser parcial ou totalmente absorvida por eles e fixar-se em anteparos, a dinâmica dos exames médicos sofreu drásticas mudanças. Com a descoberta dos Raios-X, há 100 anos, tornou-se possível a visualização de estruturas internas do corpo humano com a finalidade de observar e diagnosticar anomalias.

A formação da imagem na radiografia é conseqüência da interação dos fótons de raios-X com a matéria. Esses fótons são emitidos e atravessam o objeto, sofrendo atenuações. A atenuação é causada pela absorção total ou parcial dos fótons pelo objeto a ser registrado, sendo que o nível de absorção depende dos elementos constituintes desse objeto. Dentro do corpo humano, por exemplo, ossos, músculos e gordura absorvem os fótons diferentemente, levando a diferentes atenuações, e, conseqüentemente, diferentes intensidades de radiação no filme. É essa diferença que possibilita a formação do contraste, permitindo a identificação da estrutura anatômica no radiograma.

A mamografia constitui uma forma particular de radiografia, trabalhando com níveis de tensões e correntes em intervalos específicos, destinada a registrar imagens das mamas a fim de diagnosticar a presença ou ausência de estruturas que possam indicar doenças.

Devido às suas características é, ainda hoje, a técnica mais indicada e mais empregada no diagnóstico precoce do câncer de mama, como afirmado em [DHAWAN-86], [DHAWAN-88], [DAVIES-90], [DENGLER-93], [SHEN-93], [CHAN-94], [PLEWES-95] e em muitos outros artigos encontrados na literatura. No Reino Unido estima-se que um total de 1.440 .000 exames mamográficos são realizados por ano, conforme afirma D. H. Davies e D. R. Dance em [DAVIES-90]. 
Nos Estados Unidos, organizações como o "American Cancer Society and the National Alliance of Breast Cancer Organizations" sugerem que, a partir dos 40 anos, as mulheres realizem uma mamografia a cada um ou dois anos e, após a idade de 50 anos, seja realizada uma mamografia anualmente.

A utilização do computador no processamento de mamogramas para o reconhecimento de anomalias já é antiga. Em 1967, Fred Winsberg et al. descreviam, em [WINSBERG-67], um procedimento para detectar anomalias em mamogramas através da densidade ótica analisada computacionalmente. Apesar da antigüidade da utilização da mamografia, estudos indicam que não há padronização no seu uso. Em 1981, Fitzgerald et al. publicaram um artigo ([FITZGERALD-81]) contendo os resultados de avaliação de aparelhos mamográficos na Grã-Bretanha. O objetivo da pesquisa foi registrar detalhes dos equipamentos de raios-X, técnicas, o número de pacientes e o tempo de exposição. A conclusão a que chegaram é que, na época, havia uma grande diversidade de técnicas mamográficas e, entre essas, nenhuma se destacava como superior em termos de intensidade da dose aplicada e registro de imagem.

Obviamente a finalidade da mamografia coincide com a finalidade de todo procedimento de imagem médica: ser útil no sentido de fornecer informações para um diagnóstico correto sobre uma possível doença. Considerando esta finalidade, vários problemas devem ser resolvidos, alguns cujas soluções estão em ajustes diretamente no aparelho mamográfico, outros com soluções através da aplicação de técnicas computacionais, especialmente as de processamento de imagens. Neste capítulo pretendemos abordar os principais problemas encontrados na mamografia, principalmente aqueles que influenciam diretamente no objetivo deste trabalho: a detecção de aglomerações de microcalcificações.

\subsection{A realização da mamografia}

$\mathrm{Na}$ mamografia, geralmente dois tipos de projeções são necessárias para que o médico possa identificar anomalias: de lado (mediolateral oblíqua) e de cima (craniocaudal).

Para a impressão do filme mamográfico, um técnico ou o radiologista posiciona a mama entre duas placas de plástico cuja função é comprimi-la a fim de 
homogeneizar ao máximo a densidade a ser radiografada. O feixe de raios-X é disparado e a imagem é registrada em filme. Após a revelação do filme, um radiologista interpreta o mamograma a fim de determinar se nele existe alguma área suspeita. Caso haja, uma nova mamografia pode ser solicitada com maior enfoque na região de interesse ou utilizando-se novas projeções e, caso o médico julgue necessário, uma biópsia é solicitada. No entanto, a título de prevenção, muitas pacientes acabam submetendo-se a biópsias desnecessárias. Estatísticas indicam que, para obter-se uma segurança no diagnóstico, para cada câncer removido, de 5 a 10 mulheres são submetidas a biópsias. A diminuição das biópsias desnecessárias vem a ser um dos objetivos dos esquemas computadorizados de detecção precoce do câncer de mama, conforme afirma H-P. Chan et al. em [CHAN-87].

\subsection{Dificuldades encontradas para a visualização de estruturas importantes}

Muitos fatores influenciam na geração de imagens mamográficas com baixa qualidade. Além disso há um sério compromisso entre qualidade da imagem e prejuízo à paciente. Se esses fatos dificultam o diagnóstico médico, o efeito é ainda pior quando o mamograma serve como entrada de dados para um esquema computacional. Os detalhes e características dos mamogramas devem ser previstos de forma que seja possível estabelecer procedimentos automatizados para encontrar estruturas procuradas, segundo M. Ishida et al. em [ISHIDA-87] e A.P.Dhawan et al. em [DHAWAN-88]. E. A. Sickles em [SICKLES-82] afirma que o problema é que esses detalhes e características variam bruscamente de equipamento para equipamento e dependem muito das especificações utilizadas quanto ao filme, ponto focal, posicionamento e outros aspectos que tornam impossível o estabelecimento de um procedimento global sem interação humana.

\subsubsection{Dose absorvida}

Como os raios-X constituem radiação ionizante e o excesso de radiação traz prejuízos ao organismo humano, é imprescindível um controle a fim de que a dose recebida pela paciente não seja mais prejudicial do que o benefício a que 
ela se propõe. Alguns fatores contribuem para o aumento da dose absorvida pela paciente, como o aumento da tensão e o aumento da corrente para a produção de fótons e ainda o prolongamento do tempo de exposição. Geralmente estas práticas são aplicadas quando é desejada uma imagem com intensidade mais acentuada, como T. S. Curry III et al. afirmam em [CURRY III-90].

Esses pesquisadores citam uma solução que auxilia na redução da dose: a utilização de filtros. Filtros são placas de metais posicionadas entre a fonte de raios-X e o objeto a fim de absorver os fótons de energia baixa (os chamados "raios-X moles"), deixando transmitir os fótons de energia alta que são os principais responsáveis pela formação da imagem efetiva ([SCAFF-79]). Os metais constituintes e a espessura dessas placas variam de acordo com o nível de energia que se deseja absorver. Salienta-se que a eliminação dos raios-X moles não influencia na formação da imagem, visto que os fótons eliminados, sendo de baixa energia, são totalmente absorvidos pelo organismo e não impressionam o filme.

Com relação a esta característica, as técnicas de processamento de imagens podem contribuir no sentido de realçar a imagem de acordo com a intensidade desejada, dispensando os costumeiros aumentos de tempo de exposição, tensão e/ou corrente de tubo ([ISHIDA-83]).

\subsubsection{Tamanho do ponto focal}

De forma geral, as estruturas que indicam a presença de câncer na mama são de tamanho reduzido na fase inicial do desenvolvimento da doença. Por esse motivo, a visualização desses elementos é impossível se o ponto focal do aparelho mamográfico for maior que as estruturas a observar (microcalcificações geralmente possuem tamanho menor que $0,5 \mathrm{~mm}$ ). Vários métodos têm sido empregados para medir o tamanho efetivo do ponto focal de um aparelho mamográfico, visto que nem sempre o valor indicado pelos fabricantes corresponde à realidade ([CURRY III-90]).

O foco ideal seria somente um ponto. Este ideal é impossível de ser atingido na prática e o tamanho do foco, ainda que considerado pequeno, pode não ser suficiente, visto que muitos cânceres de mama contêm microcalcificações menores que os limites da resolução da mamografia convencional ([SICKLES-82]). 
Ponto focal com tamanho maior que o desejado pode causar penumbra (borramento) contornando a sombra (imagem real) do objeto ([HAUS-78]). Esse fato traz conseqüências para o processamento de imagens, visto que no reconhecimento de estruturas a penumbra influencia na definição de tamanho e formato do elemento reconhecido.

\subsubsection{O efeito Heel}

Este é outro sério problema a ser enfrentado pelo processamento de imagens, conforme citado em [CURRY III-90] e [WILKS-87]: a intensidade da radiação $\mathrm{X}$ do tubo não é uniforme em todas as regiões do campo, sendo dependente do ângulo em que os fótons são emitidos do ponto focal. Conseqüentemente, o nível de intensidade no filme mamográfico poderá variar para estruturas que têm o mesmo índice de absorção. Isso causa uma preocupação constante com os métodos a serem empregados nos esquemas automatizados: não se podem fixar valores de níveis de cinza que representem as estruturas de interesse após a digitalização. São aplicadas, então, técnicas adaptativas à região, como é citado em [WEE-75], [DHAWAN-88], [DENGLER-93], [CHAN-94] e [QIAN-94], entre outros, a serem descritas nos capítulos 4 e 5 .

\subsubsection{Radiação espalhada}

O espalhamento é causado por fótons desviados de suas trajetórias ideais. Por apresentar uma característica randômica, não é possível prever o seu efeito; por isso, uma das possibilidades é que cause ruídos e redução do contraste na imagem ([WILKS-87] e [CURRY III-90]). Um dos tipos de espalhamento mais descritos na literatura é o efeito Compton, onde parte da energia do fóton é absorvida pela matéria e outra parte permanece no próprio fóton. Ocorrendo o desvio deste fóton em uma direção inesperada, seu efeito pode ser desde ruídos e diminuição do contraste da imagem, conforme cita V. P. Jackson et al. em [JACKSON-93], até aumentar a dose na paciente.

Em [CURRY III-90] afirma-se que três fatores definem a quantidade de radiação espalhada: tensão, espessura do objeto e tamanho do campo, sendo que o 
último seria o mais importante deles. Em [JACKSON-93], salienta-se a contribuição do tipo e da espessura do objeto para o aumento da radiação espalhada, destacandose o problema das mamas densas como fator de acentuação deste efeito na mamografia.

Fisicamente, o efeito da radiação espalhada pode ser diminuído com a utilização de grades ([CURRY III-90], [JACKSON-93] e [SCAFF-79]). Consistem em peças compostas por uma série de faixas de chumbo separadas por espaços. Acopladas ao sistema, o objetivo ideal seria absorver essa radiação espalhada sem absorver a radiação primária, e, então, proporcionar o máximo contraste no filme sem aumentar a exposição do paciente. Todavia, não existe grade ideal.

No processamento de imagens, a forma de superar o efeito da radiação espalhada é estabelecer procedimentos que removam ruídos e aumentem o contraste da imagem, como aplicação de "thresholding" e filtros que suprimam os sinais de alta freqüência.

\subsubsection{Distorção e Ruídos}

Distorção na imagem radiográfica pode resultar da magnificação desigual de diferentes partes do mesmo objeto, conforme é afirmado por T. S. Curry III et al. ([CURRY III-90]) e H. Schiabel et al. ([SCHIABEL-94]). Muitas vezes a magnificação é desigual devido ao posicionamento do objeto. A distorção da imagem é diferente para diferentes partes do feixe de raios-X. Dois ou mais objetos podem sofrer distorções diferentes se estão posicionados em locais com distâncias diferentes do filme.

A penumbra também constitui uma forma de distorção. Consiste em uma região de borramento que contorna a imagem real do objeto no filme. $\mathrm{Na}$ mamografia geralmente a mama está em contato com o local de registro da imagem, o que, teoricamente deveria eliminar a possibilidade de penumbra. No entanto, a estrutura de interesse, estando espalhada pela mama, nem sempre está em contato com o filme, causando, dessa forma, ainda uma penumbra ([SCHIABEL-94]). Geralmente a penumbra é conseqüência do tamanho do ponto focal. Arthur G. Haus et al., em [HAUS-78], propõem um método para avaliar e minimizar a penumbra em 
equipamentos mamográficos através de cálculos matemáticos para manipular corretamente a distância foco-objeto.

Distorções causam complicações em um esquema para detecção de estruturas pequenas e cujo formato é importante. No caso das microcalcificações, é uma importante limitação a ser superada, pois o tamanho e o formato da microcalcificação é muito importante para o seu reconhecimento e classificação.

\subsubsection{Sobreposição de objetos}

Este é um outro aspecto que exerce grande influência no reconhecimento de padrões. $\mathrm{Na}$ mamografia o feixe de raios-X é aplicado em diferentes direções para gerar diferentes visões da mama. Dependendo do posicionamento das estruturas internas na mama, a imagem resultante pode apresentar sobreposição destes elementos, transformando dois ou mais objetos em um bloco único. Esta é uma limitação pouco abordada na literatura, mas, dependendo do tipo de processamento utilizado, objetos sobrepostos podem ser reconhecidos como únicos e, como conseqüência, levar a diagnósticos equivocados, como afirmado por A. S. Pereira em [PEREIRA-95].

Uma possível solução é o processamento de mamogramas com visões

diferentes, de forma que a localização de possíveis microcalcificações e o relacionamento entre suas locações forneçam ao médico mais subsídios para o diagnóstico correto. Outra maneira de solucionar a questão seria o processamento e reconstrução de imagens tridimensionais.

\subsubsection{Contraste e resolução da digitalização}

$\mathrm{Na}$ imagem radiográfica o contraste refere-se à diferença de densidades entre áreas, conforme citado em [CURRY III-90], [DHAWAN-88] e [XIONG-93]. Se o objeto cuja imagem está sendo registrada é formado por diferentes elementos e cada um desses elementos apresenta diferentes níveis de absorção dos fótons de raios-X, então o padrão a ser registrado no filme apresentará diferentes intensidades. Quanto maior for a diferença entre as intensidades, maior 
será o contraste percebido e, provavelmente, maior facilidade oferecerá para interpretação médica.

Para que seja utilizado um esquema computadorizado para reconhecimento de estruturas em mamogramas, esses filmes precisam ser digitalizados. A digitalização é um processo que "lê" a imagem do filme e a transporta para o computador, tornando-a disponível para processamento. Os equipamentos utilizados para esse processo variam muito em termos de níveis de cinza oferecidos e resolução.

Os níveis de cinza estão diretamente relacionados com o contraste. Geralmente uma faixa de densidades óticas do filme é representada por um único nível de cinza na digitalização, como mostrado em [CHAN-87]. A resolução, por sua vez, refere-se à quantidade de pontos por centímetro ou milímetro quadrado que, ao final, estabelecerá o tamanho da menor unidade da imagem digitalizada: o pixel.

Esses dois aspectos devem ser muito bem observados para se ter um esquema eficiente. Os níveis de cinza vão ser processados a fim de informarem o tamanho e localização da estrutura reconhecida. Da mesma forma, no processamento, o tamanho do pixel é muito importante: geralmente o tamanho das microcalcificações é dado em termos de números de pixels que as constituem. Se a digitalização não fornecer um tamanho suficientemente pequeno de pixel, algumas microcalcificações pequenas podem ser desprezadas e até mesmo desaparecer durante o pré-processamento ([CHAN-87] e [CHAN-94]).

\subsubsection{Algumas soluções propostas}

Exemplos de soluções para alguns dos problemas anteriormente citados são mencionados na literatura.

R. M. Nishikawa et al., em [NISHIKAWA-87], consideram três limitações técnicas como fatores de redução da eficácia da mamografia écran-filme²

2 Sistemas écran-filme são aqueles em que, além do filme, é acoplado um écran reforçador que tem o objetivo de aumentar a intensidade da imagem sem alterar os fatores que influenciam na exposição do paciente (tensão, corrente e tempo). 
1. a forma da curva característica do filme que, segundo os autores, necessita de um compromisso entre contraste de exibição e latitude do sistema;

2. a presença da granularidade do filme, a qual reduz significativamente a relação sinal-ruído da imagem exibida e degrada a habilidade para demonstrar microcalcificações;

3. a radiação espalhada, que reduz o contraste exibido e a relação sinal-ruído.

A solução desses problemas deveria produzir uma mamografia melhorada capaz de detectar lesões em um estágio inicial sem aumentar a dose. Um sistema de imagem digital que usasse um detector com intervalos dinâmicos grandes empregando processamento de imagem deveria ser capaz de superar as limitações citadas. O sistema desenvolvido pela equipe consiste de um intensificador de imagem de raios- $\mathrm{X}$ de alta resolução acoplado a um vetor linear de fotodiodos (figura 2-1).

Em [FAHRIG-94], R. Fahrig e M. J. Yaffe afirmam que os fatores que influenciam a mamografia são ajustados empiricamente e variam de usuário para usuário. Atualmente, não há critérios claros para dirigir a escolha de técnicas para otimização de registro da imagem mamográfica. Nesse artigo, os pesquisadores estudam a influência da escolha do material do anodo e da adição de filtros que afetam a forma do espectro na qualidade da imagem. Na mamografia digital ${ }^{3}$, a aquisição, a exibição e o armazenamento da imagem podem ser otimizados separadamente. No estudo realizado por esses pesquisadores, os cálculos usam dados determinados experimentalmente nas partes do sistema em que isso é possível, a fim de minimizar a quantidade de suposições. O modelo proposto prediz a relação sinalruído para uma dose constante incidente na mama, permitindo a comparação e a

\footnotetext{
${ }^{3}$ A mamografia digital é um tipo de registro da imagem da mama em que são
} utilizadas técnicas diretas de aquisição da imagem digital e exibição dos dados. Essas técnicas oferecem aumento da detectabilidade do câncer de mama através do desacoplamento dos sistemas de captura e exibição da imagem, o que muitas vezes não é possível quando se trabalha com filmes ([JACKSON-93]). 
otimização dessa relação para diferentes espectros de raio-X e diferentes formas de imagens.

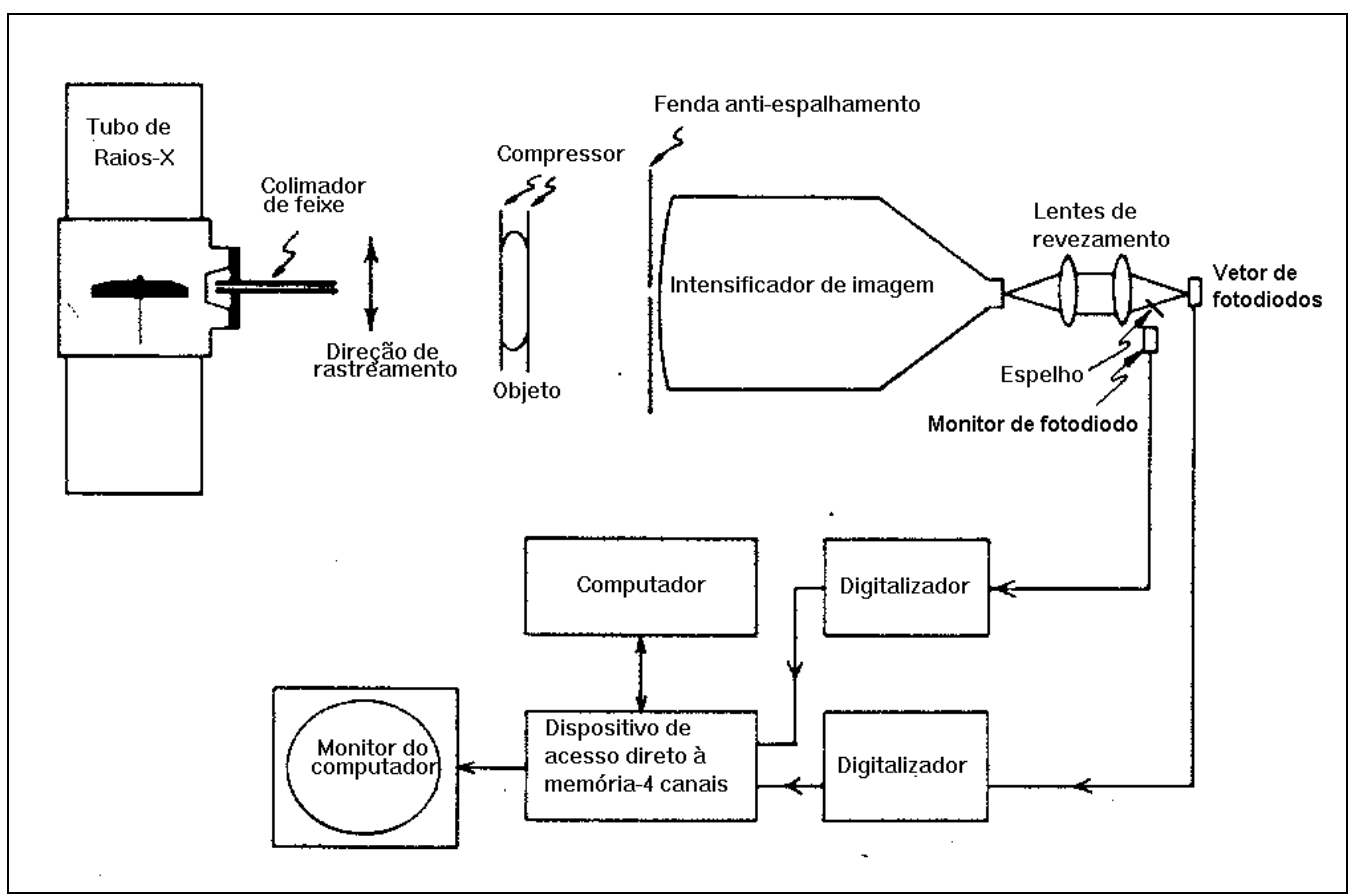

Figura 2-1 - Representação esquemática do sistema proposto em [NISHIKAWA-87].

D. B. Plewes et al. citam em [PLEWES-95] as dificuldades encontradas no registro de imagens de mamas densas: degradação na detecção de pequenos cânceres e microcalcificações e redução no contraste da imagem, entre outras. A variação na densidade das mamas examinadas torna difícil uma padronização. Para resolver esses problemas, apresentam um protótipo de equipamento mamográfico, denominado "scanning equalisation radiograph"-MSER (figura 2-2). O princípio básico da equalização é baseado no uso de um pequeno feixe de raios-X que investiga a anatomia de interesse. À medida que o feixe faz o rastreamento do objeto, a fonte de raios-X é pulsada com uma largura de pulso gerada em resposta às medidas da exposição do filme obtidas com um detector adequado que traça o caminho do feixe. O retorno do sensor opera para manter uma exposição constante do filme como uma média do feixe de rastreamento. Deste modo, a exposição do filme é equalizada para fornecer uma distribuição variável da radiação da exposição incidente no objeto. 


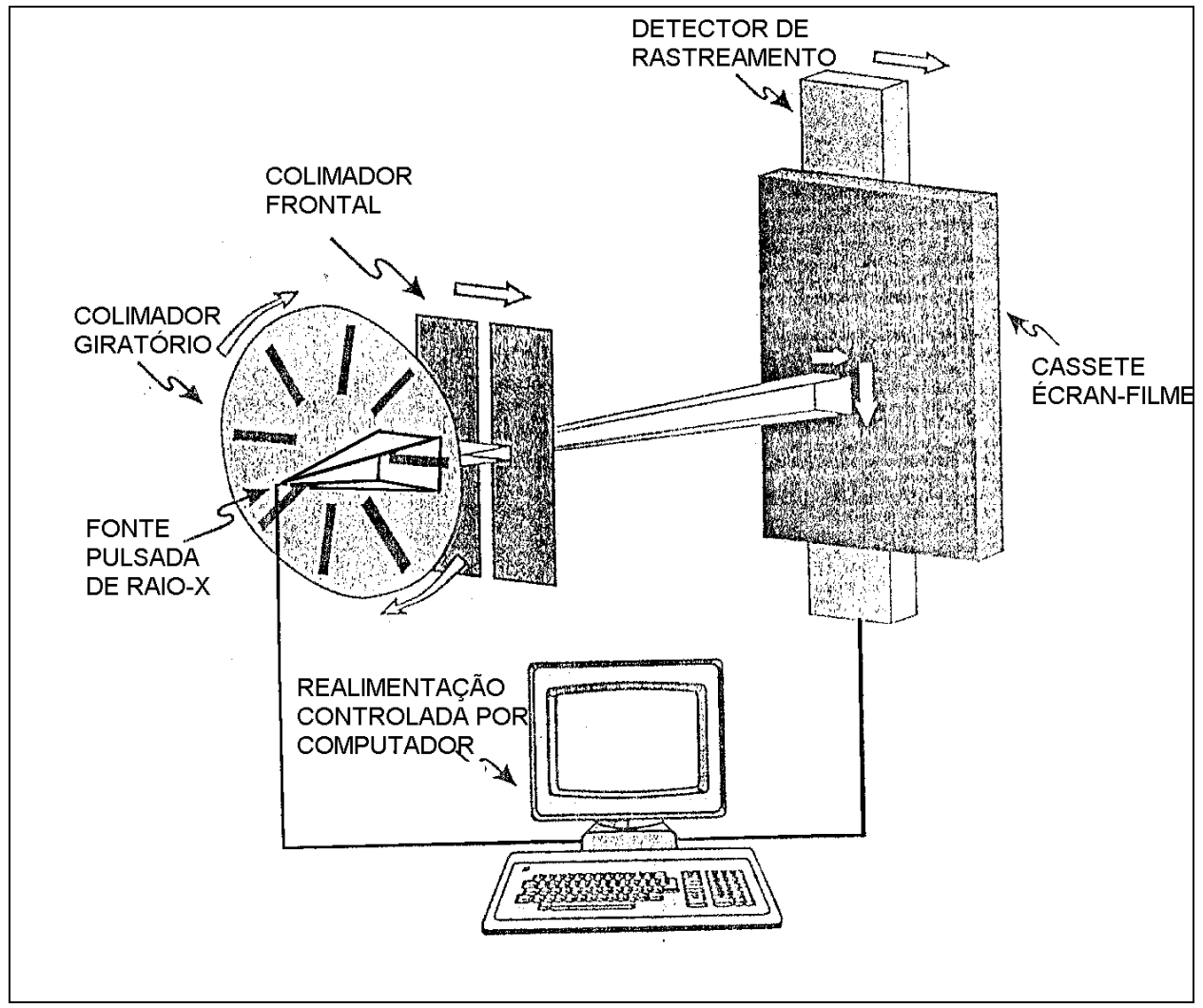

Figura 2-2 - "Scanning equalisation radiograph" (PLEWES-95).

\subsection{Conclusões}

Foram citados os principais problemas da mamografia e suas influências em esquemas computadorizados para detecção de microcalcificações. É difícil implementar algoritmos que eliminem todas essas limitações e, ao mesmo tempo, forneçam informações suficientes para um diagnóstico correto. O que se faz, geralmente, é utilizar as técnicas existentes de processamento de imagens para minimizar alguns dos aspectos.

Por isso, no próximo capítulo, analisaremos várias técnicas utilizadas na manipulação de imagens e, a seguir, veremos alguns desses métodos aplicados em esquemas hoje existentes para a detecção e classificação de "clusters" de microcalcificações. 


\section{TÉCNICAS DE PROCESSAMENTO DE IMAGENS}

Neste capítulo vamos rever definições de alguns conceitos básicos sobre processamento de imagens a fim de fornecer subsídios para uma melhor compreensão sobre as técnicas específicas utilizadas para a detecção e agrupamento de microcalcificações.

\subsection{Definições básicas}

De acordo com D. H. Ballard e C. M. Brown, em [BALLARD-82], a formação da imagem ocorre quando um sensor registra a radiação que interagiu com objetos físicos. A imagem, então, é uma representação do objeto físico que pode ser armazenada, manipulada e interpretada de acordo com as necessidades do interessado. Matematicamente, uma imagem pode ser descrita como uma função da “intensidade luminosa" refletida do objeto. A maioria das imagens considera o espaço bidimensional, sendo definida como $f(x, y)$, onde: $x$ e $y$ são as coordenadas espaciais; o valor de $f$ na coordenada espacial $(\mathrm{x}, \mathrm{y})$ fornece a intensidade, ou seja, o brilho da imagem no ponto; a imagem depende da "quantidade de luz" incidente na cena e da "quantidade de luz" refletida pelos objetos da cena.

Dessa forma, afirma-se que:

$f(x, y)=i(x, y) \cdot r(x, y)$

onde:

* $\mathrm{i}(\mathrm{x}, \mathrm{y})$ depende da fonte de luz $(0<\mathrm{i}(\mathrm{x}, \mathrm{y})<\infty)$;

* $\mathrm{r}(\mathrm{x}, \mathrm{y})$ depende do tipo de material que compõe o objeto $(0 \leq \mathrm{r}(\mathrm{x}, \mathrm{y}) \leq 1)$. Assume o valor 0 para absorção total e o valor 1 para reflexão total.

Um caso especial de imagem é constituído pelas imagens digitais, onde a representação consiste em um vetor de valores discretos. Geralmente este vetor é unidimensional e o domínio e imagem de $\mathrm{f}(\mathrm{x}, \mathrm{y})$ são também discretos. $\mathrm{O}$ 
domínio é finito (geralmente uma matriz retangular) e o conjunto imagem é formado por valores no intervalo $[0, \mathrm{M}]$. Para aplicações práticas a imagem é uma função contínua que é representada por medidas em intervalos regularmente espaçados. Os valores assumidos em cada ponto medido são quantificados em um número pertencente a uma escala de diferentes níveis de cinza. Assim, é estabelecido que o valor 0 (zero) é atribuído à cor mais escura (preto) e o valor máximo $\mathrm{M}$ relaciona-se à cor mais clara da escala (branco).

Resumindo, podemos representar uma imagem como uma matriz onde cada ponto é um valor discreto, como mostrado abaixo:

$$
f(x, y) \approx\left[\begin{array}{cccc}
f(0,0) & f(0,1) & \ldots & f(0, n-1) \\
f(1,0) & f(1,1) & \ldots & f(1, n-1) \\
\cdot & & & \\
\cdot & & & \\
\cdot & & & \\
f(m-1,0) & f(m-1,1) & \ldots & f(m-1, n-1)
\end{array}\right]
$$

Conforme percebemos em [BALLARD-82] e [GONZALEZ-87], o objetivo de definir matematicamente a imagem é a possibilidade de manipular o seu conteúdo a fim de transformá-la ou retirar dela informações importantes. Ao vasto conjunto de operações que podemos aplicar em uma matriz que representa uma imagem denominamos processamento de imagem.

Cada ponto ou elemento constituinte da matriz-imagem é chamado de "pixel” que é uma abreviação do termo em inglês "picture element". A medida de um pixel depende da resolução com a qual a imagem foi adquirida.

Como o pixel é, então, a menor unidade sobre a qual podemos realizar operações, para isso são definidas algumas relações básicas:

\subsubsection{Vizinhança}

Em [GONZALEZ-87], R. C. Gonzalez e P. Wintz definem a vizinhança de um pixel da seguinte forma: seja $p$, um pixel nas coordenadas $(\mathrm{x}, \mathrm{y})$. A vizinhança de 4 ( ou $\mathrm{N}_{4}(\mathrm{p})$ ) de um pixel é composta por seus vizinhos na horizontal e na vertical, cujas coordenadas são: $(\mathrm{x}+1, \mathrm{y}),(\mathrm{x}-1, \mathrm{y}),(\mathrm{x}, \mathrm{y}+1),(\mathrm{x}, \mathrm{y}-1)$. 
A vizinhança diagonal ( ou $\mathrm{N}_{\mathrm{D}}(\mathrm{p})$ ) de um pixel é constituída por seus vizinhos com coordenadas: $(\mathrm{x}+1, \mathrm{y}+1),(\mathrm{x}+1, \mathrm{y}-1),(\mathrm{x}-1, \mathrm{y}+1),(\mathrm{x}-1, \mathrm{y}-1)$.

A vizinhança de $8\left(\right.$ ou $\left.\mathrm{N}_{8}(\mathrm{p})\right)$ é o conjunto de todos os pixels vizinhos, ou seja: $\mathrm{N}_{4}(\mathrm{p}) \cup \mathrm{N}_{\mathbf{D}}(\mathrm{p})$.

\subsubsection{Adjacência}

A adjacência, conforme afirma-se em [GONZALEZ-87], é característica de um par de pixels vizinhos que compartilham uma borda ou um vértice, sendo que:

- um par de pixels de uma imagem que compartilham uma borda é dito "adjacente por borda" ou "4-adjacente";

- um par de pixels de uma imagem que compartilham um vértice é dito "adjacente por vértice" ou "8-adjacente".

\subsubsection{Conectividade}

É um importante conceito usado para estabelecer bordas de objetos e componentes de regiões em uma imagem. Em [GONZALEZ-87], afirma-se que dois pixels são conectados se:

a) são adjacentes e;

b) obedecem a um critério de similaridade dentro de uma escala de cinza, isto é, seus valores estão dentro de um conjunto préestabelecido de valores de cinza.

Seja $V=\left\{G_{1}, G_{2}, \ldots, G_{k}\right\}$ o conjunto de " $k$ " valores de níveis de cinza usado para definir a conectividade. São definidos três tipos de conectividade:

Conectividade-4: dois pixels $p$ e $q$ com valores em $\mathrm{V}$ e $\mathrm{q} \supset \mathrm{N}_{4}(\mathrm{p})$; Conectividade-8: dois pixels $p$ e $q$ com valores em $\mathrm{V}$ e $\mathrm{q} \supset \mathrm{N}_{8}(\mathrm{p})$; Conectividade-m: dois pixels $p$ e $q$ com valores em $\mathrm{V}$ e:
i) $\mathrm{q} \supset \mathrm{N}_{4}(\mathrm{p})$ ou
ii) $q \supset \mathrm{N}_{\mathrm{D}}(\mathrm{p})$ e $\mathrm{N}_{4}(\mathrm{p}) \cap \mathrm{N}_{4}(\mathrm{q})=\varnothing$. 


\subsubsection{Distância entre pixels}

A distância entre pixels é uma importante definição para grande parte dos algoritmos que manipulam a imagem. Conforme citado em [GONZALEZ-87], a distância $\mathrm{d}(\mathrm{x}, \mathrm{y})$ geralmente é um valor mensurável e:

$$
\begin{array}{ll}
* & d(x, y)=0, \text { se } x=y ; \\
* & d(x, y)=d(y, x) ; \\
* & d(x, y)+d(y, z) \geq d(x, z) .
\end{array}
$$

Há diversas fórmulas empregadas para a definição de distância e atualmente ainda são definidas e adaptadas fórmulas para aplicações específicas. Algumas das métricas mais conhecidas, aplicadas para dois pixels $\mathrm{p}=\left(\mathrm{x}_{1}, \mathrm{y}_{1}\right)$ e $\mathrm{q}=\left(\mathrm{x}_{2}, \mathrm{y}_{2}\right)$ são:

* Distância Euclidiana:

$$
d(p, q)=\sqrt{\left(x_{1}-x_{2}\right)^{2}+\left(y_{1}-y_{2}\right)^{2}}
$$

* Distância “City Block”:

$$
d(p, q)=\left|x_{1}-x_{2}\right|+\left|y_{1}-y_{2}\right|
$$

* Distância “Chessboard”:

$$
d(p, q)=\max \left\{\left|x_{1}-x_{2}\right|,\left|y_{1}-y_{2}\right|\right\}
$$

Introduzidos os conceitos anteriores, podemos aplicá-los no processamento de imagens, que é dividido em três níveis, cada qual com suas funções específicas:

* Processamento de baixo nível: responsável pela remoção de dados indesejáveis e realce de dados importantes;

* $\quad$ Processamento em nível médio: é a parte do processamento que identifica formas significantes. A esse processo damos o nome de "segmentação".

* $\quad$ Processamento em alto nível: é responsável pela ligação da imagem com algum banco de conhecimento.

\subsection{Processamento de Baixo Nível}


Partindo do fato de que a vizinhança de pixels na imagem tem exatamente os mesmos ou aproximadamente os mesmos parâmetros físicos, o processamento de baixo nível visa à exploração da redundância presente nessa vizinhança. Essa fase de processamento é utilizada para recuperar estruturas intrínsecas da imagem, como: descontinuidade de superfície, orientações, profundidades, velocidade etc.

As definições e técnicas apresentadas a seguir são baseadas em [BALLARD-82], [GONZALEZ-87] e [LOW-91].

\subsubsection{Histograma de uma imagem}

O histograma de uma imagem é uma função que fornece a freqüência de cada nível de cinza na imagem, como demonstrado na figura 3-1. O valor do histograma em um nível de cinza, dado por $\mathrm{H}(\mathrm{k})$, é o número de pixels da imagem com aquele nível de cinza. Esse recurso é útil para alterações globais na imagem; porém, é impossível aplicá-lo em processamentos que necessitem de conhecimento sobre a localização de pixels, uma vez que esta informação não está disponível no histograma. Várias técnicas de processamento de baixo nível são aplicadas com base no histograma da imagem, conforme descritas nos próximos itens.

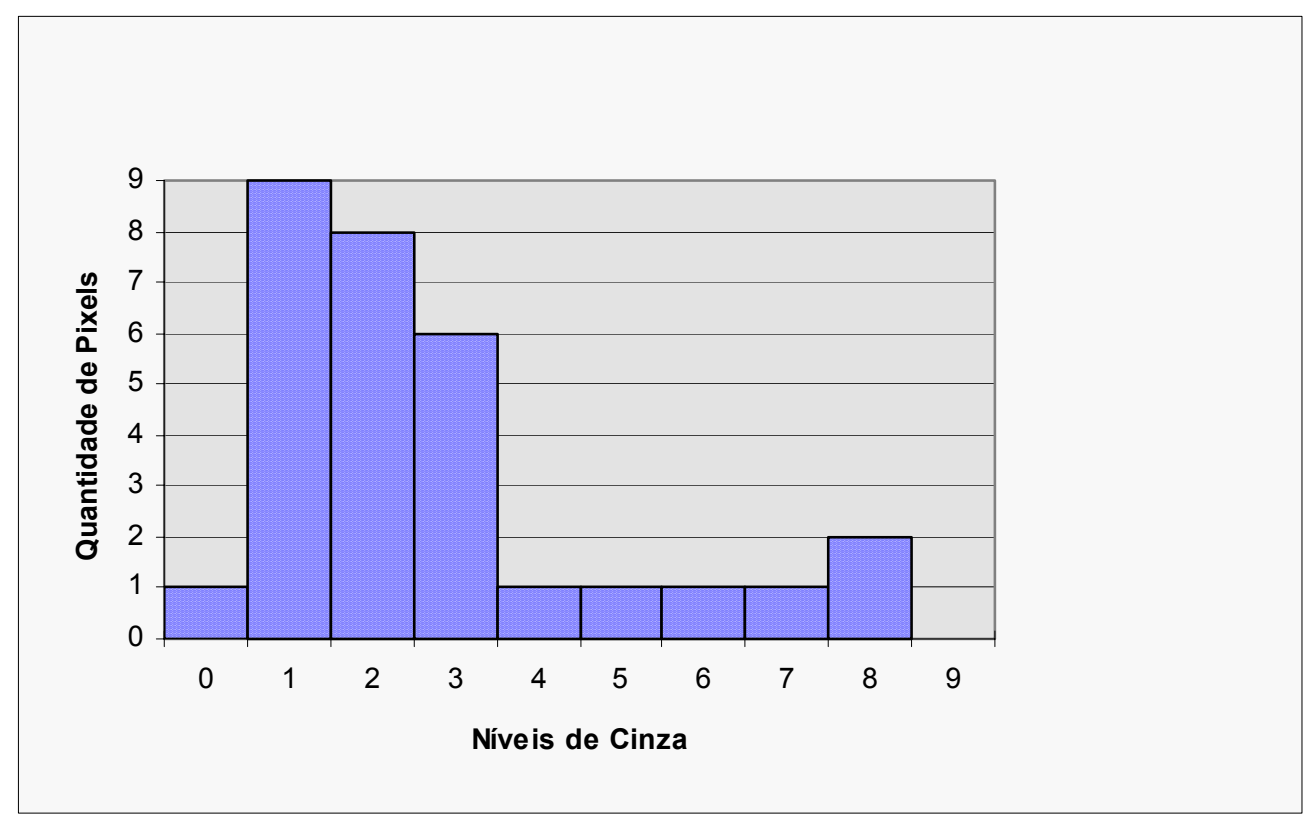

Figura 3-1 - Exemplo de histograma. 


\subsubsection{Alterações globais no brilho}

É possível tornar uma imagem mais clara ou mais escura através da soma ou subtração de uma constante em todos os pixels da imagem, como mostrado na figura 3-2.

\subsubsection{Binarização}

É um tipo de "thresholding", com o objetivo de transformar a imagem em uma matriz com somente dois níveis de cinza: zero ou intensidade máxima. É determinado um valor de limiar que será utilizado para definir os novos valores dos pixels na imagem. Os pixels com valores abaixo do limiar são transformados em zero e àqueles com valores iguais ou superiores ao limiar é atribuído o máximo valor de intensidade. Um exemplo de histograma após a operação de binarização pode ser observado na figura 3-3.

\subsubsection{Quantização do Histograma}

A quantização ou agrupamento do histograma é a redução da quantidade de níveis de cinza diferentes na imagem. É útil para remover gradações indesejáveis na imagem. Um exemplo de quantização é mostrado através dos histogramas da figura 3-4 ([GONZALEZ-87]).

\subsection{5. "Splitting"}

É uma técnica que visa aumentar o contraste de uma imagem com base no seu histograma. Como mostrado na figura 3-5, esta operação divide os pixels em dois grupos distintos de níveis de cinza.

\subsubsection{Equalização}

Também conhecida como "Linearização de Histograma", esta técnica tem a finalidade de obter um histograma uniforme, através do espalhamento da distribuição dos níveis de cinza. Aparentemente comum, esta operação é muito poderosa, conseguindo, muitas vezes recuperar imagens consideradas perdidas. Há vários métodos empregados para a realização da equalização, sendo que muitos deles 
são baseados em distribuições estatísticas. Um exemplo de um histograma equalizado pode ser observado na figura 3-6. Descrições completas da técnica podem ser encontradas em [GONZALEZ-87] e [BALLARD-82].

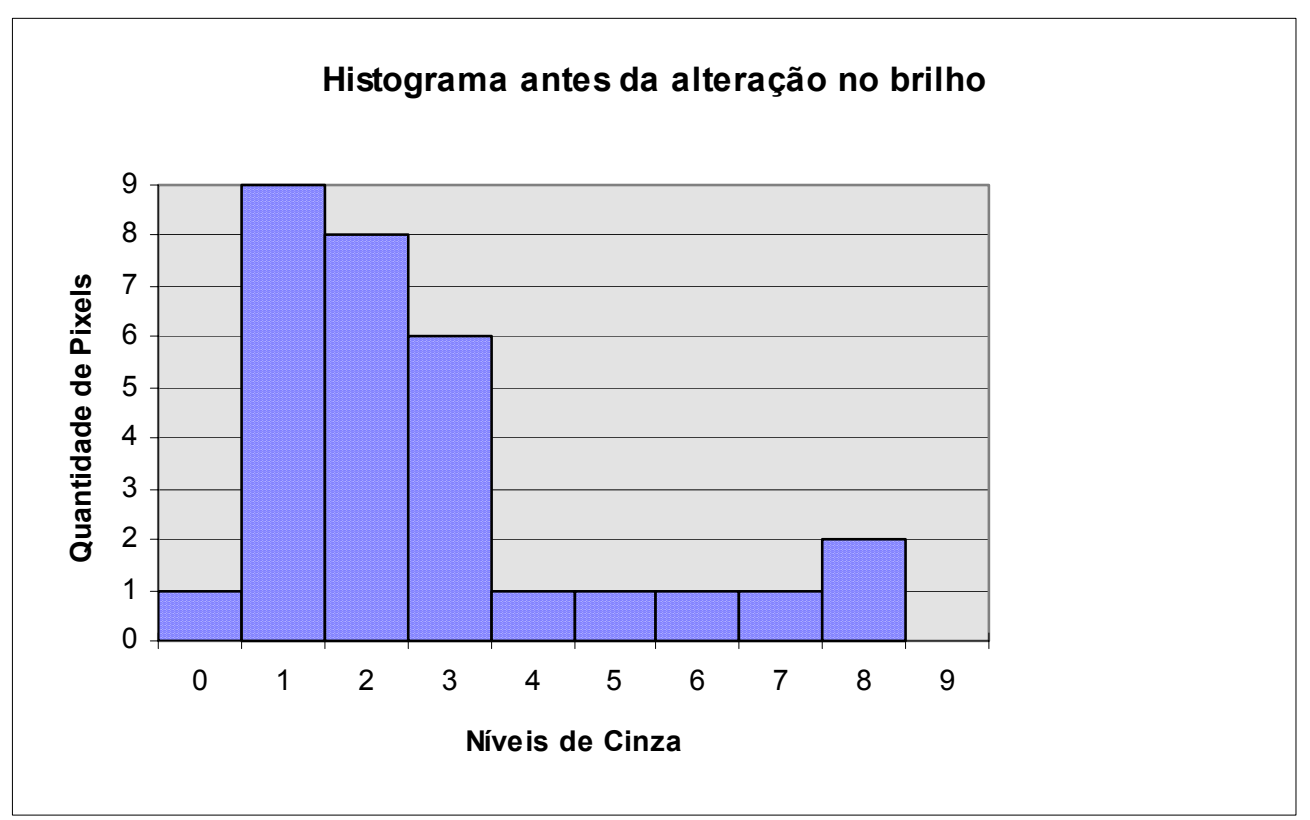

(a)

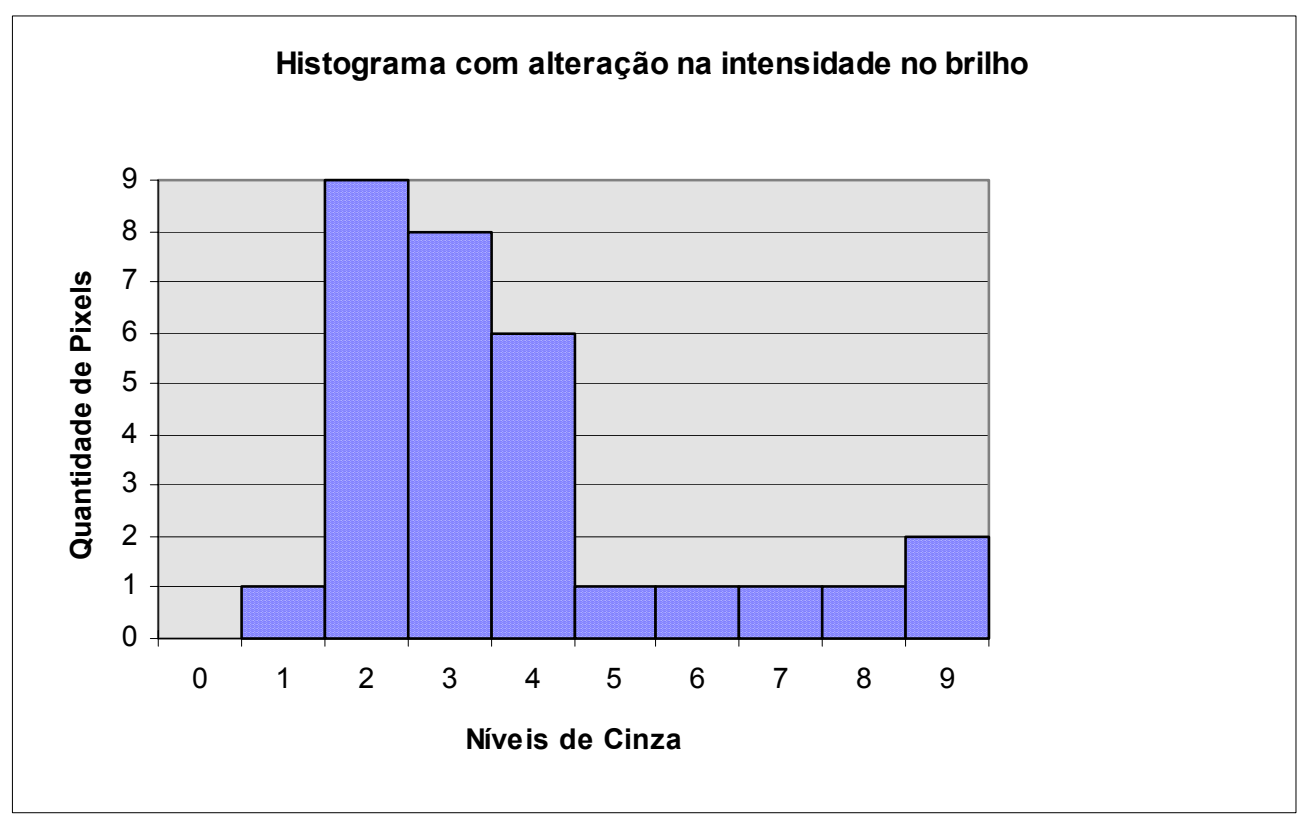

(b)

Figura 3-2 - Exemplo de alteração no brilho da imagem. a) histograma antes da alteração no brilho; b) histograma após a alteração no brilho. 


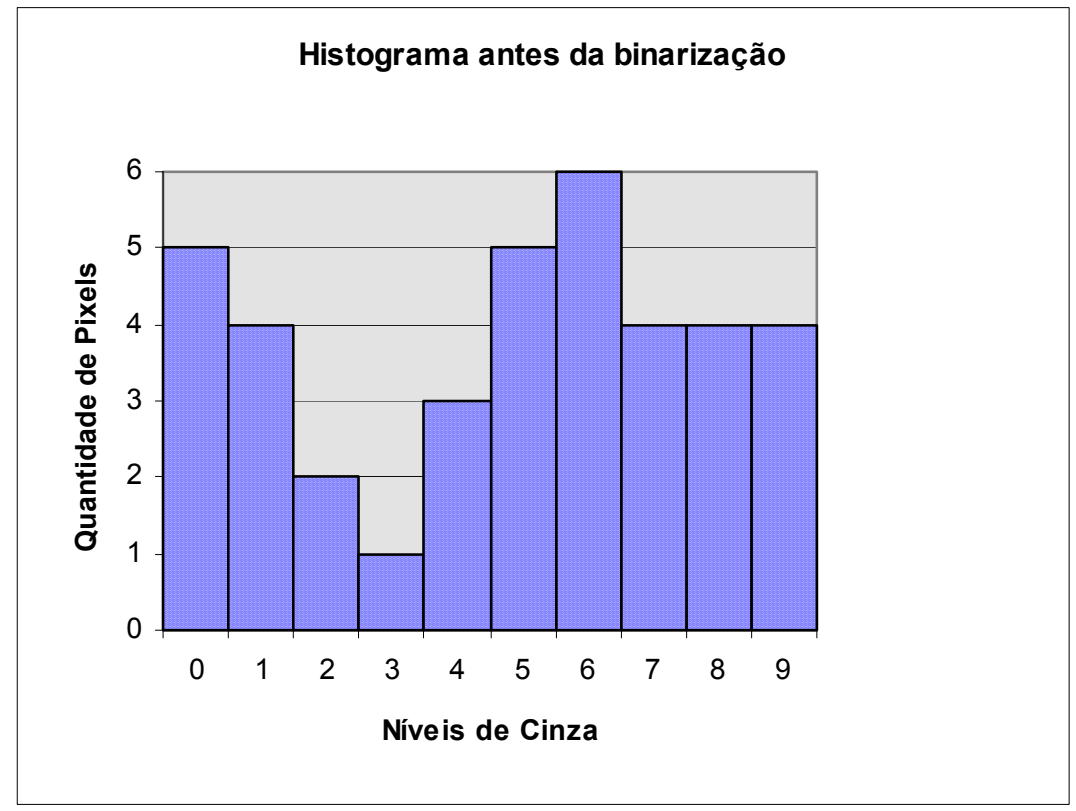

(a)

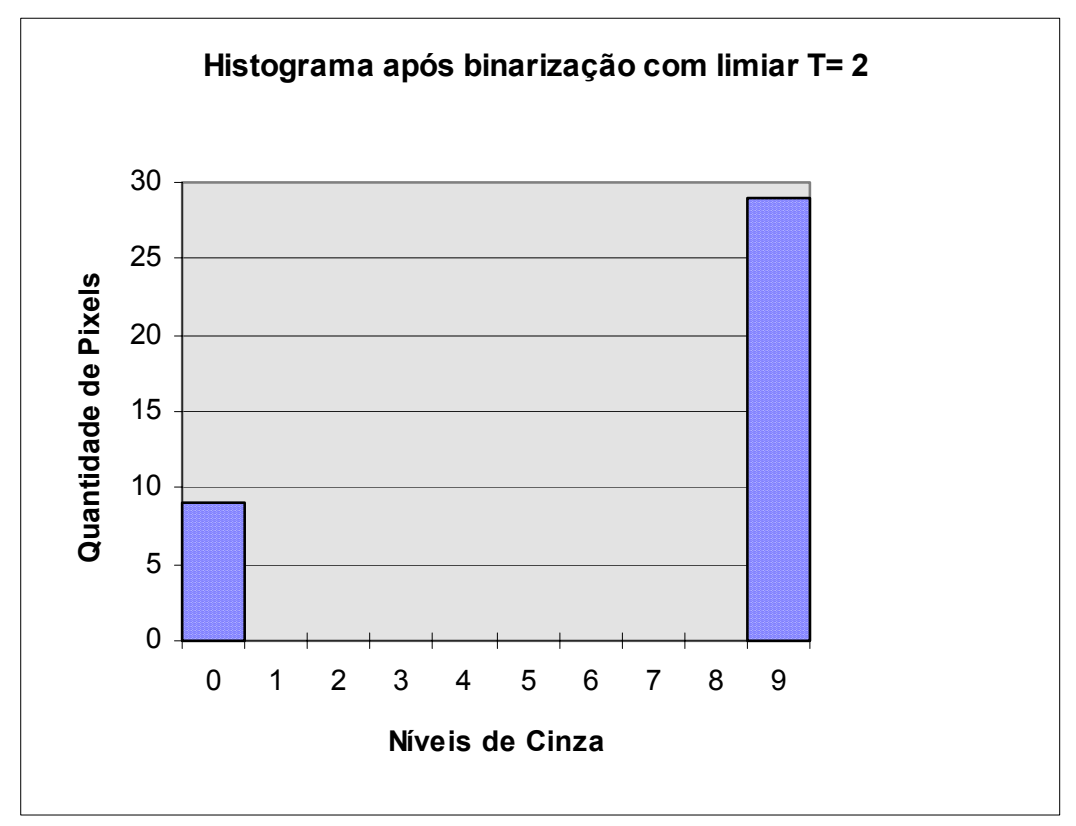

(b)

Figura 3-3 - Exemplo de binarização. a) histograma antes da binarização e b) histograma após a binarização com valor de limiar $=2$. 


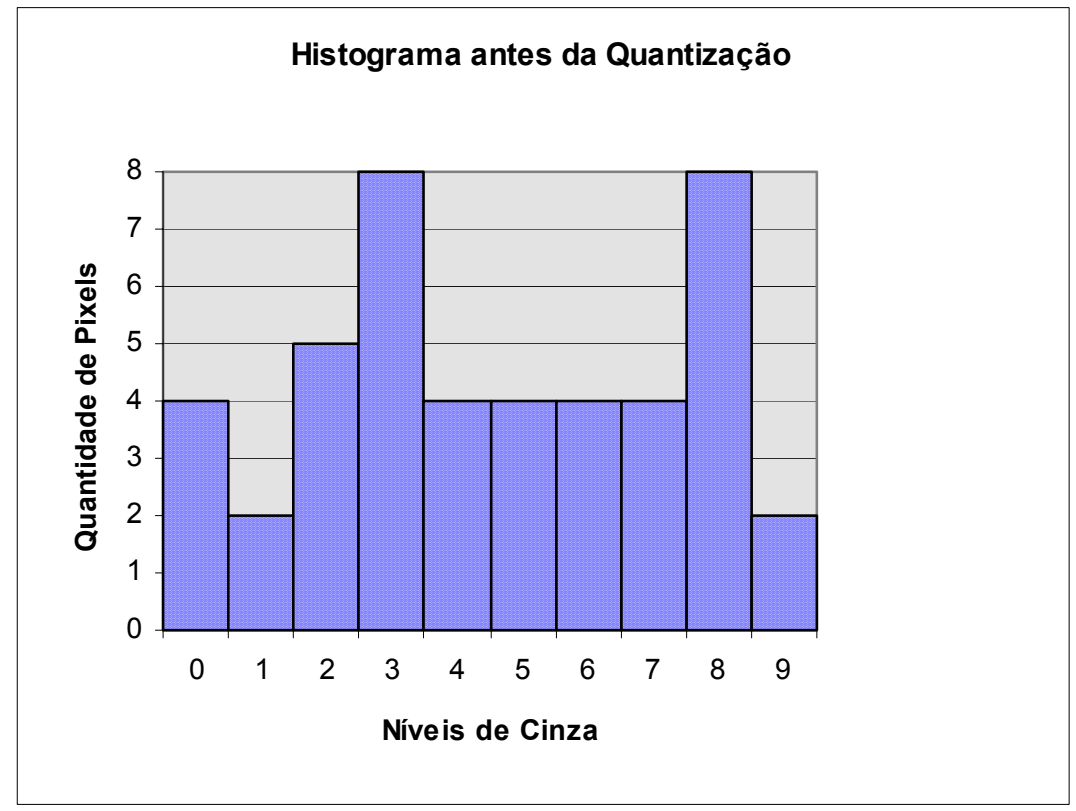

(a)

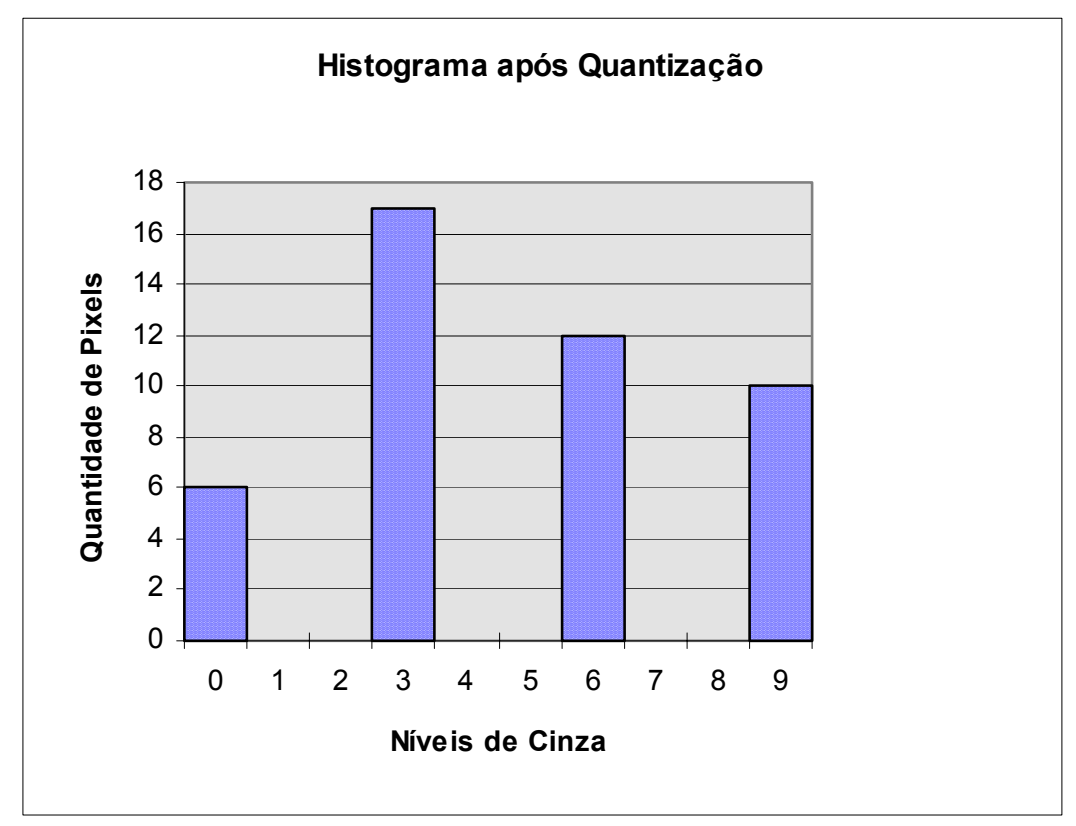

(b)

Figura 3-4 - Exemplo de quantização. a) histograma antes da quantização e b) histograma após a quantização. 


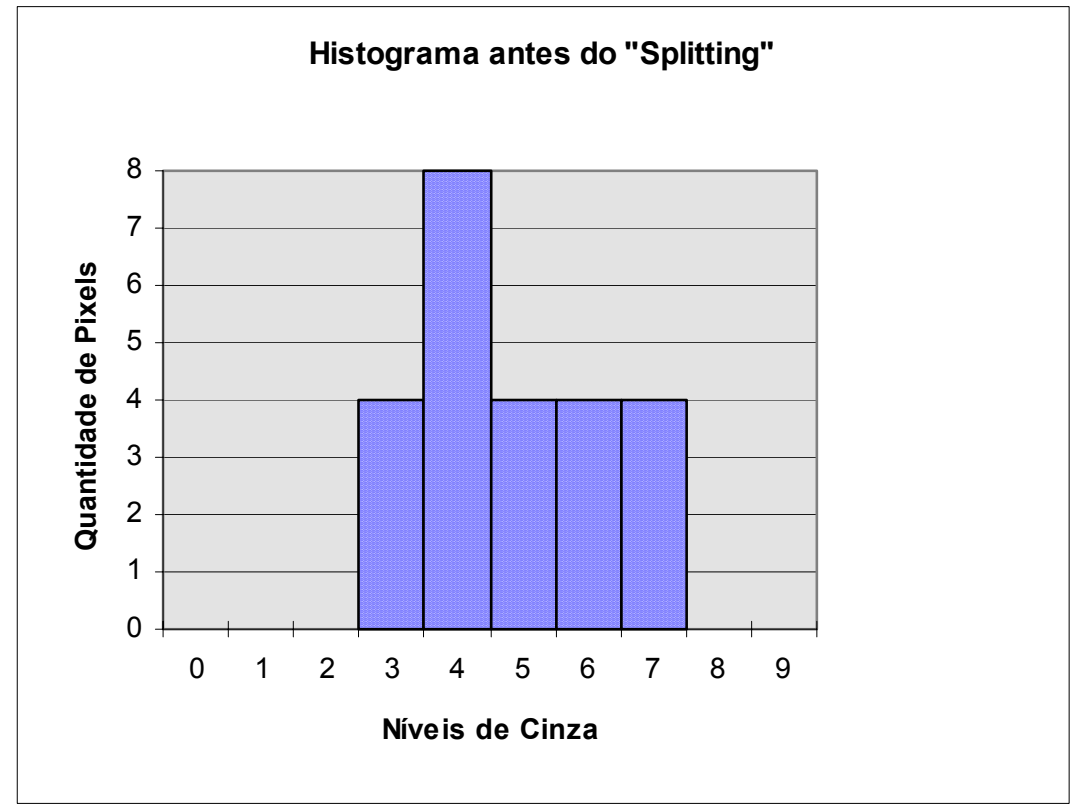

(a)

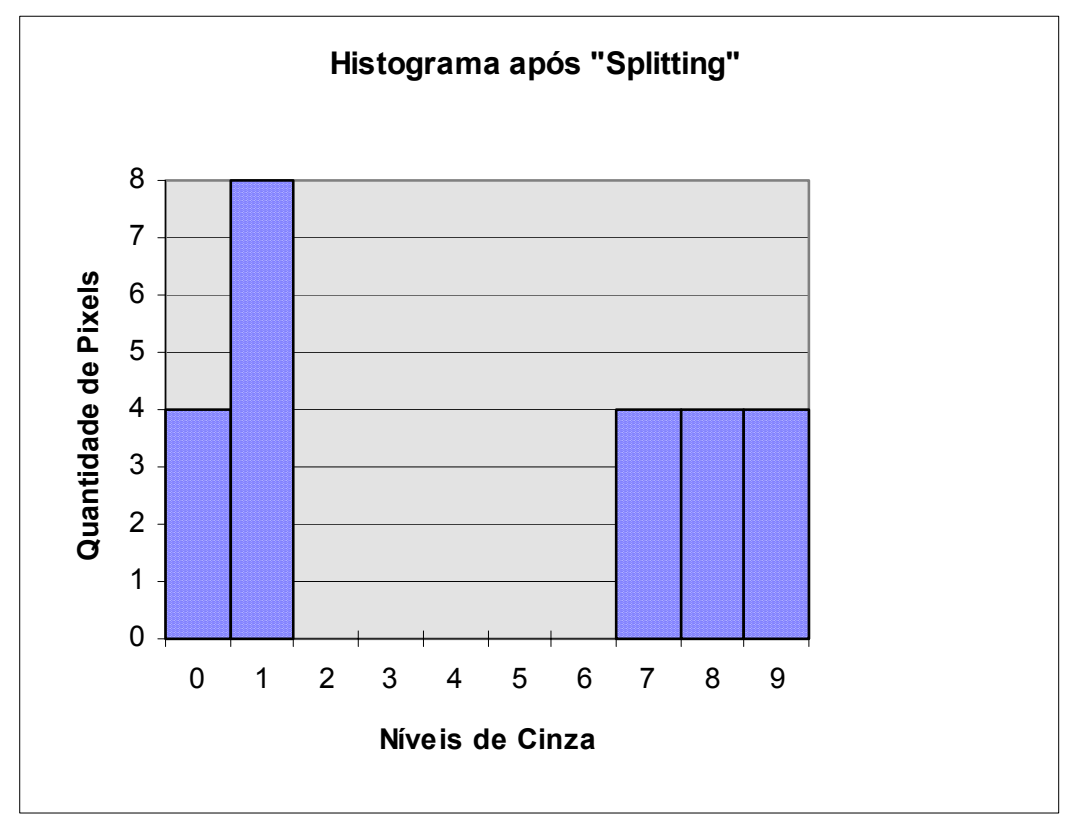

(b)

Figura 3-5 - Exemplo de "splitting". a) histograma antes da técnica de "splitting" e b) histograma após aplicação da técnica de "splitting". 


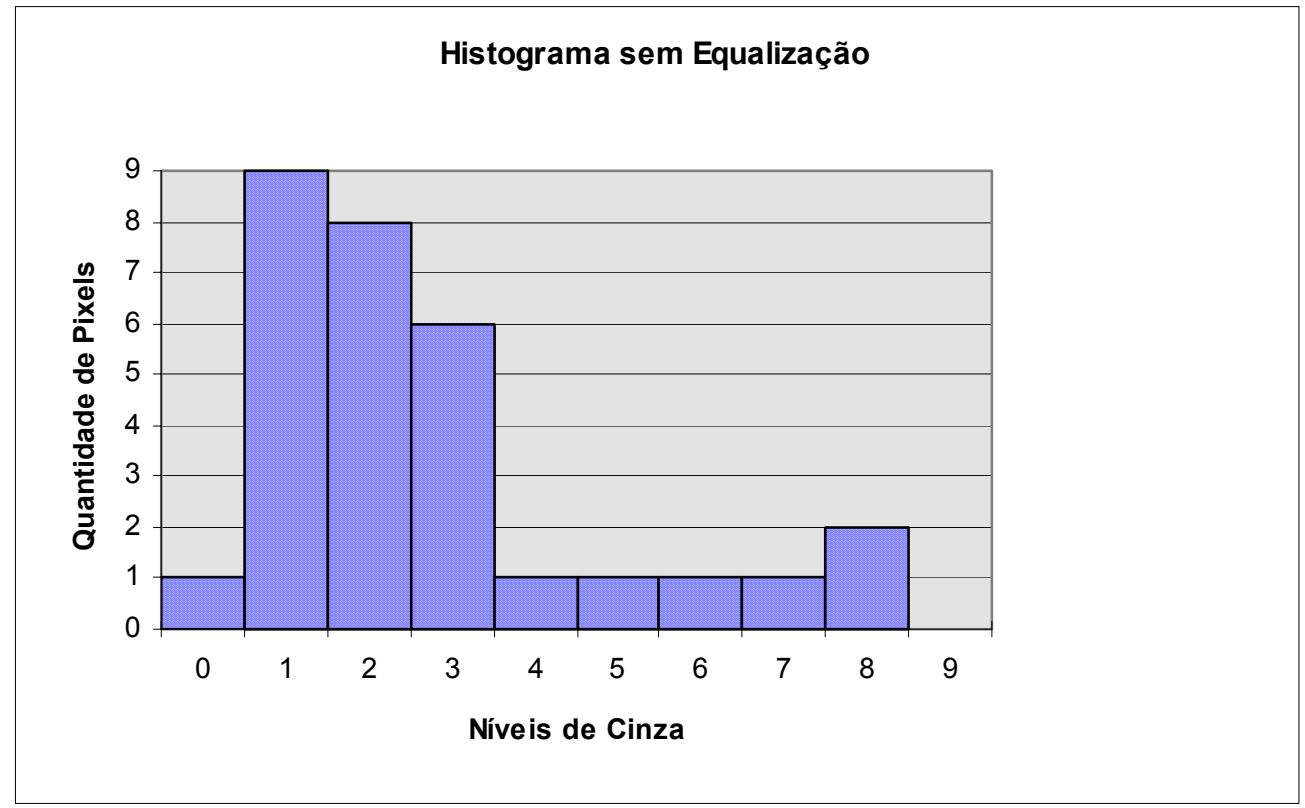

(a)

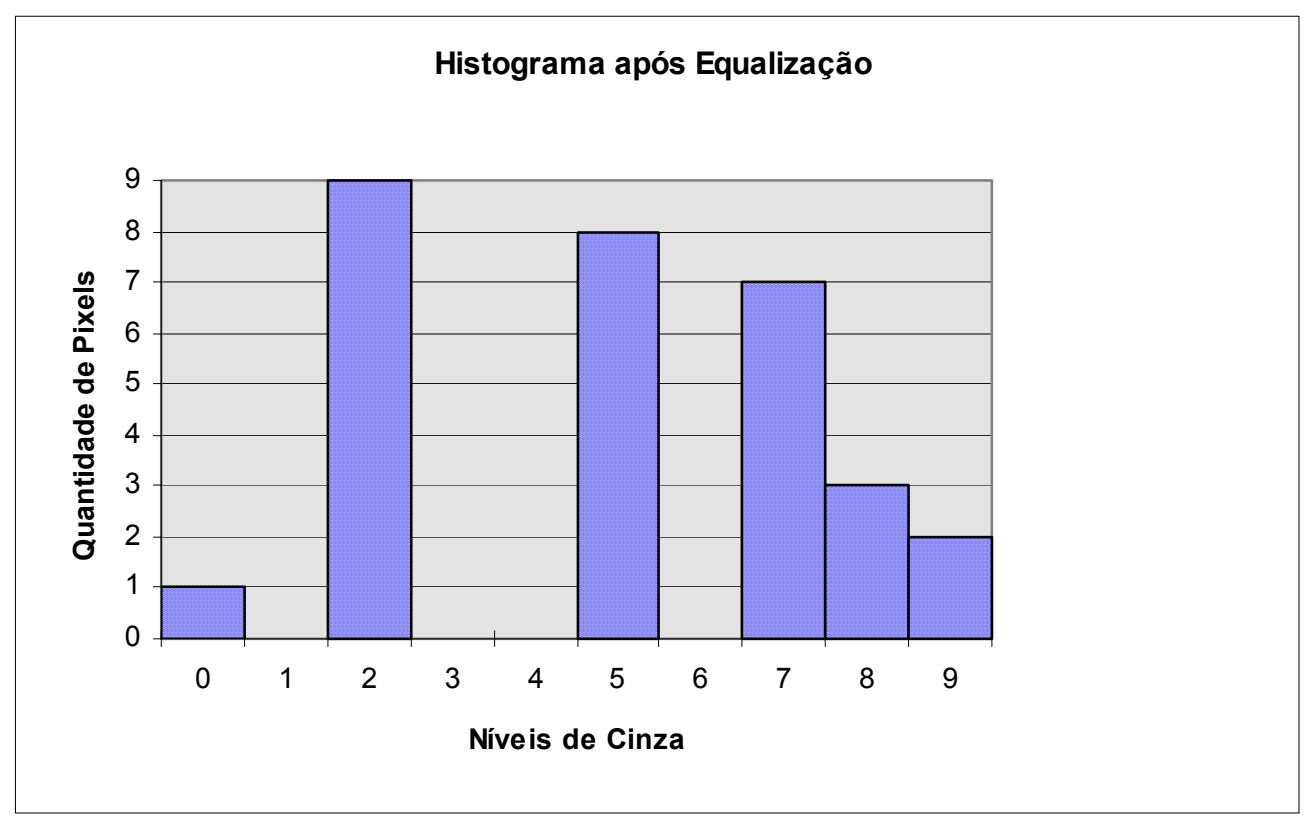

(b)

Figura 3-6 - Exemplo de equalização. a) histograma antes da equalização e b) histograma após a equalização.

\subsubsection{Subtração do fundo}

Esta técnica é amplamente usada em imagens médicas como, por exemplo, angiografia com subtração digital. Consiste em obter uma imagem em um 
estado inicial e armazená-la para posteriormente ser usada como uma "máscara de subtração". São obtidas imagens em outros instantes e, para alcançar o efeito desejado, o nível de cinza de cada pixel é subtraído do nível de cinza do pixel correspondente da máscara, criando-se uma imagem final onde é suprimida a parte redundante nas duas imagens ([BALLARD-82] e [MARQUES-90]).

\subsubsection{Suavização}

Operações de suavização são usadas para diminuir efeitos espúrios resultantes do processo de aquisição da imagem (ruídos, por exemplo). As técnicas descritas neste item foram citadas por Gonzalez e Wintz em [GONZALEZ-87].

\section{a. Média da Vizinhança}

A média da vizinhança consiste em gerar uma imagem onde o nível de cinza de cada pixel é obtido através da média dos valores de cinza dos pixels de uma vizinhança pré-definida. É uma técnica muito empregada para eliminação de ruídos na imagem, apresentando, porém, borramento na imagem final obtida e conseqüente perda na definição de bordas. Considerando a imagem $f(x, y)$ com N x M pixels, podemos definir a imagem gerada $\mathrm{g}(\mathrm{x}, \mathrm{y})$ como:

$$
g(x, y)=\frac{1}{V} \sum_{(p, q) \in S} f(p, q), \operatorname{para} \mathbf{x}=\mathbf{0}, \mathbf{1}, \ldots, \mathbf{N}-\mathbf{1} ; \mathbf{y}=\mathbf{0}, \mathbf{1}, \ldots, \mathbf{M}-\mathbf{1}
$$

onde:

* S é o conjunto de coordenadas de pontos na vizinhança do ponto $(\mathrm{x}, \mathrm{y})$, incluindo o próprio $(\mathrm{x}, \mathrm{y})$;

* V é o número total de pontos na vizinhança escolhida.

\section{b. Filtragem Mediana}

É uma técnica de suavização onde cada pixel da imagem final é substituído pelo nível de cinza mediano em uma vizinhança do pixel. O nível mediano $m$ de um conjunto de valores é tal que metade dos valores no conjunto são menores que $m$ e a outra metade é constituída de valores maiores que $m$. 


\section{c. Filtragem Passa-baixa}

É uma técnica que tem o objetivo de atenuar um intervalo específico de componentes de alta freqüência, como ruídos e bordas.

\section{d. Média de Múltiplas Imagens}

Consiste em obter uma imagem onde cada pixel é a média do mesmo pixel em várias imagens anteriores. Tem o objetivo de eliminar o ruído aleatório presente no conjunto de imagens.

\subsubsection{Realce}

O realce de imagens produz justamente o efeito contrário ao provocado pela suavização. Tem o objetivo de realçar bordas e detalhes procurados na imagem ([GONZALEZ-87]).

\section{a. Realce por Diferenciação}

A maioria dos métodos usados de diferenciação em processamento de imagens é baseada na aplicação de gradientes. Dada uma função $f(x, y)$, o gradiente de $f$ nas coordenadas $(\mathrm{x}, \mathrm{y})$ é definido pelo vetor:

$$
G[f(x, y)]=\left[\begin{array}{l}
\frac{\partial f}{\partial x} \\
\frac{\partial f}{\partial y}
\end{array}\right]
$$

Duas propriedades importantes do gradiente são:

1. o vetor $G[f(x, y)]$ aponta na direção do máximo da função $f(x, y)$;

2. a magnitude de $G[f(x, y)]$ é dada por:

$$
\operatorname{mag}[G]=\left[(\partial f / \partial x)^{2}+(\partial / \partial y)^{2}\right]^{1 / 2}
$$

Para uma imagem digital, a magnitude é aproximada pelas diferenças, sendo que uma aproximação comumente utilizada é:

$$
G[f(x, y)] \cong\left\{[f(x, y)-f(x+1, y)]^{2}+[f(x, y)-f(x, y+1)]^{2}\right\}^{1 / 2}
$$


ou, a utilização de valores absolutos que produzem resultados similares:

$$
G[f(x, y)] \cong|f(x, y)-f(x+1, y)|+|f(x, y)-f(x, y+1)|
$$

Portanto, subtraindo-se ponto a ponto a imagem resultante da diferenciação da imagem original, pode-se obter uma imagem final com detalhes realçados.

\section{b. Filtragem Passa-alta}

Este processo é o inverso da filtragem passa-baixa, já descrita. Consiste em utilizar um filtro que atenue os componentes de baixa-freqüência e realce as bordas e outros detalhes abruptos da imagem. Tem a desvantagem de realçar os ruídos presentes.

\subsection{Processamento de Nível Médio - Segmentação}

Essa fase de processamento tem a responsabilidade de identificar as formas significativas de uma imagem a fim de fornecer informações para a sua interpretação. Em [GONZALEZ-87] define-se a segmentação como "o processo que subdivide uma imagem em suas partes ou objetos constituintes". Para D. H. Ballard e C. M. Brown, em [BALLARD-82], uma imagem segmentada, em visão computacional, é resultante do agrupamento de partes de uma imagem generalizada em unidades homogêneas considerando um ou mais aspectos.

O presente item tem o objetivo de fornecer uma visão geral sobre a segmentação de imagens, citando diversas técnicas utilizadas para tal fim. A maioria das técnicas aqui apresentadas utilizam templates para produzir a imagem final. Em [GONZALEZ-87], é definido um template como uma máscara utilizada para a realização de operações na vizinhança de um pixel. Na prática, é uma matriz cujo elemento central é centralizado no pixel de interesse. Os elementos da vizinhança, incluindo o pixel em questão, são multiplicados pelos valores indicados nas posições correspondentes da matriz. A soma dos resultados obtidos substitui o valor do pixel de interesse na nova imagem. Genericamente, uma máscara de tamanho 3 x 3 pode ser representada da forma indicada na figura 3-7. 


\begin{tabular}{|l|l|l|}
\hline $\mathrm{W}_{1}$ & $\mathrm{w}_{2}$ & $\mathrm{w}_{2}$ \\
\hline $\mathrm{W}_{4}$ & $\mathrm{w}_{5}$ & $\mathrm{w}_{6}$ \\
\hline $\mathrm{W}_{7}$ & $\mathrm{w}_{8}$ & $\mathrm{~W}_{9}$ \\
\hline
\end{tabular}

Figura 3-7 - Exemplo genérico de uma máscara 3 x 3.

Considerando $\mathrm{w}_{\mathrm{i}}, \mathrm{i}=1, \ldots, 9$ os coeficientes da máscara em questão e $\mathrm{x}_{\mathrm{i}}$, $\mathrm{i}=1, \ldots, 9$ os valores dos pixels sob a máscara, o resultado que será atribuído ao pixel central será: $\mathrm{w}_{1} \mathrm{x}_{1}+\mathrm{w}_{2} \mathrm{x}_{2}+\ldots+\mathrm{w}_{9} \mathrm{x}_{9}$.

Os exemplos propostos nos itens a seguir são extraídos da literatura já citada neste capítulo.

\subsubsection{Detecção de pontos isolados}

A detecção de pontos isolados em uma imagem é útil para remoção de ruído e análise de partículas. Para uma imagem com um valor de fundo constante, essa detecção pode ser concretizada com o uso da máscara mostrada na figura 3-8.

\begin{tabular}{|c|c|c|}
\hline-1 & -1 & -1 \\
\hline-1 & 8 & -1 \\
\hline-1 & -1 & -1 \\
\hline
\end{tabular}

Figura 3-8 - Máscara que pode ser usada para detecção de pontos isolados em imagens com fundo constante.

A utilização da máscara acima é auto-explicativa. Para cada locação do template é calculado o valor da soma dos produtos dos pixels pelos coeficientes dados. $\mathrm{O}$ resultado será dado por: $-\mathrm{x}_{1}-\mathrm{x}_{2}-\mathrm{x}_{3}-\mathrm{x}_{4}+8 \mathrm{x}_{5}-\mathrm{x}_{6}-\mathrm{x}_{7}-\mathrm{x}_{8}-\mathrm{x}_{9}$. Em uma área onde o nível de cinza for constante o resultado será 0 . Se a locação coincidir com $\mathrm{x}_{5}$ sendo um ponto isolado, com intensidade maior que o valor de fundo, $\mathrm{o}$ resultado será maior que 0 e, portanto, será realçado.

\section{a. Detecção de linhas}

De forma semelhante ao item anterior, podem ser utilizadas as máscaras demonstradas na figura 3-9 para a detecção de linhas nas direções 
horizontal, $45^{\circ}$, vertical e $-45^{\circ}$, respectivamente. O cálculo do valor do pixel central é realizado conforme já demonstrado.

\begin{tabular}{|c|c|c|}
\hline-1 & -1 & -1 \\
\hline 2 & 2 & 2 \\
\hline-1 & -1 & -1 \\
\hline
\end{tabular}

\begin{tabular}{|c|c|c|}
\hline-1 & -1 & 2 \\
\hline-1 & 2 & -1 \\
\hline 2 & -1 & -1 \\
\hline
\end{tabular}

\begin{tabular}{|l|l|l|}
\hline-1 & 2 & -1 \\
\hline-1 & 2 & -1 \\
\hline-1 & 2 & -1 \\
\hline
\end{tabular}

\begin{tabular}{|c|c|c|}
\hline 2 & -1 & -1 \\
\hline-1 & 2 & -1 \\
\hline-1 & -1 & 2 \\
\hline
\end{tabular}

Figura 3-9 - Máscaras utilizadas para a detecção de linhas.

\section{b. Detecção de bordas}

Partindo da definição de borda como uma fronteira entre duas regiões com níveis de cinza relativamente distintos, os algoritmos utilizados para a detecção de bordas são estruturados de forma a detectar as descontinuidades existentes nas transições.

\section{c. Operador Gradiente}

A idéia básica de segmentação através deste método é aplicar um processamento computacional, baseado em um operador local de derivadas. Computacionalmente, consistem em obter derivadas parciais $\partial \mathrm{f} / \partial \mathrm{x}$ para todos os pixels da imagem. Considerando-se uma vizinhança de $3 \times 3$ pixels em torno de um ponto $(\mathrm{x}, \mathrm{y})$, o operador gradiente é definido como:

$$
\begin{aligned}
& G_{x}=\left(x_{7}+2 x_{8}+x_{9}\right)-\left(x_{1}+2 x_{2}+x_{3}\right) e \\
& G_{y}=\left(x_{3}+2 x_{6}+x_{9}\right)-\left(x_{1}+2 x_{4}+x_{7}\right),
\end{aligned}
$$

onde $\mathrm{x}_{5}$ é o pixel sobre o qual está sendo aplicado o operador.

Estes operadores são conhecidos como operadores de Sobel e, esquematicamente, podem ser representados pelas seguintes máscaras mostradas na figura 3-10, na qual temos, respectivamente: uma região 3 x 3, a máscara utilizada para calcular $G_{x}$ sobre o centro da região e a máscara utilizada para calcular $G_{\mathrm{y}}$ sobre o centro da região.

\begin{tabular}{|l|l|l|}
\hline $\mathrm{x}_{1}$ & $\mathrm{x}_{2}$ & $\mathrm{x}_{3}$ \\
\hline $\mathrm{x}_{4}$ & $\mathrm{x}_{5}$ & $\mathrm{x}_{6}$ \\
\hline $\mathrm{x}_{7}$ & $\mathrm{x}_{8}$ & $\mathrm{x}_{9}$ \\
\hline
\end{tabular}

\begin{tabular}{|c|c|c|}
\hline-1 & -2 & -1 \\
\hline 0 & 0 & 0 \\
\hline 1 & 2 & 1 \\
\hline
\end{tabular}

\begin{tabular}{|l|l|l|}
\hline-1 & 0 & 1 \\
\hline-2 & 0 & 2 \\
\hline-1 & 0 & 1 \\
\hline
\end{tabular}


Figura 3-10 - Região e máscaras para deteç̧ão de bordas através de operadores gradientes.

Uma vez detectadas as bordas da imagem, podem ser realizados processamentos para completá-las, se necessário, e interpretá-las, segmentando as partes desejadas.

Este método tem a vantagem de apresentar simplicidade na aplicação, não envolvendo complexidades computacionais. Como desvantagem está o fato de não apresentar boa imunidade a ruídos. Pelo contrário: a aplicação de templates inclui os ruídos nos cálculos, podendo aumentar efeitos como a suavização da imagem, perdendo definição de bordas.

\section{d. Relaxação de Transição de Borda ("Crack Edge Relaxation")}

Este é um método de reforço de bordas que envolve a atribuição de probabilidade à transição. O algoritmo completo para determinação dos valores de transição e classificação das transições de acordo com as probabilidades é apresentado em [LOW-91].

A vantagem deste método é que separa de forma eficaz as regiões e suas bordas em uma imagem. Entre as suas desvantagens estão: apresentação de uma orientação grosseira das bordas, e a subjetividade envolvida, visto que o processo é interativo, terminando quando o usuário informa que o realce obtido é satisfatório. É uma técnica indicada para figuras com bordas cuja definição tenha qualidade razoável.

\section{e. Transformada de Hough}

A Transformada de Hough é um método aplicável para detecção de bordas quando a curva a ser encontrada pode ser descrita de forma paramétrica, isto é, por retas ou cônicas. A grande vantagem do método é a sua imunidade a interrupções nas bordas e ruídos da imagem.

A técnica é direcionada para detectar bordas de um determinado tipo de curva, como, por exemplo, retas. Gonzalez e Wintz, em [GONZALEZ-87], resumem o método da seguinte forma: considerando um ponto $\left(x_{i}, y_{i}\right)$ e uma equação geral de uma reta $y_{i}=a x_{i}+b$, há um número infinito de retas que passam por $\left(x_{i}, y_{i}\right) \mathrm{e}$ 
que satisfazem a equação se forem variados os valores de $a$ e $b$. No entanto, se escrevermos a equação como $b=-x_{i} a+y_{i}$ e consideramos o plano $a b$ (também chamado espaço de parâmetros), então teremos a equação de uma linha simples para um par fixo $\left(x_{i}, y_{i}\right)$. Além disso, um segundo ponto $\left(x_{j}, y_{j}\right)$, também terá uma linha no espaço de parâmetros associado a ele e esta linha interceptará a linha relacionada com $\left(x_{i}, y_{i}\right)$ em $\left(a^{\prime}, b^{\prime}\right)$, onde $a^{\prime}$ é a inclinação da reta e $b^{\prime}$ é a interceptação da linha contendo $\left(x_{i}, y_{i}\right)$ e $\left(x_{j}, y_{j}\right)$ no plano $x y$. De fato, todos os pontos contidos nesta linha terão linhas no espaço de parâmetros que se interceptarão em $\left(a^{\prime}, b^{\prime}\right)$. Explicações mais detalhadas e sugestões de algoritmos podem ser encontrados nas referências [BALLARD-82] e [PEREIRA-95].

\section{f. Grafos}

Um grafo é um conjunto finito de nós unidos por um conjunto de pares não ordenados denominados arcos. Aos arcos são atribuídos valores denominados custos. Há um nó de início que é único e possui o nível mais baixo. Analogamente, há um único nó objetivo que indica o fim do grafo. Entre os nós inicial e final, são possíveis diversos caminhos através dos arcos. O custo de cada caminho é a soma dos custos dos arcos nele envolvidos.

A detecção de fronteira através de grafos envolve encontrar o caminho de menor custo entre o nó inicial e o nó objetivo. O "segredo" da técnica é estabelecer uma fórmula para calcular o custo de cada arco. Geralmente são utilizadas fórmulas que determinam a diferença entre níveis de cinza entre dois pixels que podem compor a borda da imagem.

\section{g. Crescimento de Região}

Este método consiste em agregar conjuntos de pixels em regiões maiores. A aproximação de processamento mais simples é a agregação de pixels, isto é: escolhe-se um pixel ou um conjunto de pixels denominados "sementes" e faz-se o crescimento da região através da agregação de pixels vizinhos às sementes que possuem propriedades similares (intensidade, cor, textura etc). O processo continua até se atingir uma condição pré-estabelecida de parada, como por exemplo, um determinado nível de cinza ou uma distância específica. 
A vantagem é que a imagem não precisa ser homogênea, pois as suas características são previamente analisadas e incluídas nos descritores de semelhança. As principais desvantagens são: dificuldade na seleção dos pixels sementes (a aplicação deve ser conhecida); dificuldade no estabelecimento das propriedades de semelhança (a aplicação e os tipos de dados da imagem devem ser conhecidos) e dificuldade na determinação de condições de parada (depende da análise da imagem). Na figura 3-11 é mostrado um exemplo de segmentação de imagem através da técnica de crescimento de região.

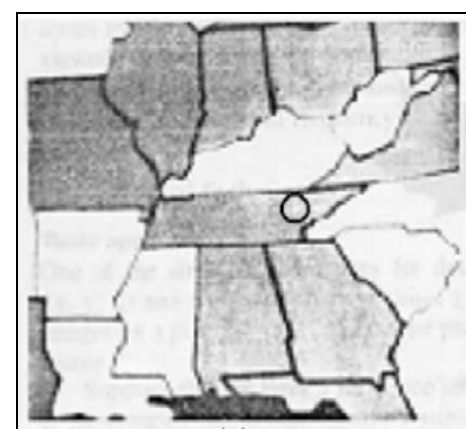

(a)

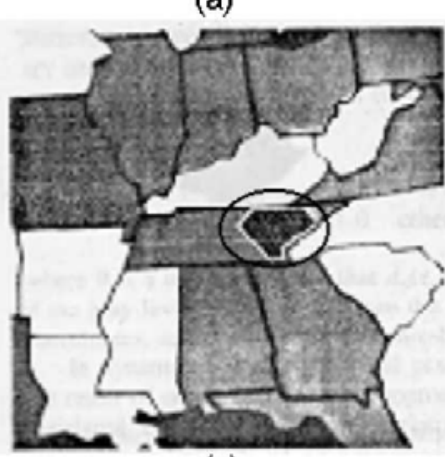

(c)

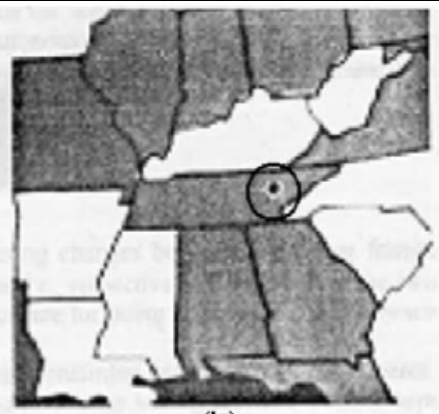

(b)

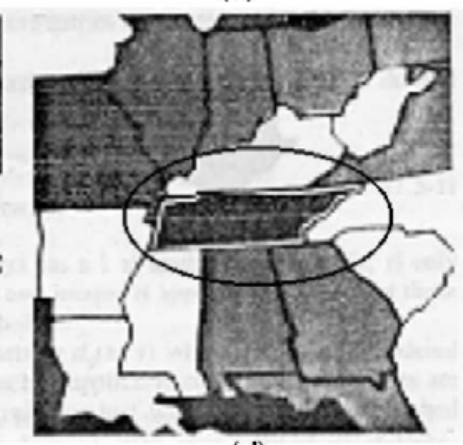

(d)

Figura 3-11 - Exemplo de aplicação da técnica de "crescimento de região".

\subsubsection{Representação de estruturas geométricas bidimensionais}

Este item tem o objetivo de indicar técnicas de representação de estruturas geométricas. São artifícios utilizados para armazenar a representação dessas estruturas para que possam ser recuperadas e reconhecidas posteriormente. 


\section{a. Representação de fronteiras através de aproximação poligonal}

O objetivo de uma aproximação poligonal é capturar a essência do formato da borda utilizando o menor número possível de segmentos de reta. O resultado é uma figura que representa a forma da imagem original.

Um exemplo que utiliza polilinhas pode ser visualizado na figura 312. Como se vê, podem-se armazenar somente as coordenadas dos pontos que definem cada segmento de reta a fim de recuperar a borda quando necessário.

Outra forma de aproximação poligonal é a inscrição de polígono convexo, em que a fronteira é descrita através dos pontos que formam os vértices do polígono convexo inscrito. Na figura 3-13 pode ser visto um exemplo deste processo. A figura (a) indica a fronteira original convexa. Na figura (b) é determinada a maior distância entre duas pontas da fronteira $(a b)$. O ponto $c$ é a maior distância da perpendicular no primeiro plano e o ponto $d$ representa a maior distância da perpendicular no segundo plano. Na figura (c) vemos o polígono convexo inscrito através da união dos pontos da fronteira a,b,c,d.

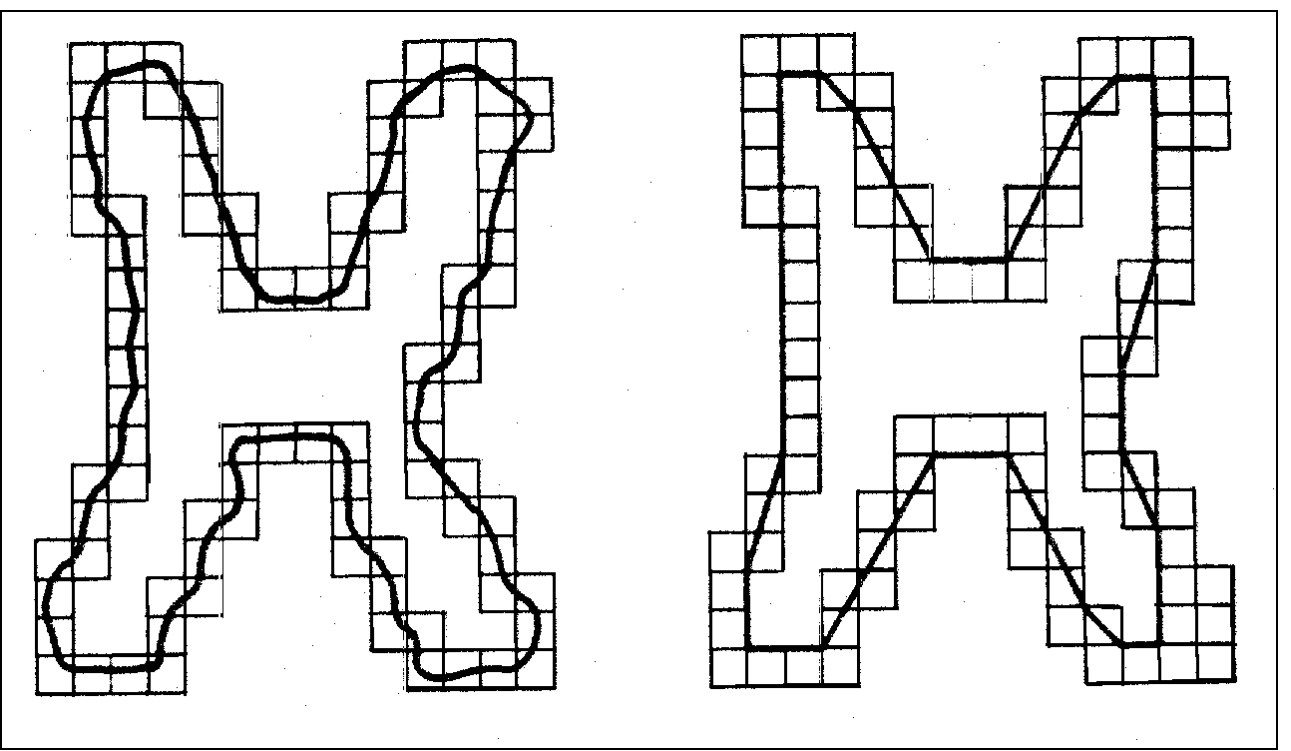

Figura 3-12 - Representação da borda de uma imagem através de aproximação poligonal. 


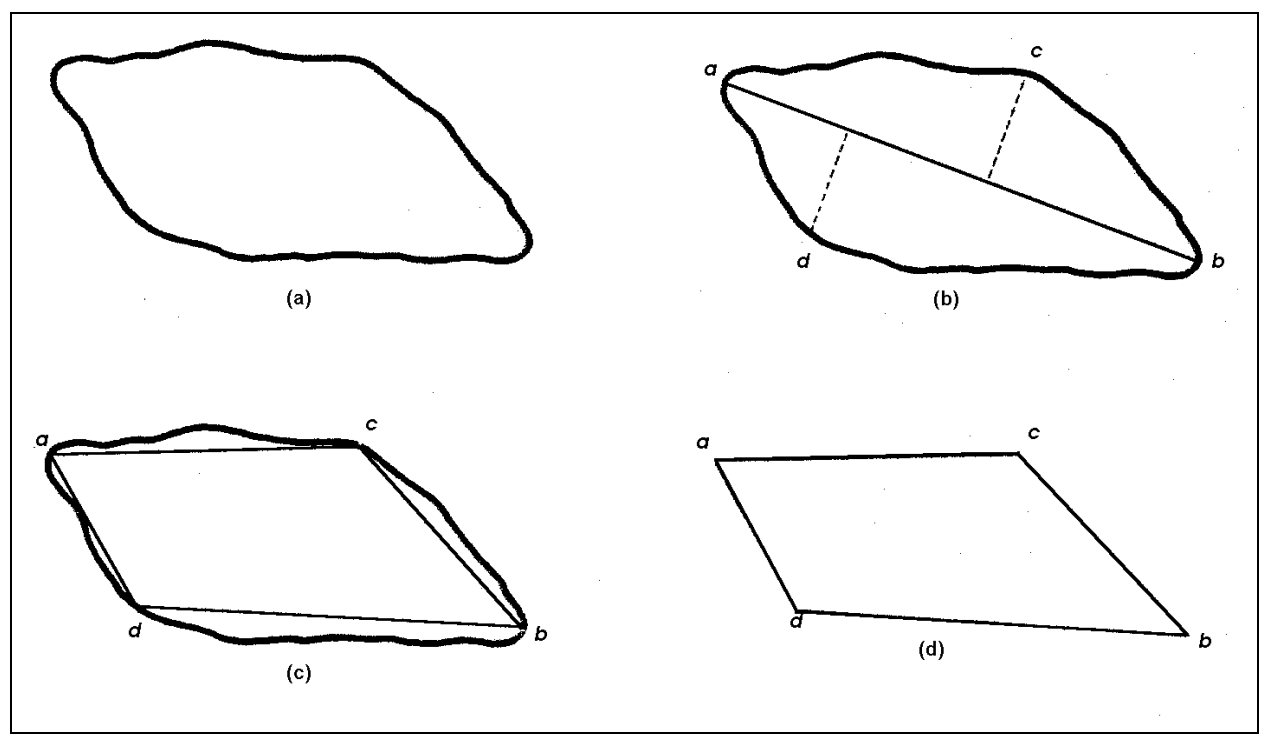

Figura 3-13 - Exemplo de descrição de fronteira através de inscrição de polígono convexo.

\section{b. Representação de fronteiras através de Código de Cadeia}

O Código de Cadeia, também conhecido como "Chain Code" ou

"Código de Freeman", representa uma fronteira através de uma seqüência conectada de segmentos, com direção e comprimento definidos. A imagem é "gradeada" e a fronteira é aproximada através dos segmentos de retas pertencentes ao código de 4 ou de 8 direções (figura 3-14). Quanto menor o espaço utilizado para o "gradeamento", melhor será a resolução da borda, porém, maior será o espaço ocupado para armazenagem. Uma borda descrita por esses códigos é mostrada na figura 3-15.

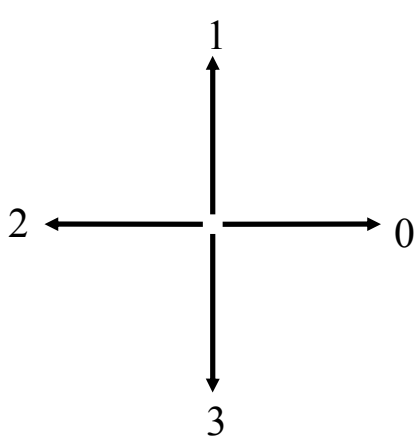

(a)

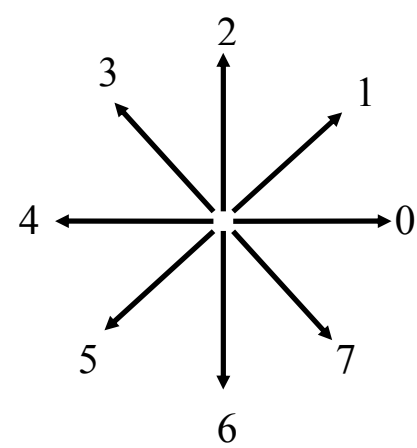

(b)

Figura 3-14 - a) Código de Cadeia de 4 direções. b) Código de Cadeia de 8 direções. 


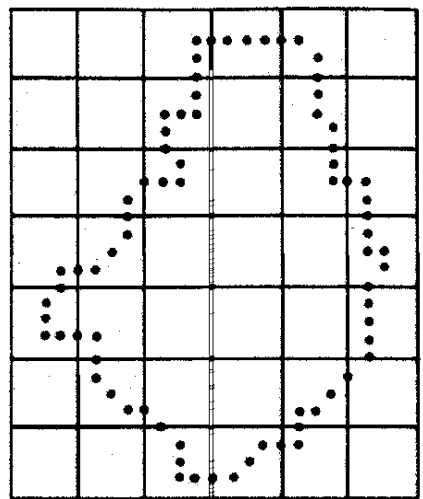

(a)

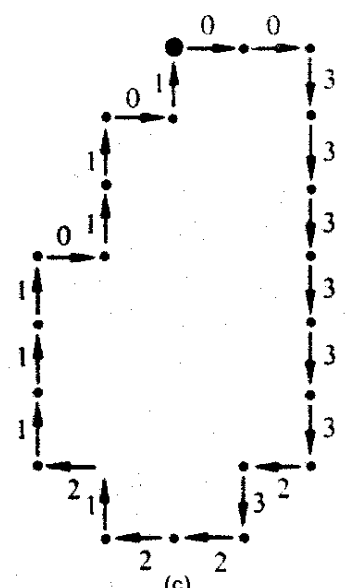

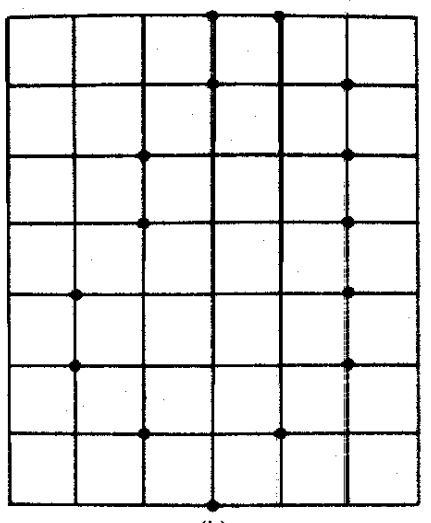

(b)

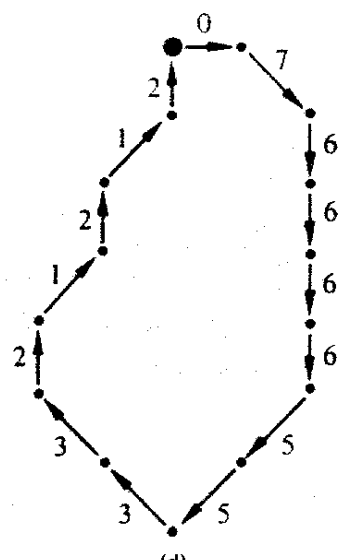

(d)

Figura 3-15 - a) Borda com sobreposição da grade a ser utilizada. b) Resultado do "gradeamento". c) Código de Cadeia de 4 direções. d) Código de Cadeia de 8 direções.

\section{c. Outros descritores de fronteira}

Outros descritores podem ser aqui citados, podendo ser amplamente encontrados na literatura. Entre eles:

* Curvas $\varphi$-S: é uma versão contínua do código de cadeia;

* Descritores de Fourier: representam a fronteira como uma função periódica que pode ser expandida em uma série de Fourier;

* Assinaturas: função unidimensional que representa uma fronteira;

* B-Splines: técnica de interpolação polinomial para aproximar uma fronteira;

* Secções Cônicas: utilização de figuras geométricas (círculos, elipses etc) para descrever uma fronteira. 


\section{d. Representação de região através de Propriedades de Formato}

As propriedades de formato são elementos intrínsecos da imagem que podem descrever a região de interesse.

Comprimento da Fronteira- é o perímetro da borda, podendo ser resultante da contagem de pixels pertencentes à fronteira.

Diâmetro da Fronteira- é definido como a distância máxima entre dois pontos quaisquer da fronteira.

Área- é o número de pixels contidos por uma fronteira.

Excentricidade- é dada pelo valor da maior diagonal em um sentido dividido pelo valor da maior diagonal no sentido perpendicular ao anterior.

Compacidade- é definida como: $C=\frac{(\text { perimetro })^{2}}{\text { area }}$

Descritores topológicos- são propriedades que não são afetadas por qualquer deformação na imagem como:

* número de furos;

* número de componentes conectados;

* número de Euler: $\mathrm{E}=\mathrm{C}-\mathrm{H}$

onde: $\mathrm{C}=$ número de componentes conectados

$\mathrm{H}=$ número de furos.

\section{e. Outros descritores de região}

Outras estratégias podem ser utilizadas para representação de região.

Algumas delas já foram citadas também para representar fronteiras:

* Assinaturas;

* Esqueleto (eixo médio);

* "Shape Numbers": derivativo do Código de Cadeia.

\subsection{Processamento de alto nível}

Esta parte do processamento de imagens é responsável pelo relacionamento da imagem com um banco de dados conhecido a fim de reconhecê-la 
e atribuir-lhe algum significado. Uma base de conhecimento é uma representação abstrata do mundo, extremamente útil para a visão de computadores. Não entraremos em detalhes nesta questão por não ser esse o objeto da pesquisa realizada. $O$ importante, no nosso caso, é lembrar que o processamento de imagem tem um objetivo primordial: poder reconhecer a que estrutura está relacionado o objeto representado. A partir daí, podemos manipular a imagem reconhecida da forma que desejarmos: classificá-la, desmembrá-la, uni-la a outra imagem, entre outras operações possíveis.

\subsection{Conclusões}

Este capítulo teve o objetivo de fornecer uma revisão resumida das técnicas básicas de processamento de imagens cujos conceitos são de extrema importância para a compreensão dos capítulos seguintes. Como as variações desses métodos são muitas, limitamo-nos a apresentar aquelas mais empregadas na literatura para detecção do câncer de mama. No próximo capítulo, veremos a utilização de alguns desses procedimentos em algoritmos para auxiliar no diagnóstico dessa doença. 


\section{4}

\section{PROCESSAMENTO DE IMAGENS PARA DETECÇÃO DE MICROCALCIFICAÇÕES}

Estudos de novas e antigas técnicas de processamento de imagens têm sido objeto de interesse para a detecção de aspectos presentes em mamogramas a fim de possibilitar um diagnóstico precoce do câncer de mama. Cada equipe de pesquisadores geralmente segue uma linha a fim de detectar microcalcificações e identificar agrupamentos dessas estruturas.

O interesse pelas microcalcificações é justificado pelo fato de que essas estruturas associadas aos tumores mamários revelam-se cada vez mais como fatores determinantes no diagnóstico, a partir de pesquisas, como a desenvolvida pelo grupo de M. Le Gal ([LEGAL-84]) que relaciona formato de microcalcificações com a malignidade dos tumores.

Uma das dificuldades a ser superada na área é a ausência de padronização de conceitos. As definições a respeito de calcificações e microcalcificações e outros termos utilizados pelos especialistas apresentam grande variação na literatura. Em 1980, R.L.Egan et al., ([EGAN-80]), após pesquisarem 42.888 estudos clínicos e radiográficos, concluíram que as calcificações apresentavam tamanho variando de 2 a $3 \mathrm{~mm}$. Em 1982, E. A. Sickles ([SICKLES-82]) fez um estudo da detectabilidade de microcalcificações utilizando diversas técnicas de formação de imagens. Nesse estudo, as microcalcificações são simuladas e seus tamanhos estão no intervalo de 0,15 a $0,55 \mathrm{~mm}$. Segundo pesquisa do mesmo autor, descrita em [SICKLES-86], as calcificações são as menores estruturas identificadas em um mamograma e são vistas em cânceres de mama como “clusters" de minúsculas partículas (menores que $0,5 \mathrm{~mm}$ ), apresentando formas lineares, curvilineares ou ramificações. F. Lefebvre et al. ([LEFEBVRE-94] destacaram a dificuldade de detecção de microcalcificações devido à apresentação de tamanhos menores que $1 \mathrm{~mm}$. 
Como mamografia é o método mais empregado para registro de imagem da mama, a maioria das técnicas computadorizadas utilizam o mamograma como fonte de dados. No entanto, o tamanho das microcalcificações, a diferença de intensidade nas diversas regiões do mamograma e os problemas inerentes ao próprio sistema mamográfico (os comentados no capítulo 2 deste trabalho) tornam trabalhosas as técnicas de processamento de imagem empregadas para a detecção automatizada de indícios de câncer. Neste capítulo veremos algumas das técnicas propostas por autores de vários centros de pesquisa, ressaltando que geralmente utilizam os métodos originais ou modificados de processamento de imagem descritos no capítulo anterior.

\subsection{Dificuldades na detecção e processamento de imagens de microcalcificações mamárias}

Muitos são os fatores que dificultam a detecção e o processamento computadorizado de imagens de microcalcificações mamárias. Alguns deles relacionam-se às características do mamograma, outros são resultantes de limitações da digitalização e outros ainda constituem características intrínsecas da própria microcalcificação.

Sickles apresentou em [SICKLES-82] testes realizados a fim de estudar a detectabilidade de pequenas estruturas em mamografias com sistemas écran-filme e em xero-radiografia ${ }^{4}$. O objetivo principal foi demonstrar a detectabilidade dessas estruturas nos sistemas testados, de acordo com seu tamanho, técnicas utilizadas, fabricante do equipamento, tamanho do ponto focal, intensidade da dose e outras características particulares de cada sistema.

Foram avaliadas 24 técnicas radiográficas, usando uma grande variedade de tubos de raios-X, sistemas de registro de imagem e graus de magnificação. No trabalho, simularam-se microcalcificações por grãos de óxido de

\footnotetext{
4 Xero-radiografia é a produção de uma imagem visível utilizando a superfície
} carregada de um fotocondutor como meio de detecção que dissipa parcialmente a carga quando há incidência de raios-X para formar uma imagem latente. A imagem latente torna-se visível através de processo xerográfico (CURRY III-90). 
alumínio, de tamanho variando entre 0,15 e $0,55 \mathrm{~mm}$. Os pontos simulados foram arranjados randomicamente em "clusters", sendo alocadas, para cada "cluster", de 4 a 12 partículas de cada um dos seis tamanhos definidos para as microcalcificações. As estruturas simuladas foram coladas em tiras de tecidos de mamas humanas de mulheres adultas. $\mathrm{O}$ o autor chegou às seguintes conclusões principais:

* a detectabilidade das partículas foi melhorada com todas as técnicas de ponto microfocal ${ }^{5}$, especialmente aquelas que incluem uma magnificação radiográfica;

* nenhuma das calcificações simuladas menores que $0,29 \mathrm{~mm}$ foi detectada por técnicas convencionais; todas as técnicas de magnificação, porém, registraram com sucesso pelo menos alguns dos pontos com tamanho igual ou inferior a $0,22 \mathrm{~mm}$;

* a detectabilidade de pontos foi superior para técnicas de xero-radiografia quando comparada com técnicas de sistemas écran-filme, salientando-se que a superioridade da xero-radiografia é prejudicada pela necessidade de grande aumento na dose de raios-X aplicada para o registro da imagem.

H-P Chan et al. publicaram em [CHAN-94] uma avaliação da influência do tamanho e da intensidade do pixel em mamogramas digitalizados na previsão do esquema automatizado de detecção.

Foram digitalizados 25 mamogramas obtidos de um sistema com ponto focal de 0,3 mm, anodo de Molibidênio e filtro de Molibidênio de 0,3 mm, contendo cada mamograma um "cluster" de microcalcificações sutis comprovado por biópsia. Esses mamogramas foram digitalizados com tamanho de pixel de $0,035 \mathrm{~mm} \times 0,035 \mathrm{~mm}$ e 12 bits (4096 níveis de cinza). O sistema de aquisição foi calibrado de tal forma que a densidade fosse linearmente relacionada com valores de pixel no intervalo 0,1-2,8 unidades de densidade ótica, sendo que cada valor de pixel representava 0,001 unidade. Mamogramas digitalizados com tamanho de pixel

\footnotetext{
${ }^{5}$ neste estudo um equipamento foi considerado como possuidor de ponto microfocal quando o tamanho nominal do seu ponto focal era menor que $0,1 \mathrm{~mm}$.
} 
grande ou menor número de bits foram simulados através da média de pixels adjacentes ou truncando-se bits menos significativos, respectivamente.

O esquema de detecção computadorizada de microcalcificações utilizado para o teste consistiu em três passos: pré-processamento, segmentação e classificação. No primeiro passo, a relação sinal-ruído da imagem das microcalcificações foi realçada com uma técnica de diferença de imagem. Foi usado um filtro de realce de sinal para destacar a microcalcificação e suavizar o ruído randômico. Um filtro de supressão de sinal foi empregado para suavizar o ruído. As duas imagens resultantes foram então subtraídas para que na imagem resultante a estrutura de fundo de baixa freqüência fosse removida e o ruído de alta freqüência fosse suprimido. Neste estudo, os filtros usados foram lineares. Para a segmentação foi utilizado um "thresholding" local adaptativo. Foi construído o histograma da imagem da diferença e as regiões com pixels cujas intensidades eram maiores que um valor de limiar foram determinadas por um "thresholding" global em combinação com uma técnica de crescimento da região. O procedimento foi repetido até que o número de regiões obtidas caísse dentro de um intervalo que foi definido pelo usuário. As características determinadas das estruturas foram: centro, tamanho, contraste máximo e forma. Para discriminar se um conjunto de pixels constituía ou não um sinal, em cada reconhecimento de sinal, três procedimentos foram adotados:

1. um "thresholding" de tamanho foi ajustado para excluir sinais abaixo de um certo tamanho (que provavelmente eram ruídos);

2. foi empregado um "thresholding" de contraste para excluir possíveis sinais que apresentassem um contraste maior que o número de entradas dos desvios-padrões acima da média de contraste de todos os sinais em potencial;

3. foi aplicado um procedimento de aglomeração regional, onde um sinal foi considerado positivo se o número de sinais encontrados na vizinhança dentro de um diâmetro de entrada em volta do sinal fosse maior que um número pré-estabelecido; os sinais remanescentes que não estavam inseridos em aglomerações foram considerados ruídos, e, conseqüentemente, foram excluídos. 
Os sinais que passaram nos testes foram comparados com um arquivo verdadeiro da imagem de entrada e contabilizado o número de sinais verdadeiropositivos (VP) e falso-positivos (FP). Um sinal foi considerado VP se sua localização espacial estivesse dentro de uma distância de $0,35 \mathrm{~mm}$ (tamanho de 10 pixels) da localização de uma microcalcificação verdadeira do arquivo de entrada.

O mesmo esquema de detecção foi aplicado a imagens de vários tamanhos e intensidades de pixel. Para cada tamanho foi testado um conjunto de parâmetros. Os resultados podem ser observados na figura 4-1 e figura 4-2. A figura 4-1 mostra a influência do tamanho do pixel na detecção de microcalcificações sutis e na figura 4-2 percebe-se o quanto a precisão do esquema depende da intensidade do pixel.

Os pesquisadores concluíram que os efeitos dos parâmetros de digitalização na precisão de detecção dependem muito das imagens utilizadas para teste. Se as imagens possuíssem microcalcificações sutis, essa dependência era muito grande. Os efeitos da intensidade do pixel nessa precisão dependeu também do ruído do sistema de imagem.

\subsection{Classificação de calcificações em relação aos tipos de tumores associados}

Um esquema computadorizado completo para auxiliar na detecção de câncer de mama deveria prover uma classificação de lesões em benignas e malignas a fim de fornecer ao médico um diagnóstico inicial. A decisão final, todavia, sempre cabe ao médico, mas o esquema pode dar subsídios para a formação de tal opinião. Com este propósito, vários pesquisadores têm mostrado interesse em estabelecer métodos para classificar calcificações e microcalcificações de acordo com sua associação com tumores benignos ou malignos. 


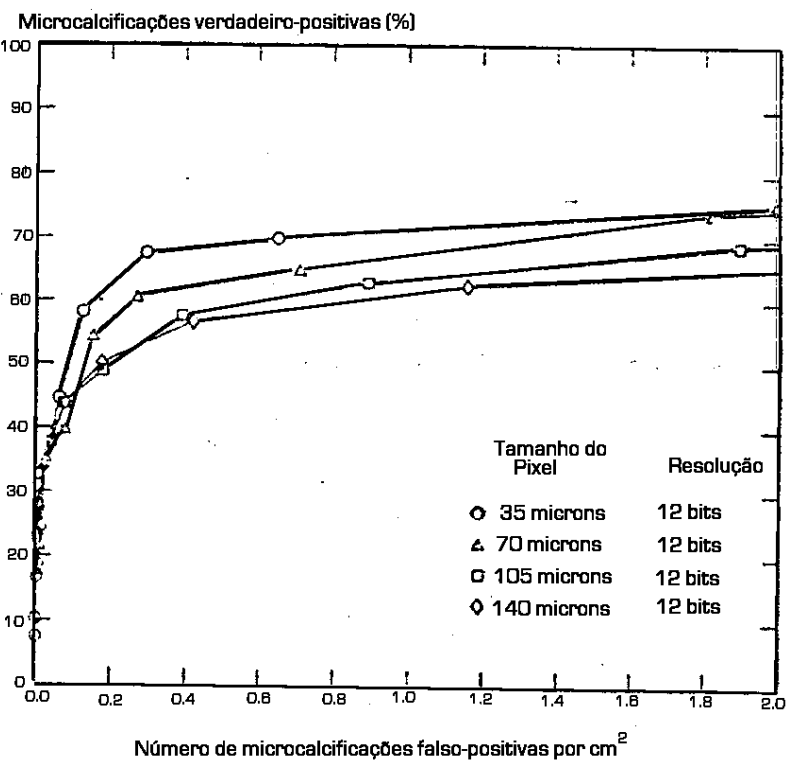

Figura 4-1 - Influência do tamanho do pixel na precisão da detecção ([CHAN-94]).

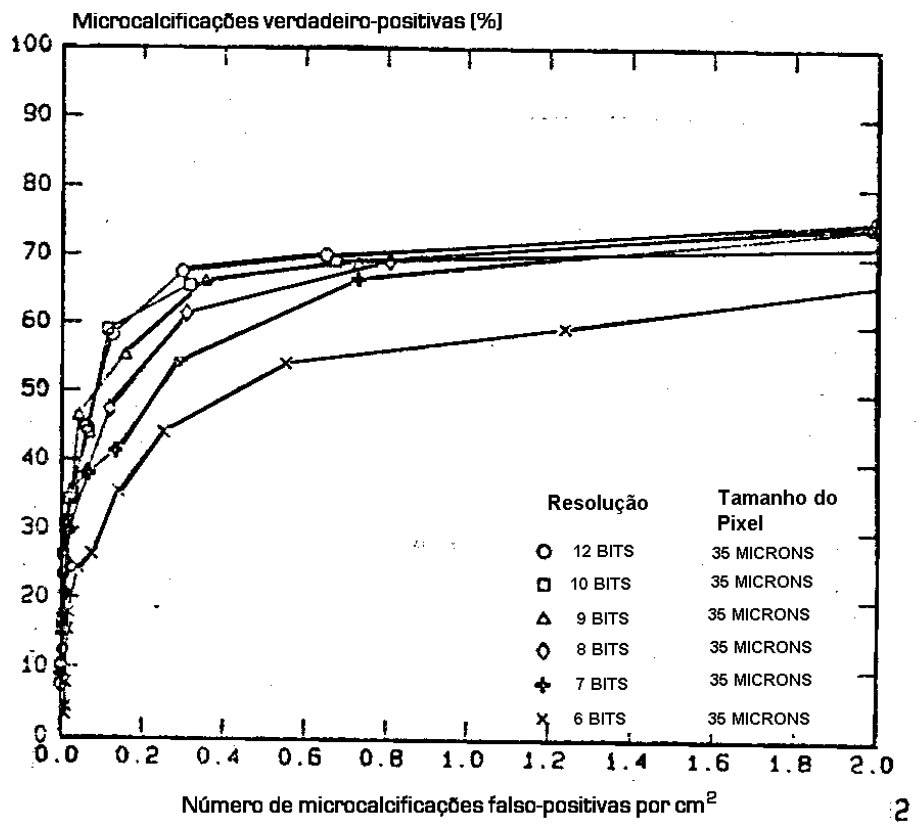

Figura 4-2 - Influência da intensidade do pixel na precisão da deteç̧ão ([CHAN-94]).

E. Sickles, em 1986 ([SICKLES-86]), publicou resultados de sua pesquisa em torno da classificação de microcalcificações, propondo uma forma de avaliação. Segundo ele, o primeiro passo é identificar aqueles casos em que as estruturas são caracterizadas como benignas, sem requerer estudos adicionais. Neste grupo estão incluídas: calcificações com centros brilhantes, calcificações arteriais, duct ectasi (calcificações com secreções), fibroadenomas calcificados, calcificações 
pós-cirúrgicas, leite de cálcio em cistos benignos finos e granulomas devidos à injeção de corpos estranhos.

O autor afirma que, exceto no caso dessas estruturas, as demais levam à suspeita de malignidade, devendo, portanto, sofrer um exame mais detalhado. Salienta ainda que duas características mamográficas que sugerem malignidade são o tamanho reduzido das estruturas (menor que $0,5 \mathrm{~mm}$ ) e a sua distribuição em agrupamentos. A autenticidade dessa informação, segundo Sickles, advém de que muitos radiologistas suspeitam de malignidade quando são encontradas no mínimo cinco partículas menores que $0,5 \mathrm{~mm}$ dentro de um volume comprimido de $1 \mathrm{~cm}^{3}$.

M. Le Gal et al. citam em [LE GAL-84] outra forma de classificação de microcalcificações de acordo com o seu formato, relacionando-as à benignidade ou malignidade. Através do estudo de resultados de biópsias, os autores fornecem um dado muito importante, afirmando que a morfologia das microcalcificações sugere a classificação em 5 tipos, de acordo com os estudos realizados:

Tipo 1: anelares - relacionadas a 100\% de lesões benignas;

Tipo 2: puntiformes regulares - $22 \%$ de lesões malignas e $60 \%$ de benignas;

Tipo 3: elementos pequenos que ainda não apresentam formas definidas - $40 \%$ de lesões malignas e $50 \%$ de benignas;

Tipo 4: puntiformes irregulares - $66 \%$ de lesões malignas e $23 \%$ de lesões benignas;

Tipo 5: vermiformes - $100 \%$ de lesões malignas.

As formas determinadas por essa pesquisa podem ser conferidas na figura 4-3.

Esforços para estabelecer métodos de classificação para calcificações também foram realizados por uma equipe de pesquisadores da Universidade de Calgary, no Canadá. L. Shen et al., em [SHEN-93], propuseram um esquema de classificação usando redes neurais artificiais, onde havia o aprendizado sobre as similaridades entre padrões diretamente de um conjunto usado para o treinamento. 


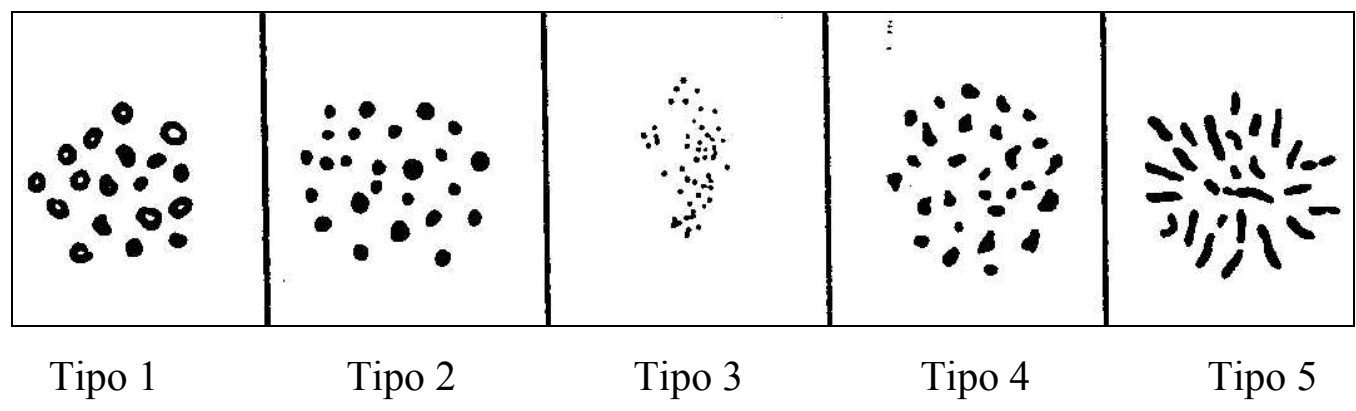

Figura 4-3 - Classificação de microcalcificações de acordo com suas formas ([LE GAL-84]).

A proposta consistia em primeiramente aplicar um método de crescimento de região, para a detecção de trechos que podiam constituir calcificações, e extração de seus contornos. O método utilizou uma distância métrica calculada sobre um conjunto de aspectos que incluía medidas de forma, centro de gravidade e tamanhos obtidos para vários valores de tolerância de crescimento a fim de determinar os parâmetros mais adequados. Foi empregado um sistema de redes neurais em dois níveis a fim de classificar as calcificações de acordo com os aspectos de forma. A rede aprendia as similaridades entre padrões diretamente de seus exemplos no conjunto de treinamento. Foram realizados testes sobre imagens segmentadas de calcificações de mamogramas reais, com diagnósticos comprovados por biópsia e, segundo os autores, o algoritmo detectou corretamente $94 \%$ das calcificações relacionadas a tumores benignos e $87 \%$ das relacionadas a tumores malignos.

Os mesmos pesquisadores, em 1994 ([SHEN-94]), publicaram resultados de pesquisas desenvolvidas no sentido de classificar as calcificações, em benignas e malignas, de acordo com suas formas. Para extrair os contornos das regiões de interesse, foi utilizado o método de crescimento de região. Após a extração do contorno desejado, foram calculadas algumas medidas: momentos regulares - que são os tipos mais populares de momentos - e momentos das regiões de fronteira. Os primeiros são definidos como:

$$
m_{p q}=\int_{-\infty}^{+\infty} \int_{-\infty}^{+\infty} x^{p} y^{q} f(x, y) d x d y, \quad \text { para } p, q=0,1,2, \ldots
$$

onde $\mathrm{f}(\mathrm{x}, \mathrm{y})$ é uma imagem bidimensional e contínua.

Foi sugerido, então, um novo conjunto de momentos, derivado pelos autores, e outros números, como descritores de Fourier e compacidade, foram 
calculados e analisados para algumas formas básicas definidas (figura 4-4). Observou-se que algumas medidas variaram e outras permaneceram constantes de acordo com a forma da estrutura. Após a obtenção desses resultados, o método foi testado para calcificações mamográficas, tendo sido avaliados 80 mamogramas com dados comprovados por biópsia. No geral, as calcificações associadas com condições benignas apresentaram-se maiores, mais arredondadas, em número pequeno e distribuídas de forma difusa, além de apresentar maior homogeneidade em termos de forma e tamanho. Os autores comentam ainda que uma das maiores diferenças entre calcificações malignas e benignas é a rugosidade de suas formas.

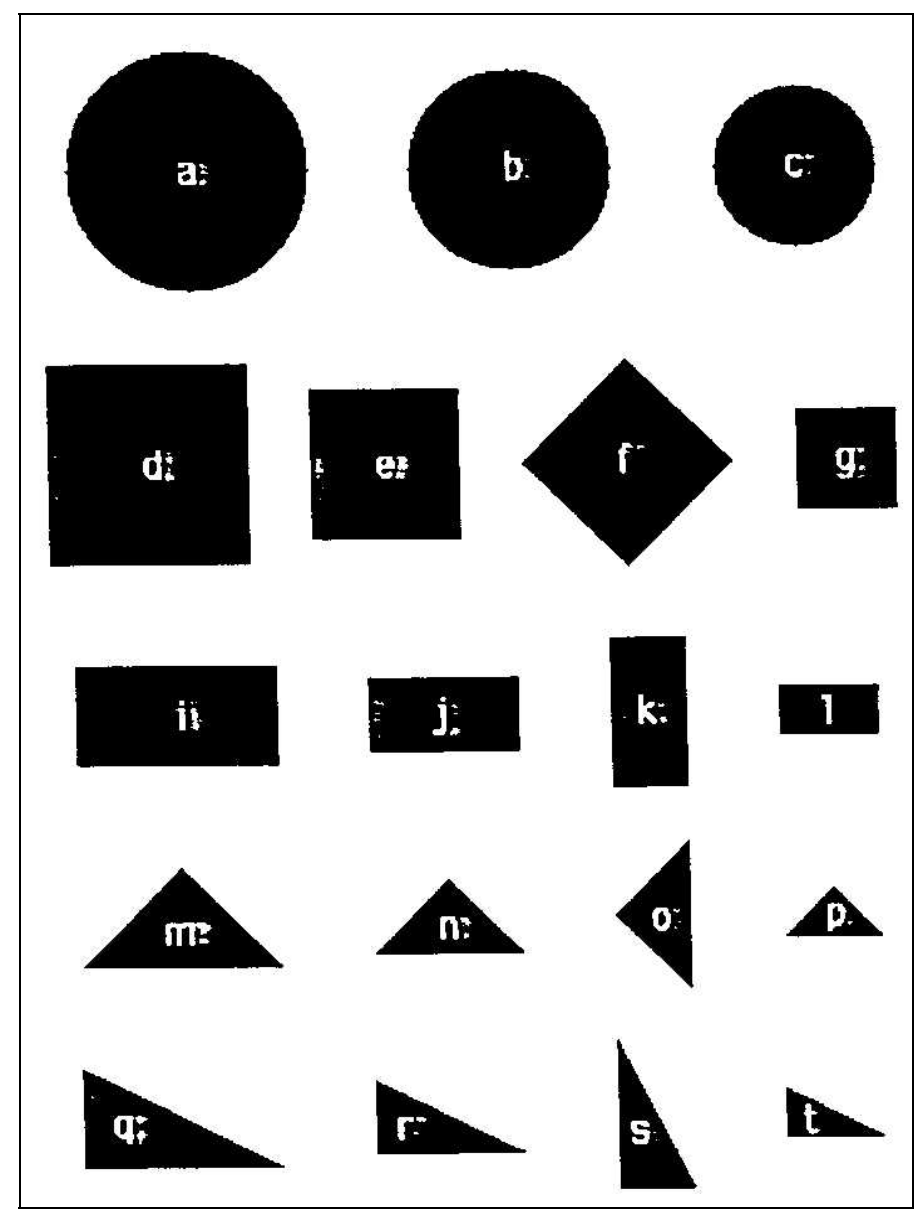

Figura 4-4 - Conjunto básico de formas utilizadas para medidas com a finalidade de classificação ([SHEN-94]).

Os dados obtidos nos trabalhos citados são de extrema importância, uma vez que, além da detecção de microcalcificações em mamogramas, é necessária a sua classificação de acordo com a possibilidade de relacionamento com tumores 
malignos ou benignos para que seja efetiva a contribuição dos esquemas computadorizados em diagnósticos precoces do câncer de mama.

\subsection{Técnicas para realce de contraste em imagens radiográficas}

Um dos grandes problemas encontrados nas imagens radiográficas é o baixo contraste existente no registro, resultante da pouca diferença de absorção entre tecidos humanos normais e tecidos que apresentam anormalidades. $\mathrm{O}$ olho humano consegue perceber contraste somente acima de $2 \%$, o que dificulta a percepção de algumas estruturas presentes em mamogramas. Além disso, a distribuição irregular de intensidade e o espalhamento dos fótons de raios-X vêm contribuir para a dificuldade de detecção de certas estruturas, principalmente quando pequenas, nas imagens em questão. Grupos de pesquisadores têm estudado a aplicação de técnicas para resolver ou, pelo menos, minimizar, esses problemas.

Em 1983, Ishida et al. publicaram um artigo ([ISHIDA-83]) onde descreveram um sistema de simulação e processamento de imagens de alta qualidade a fim de pesquisar o efeito dos parâmetros físicos e técnicas de processamento de imagens em sistemas radiográficos. Segundo os autores, o contraste de padrões radiográficos pode ser aumentado com técnicas de processamento de imagens sem que seja aumentada a exposição no paciente. Dessa forma, propuseram um sistema de "hardware" onde o radiograma original era digitalizado em um tambor de leitura e sua imagem era gravada. Após o processamento da imagem digital, esta era convertida de volta em sinais analógicos através de um conversor D/A. Um filme fotográfico era exposto a um tubo incandescente cuja luz de saída era modulada através dos sinais da imagem processada. O sistema apresentado, segundo os autores, é uma ferramenta poderosa para estudos do potencial da radiografia digital, pois vários parâmetros podem ser variados durante os testes.

Em [ISHIDA-84], os mesmos pesquisadores apresentaram novos resultados dos efeitos do processamento de imagens na detectabilidade de padrões radiográficos de baixo contraste. Neste artigo, salientaram a vantagem da radiografia digital sobre os sistemas convencionais no que se refere à possibilidade de aplicação de técnicas como filtragem e ampliações, auxiliando melhorias na detectabilidade de anormalidades. O trabalho da equipe consistiu em realçar imagens de forma global a 
fim de possibilitar maior detectabilidade de objetos por especialistas. Foram variados parâmetros como nível de ruído, tamanho do objeto, contraste do sinal e fator de realce do contraste. Apurando os resultados obtidos, chegou-se à conclusão de que a detectabilidade de padrões radiográficos simulados de baixo contraste podia ser aumentada significativamente através do realce global do contraste. Os ganhos na detectabilidade dependem muito das características do observador, como a resposta visual a ruídos internos.

Entre 1986 e 1988, Dhawan et al. publicaram pesquisas em torno do realce do contraste de mamogramas ([DHAWAN-86] e [DHAWAN-88]) a fim de minimizar a amplificação do ruído da imagem. Propuseram um método para definir o centro e a região circundante de um pixel (figura 4-5) e definiram funções para o realce de contraste.
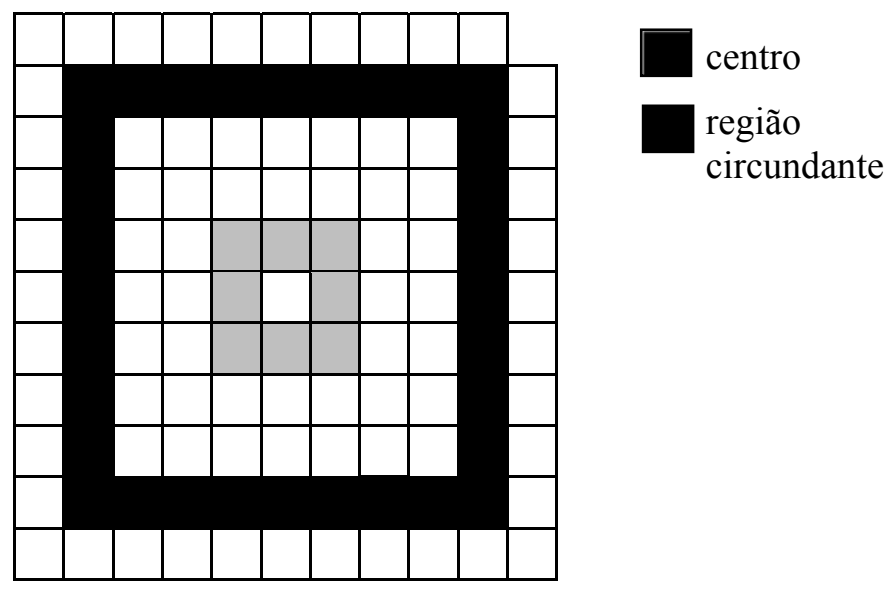

Figura 4-5 - Demonstração da definição de centro e região circundante ([DHAWAN-86]) .

O contraste local $\Gamma$ para a vizinhança foi definido por:

$$
\Gamma=\frac{|p-a|}{|p+a|}
$$

onde $p$ e $a$ eram as densidades médias do centro e da região circundante, respectivamente. $\mathrm{O}$ contraste poderia ser realçado através do uso de uma função específica. Foram estudadas funções que apresentassem a capacidade de realçar características mamográficas, como raiz quadrada $(\sqrt{\Gamma})$, exponencial $\left(1-e^{-k \Gamma}\right)$, logarítmica $(\ln (1+k \Gamma))$ e trigonométricas $(\operatorname{sen}(k \Gamma), \operatorname{tg}(k \Gamma)$ e $\operatorname{tgh}(k \Gamma))$. A constante $k$ foi escolhida para atender requisitos que não ampliassem ruídos. Também foram 
adotados procedimentos para estimar o tamanho ótimo da vizinhança, testando-se a região circundante com razão constante ou largura de diferença constante. Os resultados obtidos, segundo os autores, indicaram o potencial das técnicas de processamento de imagens para realçar os objetos desejados a fim de melhorar a visibilidade humana. Afirmaram que é possível até mesmo produzir imagens com qualidade semelhante à encontrada em xero-mamogramas a partir de mamografias convencionais, sem a necessidade de aumento da dose de raios-X.

A fim de aperfeiçoar o trabalho, A. P. Dhawan e E. Le Royer sugeriram, em [DHAWAN-88], um algoritmo baseado em processamento de imagens adaptativo para realçar o contraste de aspectos selecionados de um mamograma enquanto minimizava a amplificação do ruído. O método aplicado visava definir o aspecto adaptativo da vizinhança e um modelo global para calcular a melhor função de realce de contraste sobre um tipo de característica mamográfica previamente conhecida. O processo começa com a aquisição da imagem digital do filme mamográfico e a aplicação de um operador sobre pixels na imagem a fim de obter o centro e as regiões ao redor dele, cujos aspectos locais são baseados em critérios adaptativos da vizinhança. Foi atribuído um valor de contraste (média dos valores de níveis de cinza) ao pixel do centro e das regiões citadas. O realce dos aspectos realizado tem por base uma função de realce de contraste pré-estabelecida. O passo final é a transformação dos valores dos pixels com a finalidade de exibi-los na forma negativa ou positiva, conforme desejado.

Em [MORROW-92], W.M.Morrow et al. afirmam que a grande variação no tamanho e forma dos aspectos reduz a eficácia dos processamentos convencionais sobre mamogramas. A partir dessa asserção, desenvolveram e apresentaram uma técnica de processamento de imagem que denominaram "processamento de imagem baseado na região".

Os autores afirmam que podia existir um nível de contraste entre tecidos normais e tecidos malignos no mamograma, mas ele poderia não ser humanamente visível, principalmente em imagens de mamas mais espessas. A equipe de pesquisadores utilizou digitalização de alta resolução (pixel com menos de $0,1 \mathrm{~mm}^{2}$ ) para possibilitar o aumento do contraste na imagem. $O$ contraste foi definido em termos da luminância do objeto em relação às regiões que o 
circundavam. Considerando um objeto distinto de seu fundo uniforme e definindo a diferença entre a luminância da área central e da imagem toda como $\Delta L$ e a luminância da imagem toda como $L$, a razão entre essas duas medidas, denominada Razão de Weber, foi definida como:

$$
W=\frac{\Delta L}{L}
$$

A Razão de Weber apresenta grande variação de acordo com o tamanho e a forma do objeto e do seu fundo. Morrow et al. utilizaram a definição de contraste como:

$$
C=\frac{f-b}{f+b}
$$

onde $f$ era a luminância máxima na imagem e $b$ era a luminância mínima. Aqui $f$ foi definida como a média dos valores de níveis de cinza de um particular objeto na imagem e $b$ como sendo a média do nível de cinza de uma região que circundava o objeto. Para que o contraste seja percebido pelo olho humano, $C$ deve estar acima de $0,02(2 \%)$.

Na proposta dos autores, uma vizinhança foi definida sobre cada pixel da imagem, sendo que a extensão da região dependia das características da imagem em torno do pixel. À vizinhança definida foi dado o nome de região. $\mathrm{Na}$ segmentação da imagem, foram procurados grupos de pixels que tivessem uma propriedade comum, como, por exemplo, o nível de cinza. Isso foi obtido através da técnica de crescimento de região ou agregação de pixel, descrita no capítulo 3, item 3.3.1.g, deste trabalho. Morrow et al. trabalharam com região 4-conectadas e consideraram o nível de cinza como condição de similaridade para que um pixel fizesse parte de uma determinada região. O realce do contraste foi realizado com a aplicação da seguinte equação, derivada da equação 4-4, onde C foi substituído pelo contraste incrementado $C^{\prime}$ :

$$
f^{\prime}=b \frac{1+C^{\prime}}{1-C^{\prime}}
$$

O contraste pode ser melhorado com a mudança de $f$ ou $b$ e $f^{\prime}$ é o novo valor do objeto. Segundo os autores, a técnica proposta apresentou resultados 
mais eficientes quando comparados com resultados obtidos por outras técnicas, os quais foram testados com mamografias de casos comprovados por biópsia. Em alguns dos casos estudados, determinadas características só puderam ser observadas após o realce da imagem.

W. Qian et al. sugerem, em [QIAN-94], a utilização de filtros não lineares para o realce da imagem em mamogramas. $\mathrm{O}$ algoritmo consiste de dois blocos de filtros: (a) um filtro multiestágio estruturado em árvore para realce de imagem que usa filtros medianos com pesos centrais como blocos de sub-filtragem e (b) um detector de bordas. O filtro estruturado em árvore, abreviado por TSF, é um filtro multiestágio simétrico que, segundo os autores, combina as vantagens dos filtros medianos com pesos centrais, janelas lineares e curvas, e operações multiestágio que comparam seqüencialmente imagens filtradas e não filtradas com o objetivo de obter características mais robustas de supressão de ruído e preservação de detalhes. O filtro mediano com pesos centrais (no artigo denominado CWMF) é um caso especial entre os filtros que envolvem medianas. Para o caso de processamento de mamogramas foram realizadas duas modificações: 1) o uso de janelas de filtro variáveis com diferentes formas lineares e curvas adaptativas a cada pixel na imagem a fim de permitir a preservação de detalhes; e 2) o uso de uma série de filtros medianos em uma arquitetura multiestágio estruturada em árvore a fim de fornecer uma preservação de detalhes mais efetiva em uma determinada direção. Uma arquitetura esquemática da filtragem estruturada em árvore com $N$ estágios é mostrada na figura 4-6. 


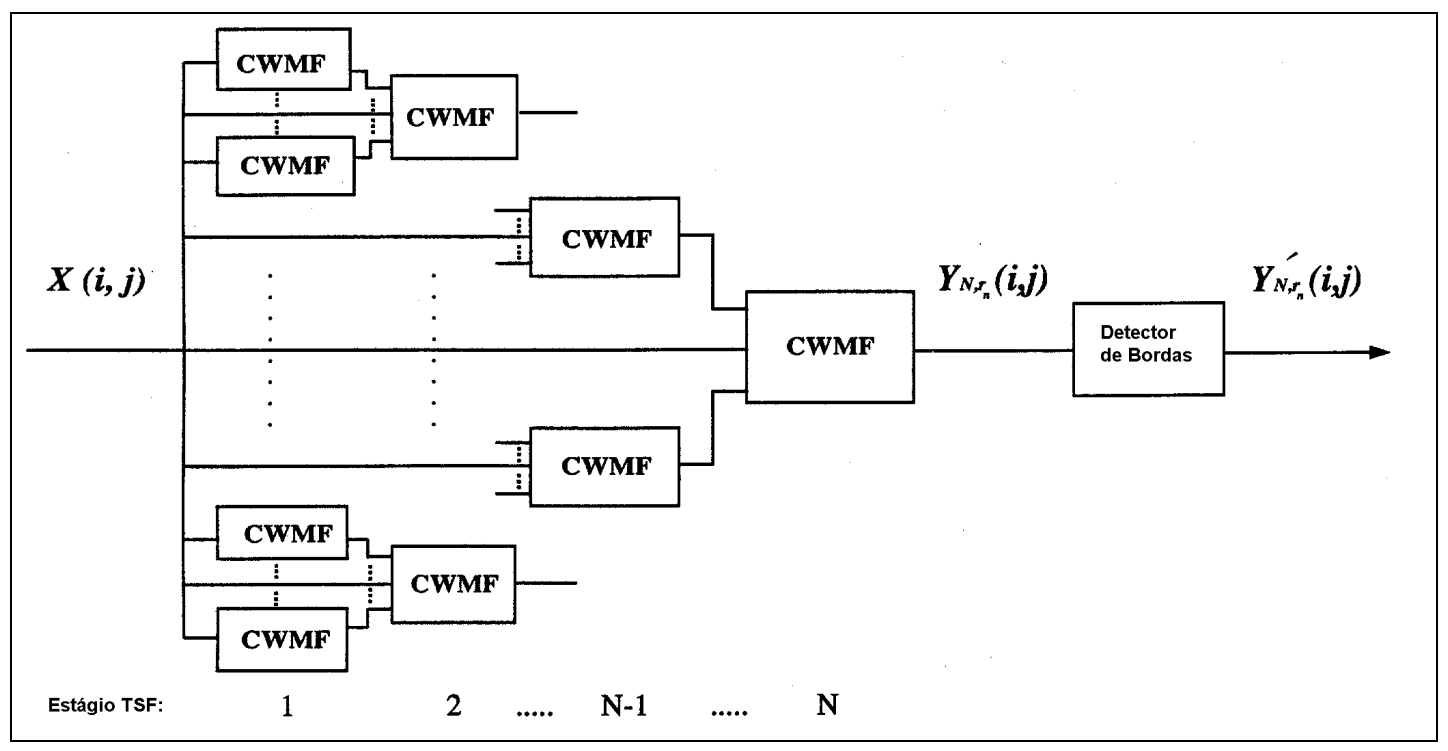

Figura 4-6 - Esquema de um filtro estruturado em árvore ([QIAN-94]).

A. Laine et al., em 1995 ([LAINE-95]) descrevem o uso de "wavelet", para o realce de contraste em mamogramas digitais. $O$ método baseia-se em processamentos matemáticos complexos e há necessidade de uma estrutura computacional de processamento paralelo para suportar uma interface interativa com o usuário a fim de possibilitar diagnósticos assistidos por computador. A digitalização utilizada para o teste do método apresentou pixels amostrados com tamanho de 210 mícrons e, segundo os autores, as estruturas das lesões foram percebidas mais claramente após o realce de contraste pela técnica apresentada.

A utilização de "wavelets" para o realce de imagens de mamogramas e detecção de aspectos importantes em mamografia também é citada por W. Richardson et al. em [RICHARDSON-95] e W. Qian et al. em [QIAN-95]. Em [COIFMAN-95], R. R. Coifman et al. apresentam a utilização da mesma técnica para supressão de ruídos em imagens médicas.

6"Wavelets" consistem em funções matemáticas que dividem dados em diferentes componentes de freqüência e estudam cada componente com uma resolução relacionada à sua escala. Essas funções apresentam vantagem sobre os métodos tradicionais de Fourier quando se trata de análise de situações físicas onde os sinais contêm descontinuidades e picos abruptos ([GRAPS-95]). 


\subsection{Técnicas de segmentação em mamogramas para detecção de microcalcificações}

Os principais requisitos de métodos computacionais para detecção de estruturas de interesse em mamogramas é que preservem a forma e o tamanho das estruturas individuais da imagem. Vários problemas devem ser superados, como a variação no contraste e o tamanho reduzido da estrutura procurada, que muitas vezes a tornam semelhante a ruídos do sistema.

S. Yabashi et al. descrevem, em [YABASHI-89], um processo para identificação de microcalcificações e estimação de lesões malignas em mamogramas. No processamento da imagem utilizaram operações Laplacianas para enfatizar mudanças entre pixels adjacentes. Foi efetuada uma suavização através de um filtro bidimensional para representar a estrutura interna da mama. A finalidade desse procedimento foi observar a opacidade do tumor e a opacidade radial, bem como as estruturas internas dos tumores. Após essas operações, foi aplicado um "thresholding" para extrair as microcalcificações. Verificaram, então que, apesar de existir opacidade da microcalcificação tanto para casos benignos, como para malignos, esta opacidade diferia em termos de configurações na distribuição e no número de pontos opacos.

Em [KALLERGI-92], M. Kallergi et al. fazem uma comparação entre utilização de "thresholding" local e crescimento de região para a segmentação de imagens em mamografia digital. Apesar da finalidade não ser a segmentação de microcalcificações, é interessante citar este trabalho devido à comparação realizada e suas conclusões. Os autores afirmam que em um mamograma há quatro intervalos de níveis de intensidade existentes. O mais baixo corresponde ao fundo, o segundo mais baixo relaciona-se à gordura, o terceiro nível corresponde ao tecido parenquimal da mama e o mais alto nível representa as calcificações. Kallergi et al. estudaram os padrões parenquimais mamográficos existentes, visto que certos tipos são indicativos de câncer de mama.

Inicialmente foi avaliada a performance de dois métodos de segmentação a partir de resultados obtidos de imagens de "phantoms", verificando-se o nível de contraste adquirido com diferentes condições de exposição e tempo. Os 
resultados foram comparados em termos do algoritmo utilizado, do contraste, das condições de exposição e do tempo de aquisição de imagem. A performance de algoritmos utilizados para calcular a densidade parenquimal foi avaliada com base em resultados obtidos de testes realizados com mamogramas de mulheres assintomáticas.

Após a digitalização dos mamogramas, o pré-processamento separava a mama da estrutura de fundo, delineando-se a área da mama com um "mouse" de computador. Aos pixels fora dessa área atribuiu-se o valor zero e foi realizado, então, o processamento para os demais pixels. A técnica de "thresholding" local considerou dois parâmetros: tamanho da janela utilizada e valor de limiar. Os parâmetros foram selecionados com base na performance dos algoritmos a partir das imagens dos "phantoms".

O método de crescimento de região através da agregação de pixels foi aplicado localmente a fim de escolher-se o pixel "semente". Também com base nos resultados das imagens dos "phantoms", foram determinados o tamanho da janela e a diferença absoluta de nível de cinza entre os pixels para serem agregados na região de crescimento. Ao final do procedimento, havia dois tipos de regiões distintas: região de crescimento e região circundante. Se a região de crescimento apresentasse intensidade maior que a região circundante, então o pixel semente era classificado como tecido parenquimal; caso contrário, era classificado como gordura.

Os resultados obtidos foram estabelecidos em função do contraste, das condições de exposição e do tempo. Segundo os autores, a técnica de "thresholding" mostra maior estabilidade, porém é mais dependente da seleção de parâmetro do que o crescimento de região.

Dengler et al. apresentam, em [DENGLER-93], um algoritmo em dois estágios para detecção de pontos e extração da forma. Salientam que vários problemas foram encontrados durante a segmentação, como o tamanho das microcalcificações $(0,3 \mathrm{~mm}$ em média) e a constatação de que objetos menores que $0,1 \mathrm{~mm}$ dificilmente eram vistos em mamogramas devido ao tecido que compõe a textura do fundo e aos ruídos. Outra limitação constatada foi que os objetos estão em fundos heterogêneos, refletindo a estrutura do tecido da mama. A estrutura do fundo podia ser mais clara em algumas partes da imagem do que em outras. Por isso não 
poderia ser usado um simples "thresholding" para a segmentação. Além disso, havia o baixo contraste das microcalcificações quando comparadas com o fundo.

Como calcificações com forma arredondada ou oval são provavelmente de origem benigna, mas aquelas com limites irregulares são mais freqüentemente causadas por lesões malignas, os autores afirmam ainda que uma segmentação automatizada requer não só uma detecção segura de todas as estruturas, mas a preservação de seus tamanhos e formas. Uma observação importante é que calcificações que se tocam não podem ser interpretadas com uma única calcificação.

O primeiro passo do processo de detecção proposto foi tornar o método independente do nível de cinza do fundo. Isto foi feito com um filtro passa-alta que foi executado subtraindo-se a imagem original de um filtro passabaixa usando um filtro gaussiano $G_{\sigma}$ de largura $\sigma$. Essa largura foi escolhida como sendo maior que o tamanho máximo esperado para os objetos. A imagem processada resultou da seguinte equação:

$$
I_{1}(x, y)=I(x, y)-G_{\sigma} * I(x, y)
$$

Após esse procedimento, foi realizada uma operação para descartar a parte negativa não linear e, neste ponto, a imagem já estava clara para uma interpretação visual.

Em seguida foi aplicado um filtro gaussiano com diferenças entre os pesos a fim de aproximar o tamanho dos sinais e saber a distância entre eles. A idéia básica era que a média dos valores de cinza dentro de um sinal deveria ser significativamente maior que a média em torno dele. A fim de tornar independente o nível de ruído local, foi usado um método adaptativo para as variações locais de nível de cinza, atribuindo pesos diferentes aos dois núcleos de convolução Gaussiana. Devido ao filtro gaussiano, a forma dos sinais ficava distorcida, pois suas bordas eram suavizadas. A reconstrução foi executada com um filtro morfológico. As duas operações morfológicas básicas foram a erosão e a dilatação. Após o processo, um “thresholding” eliminava o ruído.

A avaliação do método foi realizada através da comparação com o diagnóstico de radiologistas, chegando-se à conclusão de que atingiu a sensibilidade de $97 \%$. Entre as conclusões, destaca-se que a preservação da forma é menos 
importante para as microcalcificações com formato arredondado, mas muito importante para as microcalcificações com formatos alongados, ramificados ou angulares, pois essas últimas caracterizam um processo de malignidade. Os autores observaram ainda que os radiologistas conseguem reconhecer mais microcalcificações após olhar as imagens segmentadas automaticamente.

Uma segmentação de microcalcificações em mamogramas utilizando filtros morfológicos foi apresentada por Hua-Rong Jin e Hidefumi Kobatake em [JIN-93]. O filtro proposto para a detecção utilizou elementos de estruturas múltiplas e multiescalares, apresentando, segundo os pesquisadores, as seguintes características: eficiência na extração das microcalcificações, resultado não afetado pelo fundo da imagem e extração de microcalcificações sem muitas distorções.

Outras formas de segmentação de microcalcificações em mamogramas serão citadas no próximo item, onde são descritos esquemas completos para a detecção dessas estruturas.

\subsection{Esquemas assistidos por computador para detecção de microcalcificações mamárias}

$\mathrm{Na}$ Universidade de Calgary, no Canadá, vêm sendo realizados estudos de processamento de imagens para detecção e classificação de calcificações. Para tanto têm sido utilizados principalmente métodos de crescimento de região (item 3.3.1.g). A classificação primeiramente é feita com base em fatores calculados a partir das formas dos objetos e, posteriormente, desenvolvidos sistemas de redes neurais. Descrições desses trabalhos são encontradas em [SHEN-93] e [SHEN-94], que já foram citados no item 4.2 deste trabalho.

Em [PEREIRA-95], A. S. Pereira utiliza a "Transformada de Hough" para reconhecer a forma de microcalcificações associadas a tumores a fim de auxiliar o diagnóstico precoce do câncer de mama. Com base na classificação morfológica das microcalcificações proposta por M. Le Gal et al., em [LE GAL-84], foram desenvolvidos algoritmos para reconhecer e classificar as estruturas como relativas a tumores benignos ou malignos, de acordo com o seu formato. Foi proposto, então, um algoritmo objetivando determinar o contorno do elemento e, posteriormente, 
todos os pontos internos ao contorno. Esse algoritmo percorre cada ponto da imagem e verifica a sua vizinhança de 8 , determinando qual dos pixels vizinhos dá continuidade à fronteira procurada.

Após encontrar a fronteira, o programa parte para a obtenção de linhas que indiquem microcalcificações com formato vermiforme, utilizando transformada de Hough para o reconhecimento de retas. Estruturas que possuem pontos em torno de uma reta, com uma distância máxima estabelecida, são reconhecidas como possuindo formato vermiforme. No caso da investigação de microcalcificações com formatos aproximadamente anelares, como a aplicação da transformada de Hough exigiria uma grande quantidade de memória e grande esforço computacional, foram propostos métodos modificados baseados em propriedades geométricas da elipse por determinação de algumas retas cujos pontos tangentes são localizados em posições estratégicas da elipse procurada.

$\mathrm{O}$ esquema descrito foi testado com dados simulados e com imagens obtidas de mamografias contendo microcalcificações com formas anelares e vermiformes, cujos diagnósticos patológicos eram conhecidos. Para as imagens simuladas, foi obtido um índice de acerto de 95,7\% para as formas anelares e $100 \%$ para as vermiformes. Nas imagens mamográficas reais de tumores malignos foram obtidos 5,94\% de "anelar e vermiforme", $18,8 \%$ de "elíptica cheia e vermiforme" simultaneamente e $1,98 \%$ de anelares. Nas imagens de tumores benignos, foram detectadas $17,11 \%$ de microcalcificações anelares, 2,56\% de "vermiformes e anelares", 4,27\% de "formas elípticas cheias e vermiformes" contra 11,96\% de vermiformes.

Segundo o autor, melhorias no processo de aquisição de dados e no pré-processamento de imagens poderiam aperfeiçoar a identificação segura das estruturas. 


\section{5}

\section{DETECÇÃO DE AGRUPAMENTOS DE MICROCALCIFICAÇÕES EM DIAGNÓSTICO ASSISTIDO POR COMPUTADOR (CAD)}

As microcalcificações agrupadas também constituem um indício importante para a investigação do câncer de mama, pois, conforme afirmam M. Le Gal et al., quando se observam mais que 10 na mesma região, a probabilidade de se tratar de um carcinoma é maior que $60 \%$.

Como já citamos, as conceituações de calcificações e microcalcificações variam de autor para autor. Maior ainda é a diversidade de definições de agrupamentos. Em [EGAN-80], Egan et al. definiram um “cluster" como um conjunto de três ou mais calcificações em uma área máxima de 0,5 X 0,5 cm. Sickles ([SICKLES-86]) afirma que muitos radiologistas suspeitam da malignidade quando encontram um grupo de calcificações dentro de $1 \mathrm{~cm}^{3}$ de volume comprimido com, no mínimo, 5 partículas menores que 0,5 $\mathrm{mm}$. Salienta ainda que, para outros especialistas, três ou quatro pequenas calcificações são consideradas significantes. B.W. Fam et al. ([FAM-88]) apresentaram um algoritmo para a detecção de calcificações agrupadas, definindo um "cluster" como três ou mais calcificações em uma área de $1 \times 1 \mathrm{~cm}$ para utilização em detecções automatizadas. Pesquisando a detecção automatizada de microcalcificações, Nishikawa et al. ([NISHIKAWA-93b]) usaram a definição de "cluster" como três ou mais sinais dentro de uma área de 3,2 $\mathrm{mm}^{2}$. Em [JIN-93], H-R. Jin e H. Kobatake definiram um "cluster" como um conjunto de 8 a 10 microcalcificações em $1 \mathrm{~cm}^{2}$.

A detecção de microcalcificações é antigo objeto de estudo de pesquisadores. Em 1975, W. G. Wee et al. ([WEE-75]) publicaram resultados de trabalhos cujo objetivo era avaliar calcificações mamográficas usando programas de computador. O processamento da imagem consistiu na aplicação de métodos de suavização e realce para melhorar a baixa qualidade dos mamogramas. Após essas 
filtragens, as áreas de interesse foram divididas em pequenas regiões retangulares cujo processamento foi realizado de forma individual. Empregou-se, então, um algoritmo de detecção de pontos usando "thresholdings" adaptativos a fim de encontrar as fronteiras das calcificações. $\mathrm{O}$ reconhecimento da fronteira das estruturas de interesse empregava princípios propostos por Freeman (item 3.3.2.b deste trabalho): há oito pontos vizinhos para cada ponto de interesse na imagem; a direção do contorno é indicada por uma posição relativa de cada ponto ao redor do ponto central. A primeira direção preferível estabelecida para cada ponto é definida pela direção dada no ponto anterior. Se esta direção não foi satisfeita, é procurada a segunda direção preferível, que está a $45^{\circ}$ no sentido horário da primeira e assim por diante. O procedimento se completa quanto é encontrado o ponto de início do traçado da fronteira.

Após o reconhecimento da fronteira, foram realizados processamentos que visavam estabelecer características das estruturas: área da calcificação, média do nível de cinza dentro da área, contraste, suavização dentro da área da calcificação, comprimento horizontal e vertical, forma e profundidade da calcificação. O trabalho teve como objetivo uma tentativa de relacionar as medidas encontradas com malignidade ou benignidade associada à calcificação. Os resultados, segundos os autores, foram encorajadores, necessitando, no entanto, da realização de testes de forma mais exaustiva.

No período de 1975 a 1987, a literatura pesquisada não incluiu trabalhos sobre o agrupamento de microcalcificações. Neste intervalo, os trabalhos encontrados limitavam-se à segmentação dessas estruturas. A seguir, citamos as pesquisas localizadas a partir dessa época.

\subsection{Uma técnica de detecção de "clusters"}

Segundo Chan et al., em [CHAN-87], as microcalcificações representam a fonte ideal para a detecção automatizada, visto que são freqüentemente o primeiro e, algumas vezes, o único sinal suspeito encontrado em mamogramas quando o câncer ainda está em estágio inicial, e, portanto, possibilitando grandes chances de cura. 
O enfoque inicial daquele trabalho foi concentrado na detecção dos sinais, não havendo preocupação com a discriminação entre aspectos benignos e malignos. Inicialmente, o algoritmo geral do sistema automatizado foi idealizado de acordo com o diagrama da figura 5-1.

Para realçar as microcalcificações foi usado um "matched filter" (filtro casado) com tamanho e variações de contraste de uma típica microcalcificação de mama (figura 5-2) . Este filtro difere dos convencionais por duas razões:

- não leva em conta o conteúdo da freqüência do ruído da imagem de fundo;

- não é possível projetar filtros que coincidam exatamente com cada microcalcificação, pois a forma e o tamanho dessas estruturas são enormemente variáveis.

Foi usado, então, um modelo simplificado em que o filtro tinha um núcleo quadrado de n X n (n ímpar) pixels, aplicado sobre a imagem de entrada. Foi aproximada a variação de contraste com fatores de peso para o "matched filter". Por exemplo: para $\mathrm{n}=3$ foi atribuído o valor 0,75 para os 8 elementos da fronteira do núcleo e o valor 1 ao elemento central (figura 5-2). Para $n>3$, os elementos da fronteira mais externa receberam o peso 0,5 ; foi atribuído o peso 0,75 aos elementos da segunda fronteira mais externa e todos os outros elementos receberam o peso com valor 1 .

Para a identificação do sinal, foram testados dois tipos de filtros: o de filtragem mediana e o de constraste-reverso. A filtragem mediana pode eliminar microcalcificações da imagem e suavizar o ruído sem mudar o fundo global e o filtro de contraste-reverso, como o próprio nome indica, reverte o contraste de microcalcificações enquanto mantém a estrutura de fundo de baixa freqüência e suprime ruídos de alta freqüência.

O filtro de contraste-reverso foi descrito da seguinte forma:

$$
F(u)=\left[2 F_{a}(u)-1\right] F_{B}(u)
$$

onde:

$\mathrm{F}_{\mathrm{A}}(\mathrm{u})=$ filtro de suavização passa-baixa, $\mathrm{F}_{\mathrm{B}}(\mathrm{u})=$ filtro que suprime ruído de alta freqüência. 
A diferença de imagem foi obtida, subtraindo-se a imagem com supressão do sinal da imagem com realce do sinal. Visto que a estrutura de fundo de baixa freqüência coincide nas duas imagens, esta componente é removida, não aparecendo na imagem resultante da diferença. A fim de compensar a perda do fundo, foi adicionado o valor constante 512 a todos os pixels na imagem final.

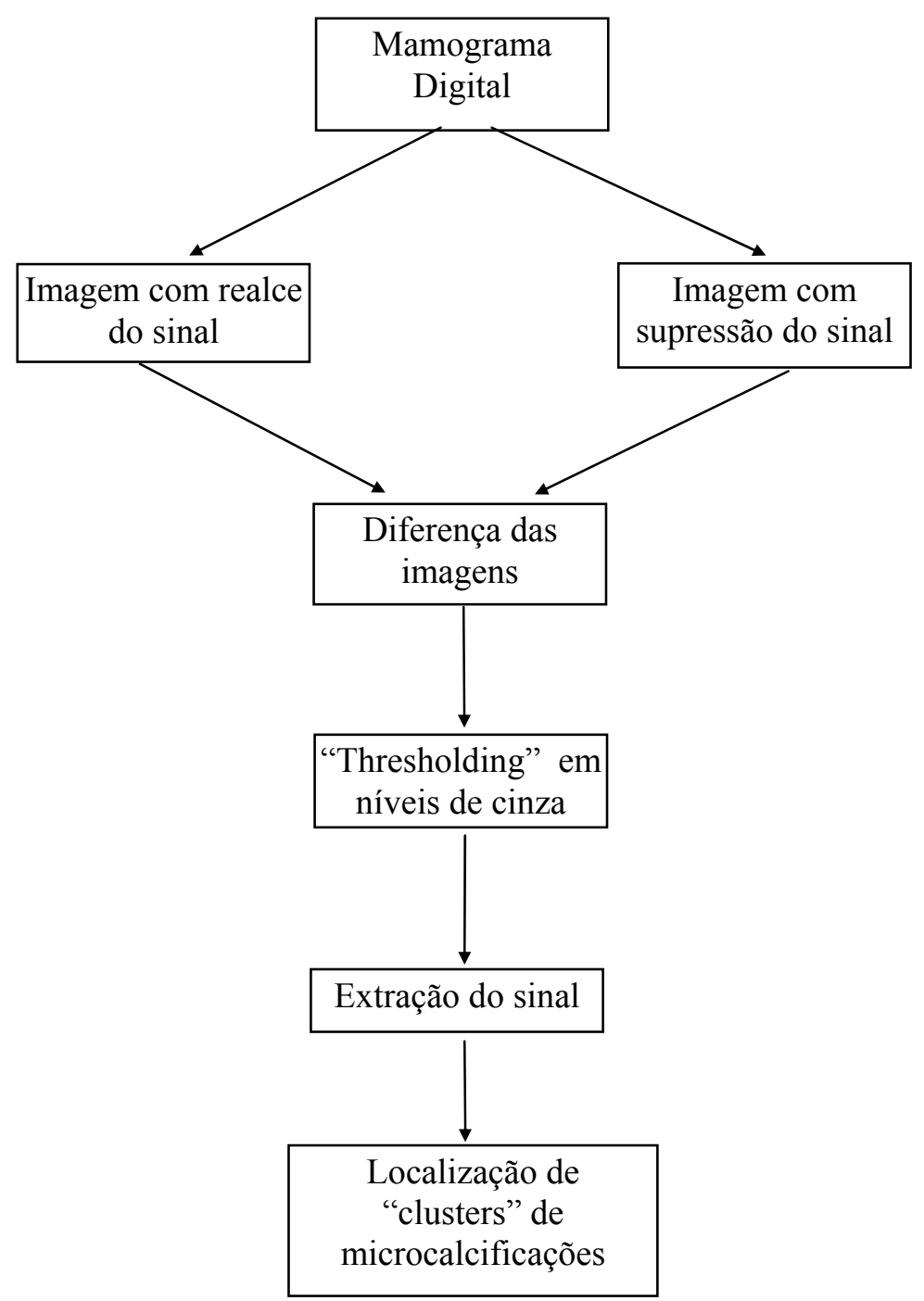

Figura 5-1 - Esquema geral da detecção computadorizada de microcalcificações em mamogramas ([CHAN-87]). 


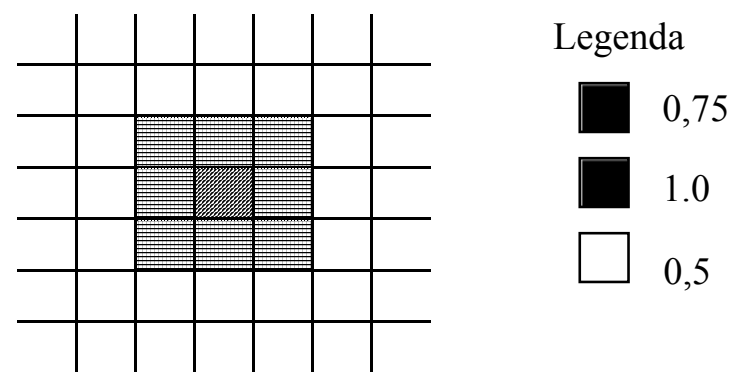

Figura 5-2 - "Matched filter" usado para realce do sinal .

Foi aplicado um "thresholding" em níveis de cinza na imagem resultante da diferença para isolar as microcalcificações do ruído de fundo ainda remanescente. Foram estudados dois tipos de "thresholding": um método global (onde o computador mantém uma porcentagem de pixels com valores mais altos no histograma e aos demais pixels da imagem da diferença é atribuído um valor constante) e um método local em que o computador determina as estatísticas locais dentro de um núcleo quadrado centralizado no pixel de interesse. Neste último método, o pixel de interesse era retido somente se seu valor fosse maior que o valor médio de um múltiplo pré-selecionado do desvio padrão. O núcleo escolhido deveria ser suficientemente grande para fornecer uma boa estimativa da flutuação do ruído de fundo (nos estudos foi escolhido um núcleo de 51 x 51 pixels). Após esta etapa, o resultado obtido foi uma imagem onde os grupos de pixels com valores acima do limiar foram sobrepostos em um fundo absolutamente uniforme.

A extração computadorizada do sinal foi realizada da seguinte maneira: aplicou-se um programa de detecção de bordas no mamograma original para determinar a região da mama. Foi feita a procura do sinal na região determinada pelo programa anterior, sobre a imagem final (após o “thresholding”), para determinar a localização, a área e contraste de cada ponto. Imposto um critério de “thresholding” de área sobre os sinais detectados para eliminar os pontos que apresentassem área menor que um número de pixels pré-estabelecido, foi usado finalmente um critério de agrupamento para identificar "clusters" que contivessem mais que um número pré-selecionado de sinais dentro de uma região com diâmetro também pré-estabelecido. Os valores pré-determinados basearam-se tanto na experiência de radiologistas como através do processamento de um número de mamogramas de teste com microcalcificações conhecidas. Os resultados obtidos variaram de acordo com o filtro utilizado. Para os testes, foram utilizadas 
microcalcificações simuladas pelo método de Monte Carlo, sobrepostas em fundos de mamogramas reais. Este método de simulação será descrito posteriormente.

\subsection{Melhorias nos sistemas de [Chan-87]}

Em [CHAN-88a] foram descritas as principais características das microcalcificações mamográficas clínicas utilizadas para a automatização da extração dessas estruturas. O método utilizado pode ser esquematizado pelo diagrama da figura 5-3.

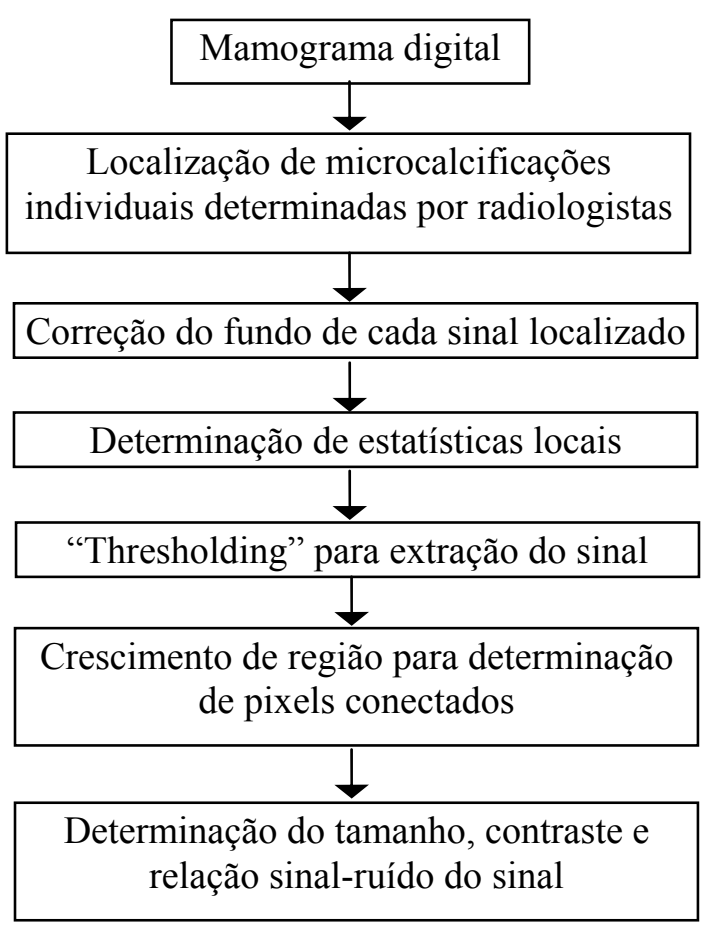

Figura 5-3 - Diagrama esquematizado do processamento automatizado para identificação de microcalcificações ([CHAN-88a]).

Para cada mamograma, as microcalcificações individuais foram identificadas primeiramente por um radiologista experiente. O computador, então, extraiu as características do sinal para cada local identificado, da seguinte forma: o fundo foi estruturado em uma região local centralizada no sinal, sendo estimado pela correspondência a uma superfície bidimensional e, sendo, então, subtraído da região. Foram calculados a média e o desvio padrão da variação do ruído na região subtraída e foi determinado um valor de limiar acima do qual o pixel podia ser considerado pertencente à região. Em seguida, empregou-se uma técnica de crescimento de região 
com a finalidade de localizar os pixels conectados com valor acima do "thresholding" estabelecido. O tamanho do sinal foi considerado como o número de pixels conectados e o contraste do sinal, como a diferença entre o valor máximo de pixel do sinal e a média dos valores de pixel do fundo. A relação sinal-ruído foi estabelecida como a razão entre o contraste do sinal e o desvio padrão da variação do ruído. Calculado o espectro de potência de todos os "clusters", foi obtida uma média a qual foi comparada com espectro de potência médio de fundos mamográficos através da normalização de ruído de alta-freqüência para a mesma potência. Este trabalho visava obter as características físicas de microcalcificações a fim de auxiliar no desenvolvimento do incremento da relação sinal-ruído e técnicas de extração para detecção automatizada de microcalcificações em mamogramas. Segundo esses autores, de 20 mamogramas clínicos que continham microcalcificações sutis agrupadas, o esquema computadorizado localizou corretamente $90 \%$ dos “clusters".

A mesma equipe, em [CHAN-88b] apresentou otimizações das pesquisas anteriormente desenvolvidas, propondo a utilização de novos filtros espaciais. A fim de melhorar a filtragem para a supressão do sinal, foi proposto um filtro denominado "box-rim" o qual consiste basicamente de um filtro de médias de modo a atribuir fatores de peso 0 para a região central, fazendo com que estes pixels sejam excluídos do cálculo. A seleção do tamanho do núcleo e da região central foi estabelecida de acordo com o tamanho do sinal encontrado. A resposta em freqüência dos filtros depende dos parâmetros escolhidos. Se esses parâmetros são escolhidos de forma apropriada, pode-se, ao mesmo tempo, suprimir o fundo de baixa freqüência e o ruído de alta freqüência da imagem. Um esquema dos filtros utilizados pode ser observado na figura 5-4.

Após a filtragem da imagem, foram realizados procedimentos de “thresholding” (global e local), como já citados em trabalhos anteriores do grupo. Foi aplicada, então, a técnica de crescimento de região, responsável por conectar pixels cujos valores de níveis de cinza são maiores do que o valor do "thresholding" local. O tamanho do sinal foi determinado pelo número de pixels conectados e o contraste foi estabelecido como sendo a diferença entre o valor máximo de pixel e a média dos valores dos pixels de fundo do sinal detectado. A extração do sinal teve o objetivo de diferenciar uma possível estrutura de um ruído da imagem. 
Primeiramente, foram utilizados critérios para eliminação de sinais cujo tamanho fosse menor que um limite pré-estabelecido. Em segundo lugar, áreas maiores que a fronteira ou com contrastes maiores que a fronteira foram usadas para exclusão de sinais detectados que possuíam área grande ou contraste alto, pois esses poderiam ter sido causados por artefatos ou por calcificações benignas grandes. Finalmente, foi executado um procedimento de agrupamento que procurava um número mínimo de sinais detectados dentro de uma área com um diâmetro préselecionado. Os resultados obtidos sobre testes em microcalcificações simuladas indicou que os critérios utilizados para extração do sinal não foram eficazes no que diz respeito à distinção entre sinais e ruídos.

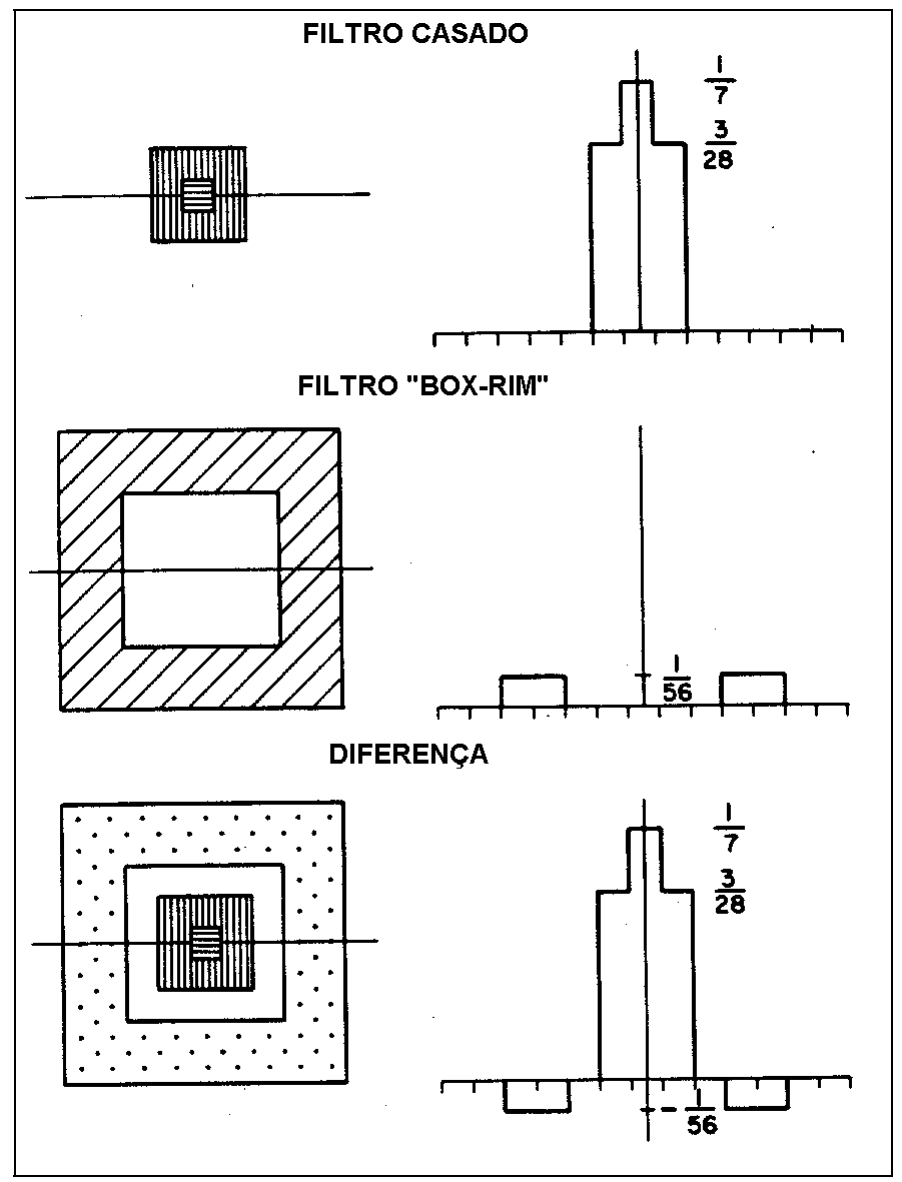

Figura 5-4 - Filtros espaciais usados na aproximação da diferença de imagem ([CHAN-88b]). O "matched filter" tem um núcleo com tamanho de 3 x 3 pixels. $O$ filtro "box-rim" tem a largura da área externa de 9 pixels e uma largura interna de 5 pixels. Os gráficos da coluna da esquerda mostram a forma do filtro no plano imagem. Os fatores de peso ao longo da linha no centro dos núcleos dos filtros são mostrados nos gráficos da coluna da direita.

Em [CHAN-90], a mesma equipe de pesquisadores publicou resultados de testes adicionais realizados com o esquema de detecção automatizada 
que desenvolveu. Desta vez os pesquisadores conduziram um estudo através de curvas das características de operação do receptor, as curvas ROC (receiver operating characteristic), que tinha o objetivo de comparar a performance da detecção humana com e sem o auxílio do computador. Foram selecionados 60 mamogramas, sendo escolhida uma visão craniocaudal simples ou mediolateral oblíqua para cada paciente. Desse conjunto, 30 mamogramas continham um "cluster" simples de microcalcificações, verificadas previamente através de biópsia ou a partir de uma imagem magnificada. Estes filmes foram selecionados de um arquivo grande de imagens contendo microcalcificações aglomeradas consideradas difíceis de visualizar, formado nos cinco anos anteriores na Universidade de Chicago. Um "cluster" foi escolhido somente se não fosse bem visível no filme. Cada "cluster" continha quatro ou mais microcalcificações, sendo que a maioria delas apresentava diâmetro menor que $0,3 \mathrm{~mm}$.

A outra metade dos mamogramas usados na pesquisa correspondia a casos normais que não registravam microcalcificações agrupadas. Alguns desses mamogramas mostraram fenômenos anormais, tais como área com aumento de densidade ou distorção parenquimal, mas foram classificados como normais levandose em consideração somente o fato de não apresentarem microcalcificações. Os 60 mamogramas estavam inseridos em um intervalo típico de tamanho e densidade de mamas.

No estudo com curvas ROC, a avaliação foi realizada com base nos diagnósticos de radiologistas para os quais foram apresentados mamogramas digitalizados em cada uma das três seguintes condições:

1. Um mamograma simples foi interpretado sem auxílio do esquema computadorizado.

2. Um par de mamogramas idênticos foi apresentado lado a lado, com círculos sobrepostos em um dos filmes, indicando a localização em que o programa de computador detectou microcalcificações agrupadas. Nesta condição, o esquema apresentava $87 \%$ de precisão - detecção de "clusters" verdadeiro-positivos com uma média de 4 "clusters" falso-positivos por imagem; 
3. Um par de mamogramas idênticos foi apresentado tal qual a condição 2 , exceto pelo fato de ter sido simulada uma precisão de $87 \%$ do esquema computadorizado com uma média de apenas 1 “cluster" falso-positivo em cada duas imagens.

Os resultados obtidos foram dispostos em uma tabela e observou-se que a performance dos radiologistas que participaram do teste foi fraca na condição 1, melhorou na condição 2 e apresentou ainda mais melhorias na condição 3. Esses resultados proporcionaram aos pesquisadores a crença de que, quando um programa de computador com alta sensibilidade é combinado com a habilidade do observador humano, chega-se à maioria das detecções verdadeiro-positivas, melhorando a performance do esquema geral.

\subsection{Diminuição da taxa de detecção de sinais falso-positivos}

Em 1992, conforme descrito em [JIANG-92], Y. Jiang et al. publicaram o desenvolvimento de um novo método de extração de sinais com a finalidade de diminuir a taxa de detecção de sinais falso-positivos, sem diminuir a sensibilidade do esquema computadorizado. A estratégia indicada foi a utilização de duas medidas para diferenciar sinais verdadeiros de sinais falsos. Considerando que o contraste do sinal é um fator importante para o seu reconhecimento e que, em imagens radiográficas, a curva do sistema écran-filme mostra que este contraste é amplificado de forma não linear, os autores afirmam que microcalcificações com a mesma forma e espessura terão o mesmo contraste de radiação, mas poderão apresentar diferentes contrastes radiográficos em termos de densidade ótica. Isso acontece porque o contraste radiográfico depende da densidade do fundo do filme e esta é variável. O método desenvolvido consistiu em converter o contraste radiográfico de um sinal em seu contraste de radiação e, subseqüentemente, derivar sua espessura efetiva. A espessura do sinal foi introduzida a fim de permitir uma comparação direta com a área do sinal.

Esperava-se, desta forma, que as duas quantidades (espessura e área) pudessem ser utilizadas como características que discriminassem sinais falsos de sinais verdadeiros. Desse modo, a técnica proposta consistiu em extrair da imagem a área e a espessura do sinal. Utilizando-se das equações relacionadas aos 
equipamentos radiográficos, os autores definiram a espessura de uma microcalcificação em função do contraste radiográfico encontrado.

Segundo esses autores a radiação de contraste em termos de exposição de uma microcalcificação imersa no tecido da mama pode ser definida como:

$$
R_{c}=2 \frac{\left|n-n^{\prime}\right|}{n+n^{\prime}}
$$

onde n e n' são as fluências do sinal e do fundo que o cerca. Desta definição resulta que a radiação de contraste de uma microcalcificação pode ser expressa como:

$$
R_{c}\left(L_{x}\right)=2 \frac{1-e^{-\Delta \mu} L_{x}}{S-e^{-\Delta \mu} L_{x}}
$$

onde

$$
\Delta \mu=\left|\left(\frac{\mu}{\rho}\right)_{x} \rho_{x}-\left(\frac{\mu}{\rho}\right) \rho\right|
$$

$\mathrm{e}$

$$
S=\frac{1+c F}{1-c F}
$$

onde:

- $\mu$ é a diferença nas propriedades de atenuação entre a microcalcificação e o tecido da mama onde ela está inserida;

- $\left(\frac{\mu}{\rho}\right)_{x}$ e $\rho_{x}$ correspondem ao coeficiente de atenução da massa e à densidade da microcalcificação, respectivamente;

- $\left(\frac{\mu}{\rho}\right)$ e $\rho$ correspondem ao coeficiente de atenuação de massa e à densidade do tecido glandular, respectivamente;

- $\mathrm{L}_{\mathrm{x}}$ é a espessura da microcalcificação;

- $c$ é o fator de contaminação de grade, que é igual à relação entre a radiação espalhada transmitida e a radiação incidente; 
- F é a fração espalhada, que é igual à relação entre o espalhamento e o total de radiação transmitida.

O contraste radiográfico de uma microcalcificação é igual à diferença nas densidades óticas do filme entre o sinal e o seu fundo, podendo ser expresso como:

$$
\Delta D\left(D, L_{x}\right)=\log _{10} e G(D) R_{c}\left(L_{x}\right) A / A_{0}
$$

onde $\mathrm{G}$ é o gradiente do sistema écran-filme na densidade ótica $\mathrm{D} ; \mathrm{A} / \mathrm{A}_{0}$ é o termo de correção para a FTM (função de transferência de modulação) do sistema écran-filme e é uma função da área da microcalcificação.

Finalmente, o contraste radiográfico das microcalcificações pôde ser traduzido para o contraste do sinal em termos de valores de pixel através do uso da curva característica do digitalizador, que é aproximadamente linear.

A espessura de uma microcalcificação pode ser calculada a partir do seu contraste radiográfico através da inversão das equações 5-9 e 5-12. Estas novas equações podem ser descritas da seguinte forma:

$$
R_{c}\left(L_{x}\right)=\frac{\Delta D}{\log _{10} e G(D) A / A_{0}}
$$

$\mathrm{e}$

$$
L_{x}=\frac{1}{\Delta \mu} \ln \left(\frac{2+R_{c}\left(L_{x}\right)}{2-S R_{c}\left(L_{x}\right)}\right)
$$

A equação 5-13 converte o contraste radiográfico do sinal em sua radiação de contraste e a equação 5-14 dá a espessura do sinal. A tabela 5-1 mostra os parâmetros usados. Os cálculos foram realizados assumindo-se um feixe monoenergético de raios-X de $20 \mathrm{keV}$ e uma espessura de mama de $4 \mathrm{~cm}$.

Tabela 5-1 - Parâmetros usados nos cálculos de espessura do sinal a partir de seu contraste ([JIANG-92]).

\begin{tabular}{lcccc}
\hline & \multicolumn{2}{c}{ Parâmetros de atenuação } & \multicolumn{2}{c}{ Parâmetros de espalhamento } \\
\cline { 2 - 5 } & $\mu / \rho\left(\mathbf{c m}^{2} / \mathbf{g}\right)$ & $\rho\left(\mathbf{g} / \mathbf{c m}^{3}\right)$ & $\mathbf{c}$ & $\mathbf{F}$ \\
\hline Microcalcificação & 6,413 & 1,85 & 0,21 & 0,38 \\
Tecido glandular & 0,813 & 1,035 & & \\
\hline
\end{tabular}


A técnica de extração do sinal consistiu em realizar a correção do fundo da imagem e extrair os sinais através de crescimento de região. A avaliação do método foi realizada através de simulações, em que as espessuras das microcalcificações foram estabelecidas a partir de parâmetros fornecidos pela curva característica do sistema écran-filme. Os resultados dessa simulação mostraram que a técnica foi eficaz para extrair a área e o contraste de sinais com espessura maior que 0,1 mm. A partir desses parâmetros, segundo os autores, foi possível diferenciar sinais verdadeiros de estruturas falsas.

\subsection{Esquema automatizado desenvolvido na Universidade de Chicago}

Ainda em 1992, a equipe de Chicago publicou um resumo do esquema desenvolvido até então, propondo melhorias na extração do sinal. O esquema automatizado é mostrado na figura 5-5 conforme descrito em [NISHIKAWA-92].

No pré-processamento, foi utilizada a técnica de diferença de imagem para realçar o sinal das microcalcificações através da supressão da estrutura de fundo do mamograma digitalizado. Isso foi feito através da utilização de dois filtros lineares cujos núcleos são mostrados na figura 5-6. O núcleo na figura 5-6a realçou a aparência de pequenas estruturas, enquanto que o filtro da figura 5-6b suprimiu as mesmas estruturas. Através da subtração das duas imagens (aquela com os sinais suprimidos daquela com os sinais realçados) foi obtida a imagem da diferença. $\mathrm{Na}$ prática, os dois filtros lineares foram combinados em um simples filtro linear.

Operações baseadas em "thresholding" e "operadores morfológicos" foram então aplicadas para extração de sinais da imagem. O "thresholding" foi realizado com base no histograma de níveis de cinza da imagem completa, sendo escolhidos valores de tal forma que $98 \%$ dos pixels fossem ajustados para um valor de fundo. Foi aplicada, então, uma erosão morfológica através dos elementos estruturados mostrados na figura 5-7, que tiveram a função de eliminar sinais com tamanho menor que 3 pixels. 


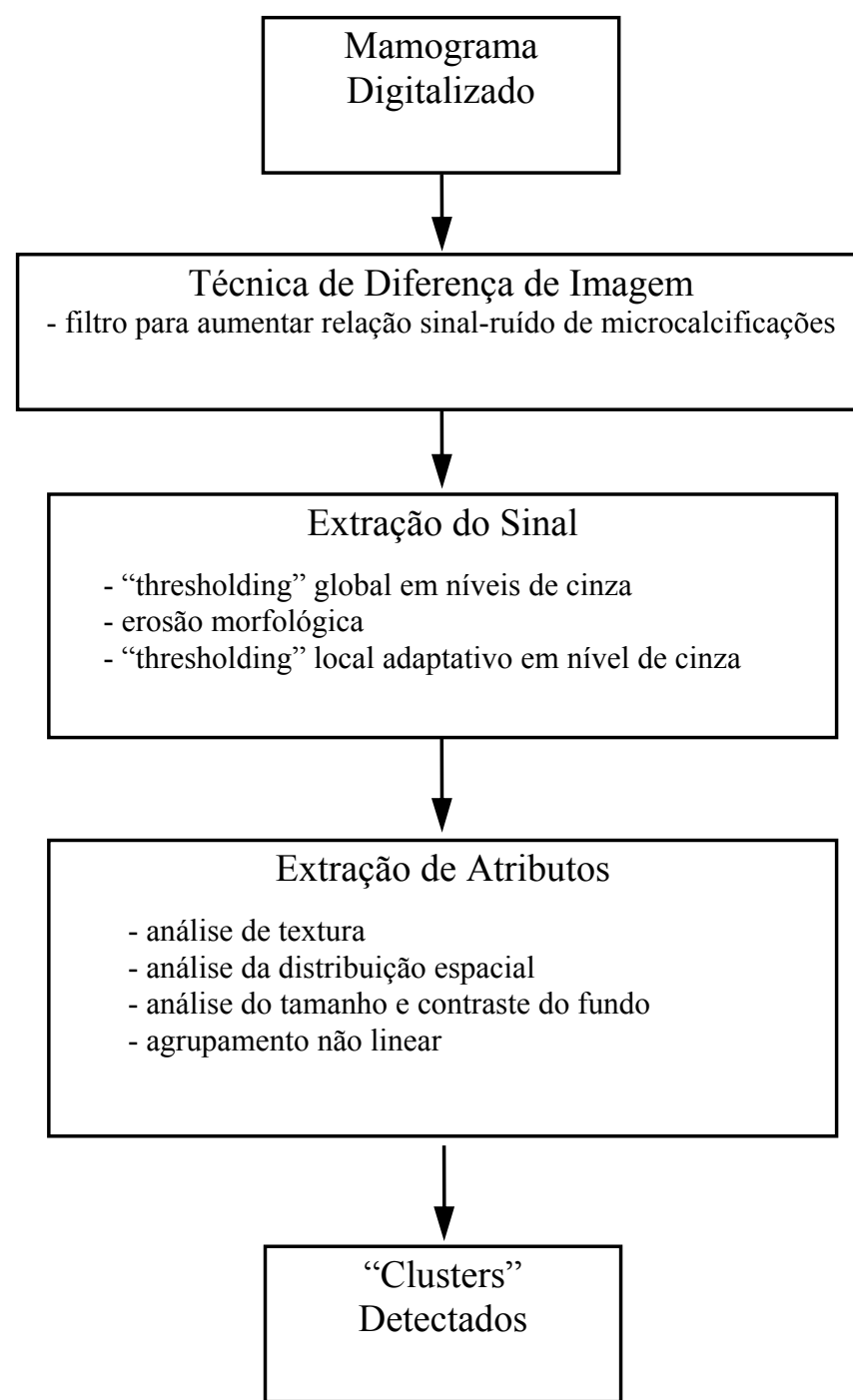

Figura 5-5 - Esquema para deteç̧ão automatizada de agrupamentos de microcalcificações ([NISHIKAWA-92]).

Após o pré-processamento, passou-se, então, à fase de extração dos aspectos, com base em três diferentes técnicas: análise de textura, análise de contraste, tamanho em relação ao fundo e agrupamento de sinais.

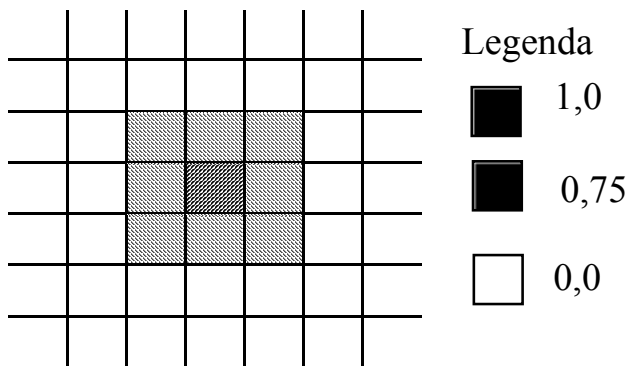

(a) 


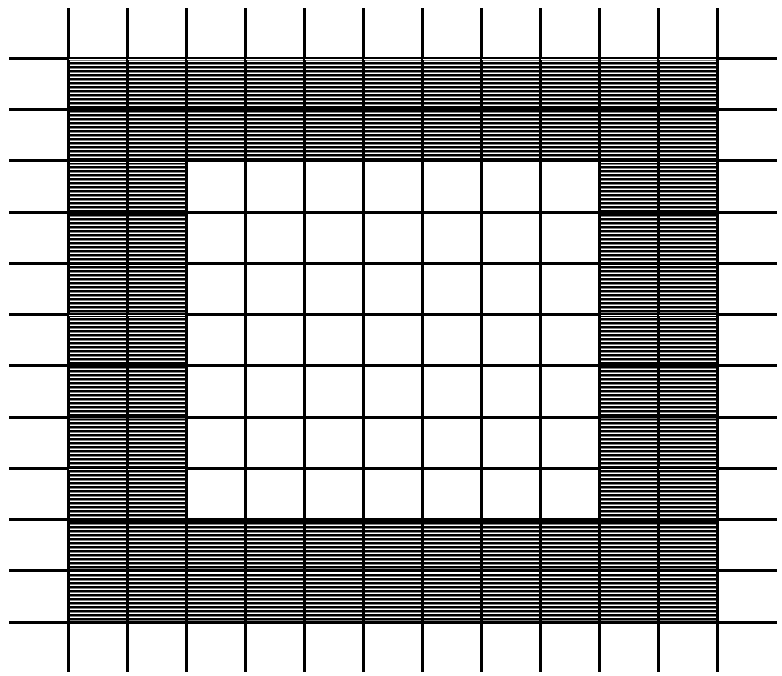

(b)

Figura 5-6 - "Matched filter" usado para realce do sinal ([NISHIKAWA-92]).
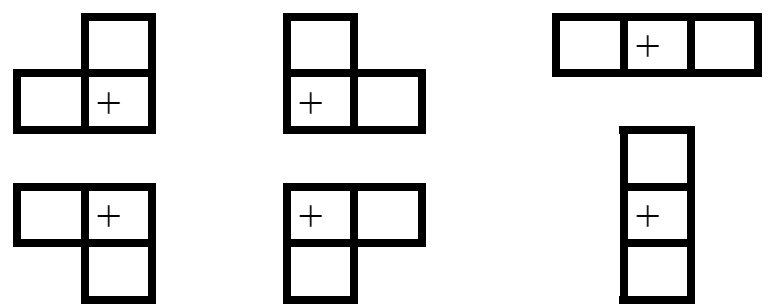

Figura 5-7 - Elementos estruturados usados na erosão morfológica ([NISHIKAWA-92]).

A análise de textura foi aplicada da seguinte forma: para cada sinal remanescente na imagem, após a extração do sinal, foi analisada uma região de 6,4 x 6,4 mm centralizada no sinal de interesse. Primeiramente, foi feita uma correção do fundo com a aplicação de um polinômio de grau 3. Então, foi calculado um espectro de potência de Fourier bidimensional. Se o primeiro momento do espectro fosse maior que 3,0 ciclos por milímetro, o sinal era eliminado. Após esse procedimento, foi analisada a distribuição espacial dos sinais restantes através da determinação do número de sinais em regiões de $3,2 \times 3,2 \mathrm{~mm}$. Os sinais que não estavam junto com outros dois sinais na região considerada foram removidos da imagem. Usando a imagem original, para cada sinal detectado foram calculados: a média dos valores de pixel dos pixels que formavam o sinal, o tamanho do sinal e o valor dos pixels de fundo.

Além disso, foi estimado o contraste de radiação (medido em termos da exposição relativa de raios-X) baseado no valor do pixel e no valor de fundo do sinal. O contraste foi obtido com o uso das curvas características do sistema écran- 
filme e do digitalizador de filmes. Para remover sinais falsos, foram aplicados três testes: primeiro, eliminaram-se os sinais cujos pixels de fundo estavam abaixo do valor 110, o que causou a remoção de sinais em áreas muito escuras da imagem; em segundo lugar, foram eliminados sinais com contraste muito baixo (que correspondiam a ruídos resultantes do "thresholding" executado); e por último, eliminaram-se sinais cujos contrastes eram grandes, mas que possuíam tamanho pequeno (causados por artefatos).

Finalmente, os sinais restantes na imagem foram agrupados da seguinte forma: se houvesse 3 ou mais sinais em uma área de 3,2 x 3,2 mm, estes sinais eram copiados para a imagem final, a qual, desta forma, incluiu os "clusters" procurados com destaque do centro de cada "cluster" encontrado.

O método foi testado com um conjunto de 78 mamogramas, dos quais metade não apresentava "clusters" visíveis e a outra metade apresentava pelo menos um "cluster". A performance do esquema foi testada utilizando-se diversos valores de "thresholding" local. A técnica foi capaz de detectar $85 \%$ dos "clusters" verdadeiros, com uma média de duas detecções falso-positivas por imagem.

\subsubsection{Transformação área-ponto recursiva}

Continuando a melhorar o esquema computadorizado até então desenvolvido, Nishikawa et al., em [NISHIKAWA-93a], apresentaram novas técnicas para extração e agrupamento de microcalcificações. Um novo método, chamado "transformação recursiva área-ponto", ou transformação AP, é apresentado com a finalidade de transformar uma microcalcificação em um único pixel a fim de facilitar a contagem no momento da identificação de "clusters".

A transformação é realizada da seguinte maneira: um máscara de 3 x 3 pixels é passada sobre a imagem começando do canto superior esquerdo. Para cada locação, é contabilizado o número de pixels com nível de cinza superior ao do fundo da imagem. Havendo dois ou mais pixels com essa característica, todos os pixels sob a máscara são ajustados para um valor igual ao do fundo, menos o pixel do canto inferior direito do núcleo, que é ajustado para o valor máximo (1023 para imagem de 10 "bits"). O núcleo é então movido 2 pixels para a direita e o processo é repetido. O processo salta de 2 em 2 linhas até atingir o fim da imagem. Um exemplo do 
andamento da técnica pode ser observado na figura 5-8, onde os retângulos escuros representam os pixels constituintes de uma microcalcificação. A cada passo os pixels têm seu valor alterado (na figura, transformam-se em retângulos hachurados) e quando o processo termina, a microcalcificação transforma-se em um único pixel.
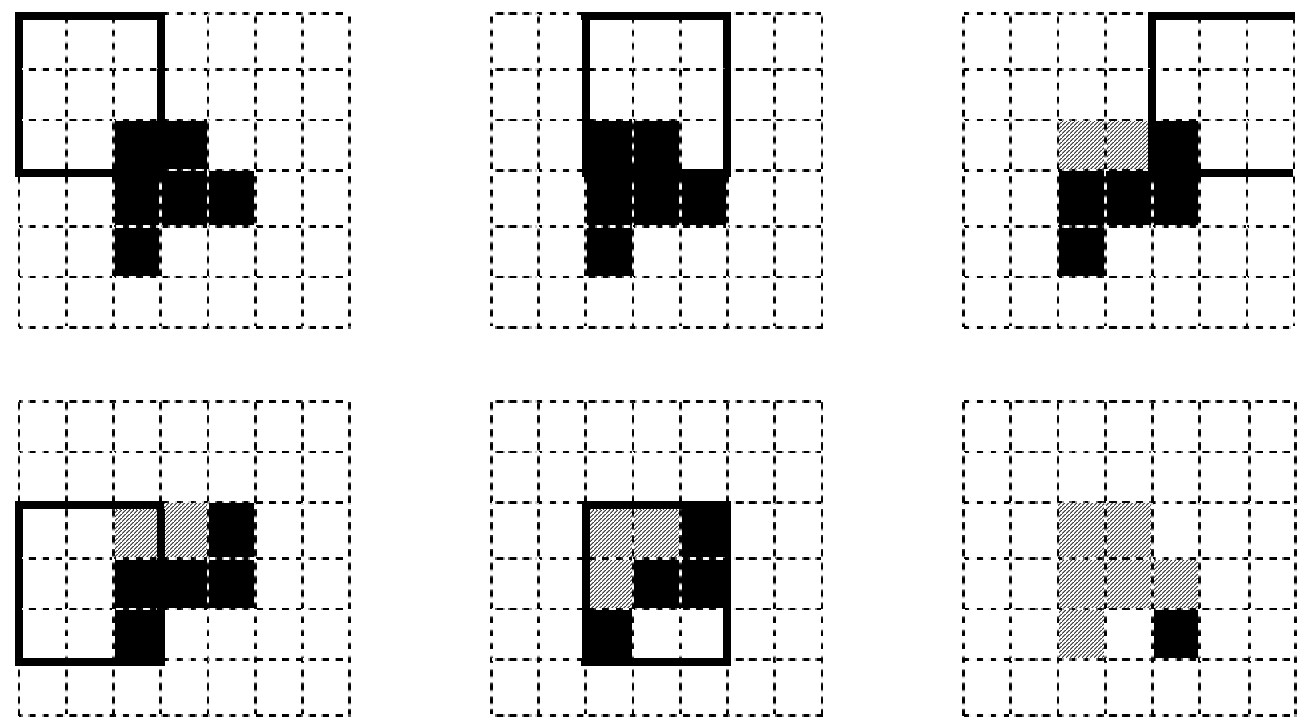

Figura 5-8 - Uma representação da "transformação

recursiva área-ponto" ([NISHIKAWA-93a]).

Segundo Nishikawa et al., esse método pode não funcionar como esperado se o sinal estiver em forma de "Y" ou "V". Se houver mais de três pixels entre os dois braços do $\mathrm{Y}$ ou $\mathrm{V}$, o sinal será transformado em dois pixels e não em um só. Pode ser usado um operador morfológico antes da aplicação dessa técnica para garantir que os sinais sejam suficientemente compactos. Mas tal fato não constitui necessariamente uma desvantagem, visto que microcalcificações com aquele formato provavelmente constituem indício de tumor maligno e, portanto, é melhor mantê-las do que eliminá-las. Um exemplo da técnica aplicada sobre um sinal com formato em "Y" é mostrada na figura 5-9.
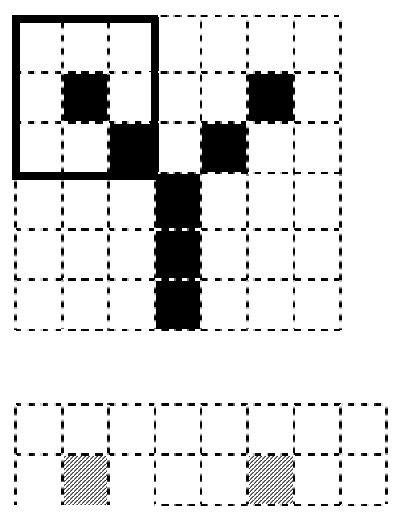
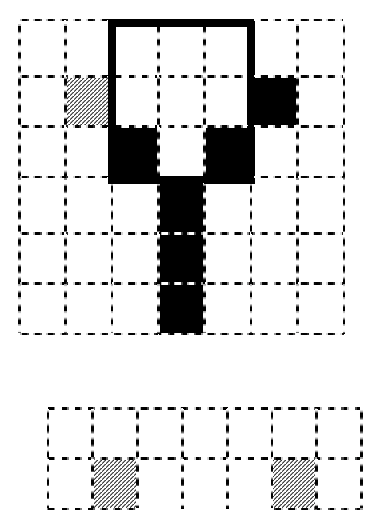
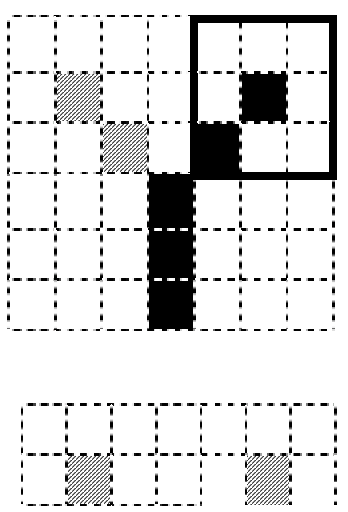

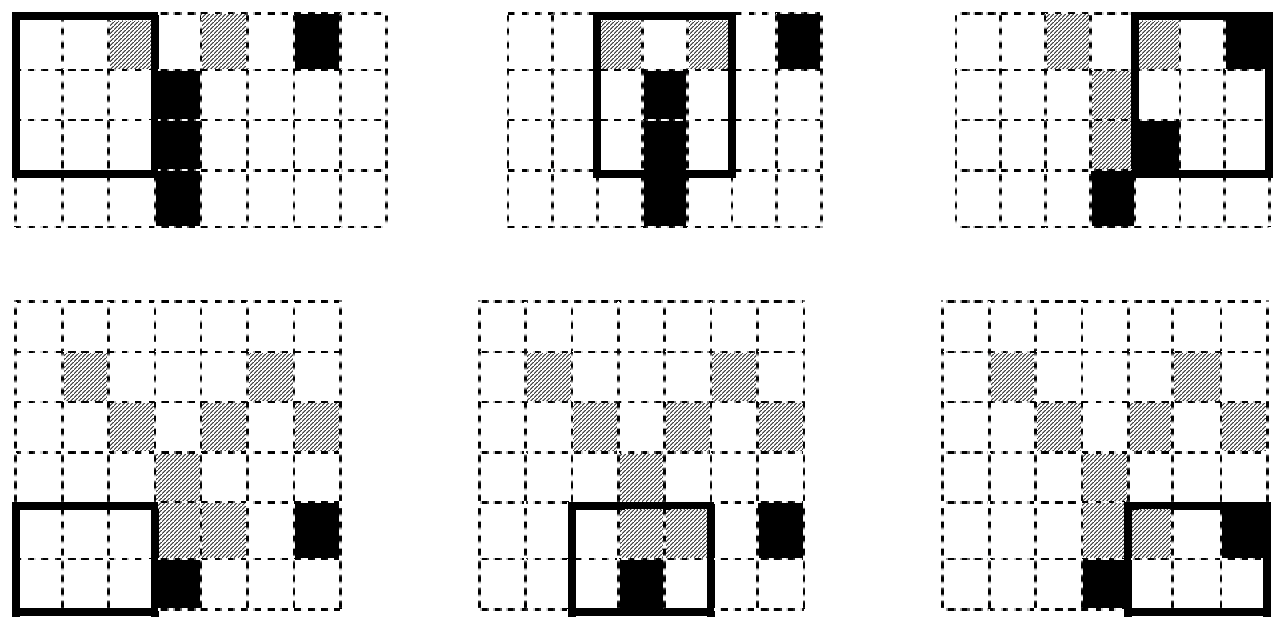

Figura 5-9 - Uma representação da "transformação recursiva área-ponto" para um sinal em formato de "Y".

\subsubsection{Identificação de "clusters"}

Para a identificação do agrupamento de sinais espalhados foi estabelecido o seguinte critério: os pixels identificados como microcalcificações foram passados para a imagem final somente quando três ou mais sinais estavam presentes dentro de um núcleo de tamanho e forma pré-definidos, isto é, se três ou mais sinais estavam presentes no núcleo, o conteúdo do núcleo era reproduzido, pixel a pixel, na imagem de saída. As microcalcificações isoladas, foram, desta forma, eliminadas da imagem. Cada pixel foi examinado na imagem de entrada de forma a produzir uma imagem de saída que indicasse regiões contendo sinais agrupados. Um exemplo deste procedimento é visualizado na figura 5-10. Sendo uma microcalcificação representada por um único pixel, então, a técnica poderia trabalhar através da simples contagem de pixels que estivessem acima do nível de fundo a fim de determinar o número de sinais presentes dentro do núcleo. A técnica também poderia ser aplicada sem a transformação recursiva área-ponto, mas seria muito mais trabalhoso reconhecer o sinal, de acordo com o que expõem os autores. 


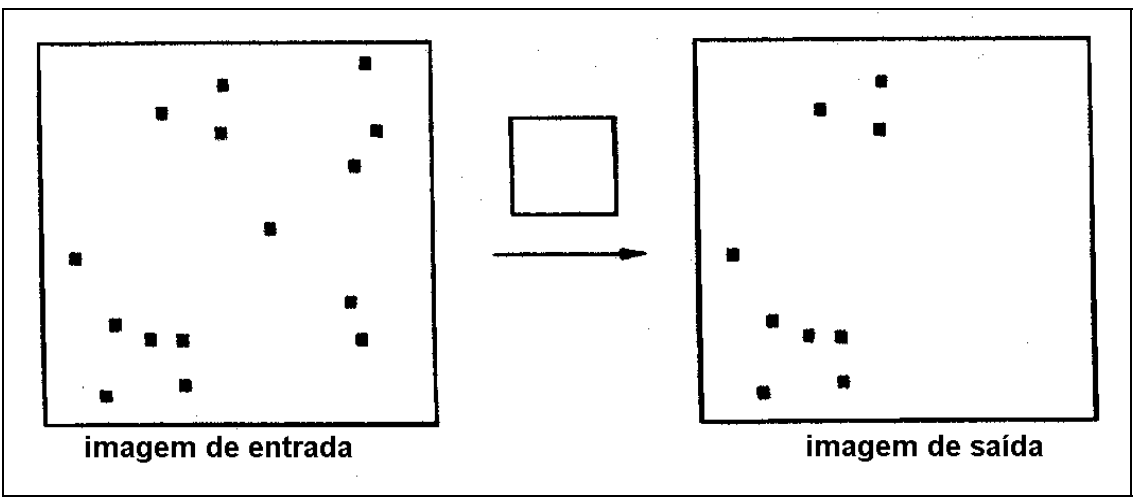

Figura 5-10 - Representação do agrupamento de microcalcificações. Se três ou mais sinais estão presentes no núcleo do "cluster", que é passado sobre a imagem de entrada, então, todos os sinais são passados para a imagem de saída ([NISHIKAWA-93a]).

Para que os sinais sejam considerados pertencentes à mesma aglomeração, os núcleos que os agruparam devem estar sobrepostos. Caso as microcalcificações que os compõem estejam espalhadas devido à distribuição dessas estruturas dentro do "cluster", ou se não são detectadas todas as microcalcificações do agrupamento, pode acontecer de um “cluster" grande ser detectado como dois ou mais grupos. Para amenizar este efeito, a técnica realizou um passo final, em que grupos de sinais cujos perímetros estavam longe até 50 pixels $(5 \mathrm{~mm})$ um do outro foram considerados pertencentes ao mesmo "cluster".

O tamanho do núcleo para detectar o agrupamento foi escolhido através do exame de vários tamanhos, desde 20 até 40 pixels. Foram usados nove mamogramas para este teste: oito imagens contendo um "cluster" verdadeiro cada uma (identificado por um médico experiente) e uma contendo dois "clusters". Para esse conjunto, foi verificada a porcentagem de "clusters" verdadeiros e o número de "clusters" falsos para diferentes tamanhos de núcleos. Para cada um dos tamanhos, foram obtidos diferentes pares de taxas de sinais verdadeiro-positivos e falsopositivos, mudando-se também o valor de "thresholding" local em níveis de cinza. A figura 5-11 mostra o número médio de "clusters" falsos detectados como verdadeiros em função do tamanho do núcleo escolhido. Para cada ponto, o "thresholding" local foi variado para manter a sensibilidade do esquema em 90\%. O tamanho de núcleo que forneceu a melhor performance foi de 32 × 32 pixels. 


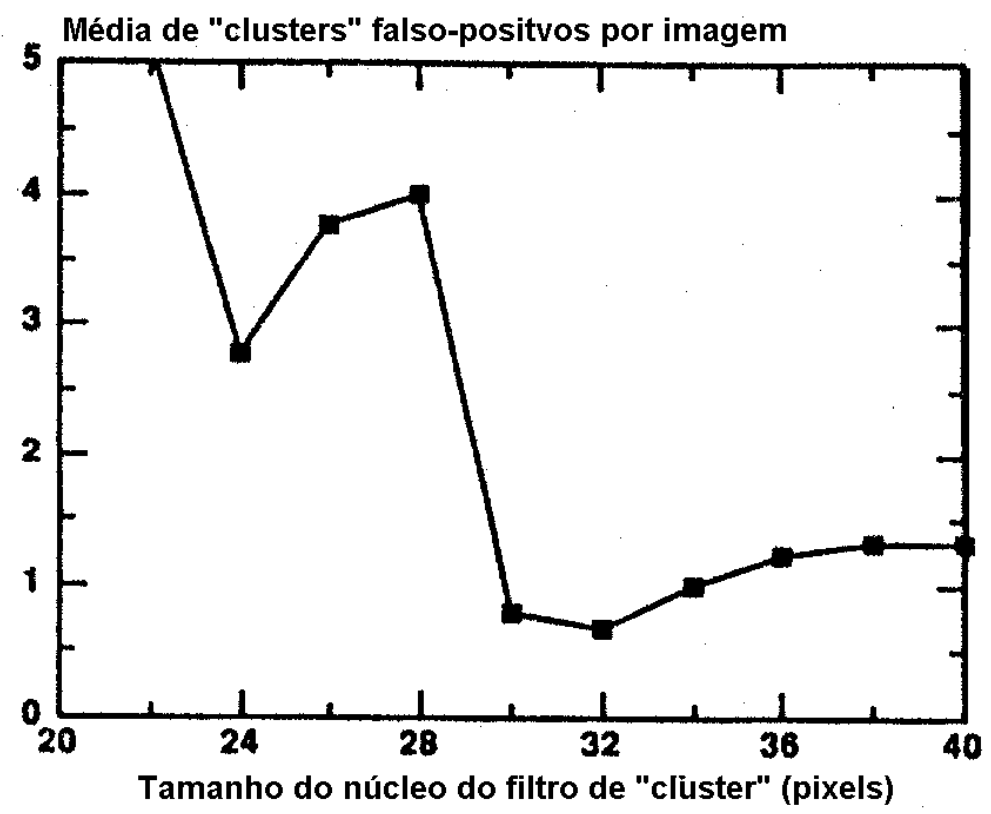

Figura 5-11 - Efeito do tamanho do núcleo usado para o processo de agrupamento de microcalcificações no número médio de "clusters" falsos detectados por imagem ([NISHIKAWA-93a]).

\subsubsection{Resultados e discussões}

As técnicas de identificação de "clusters" através da transformação área-ponto foram comparadas através de testes em 78 mamogramas, sendo que a metade possuía, no mínimo, um "cluster" (incluindo dois mamogramas com 2 “clusters" cada um) e a outra metade não possuía "clusters". Os mamogramas foram verificados por médicos experientes. Todos os "clusters" presentes nas imagens foram considerados verdadeiros (ou seja, continham microcalcificações), independentemente de estarem relacionados a tumores benignos ou malignos. Cada um dos 41 "clusters" apresentaram uma média de 14,3 microcalcificações, com um desvio padrão de 12,0. A área média de microcalcificações foi de 8,8 pixels com um desvio padrão de 7,8. O contraste médio de microcalcificações (medido como sendo a diferença entre as densidades da microcalcificação e do fundo do filme) foi 0,11 com um desvio padrão de 0,04 .

A escolha de mamogramas influencia profundamente a performance obtida pelo esquema computadorizado, segundo afirmam Nishikawa et al. em [NISHIKAWA-94]. Para calcular a variação dessa performance com o banco de 
dados de 78 mamogramas, foram formados 100 diferentes subconjuntos com 60 mamogramas cada um, tendo como critério que metade deles não deveria conter "clusters". Observou-se que a performance do esquema aumentava quando era analisado um conjunto de casos mais típicos, isto é, quando os "clusters" eram compostos por microcalcificações mais evidentes.

Foi observada melhoria na performance proporcionada pela técnica utilizando transformação AP em relação à técnica com emprego de crescimento de região, para a identificação de aglomerações. O número de "clusters" falso-positivos detectados por imagem diminuiu de 4,2 para 2,5, mantendo a sensibilidade do esquema em $85 \%$.

Desta forma, a técnica que denominamos aqui simplesmente de transformação AP, não só incrementou a sensibilidade do esquema computadorizado como também reduziu o número de detecções falsas obtidas. Segundo Nishikawa et al., o ganho obtido foi resultante do menor valor de "thresholding" local usado na técnica. Em geral, quando se diminui o valor do "thresholding", aumenta tanto a sensibilidade como o número de detecções falsas. Nesta técnica, porém, o número de falsas detecções foi reduzido amplamente. Por exemplo: para um valor de "thresholding" de 3,4 vezes o desvio padrão na vizinhança local, o método com aplicação de crescimento de região produziu uma sensibilidade de 90,2\% com 11,9 detecções falsas por imagem. Usando a nova técnica com um "thresholding” de 3,2 vezes o desvio padrão, a mesma sensibilidade foi obtida com 7,6 detecções falsas por imagem. Se este último valor de "thresholding" fosse usado para o método de crescimento de região, a sensibilidade seria de $95,1 \%$ com 21,6 "clusters" falsos por imagem.

O motivo da diminuição do número de "clusters" falsos está relacionado à distância entre os sinais do mesmo "cluster". Os autores observaram que, para "clusters" verdadeiros, a distância mínima entre dois sinais era menor que 32 pixels, enquanto que para muitos "clusters" falsos, a mínima distância era maior que esse valor. Isto pode ocorrer principalmente devido ao ruído randômico que produz falsos sinais no mamograma. O ruído tende a distribuir-se pela imagem aleatoriamente, enquanto que um "cluster", sendo um processo fisiológico, tende a apresentar os sinais em locais próximos. Considerando que a técnica utilizando 
transformação AP e novos conceitos para identificação de agrupamentos pode eliminar um "cluster" potencial onde a distância entre vizinhos é maior que o tamanho do núcleo usado, o número de "clusters" falso-positivos pode ser diminuído sem causar redução na quantidade de "clusters" verdadeiros detectados.

De acordo com Nishikawa et al., freqüentemente os radiologistas usam um critério em que se considera, no mínimo, 5 microcalcificações em um centímetro quadrado para que a área seja considerada como um "cluster". O esquema descrito considerou, porém, no mínimo 3 microcalcificações dentro de uma área de 3,2 x 3,2 mm. Observou-se que se fosse utilizada a definição dos radiologistas, a performance do esquema diminuiria: o número de detecções falso-positivas por imagem aumentou de 0,7 para 1,8 , considerando-se uma sensibilidade de $80 \%$.

Outro problema apresentado foi que, enquanto o esquema assistido por computador utilizando a transformação AP apresentou $85 \%$ de capacidade de detectar "clusters" verdadeiros, o mesmo esquema detectou menos de 50\% das microcalcificações. Por exemplo: em um "cluster" que continha 8 microcalcificações, apenas 3 delas puderam ser identificadas. Isso ocorreu devido ao rígido processo de filtragem ao qual foi submetida a imagem. Além disso, a técnica foi direcionada para detectar microcalcificações sutis, o que a tornou muito sensível ao ruído nos mamogramas. Era mais provável que o ruído produzisse 5 sinais falsos em uma área de um centímetro quadrado ao invés de aparecerem 3 sinais falsos em uma área de 3,2 $\mathrm{mm}^{2}$. Por esse motivo, foi utilizada a definição de "cluster" citada.

Todas as técnicas desenvolvidas por esses pesquisadores foram submetidas a testes exaustivos, ora com mamogramas reais, com laudo comprovado por biópsia, ora com mamogramas com aspectos simulados. Muitas vezes, os resultados apresentaram-se diferentes, de acordo com o banco de dados utilizados para os testes. Em [NISHIKAWA-94], Nishikawa et al. comentam a influência da seleção de casos na performance dos esquemas de detecção, afirmando que quanto maior a sutileza dos sinais de interesse, pior a performance do processamento.

\subsection{Pesquisa do MITRE Corporation - Burlington (EUA)}

Uma outra linha de pesquisa foi desenvolvida por um grupo de pesquisadores do MITRE Corporation, em Burlington, nos Estados Unidos. Em 
[FAM-88], B. W. Fam et al. descrevem algoritmos utilizados para a detecção de estruturas, as quais denominaram calcificações finas, em mamogramas cujos casos foram comprovados através de biópsias. Nesse caso, um "cluster" foi considerado como um grupo de três ou mais microcalcificações localizadas em uma área de $1 \mathrm{~cm}^{2}$.

O primeiro passo aplicado foi identificar, nas imagens digitalizadas, pixels correspondentes a áreas que potencialmente continham cálcio. Após a identificação, foi realizado um processo que agrupou pixels de cálcio adjacentes em estruturas simples de calcificação. Então, foi aplicada uma segunda bateria de testes nas estruturas a fim de eliminar aquelas que não se enquadravam nos critérios definidos para calcificações, os quais foram desenvolvidos a partir de critérios clínicos e observações das imagens digitais. Considerando 256 níveis de cinza, verificaram que os pixels mais fracos referentes a calcificações tinham intensidade mínima correspondente ao nível 20, e 94\% dos pixels apresentavam intensidade correspondente aos níveis de 80 a 255. Foi feita estatística com os dados obtidos (em relação aos pixels de calcificações e seus vizinhos) e, a partir daí, estabeleceram-se critérios para a detecção dos elementos desejados. As estruturas foram detectadas com base nesses critérios, utilizando-se técnicas de crescimento de região para definir a calcificação e detecção de bordas através de gradientes para a segmentação. A última tarefa do algoritmo foi definir o centro da estrutura reconhecida.

Após esse processamento, foi realizada a identificação de "clusters", da seguinte forma: os pixels identificados como parte de uma calcificação foram marcados com um nível único de cinza; os centros das calcificações com mais de um pixel e as calcificações formadas por somente um pixel foram marcadas por outro nível de intensidade. A partir disso, aplicou-se um filtro para identificar o "cluster", baseado no critério de que três ou mais calcificações em um volume de $1 \mathrm{~cm}^{3}$ formam um "cluster".

O algoritmo desloca uma janela de 49 x 49 pixels (para tamanho de pixel de 0,2 $\mathrm{mm}$ ) ou 99 x 99 pixels (para tamanho de pixel de 0,1 mm ) em volta de cada centro de calcificação, movendo-a para todas as posições que podem conter o centro. Para cada posição, os pixels dentro da janela foram checados para determinar quantas outras calcificações estavam contidas na janela. Havendo três ou mais sinais, 
todas as estruturas na janela eram marcadas como parte de possíveis "clusters". Se, para algum centro, não fosse atendido um critério de densidade mínima, os pixels marcados como pertencentes à calcificação teriam seu valor retornado ao valor original (antes de qualquer processamento).

Os autores afirmam que esse algoritmo apresentou resultados encorajadores, mas, mesmo assim, necessitava de melhorias.

Em [OLSON-88], os pesquisadores de Burlington publicaram resultados sobre pesquisas a fim de analisar as características da imagem de calcificações identificadas manualmente em tecidos de mamas. $\mathrm{O}$ objetivo era registrar intervalos de parâmetros necessários para os esquemas computadorizados de detecção.

A experiência envolveu 52 "clusters" de calcificações encontrados em 48 casos. Todos os casos possuíam comprovação através de biópsia. Com base na localização, foram registradas automaticamente as seguintes informações: tamanho das calcificações, intensidade, média de regiões de tecido em torno da calcificação, tamanho do "cluster", densidade de calcificações e média das distâncias entre calcificações dentro do "cluster". Após a obtenção desse conjunto de dados, outros programas foram executados para seleção e análise de porções de dados.

Foram obtidas características interessantes a respeito das calcificações e das regiões estudadas. Entre elas, foram pesquisados a idade das pacientes, o tamanho do "cluster", o tamanho da calcificação, a distância média entre calcificações, a média da intensidade dos tecidos na área, o tipo de equipamento mamográfico e a média da intensidade das calcificações.

Olson et al. concluíram que há muitas características importantes na população pesquisada. Por exemplo, as pacientes mais velhas apresentaram maior número de malignidades do que as pacientes mais jovens. Outra observação importante para a qual o significado clínico ainda não é bem compreendido é que a distância média entre "clusters" nos processos malignos é bem maior que a distância média de calcificações nos casos benignos. 


\subsection{Detecção de microcalcificações baseada na análise de aspectos e na análise "wavelet"}

Com o mesmo objetivo de produzir um esquema computadorizado para detecção de "clusters" de calcificações em mamogramas, D. H. Davies e D. R. Dance, em [DAVIES-90], propuseram o algoritmo esquematizado na figura 512. O primeiro passo do algoritmo proposto foi o pré-processamento do mamograma digitalizado a fim de produzir fundo uniforme. Sobre a imagem resultante foi aplicado um "thresholding" usando uma técnica de área local para obter uma imagem segmentada, que deveria incluir todas as possíveis localizações de calcificações. Analisadas as propriedades das estruturas encontradas na imagem segmentada, aquelas que satisfaziam determinados critérios foram classificadas como prováveis calcificações. Detectado algum "cluster", produzia-se, então, uma nova imagem segmentada (com novos valores de "thresholding"). Em seguida, os objetos encontrados eram analisados novamente e, ao se verificar que algum deles pertencia a alguma estrutura maior (geralmente vasos), ele era eliminado. Finalmente, foi reaplicado o algoritmo de agrupamento para localizar e marcar os grupos remanescentes de calcificações.

As características observadas para classificar um objeto como uma calcificação foram: área, média do nível de cinza, razão da área para o quadrado da dimensão linear máxima, parâmetro de forma e comprimento da borda. Foram identificadas calcificações com área entre 0,3 a $1,5 \mathrm{~mm}^{2}$. Para o procedimento de agrupamento impôs-se o seguinte critério: se a distância máxima da calcificação mais próxima é menor que uma determinada distância e se há mais que um número pré-selecionado de ligações feitas naquele sentido, naquela posição existe um “cluster". Segundo Davies e Dance, a experiência clínica de radiologistas afirma que um “cluster" tem, no mínimo, 3 calcificações, cujas distâncias entre si são menores que $5 \mathrm{~mm}$. 


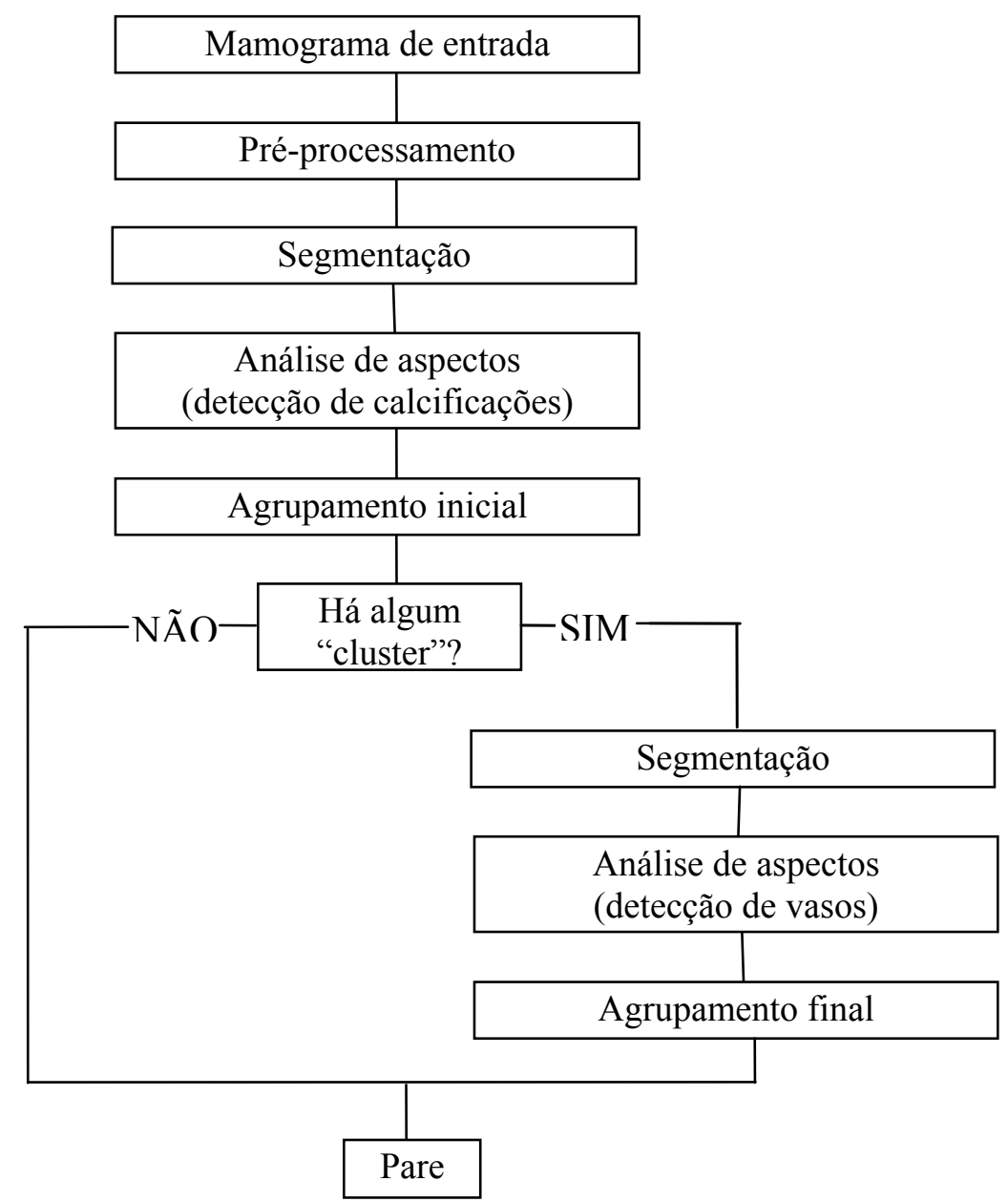

Figura 5-12 - Esquema do sistema computadorizado ([DAVIES-90]).

O método desenvolvido em [DAVIES-90] foi testado com 50 mamogramas. O resumo dos resultados obtidos é mostrado na tabela 5-2. O esquema reconheceu 47 dos 49 "clusters" indicados por radiologistas nos mamogramas. Encontrou também 9 "clusters" falsos. Foram classificados corretamente 46 casos (dos 50 existentes), apresentando, segundo os pesquisadores, $92 \%$ de classificação correta. Não houve classificação incorreta de filmes.

Recentemente, alguns pesquisadores têm estudado a possibilidade da aplicação da análise "wavelet"7 para a detecção de microcalcificações em mamogramas. Em [RICHARDSON-95], W. B. Richardson Jr. et al. fizeram um resumo da análise "wavelet", expondo sua utilidade para realce de aspectos, discriminação de textura, reconhecimento de padrões, compressão de dados e aquisição de imagens. Segundo eles, a análise "wavelet" refere-se a uma coleção de

\footnotetext{
${ }^{7}$ vide item 4.3 .
} 
métodos matemáticos cuja aplicação tem aumentado nas áreas citadas. Em mamografia, eles conduziram testes para o realce e classificação de aspectos, sendo obtidas, segundo esses autores, significativas vantagens sobre os métodos tradicionais utilizados.

Tabela 5-2 - Performance da detecção de "clusters" em 50 mamogramas do esquema ([DAVIES-90]). A tabela indica as taxas de casos verdadeiro-positivos (TP), falso-positivos (FP) e falso-negativos (FN). Os filmes foram classificados de acordo com o critério de possuírem ou não no mínimo um "cluster".

\begin{tabular}{lcccccc}
\hline & $\begin{array}{c}\text { Número de } \\
\text { mamogramas } \\
\text { registrados }\end{array}$ & \multicolumn{3}{c}{ Detecção de Clusters } & Classificação dos filmes \\
\cline { 3 - 7 } & & TP & FP & FN & Correta & Incorreta \\
\hline $\begin{array}{l}\text { Normal } \\
\text { "Clusters" de }\end{array}$ & 25 & 0 & 9 & 0 & 21 & 4 \\
$\begin{array}{l}\text { calcificações } \\
\text { presentes }\end{array}$ & 25 & $47 / 49$ & 0 & 2 & 25 & 0 \\
Total & 50 & $47 / 49$ & 9 & & & 46 \\
\hline
\end{tabular}

W. Qian et al., em [QIAN-95] afirmam que os métodos de resolução, entre eles "wavelet", apresentam vantagens inerentes sobre os métodos tradicionais de filtragem de imagens, visto que esses últimos falham na preservação de detalhes clinicamente importantes. Nesse trabalho, foram utilizados métodos baseados em "wavelet" para realce de aspectos, em que imagens sem processamento e realçadas foram submetidas a testes para detecção de microcalcificações. Em situações que não havia realce, foram feitas várias detecções falso-positivas. Analisando 30 casos, a equipe concluiu que a sensibilidade do esquema desenvolvido para imagens realçadas foi de 90\%, com uma média de 0,85 detecção falso-positiva por imagem. Nos casos sem realce, a sensibilidade do esquema decaiu para $68 \%$, apresentando taxa de 1,43 diagnósticos falso-positivos por imagem.

\subsection{Simulação de microcalcificações agrupadas}

Além da detecção e reconhecimento de sinais de interesse é necessário que se estabeleçam formas de avaliação dos esquemas elaborados. Visto que a seleção de casos é um dos problemas para a avaliação da performance de algoritmos, grupos de pesquisadores têm direcionado suas pesquisas no sentido de simular estruturas de interesse com fidelidade a características reais. 
Para gerar estruturas a fim de avaliar a precisão de detecção do esquema computadorizado desenvolvido pela equipe, Chan et al. descrevem em [CHAN-87] um método para simular microcalcificações que foram sobrepostas em fundos mamográficos normais. Nesse trabalho, foram armazenadas as características das estruturas geradas, como localização, tamanho e contraste, a fim de realizar a comparação dos resultados de detecção obtidos posteriormente.

O usuário seleciona a região de interesse onde deve ser alocado o "cluster" no mamograma. As distribuições das localizações, das dimensões e do contraste das microcalcificações foram considerados como sendo gaussianas, com média e desvio padrão determinados pelo usuário. $\mathrm{O}$ algoritmo escolhe randomicamente um local dentro da região de interesse para sobrepor a microcalcificação. Com base nas dimensões da estrutura, determina-se uma forma aleatória de microcalcificação com a restrição de borda constante. O contraste de cada pixel dentro da microcalcificação também é selecionado randomicamente, sendo imposto o requisito de que o contraste máximo deve ser aplicado nos pixels centrais, diminuindo em direção à borda. A microcalcificação simulada é sobreposta no mamograma, repetindo-se o processo até ser formado um "cluster". A quantidade de microcalcificações em cada "cluster" pode ser fornecida pelo usuário ou baseada em uma distribuição fornecida pelo usuário. De acordo com Chan et al., o programa não reproduziu exatamente todas as variações de microcalcificações malignas, particularmente a tendência de tais estruturas apresentarem formatos lineares. Todavia, radiologistas experientes avaliaram os sinais gerados como bem semelhantes aos sinais reais.

Pesquisadores do Institut Gustave Roussy, na França, propuseram a simulação de "cluster" de microcalcificações a fim de criar um banco de dados bem próximo da realidade para ser utilizado nos testes dos esquemas automatizados. Em [LEFEBVRE-94], F. Lefebvre et al. descrevem o modelo matemático da simulação proposta em que estabeleceram dois bancos de dados: o primeiro contendo mamogramas comprovadamente sem microcalcificações e o segundo, com um conjunto de mamogramas, apresentando cada um deles um "cluster" simples.

Genericamente, o trabalho consistiu em digitalizar esses mamogramas, estudá-los e montar os "clusters" propostos. O primeiro grupo, 
denominado DB1, foi utilizado como fundo para as imagens geradas. Como a estrutura de fundo de uma mama é muito heterogênea preferiu-se trabalhar com estruturas reais, reservando a simulação somente para os "clusters". O segundo banco de dados (DB2) foi útil para o estudo dos "clusters" reais e a determinação de características e estatísticas usadas na simulação. Todo o processo de identificação foi auxiliado por radiologistas.

O modelo para simular microcalcificações agrupadas envolveu a criação de uma imagem binária e a atribuição de um nível de cinza para cada pixel ao longo da microcalcificação. Para criar a imagem binária, foi necessário estabelecer os aspectos globais dos "clusters" e os parâmetros que descreviam cada microcalcificação individualmente. Assim, um "cluster" foi definido através de seu tamanho, de sua localização dentro da mama e o número de microcalcificações que continha. Os parâmetros para descrever individualmente cada microcalcificação foram: tamanho, forma e localização dentro do "cluster". Todos os parâmetros descritos no modelo foram gerados randomicamente, com exceção do centro do "cluster" dentro da mama, que foi posicionado manualmente. A estatística de distribuição da maioria dos parâmetros foi estabelecida com base na análise das microcalcificações agrupadas do banco de dados DB2.

A validação do modelo simulado foi conferida por radiologistas através do uso de um banco de dados contendo "clusters" reais e simulados. Percebeu-se que não havia diferenças estatisticamente significativas entre "clusters" reais e simulados. Eles ressaltaram, ainda, que este método é muito útil para a avaliação de esquemas automatizados de microcalcificações agrupadas, pois até hoje não há uma padronização. Considerada a dificuldade existente em criar um banco de dados cujos casos são comprovados através de biópsias ou magnificação e a subjetividade envolvida na avaliação de um esquema por radiologistas, pode-se afirmar que uma simulação dessas oferece uma grande contribuição para a avaliação dos algoritmos existentes. 


\subsection{Fatores que influenciam a performance medida em um esquema de detecção computadorizado}

Cada grupo de pesquisa assume uma linha de conduta que considera a ideal para um esquema computadorizado de detecção de microcalcificações e "clusters". Mas, como avaliar, de forma coerente, a performance dos diversos esquemas existentes? Alguns fatores que influenciam a medida de avaliação da performance de esquemas de detecções automatizadas são comentados a seguir.

\subsubsection{Seleção de casos}

Geralmente a performance de um esquema automatizado é inversamente proporcional à porcentagem de casos sutis ou casos difíceis do banco de dados em uso. Desta forma, a precisão pode variar de 0 a $100 \%$ dependendo do conjunto de dados disponível. Como os bancos de dados de cada grupo de pesquisadores diferem em termos de quantidades, qualidade e proporção de casos difíceis e casos óbvios, a performance obtida de diferentes técnicas podem não ter validade se forem medidas com base em bancos de dados diferentes.

Por esse motivo, comparações de esquemas diferentes requerem que os bancos de dados utilizados para testes sejam os mesmos ou, no mínimo, sejam estabelecidos a partir de metodologias objetivas. Atualmente isto não é praticado. Uma solução proposta por Nishikawa et al., em [NISHIKAWA-93a], é o registro detalhado de medidas de características das lesões, como desvio padrão de tamanho e contraste. Segundo esses pesquisadores, este procedimento poderia fornecer uma estimativa qualitativa do grau de dificuldade dos casos utilizados. Por outro lado, F. Lefebvre et al., em [LEFEBVRE-94], propõem a simulação de microcalcificações agrupadas como possível solução para este problema.

\subsubsection{Método usado para quantificar os resultados}

Os resultados de uma pesquisa dependem do objetivo que a mesma deseja atingir. Por isso, os métodos de quantificação dos resultados e as características importantes observadas na imagem não podem ser genéricos. Por exemplo: para uma determinada pesquisa, é importante a distância entre as 
microcalcificações; para outra, o objetivo é verificar o formato dessas estruturas, e assim por diante. Não há um método universal. Nishikawa et al, em [NISHIKAWA-93a], utilizaram o seguinte método: para um esquema de microcalcificações agrupadas, uma detecção foi quantificada como verdadeira se o centro de massa do "cluster" verdadeiro e o "cluster" detectado pelo computador estivessem distantes, no máximo, $6 \mathrm{~mm}$ e se a estrutura identificada pelo computador possuísse ao menos uma microcalcificação. Quando o objetivo da pesquisa era a detecção de massas, a detecção computadorizada foi considerada correta se houvesse, no mínimo, um pixel em comum entre a massa verdadeira e a detectada pelo esquema automatizado. Já que não se pode padronizar um método de quantificação, a sugestão de Nishikawa é que os pesquisadores explicitem detalhadamente o método utilizado para quantificar as detecções falsas e verdadeiras.

\subsubsection{Método de avaliação da performance}

Atualmente há muitos métodos usados para avaliar a performance de um esquema de detecção. Alguns grupos ([CHAN-90] e [NISHIKAWA-93b]) usam curvas ROC (um método que indica a relação entre o número de diagnósticos falsos e verdadeiros) e outros tipos de curvas semelhantes. Este método geralmente é empregado quando se deseja estabelecer o quanto um esquema é sensível e a influência de diagnósticos falsos nos resultados. O importante, também, é que os métodos utilizados sejam detalhados nos trabalhos publicados. Na figura 5-13 vemos um exemplo de curvas FROC, que constituem uma forma de avaliação de performance, mostrando graficamente a relação entre o número de diagnósticos obtidos e o número de diagnósticos falsos detectados.

\subsection{Conclusões}

A finalidade de um esquema automatizado para detecção de microcalcificações em mamogramas digitalizados é fornecer dados para a formação da opinião dos radiologistas a respeito do diagnóstico do câncer de mama. A decisão final, obviamente, sempre é de responsabilidade médica. 


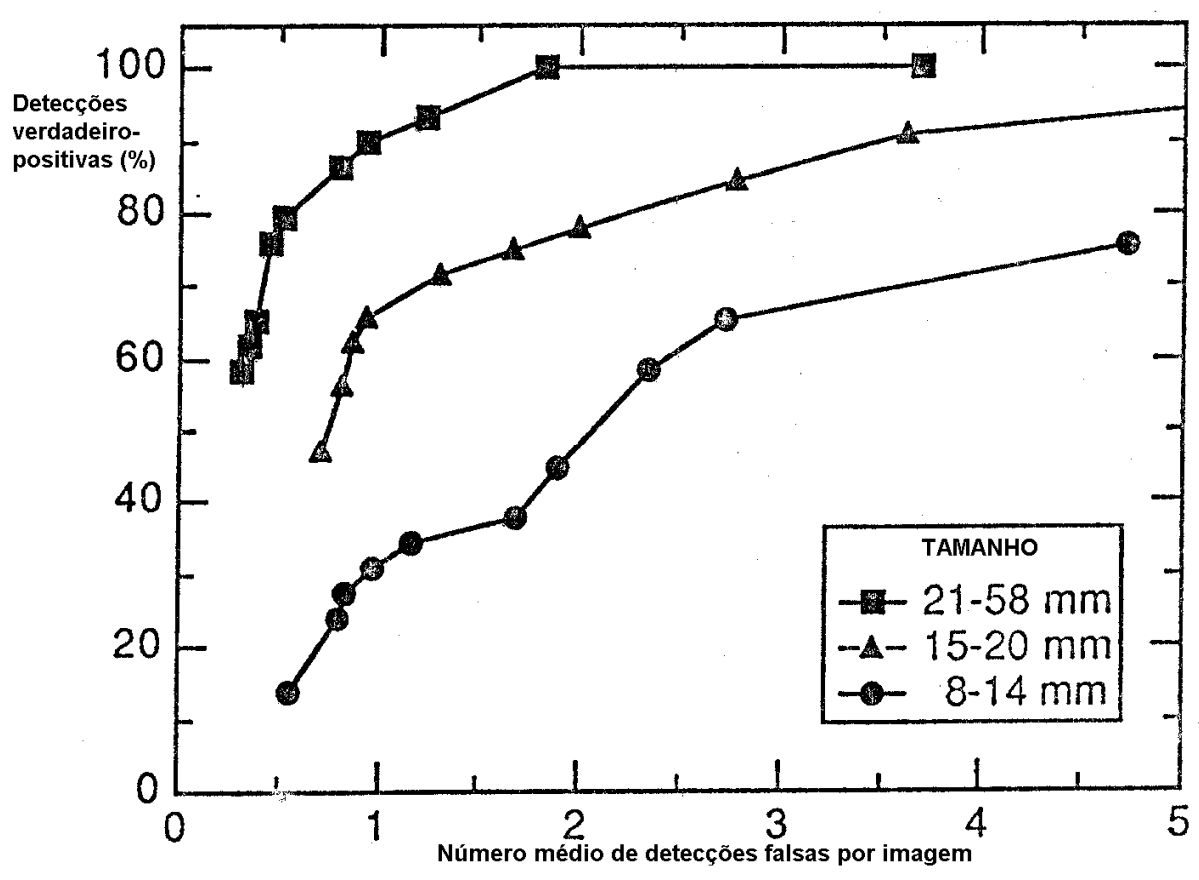

Figura 5-13 - Exemplo de uma curva FROC que pode ser utilizada para medir a performance de um esquema computadorizado de deteç̧ões ([NISHIKAWA-93b]).

Várias técnicas de processamento de imagens são empregadas no que se refere à detecção de microcalcificações. Muitas delas são modificações de métodos anteriores, através da inclusão de melhorias, relacionadas especificamente com a aplicação fim. No entanto, até 1988 nenhum dos esquemas descritos estava sendo aplicado clinicamente ([CHAN-88b]), pois os pesquisadores ainda não haviam chegado a um esquema que pudesse fornecer um segundo diagnóstico seguro, com baixas taxas de diagnósticos falso-positivos e falso-negativos. Dessa data em diante bons resultados têm sido obtidos e até hoje as pesquisas continuam no sentido de aperfeiçoar os esquemas existentes.

Um esquema completo de detecção de microcalcificações deveria reconhecê-las, reconhecer os seus agrupamentos e fornecer um diagnóstico do seu possível relacionamento com tumores benignos e malignos. No capítulo seguinte descreveremos a nossa proposta para a detecção de microcalcificações e identificação de agrupamentos dessas estruturas. 


\section{6}

\section{SISTEMA DESENVOLVIDO PARA DETECÇÃO DE “CLUSTERS"}

\subsection{Sistema computacional}

Com base nos métodos citados na bibliografia e estabelecendo-se alguns procedimentos novos, foi construído um sistema computacional para a detecção de "clusters" em mamogramas digitalizados, o qual é constituído dos passos mostrados na figura 6-1.

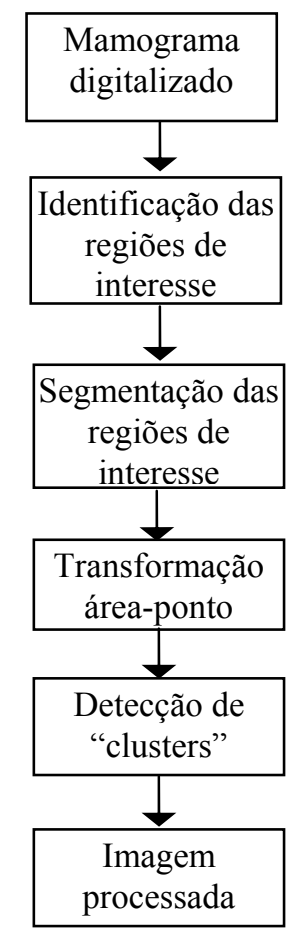

Figura 6-1 - Esquema do sistema computacional desenvolvido para detecção de "clusters" de microcalcificações.

O sistema foi implementado utilizando a linguagem Delphi 1.0, para execução sob plataforma Windows. O usuário seleciona a imagem desejada e executa os passos necessários para obter a identificação de "clusters", tendo a possibilidade de alterar os parâmetros de acordo com as características particulares 
de cada imagem. A seguir, detalharemos cada um dos passos necessários para atingir o resultado final.

\subsubsection{Detecção das regiões de interesse}

Um dos grandes problemas encontrados foi a demora no processamento, devida à grande quantidade de pontos das imagens. O tamanho diminuto das microcalcificações exige a utilização de resolução alta no processo de digitalização, pois, se esse requisito não for atendido, pode ocorrer a eliminação de alguns sinais durante o processo de aquisição da imagem. Utilizamos a resolução de 600 dpi (600 pontos por polegada), que fornece tamanho de pixel menor que as microcalcificações, mas, gera imagens com uma quantia muito elevada de pontos. Inicialmente o sistema foi idealizado para processar imagens de mamogramas inteiros. No entanto, além da impossibilidade de processar algumas imagens em razão da escassez de recursos computacionais, verificou-se que o tempo computacional dispendido para o processamento de cada imagem tornava a aplicação inviável. Decidiu-se, então, processar apenas as porções do mamograma que pudessem conter estruturas de interesse. Para isso, foi necessário criar um procedimento para identificação semi-automática dessas regiões.

A constituição das microcalcificações (cálcio) faz com que absorvam maior número de fótons de raios-X, quando comparadas com os demais tecidos que compõem a mama. Esse fato causa uma diferença de densidade ótica no filme mamográfico, fazendo com que as regiões do filme contendo microcalcificações fiquem mais claras após o processo de revelação. A conseqüência dessa propriedade é uma diferenciação em termos de nível de cinza na imagem digitalizada, ou seja, as microcalcificações em si correspondem a níveis de cinza maiores (mais próximos do branco). Desse fato decorre que, em condições ideais, as regiões com microcalcificações devem apresentar maior média de níveis de cinza em relação ao restante da imagem.

Porém, geralmente as imagens não apresentam condições ideais; muitas vezes contêm variação na distribuição de intensidade ou incluem objetos que não fazem parte da estrutura da mama. Dessa forma, não basta selecionar apenas os trechos que apresentam média de níveis de cinza maior que a média geral da 
imagem, pois as deformações presentes influenciam no valor da média geral, tornando-o maior e impedindo que as regiões de interesse sejam identificadas. Por esse motivo, na implementação da técnica de identificação dessas regiões, atentou-se para fornecer ao usuário a possibilidade de escolher qual a porcentagem da média geral de cinza que deve ser usada como parâmetro de comparação para a identificação das regiões de interesse.

Pelo exposto anteriormente foi decidido que, no sistema desenvolvido, uma porção do mamograma seria considerada de interesse quando sua média de níveis de cinza fosse maior que uma determinada porcentagem da média geral do mamograma. Através da informação de alguns parâmetros (detalhados adiante), então, é possível definir algumas características das regiões de interesse, conforme observado no fluxograma da figura 6-2.

O procedimento realiza os seguintes passos:

1. Redução da imagem: reduz a imagem para $1 / 4$ do tamanho original a fim de diminuir o tempo de processamento da identificação das regiões de interesse;

2. Filtragem para realce dos sinais: aplica um filtro para realce dos pixels de interesse;

3. Subtração: subtrai a imagem realçada da imagem original;

4. "Thresholding" global: aplica um procedimento de "thresholding", onde permanecem brancos na imagem somente uma porcentagem de pixels estabelecida pelo usuário;

5. Armazenamento dos dados das regiões: armazena em um vetor somente as regiões que possam despertar interesse, de acordo com parâmetros fornecidos previamente ("tamanho da região" e “porcentagem da média geral de nível de cinza considerada");

6. Gravação das regiões: faz a demarcação da região de interesse na tela e espera o usuário confirmar seu desejo de armazenar a região indicada. 


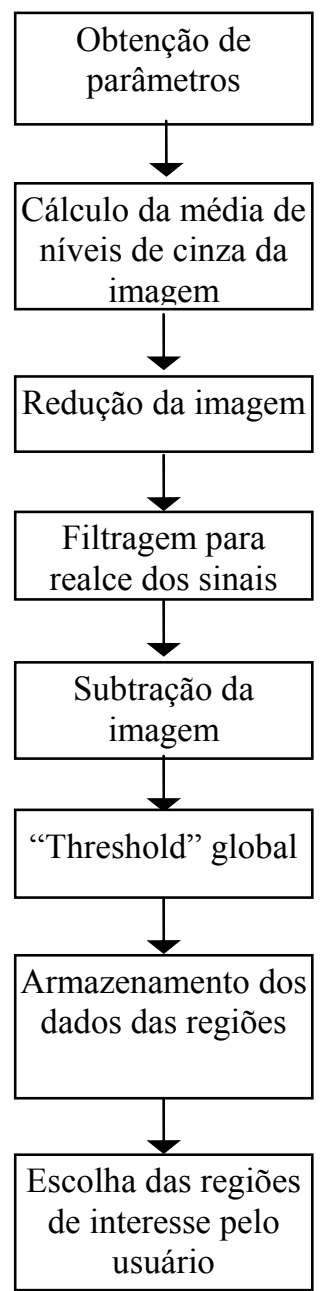

Figura 6-2 - Esquema dos passos executados para identificação das regiões de interesse.

$\mathrm{Na}$ figura 6-3 pode ser observada a tela inicial com os parâmetros referentes às regiões desejadas. A tabela 6-1 explica cada um desses parâmetros.

Os valores padrão apresentados na tabela 6-1 foram escolhidos a partir das definições de "cluster" encontradas na literatura e de testes realizados com as imagens:

* tamanho da região (altura e largura): é um tamanho que corresponde a uma área ligeiramente maior que $1 \mathrm{~cm}^{2}$ da imagem, considerando resolução de 600 dpi; é importante lembrar aqui que o nosso processo de identificação de "cluster" considera a existência de um "agrupamento" quando são encontrados 3 ou mais sinais em uma área de $1 \mathrm{~cm}^{2}$ ([SICKLES-86], [JIN-93]). 


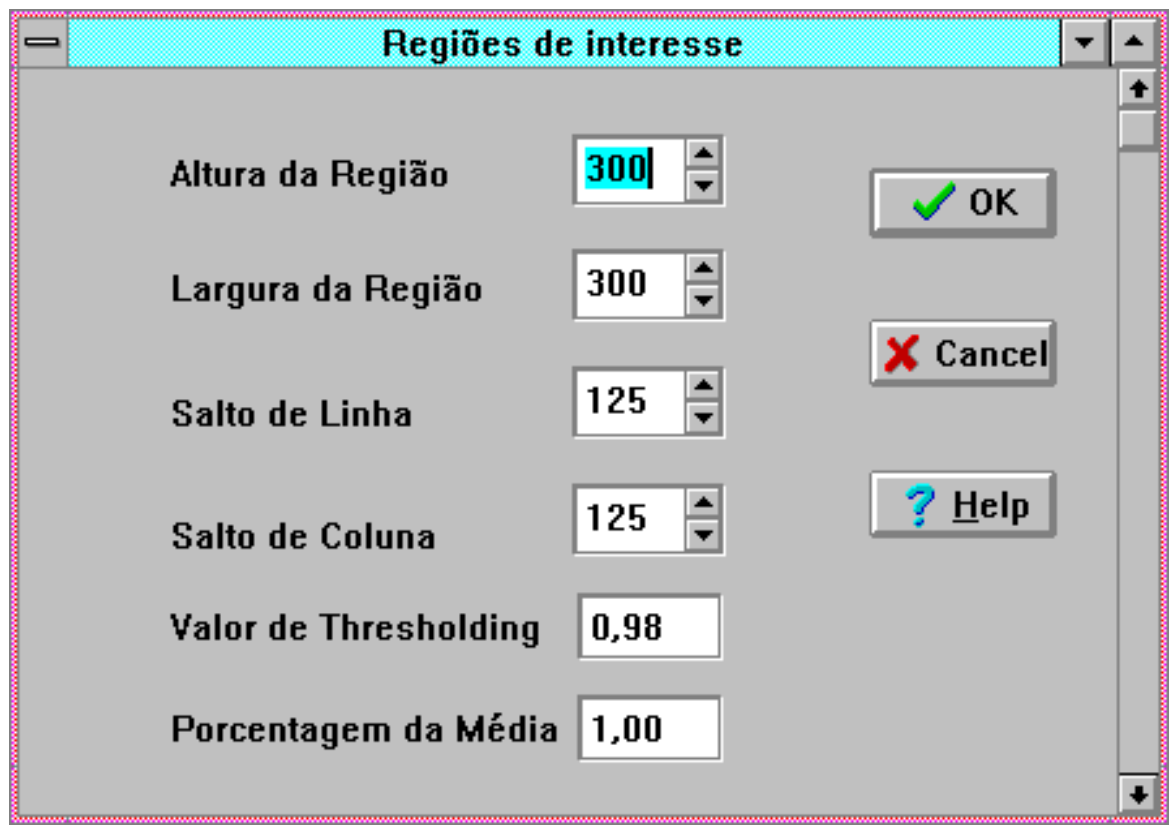

Figura 6-3 - Tela inicial da identificação das regiões de interesse.

Tabela 6-1 - Parâmetros para a identificação das regiões de interesse.

\begin{tabular}{llc}
\hline \multicolumn{1}{c}{ Parâmetro } & \multicolumn{1}{c}{ Descrição } & Valor padrão \\
\hline Altura da Região & Quantidade de linhas de cada região de interesse & 250 \\
Largura da Região & Quantidade de colunas de cada região de interesse & 250 \\
Salto de Linha & $\begin{array}{l}\text { Quantidade de linhas que serão saltadas em cada } \\
\text { iteração do reconhecimento de regiões de interesse }\end{array}$ & 125 \\
Salto de Coluna & $\begin{array}{l}\text { Quantidade de colunas que serão saltadas em cada } \\
\text { iteração do reconhecimento de regiões de interesse }\end{array}$ & 125 \\
Valor de "Thresholding"” & $\begin{array}{l}\text { Quantidade de pixels que deverão permanecer } \\
\text { brancos durante o procedimento de "thresholding" } \\
\text { global. Exemplo: 0,98 significa que permanecerão }\end{array}$ & \\
& $\begin{array}{l}\text { brancos na imagem somente os 98\% de pixels mais } \\
\text { claros. }\end{array}$ & \\
Paxa da média de níveis de cinza da imagem toda & 1,00 \\
& $\begin{array}{l}\text { que será utilizada para considerar uma região como } \\
\text { sendo de interesse. Exemplo: para o valor 0,50, } \\
\text { todas as regiões cuja média de cinza for maior ou }\end{array}$ & \\
& $\begin{array}{l}\text { igual a 50\% da média de cinza da imagem toda, } \\
\text { serão consideradas como regiões de interesse. }\end{array}$ & \\
&
\end{tabular}

* salto de linha e salto de coluna: foram estabelecidos como metade dos valores de altura e largura da região, respectivamente, a fim de que possíveis "clusters" não sejam divididos ao meio; se isso ocorrer em uma iteração, as iterações seguintes permitirão que a $2^{\mathrm{a}}$ parte da imagem (vertical ou 
horizontalmente) seja novamente verificada, abrangendo, dessa forma, o "cluster" de forma completa.

* valor de "thresholding": foi estabelecido com base em testes durante o processo de desenvolvimento dos programas de segmentação. Esse parâmetro informa ao sistema qual a porcentagem de pixels mais claros que deverá permanecer na imagem; os valores dos pixels dentro dessa porcentagem serão transformados no valor mais alto de nível de cinza (branco).

* $\quad$ porcentagem da média de cinza: foi padronizada como "1", significando que serão identificados somente os trechos da imagem com média de cinza maior que a média geral da imagem toda; se houver variação de intensidade ou a presença de objetos externos, o usuário deverá diminuir este valor.

A figura 6-4 exibe a tela onde o usuário informa se deseja considerar ou descartar a região identificada como sendo de interesse (passo 6 do procedimento de identificação de regiões de interesse).

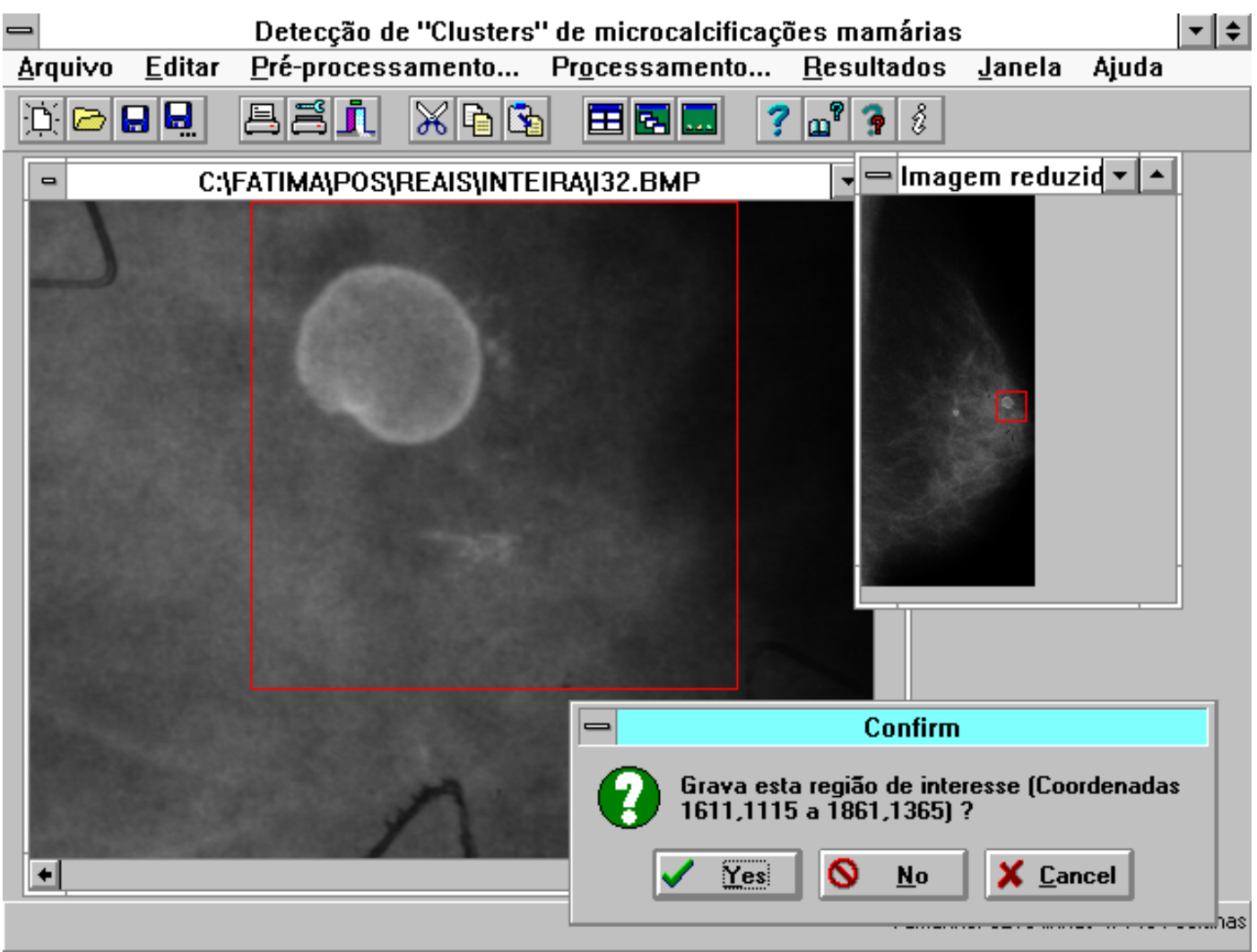

Figura 6-4 - Tela de gravação da região de interesse. 
Um mamograma original digitalizado e as regiões de interesse extraídas dele podem ser visualizados na figura 6-5. Neste caso, foram utilizados os seguintes parâmetros: altura da região: 250; largura da região: 250; salto de linha: 125; salto de coluna: 125; valor de "Thresholding": 0,98 e porcentagem da média de cinza: 0,50 .

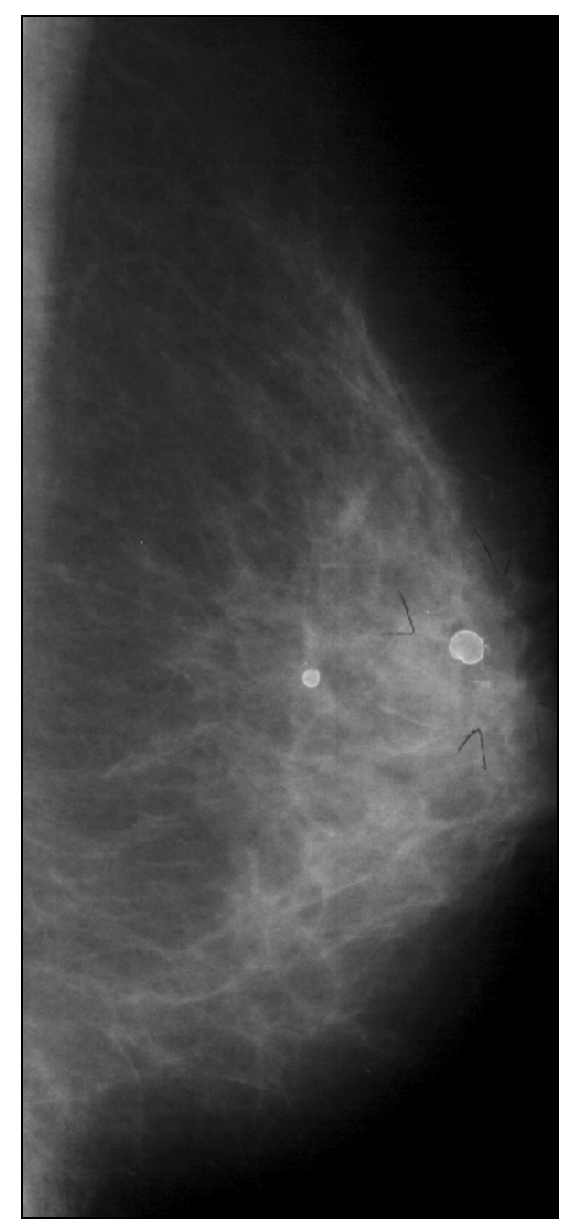

(a)
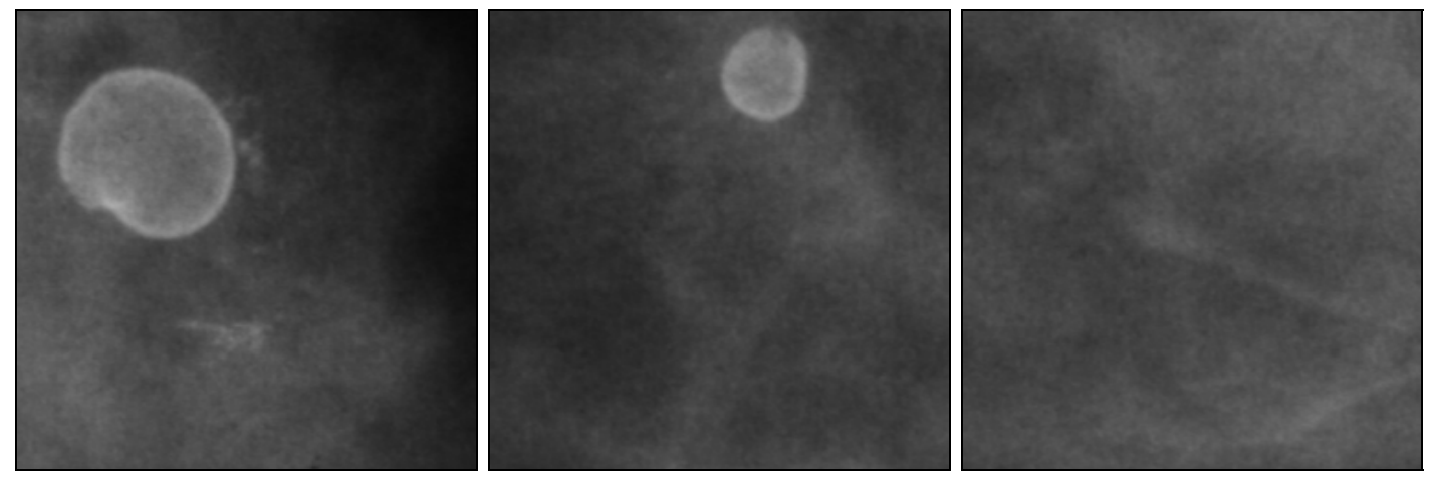

(b)

Figura 6-5 - a) Mamograma digitalizado e b) regiões de interesse identificadas e armazenadas. 
Após a identificação dos segmentos de interesse, cada nova imagem gravada é submetida aos passos de pré-processamento e processamento para a detecção efetiva dos "clusters". Esses passos são descritos nos itens 6.1.2 a 6.1.4.

\subsubsection{Segmentação}

A segmentação é o processo onde as estruturas de interesse devem ser reforçadas e os ruídos e artefatos devem ser eliminados da imagem. Após um estudo comparativo de vários métodos de segmentação realizado por Villela et al. ([VILLELA-96]), decidiu-se escolher o procedimento utilizado por Nishikawa et al. em [NISHIKAWA-92]. O esquema do processamento pode ser visualizado na figura 6-6, envolvendo as etapas descritas abaixo, onde o processamento da imagem em uma fase é realizado sobre a imagem resultante do passo anterior:

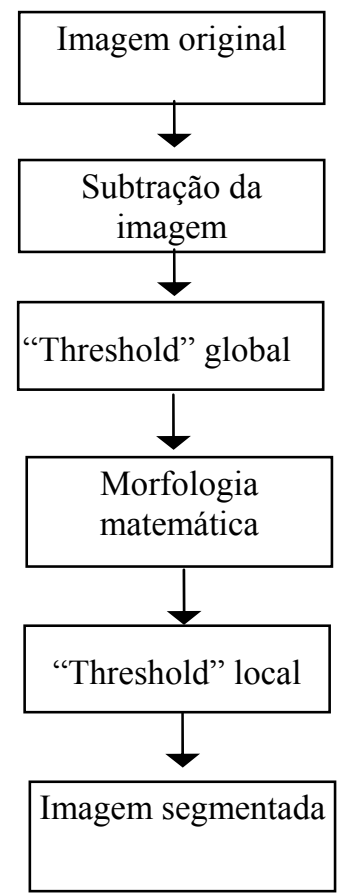

Figura 6-6 - Esquema utilizado para segmentação das microcalcificações.

1. Subtração da imagem: é um pré-processamento com o objetivo de incrementar a relação sinal-ruído. Consiste em realizar a subtração de uma imagem com os sinais realçados de uma imagem com os sinais suavizados. 
2. "Thresholding" global: consiste em aplicar a técnica de "thresholding", baseando-se em parâmetros pré-determinados pelo usuário. Esse processamento deixa na imagem somente uma porcentagem dos pixels com os maiores níveis de cinza. $\mathrm{O}$ objetivo deste passo é eliminar o fundo da imagem.

3. Morfologia matemática: tem o objetivo de eliminar da imagem todos os sinais com menos de três pixels na sua composição, visto que, provavelmente, relacionam-se a ruídos da imagem.

4. "Threshold" local: é o último procedimento. Consiste em eliminar os sinais falso-positivos restantes da imagem, através da verificação do contraste de cada estrutura em relação à sua vizinhança.

Na figura 6-7 é exibida a tela onde são fornecidos os parâmetros da segmentação, cujas descrições encontram-se na tabela 6-2:

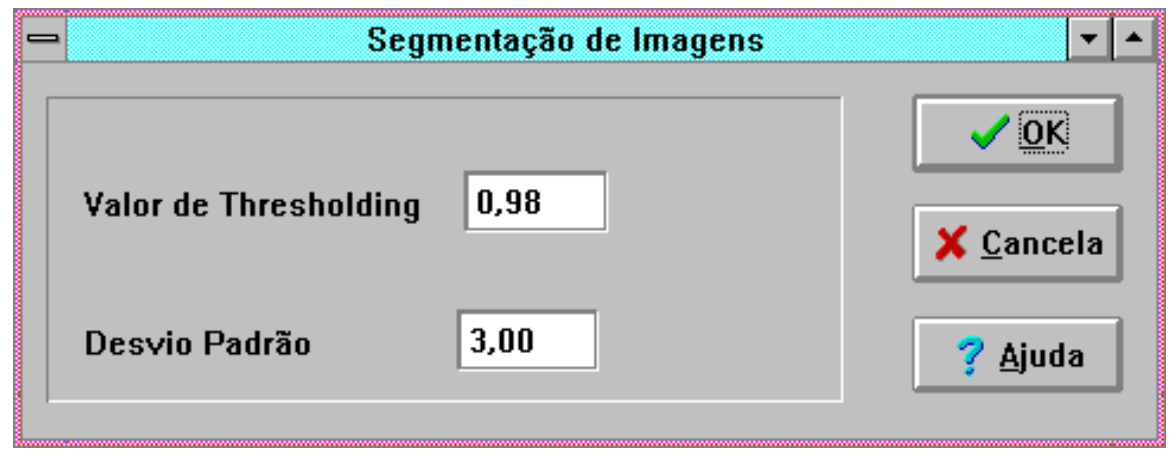

Figura 6-7 - Tela inicial do procedimento de segmentação

Tabela 6-2 - Parâmetros da segmentação

\begin{tabular}{|c|c|c|}
\hline Parâmetro & Descrição & Valor padrão \\
\hline $\begin{array}{l}\text { Valor } \\
\text { "Thresholding" }\end{array}$ & $\begin{array}{l}\text { Porcentagem dos pixels que deverão permanecer } \\
\text { brancos durante o procedimento de "thresholding" } \\
\text { global. Exemplo: } 0,98 \text { significa que permanecerão } \\
\text { na imagem somente } 98 \% \text { dos pixels mais claros. }\end{array}$ & 0,98 \\
\hline Desvio padrão & $\begin{array}{l}\text { Desvio Padrão - valor de um múltiplo do desvio } \\
\text { padrão que será somado à média de nível de cinza } \\
\text { da imagem para que os pixels sejam transformados } \\
\text { em branco ou preto. Exemplo: para valor padrão } 3 \text { - } \\
\text { se o nível de cinza de um pixel for menor que a } \\
\text { soma da média }+3 \text { vezes o desvio padrão, então } \\
\text { este pixel será transformado em preto; caso } \\
\text { contrário, será transformado em branco. }\end{array}$ & 3,00 \\
\hline
\end{tabular}


Na figura 6-8 observa-se uma região de interesse original e a mesma região após o processo de segmentação.

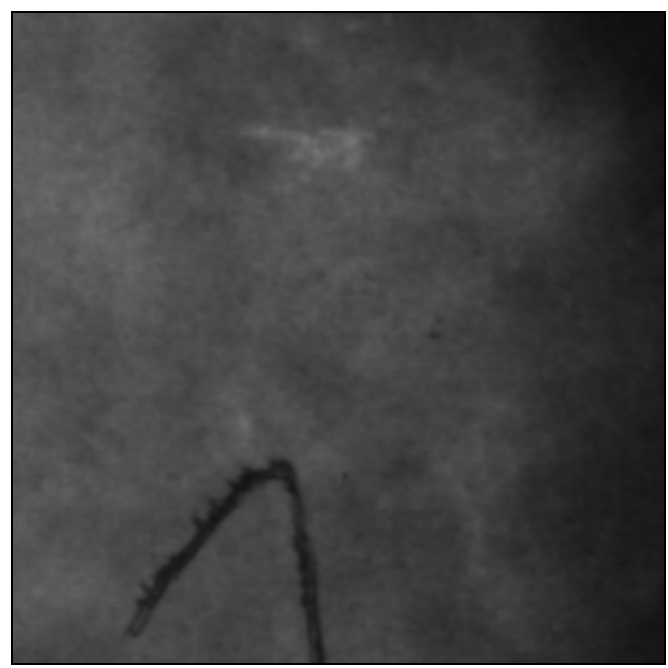

(a)

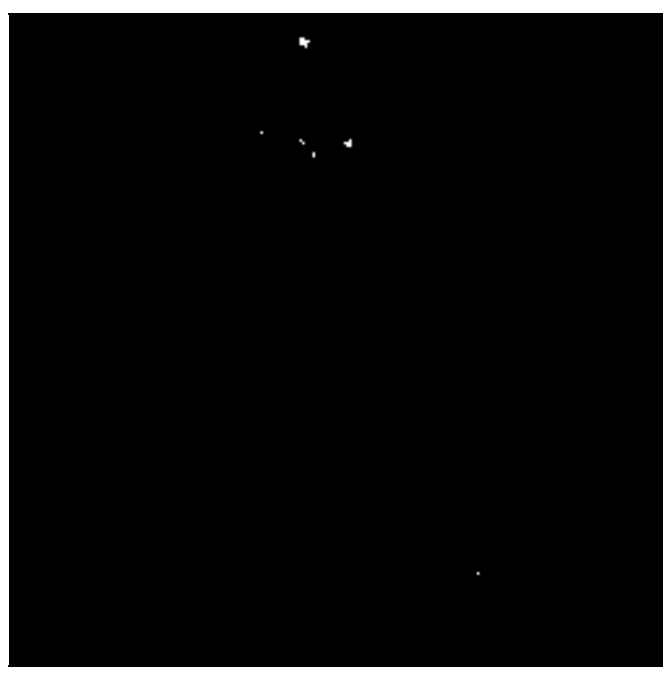

(b)

Figura 6-8 - Processo de segmentação. a) imagem original; b) imagem segmentada.

\subsubsection{Transformação área-ponto}

A transformação área-ponto é um procedimento cujo objetivo é transformar cada estrutura de interesse, presente na imagem segmentada, em um único pixel. O objetivo desse processo é facilitar a contagem das estruturas para a identificação dos possíveis "clusters" da imagem. O método está descrito detalhamente no capítulo 5 (item 5.4.1). Para torná-lo um procedimento mais flexível, alguns parâmetros foram mantidos como variáveis, possibilitando ao usuário a escolha dos valores mais adequados a cada situação. Os valores que escolhemos como padrão são aqueles que alcançaram melhores resultados nos nossos testes. Na figura 6-9 é exibida a tela inicial da transformação área-ponto, onde o usuário fornece os parâmetros desejados. A descrição desses parâmetros encontra-se na tabela 6-3.

Um exemplo da técnica de transformação área-ponto pode ser observado na figura 6-10: em (a) vê-se uma imagem binarizada, resultante do processo de segmentação e, em (b), está a imagem resultante após a aplicação da transformação área-ponto. 


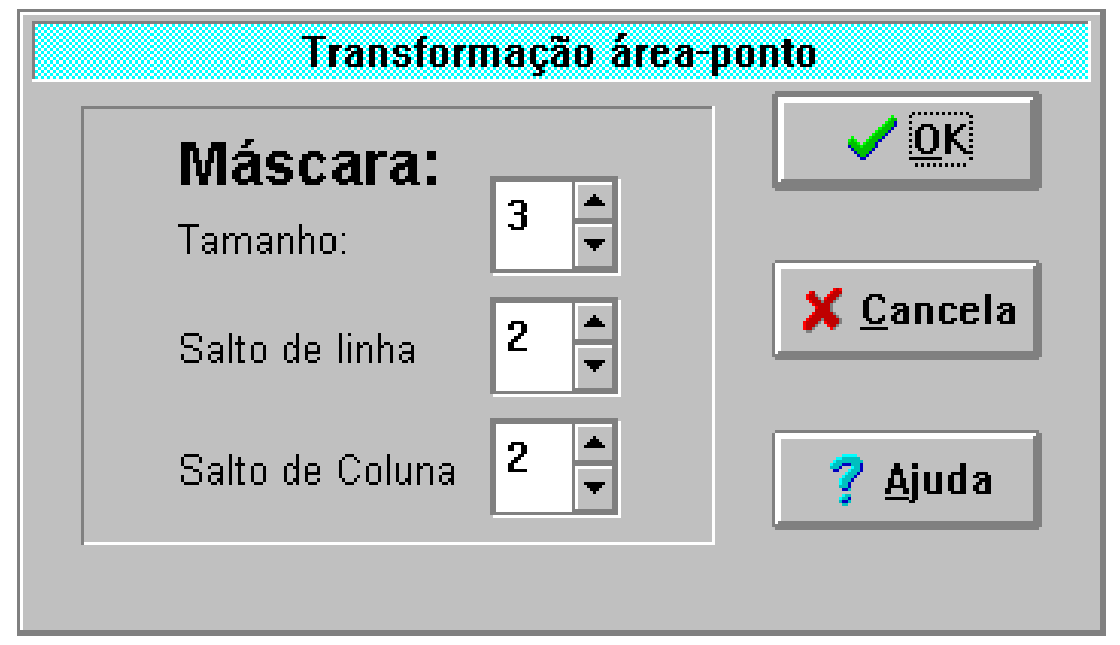

Figura 6-9 - Tela inicial da transformação área-ponto.

Tabela 6-3 - Parâmetros da transformação área-ponto.

\begin{tabular}{llc}
\hline \multicolumn{1}{c}{ Parâmetro } & \multicolumn{1}{c}{ Descrição } & Valor padrão \\
\hline Tamanho da máscara & $\begin{array}{l}\text { Tamanho da máscara quadrada (mesmo número de } \\
\text { linhas e colunas) que será considerada em cada } \\
\text { iteração para a redução dos pixels presentes em um } \\
\text { único pixel. }\end{array}$ & 3 \\
Salto de linha & $\begin{array}{l}\text { Quantidade de linhas saltadas em cada iteração } \\
\text { (posicionamento da máscara). }\end{array}$ & 2 \\
Salto de coluna & $\begin{array}{l}\text { Quantidade de colunas saltadas em cada iteração } \\
\text { (posicionamento da máscara). }\end{array}$ & 2 \\
\hline
\end{tabular}

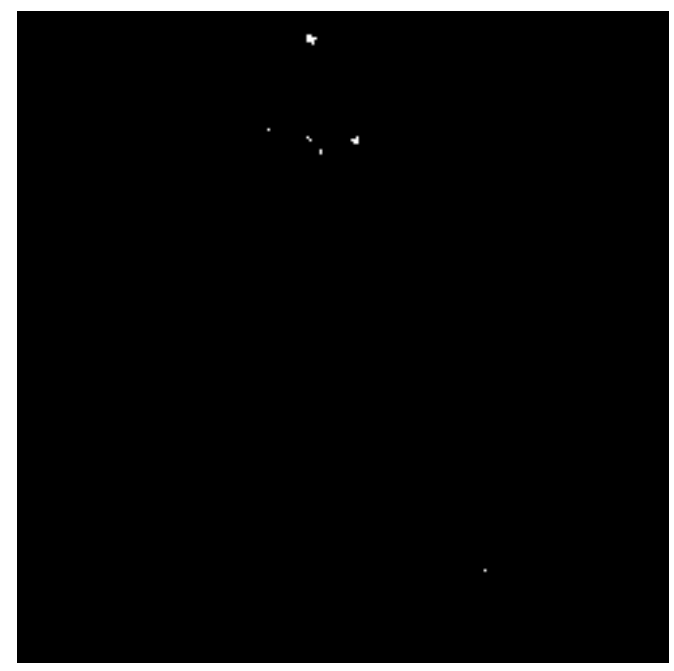

(a)

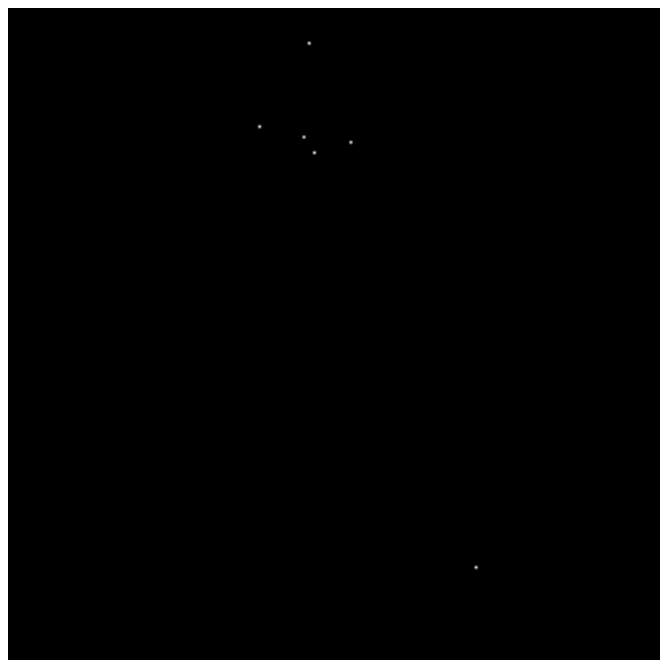

(b)

Figura 6-10 - Efeito da transformação área-ponto: a) imagem segmentada; b) imagem resultante após transformação área-ponto. 


\subsubsection{Detecção de "Clusters"}

A detecção de "clusters" é o processo que efetivamente identifica os agrupamentos que porventura existam na imagem, indicando também a sua localização e a quantidade de microcalcificações contidas. É executada sobre a imagem resultante da transformação área-ponto. Dois métodos foram implementados para essa finalidade: um utilizando máscaras (aqui denominado "mascaramento") e outro utilizando a técnica de crescimento de região (aqui denominado "crescimento de região"). A diferença entre eles está na forma como agrupam os pixels que representam microcalcificações. Dependendo da localização dos sinais, os resultados dos dois processos podem ser diferentes. As particularidades de cada método são descritas a seguir.

\section{a. Método de "mascaramento"}

Na figura 6-11 é demonstrada a tela com os parâmetros iniciais para a detecção de "clusters" através do "mascaramento". Esses parâmetros são descritos na tabela 6-4.

Com os parâmetros fornecidos, o método de mascaramento executa o seguinte algoritmo:

inicio

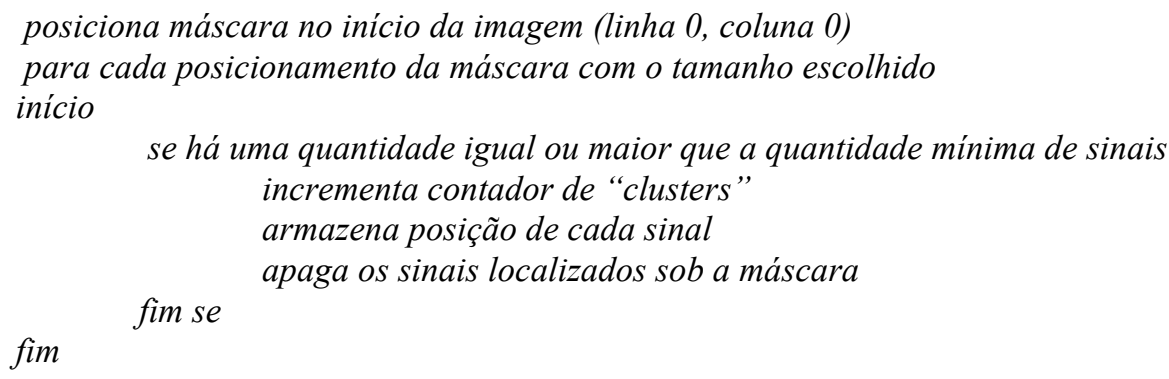

Após a aplicação desse algoritmo, alguns procedimentos são adotados para melhorar a detecção: 




Figura 6-11 - Tela com parâmetros iniciais para "mascaramento".

Tabela 6-4 - Parâmetros da detecção de "clusters" através do método de "mascaramento".

\begin{tabular}{|c|c|c|}
\hline Parâmetro & Descrição & $\begin{array}{l}\text { Valor } \\
\text { padrão }\end{array}$ \\
\hline Área considerada & $\begin{array}{l}\text { Tamanho em pixels da área considerada para } \\
\text { verificação de um "cluster". Esse tamanho vai } \\
\text { depender da resolução da imagem. O valor padrão } \\
\text { aqui estipulado refere-se à quantidade de pixels } \\
\text { presentes em } 1 \mathrm{~cm}^{2} \text { da imagem, com resolução de } \\
600 \text { dpi. }\end{array}$ & 236 \\
\hline $\begin{array}{l}\text { Quantidade mínima de } \\
\text { microcalcificações }\end{array}$ & $\begin{array}{l}\text { Quantidade mínima de sinais que devem ser } \\
\text { encontrados na área considerada para que seja } \\
\text { considerado um "cluster". }\end{array}$ & 3,00 \\
\hline $\begin{array}{l}\text { Distância mínima entre } \\
\text { "clusters" }\end{array}$ & $\begin{array}{l}\text { Quantidade mínima de pixels que deve existir entre } \\
\text { dois "clusters". Esse parâmetro é utilizado durante } \\
\text { a junção de "clusters". Se dois "clusters" estiverem } \\
\text { localizados a uma distância menor que esse valor, } \\
\text { eles serão considerados como um só agrupamento. }\end{array}$ & 118 \\
\hline Salto de linha e coluna & $\begin{array}{l}\text { Quantidade de linhas e colunas que deverão ser } \\
\text { saltadas a cada iteração. }\end{array}$ & 118 \\
\hline
\end{tabular}

Agrupamento de sinais isolados - tem a finalidade de agrupar sinais que ocasionalmente tenham ficado isolados durante a aplicação do algoritmo de "mascaramento". Para isso, é considerada a menor distância entre o sinal isolado e os sinais presentes em todos os "clusters". Se o valor resultante for menor ou igual ao tamanho da área considerada, o sinal é incluído no "cluster". 
Agrupamento de "clusters" próximos - esse processo é realizado para minimizar o efeito de divisão de um "cluster" em dois ou mais conjuntos durante a detecção. Os "clusters" são testados dois a dois, sendo calculadas as distâncias entre todos os seus sinais e armazenada a menor delas. Se esse valor for menor ou igual à distância mínima estabelecida nos parâmetros, os agrupamentos envolvidos são transformados em uma única aglomeração.

Para finalizar a detecção, são realizados procedimentos de: atribuição de cores aos sinais de cada "cluster"; localização de "clusters"; e demarcação de “clusters" na imagem. A descrição desses procedimentos é apresentada no item 6.4.3.

\section{b. Método de "crescimento de região"}

Na figura 6-12 é demonstrada a tela com os parâmetros iniciais para a detecção de "clusters" através do "crescimento de região". Esses parâmetros são descritos na tabela 6-5.

Com os parâmetros fornecidos, o método de "crescimento de região" executa o seguinte algoritmo:

início

armazena posição de todos os sinais em um vetor para cada sinal que ainda não foi considerado como parte de um "cluster" início

incrementa contador de "clusters"

inclui no "cluster" atual todos os sinais com distância $<$

distância máxima escolhida

fim apaga os sinais que foram incluidos no "cluster" atual

para cada "cluster" identificado

início

se quantidade de sinais do "cluster" < quantidade mínima de sinais

elimina "cluster"

fim se

decrementa contador de "clusters"

fim

fim 
Após a aplicação desse algoritmo, os procedimentos descritos no item 5.4.3 são adotados para personalizar a detecção.

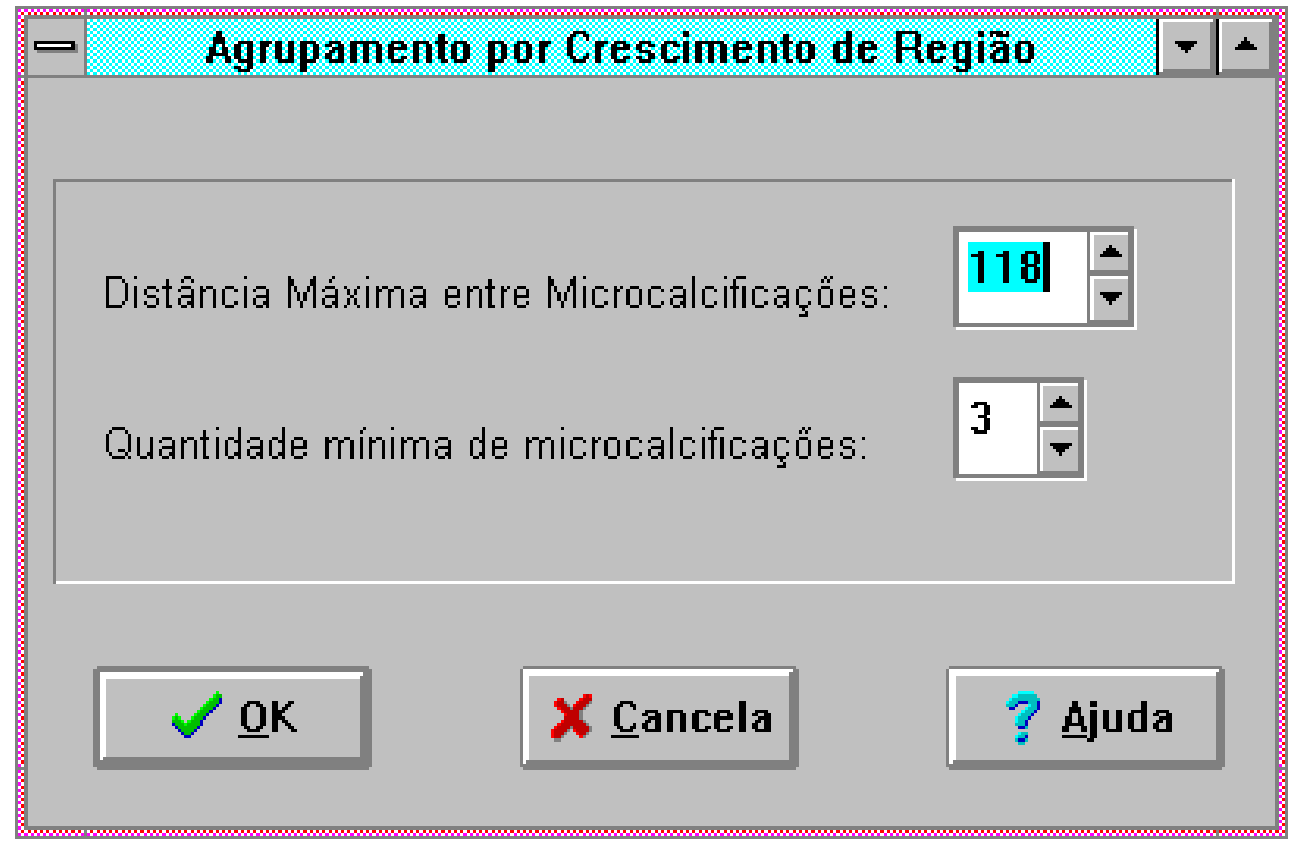

Figura 6-12- Tela com parâmetros iniciais para detecção de "clusters" através do método de "crescimento de região".

Tabela 6-5 - Parâmetros da detecção de "clusters" através do método de "crescimento de região".

\begin{tabular}{llc}
\hline \multicolumn{1}{c}{ Parâmetro } & \multicolumn{1}{c}{ Descrição } & Valor padrão \\
\hline $\begin{array}{l}\text { Distância máxima entre } \\
\text { microcalcificações }\end{array}$ & $\begin{array}{l}\text { Quantidade máxima de pixels que pode existir entre } \\
\text { dois sinais para que eles sejam considerados }\end{array}$ & 236 \\
& $\begin{array}{l}\text { pertencentes ao mesmo "cluster". } \\
\text { Quantidade mínima de }\end{array}$ & \\
$\begin{array}{l}\text { Quantidade mínima de sinais que devem existir em } \\
\text { um agrupamento para que seja reconhecido como }\end{array}$ & 3 \\
& um "cluster". & \\
\hline
\end{tabular}

\section{c. Procedimentos adicionais para otimizar a detecção de "clusters"}

A fim de tornar mais visível a identificação dos "clusters" e armazenar os dados resultantes da detecção, os procedimentos abaixo descritos, comuns aos dois métodos de detecção, são executados. 
Coloração dos sinais - aos sinais de cada "cluster" identificado é atribuída uma cor diferente a fim de diferenciá-los dos demais "clusters".

Localização dos "clusters" - com os dados armazenados durante o processo de identificação das regiões de interesse, cada agrupamento detectado é identificado em um dos quatro quadrantes da imagem: superior esquerdo, superior direito, inferior esquerdo ou inferior direito.

Demarcação dos agrupamentos - em torno de cada "cluster" é desenhado um retângulo que o contém, com a finalidade de facilitar a visualização.

Na figura 6-13 até a figura 6-18 é mostrado um exemplo do processo completo de detecção de "clusters" das imagens, sendo exibida a imagem resultante de cada fase do processamento.

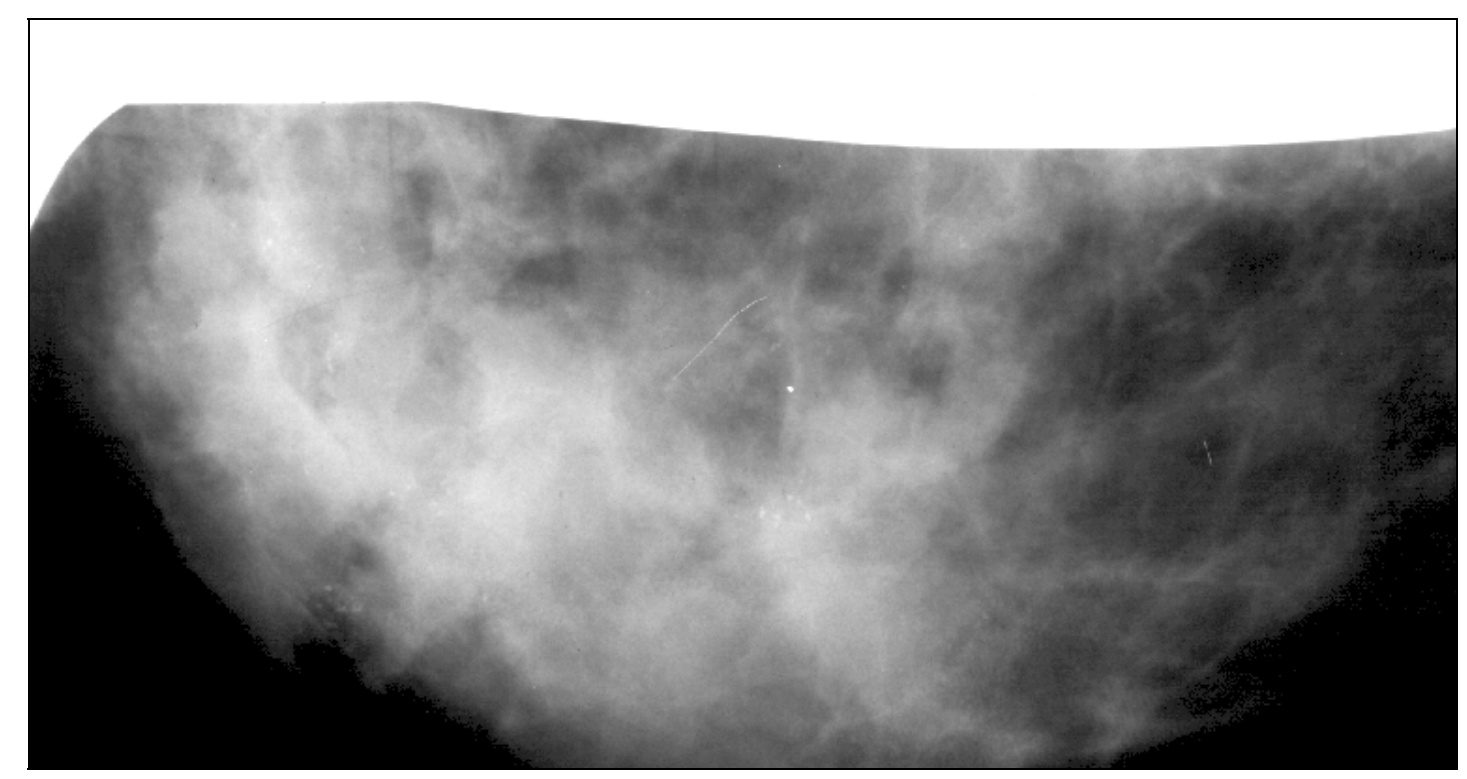

Figura 6-13 - Mamograma digitalizado. 

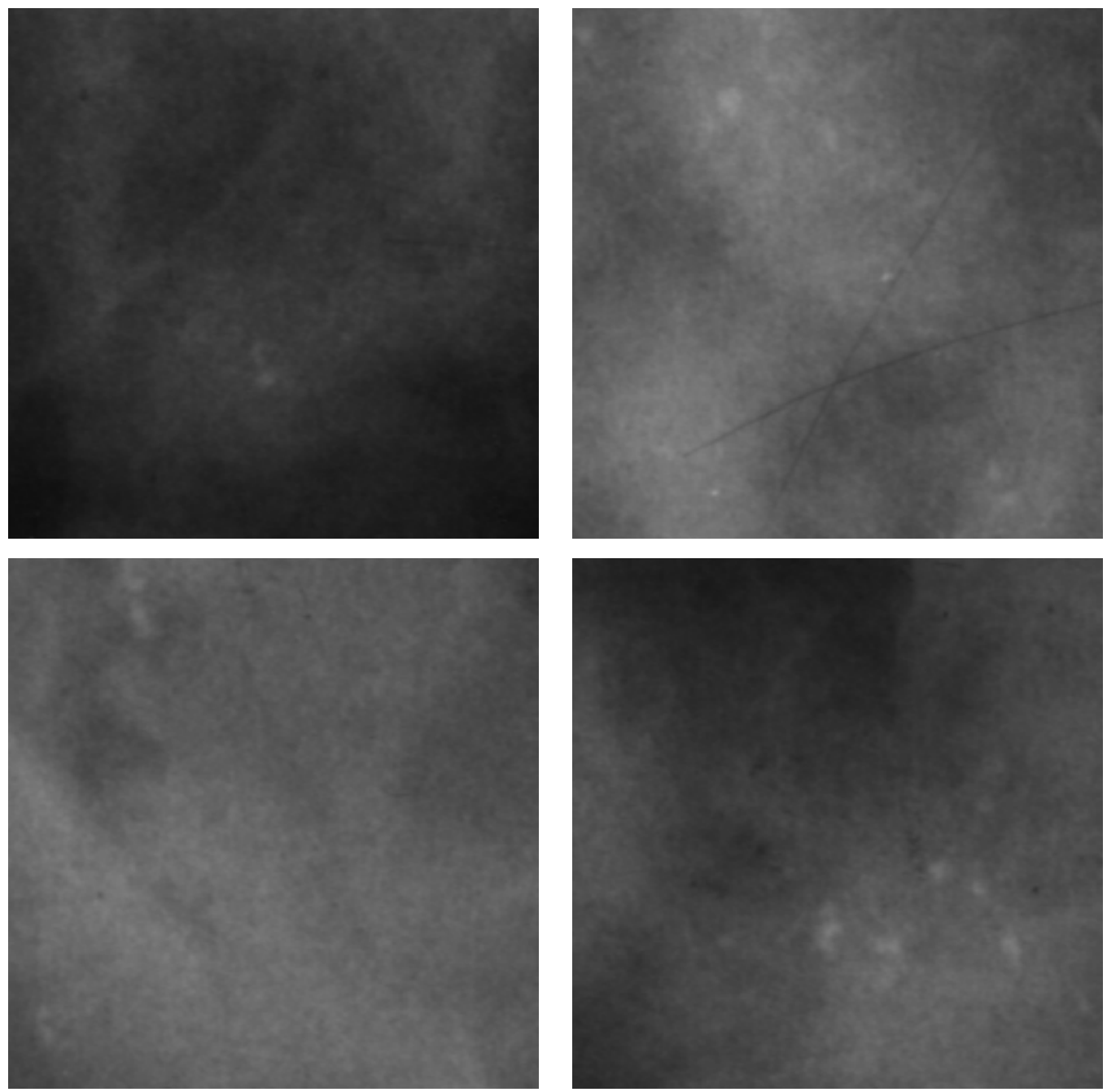

Figura 6-14 - Regiões de interesse extraídas do mamograma da figura 6-13. 

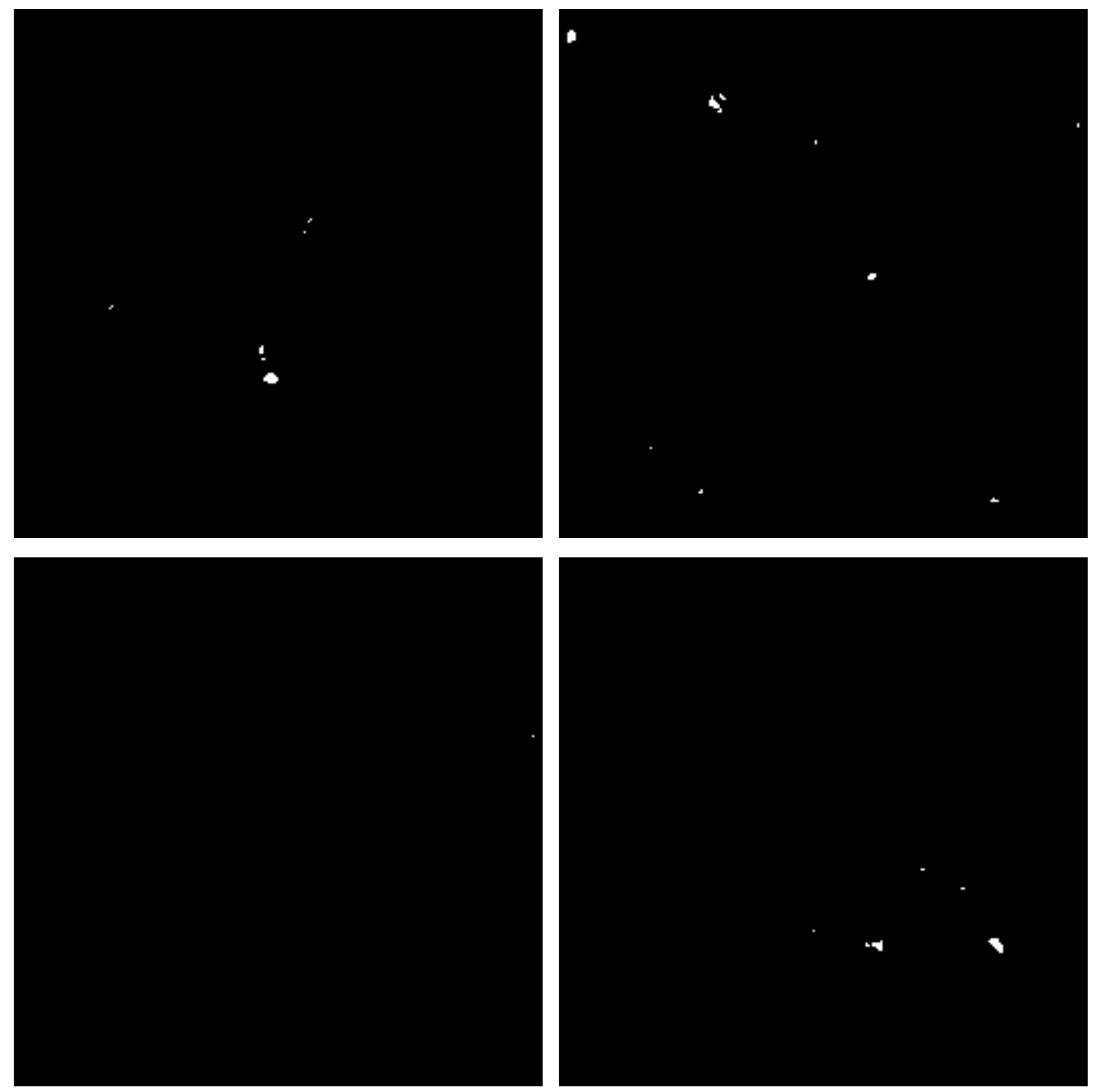

Figura 6-15 - Regiões de interesse após segmentação. 

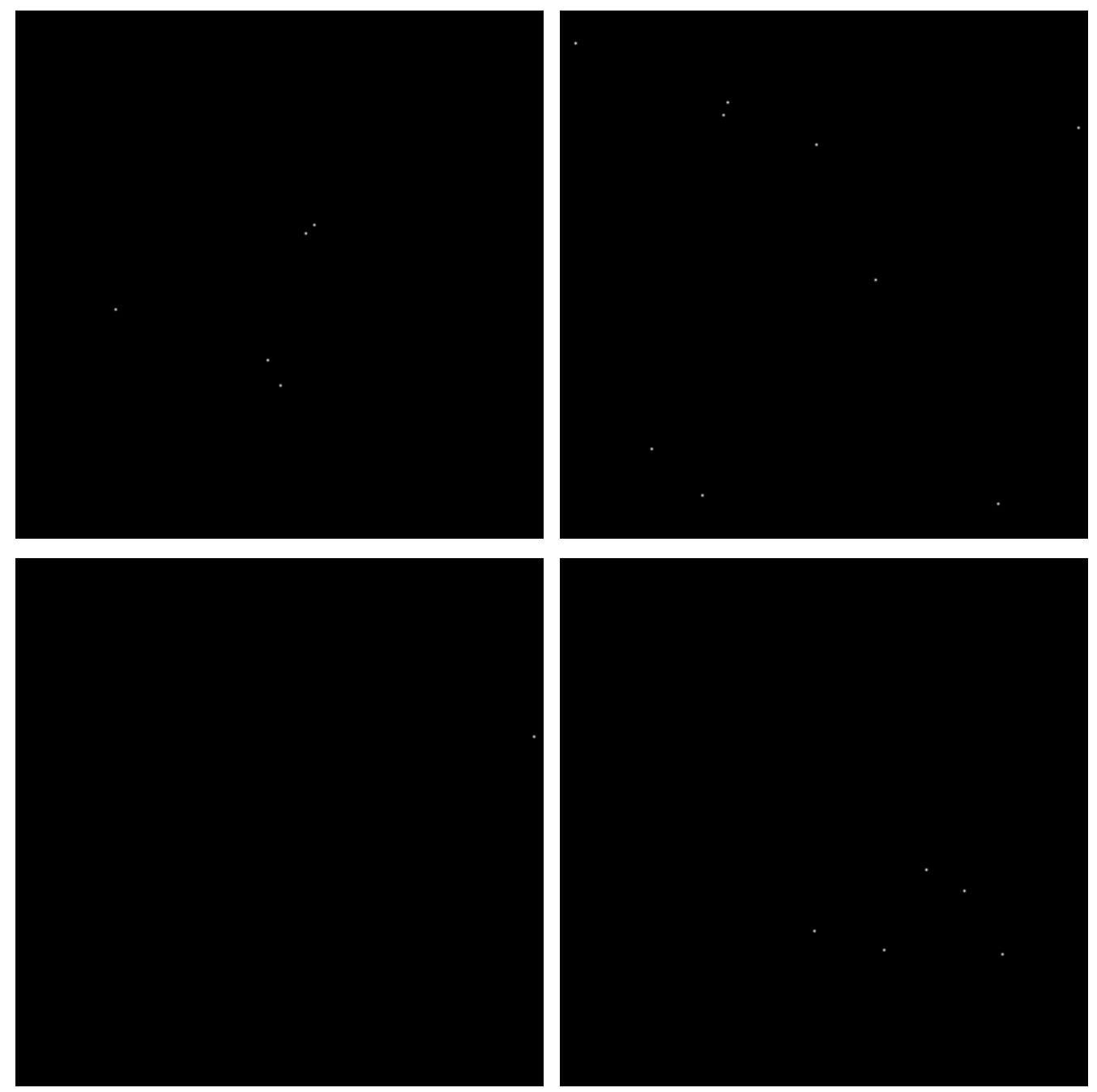

Figura 6-16 - Regiões de interesse após transformação área-ponto. 

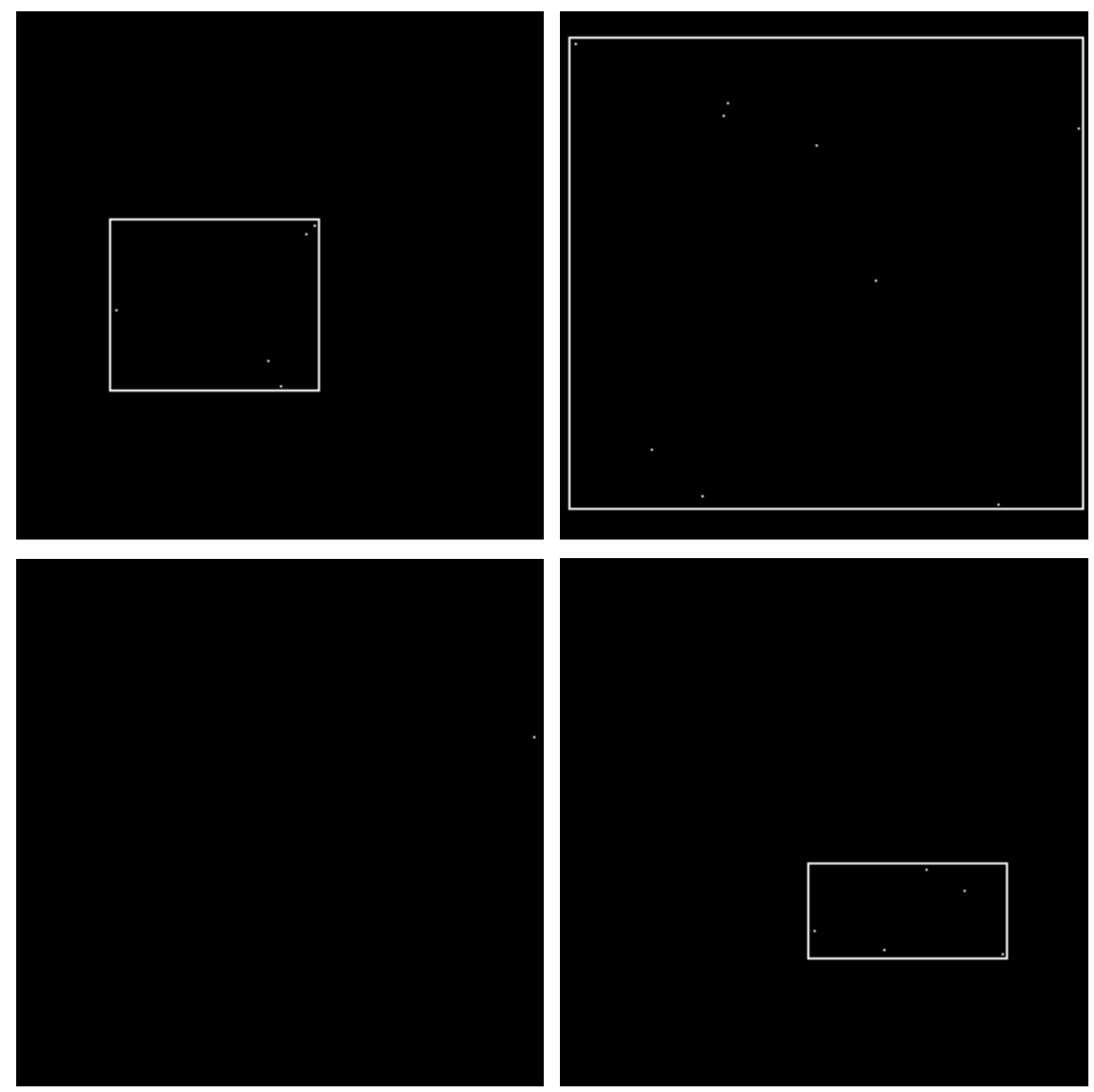

Figura 6-17 - Regiões de interesse após a detecção de "clusters" pelo método de "mascaramento". 

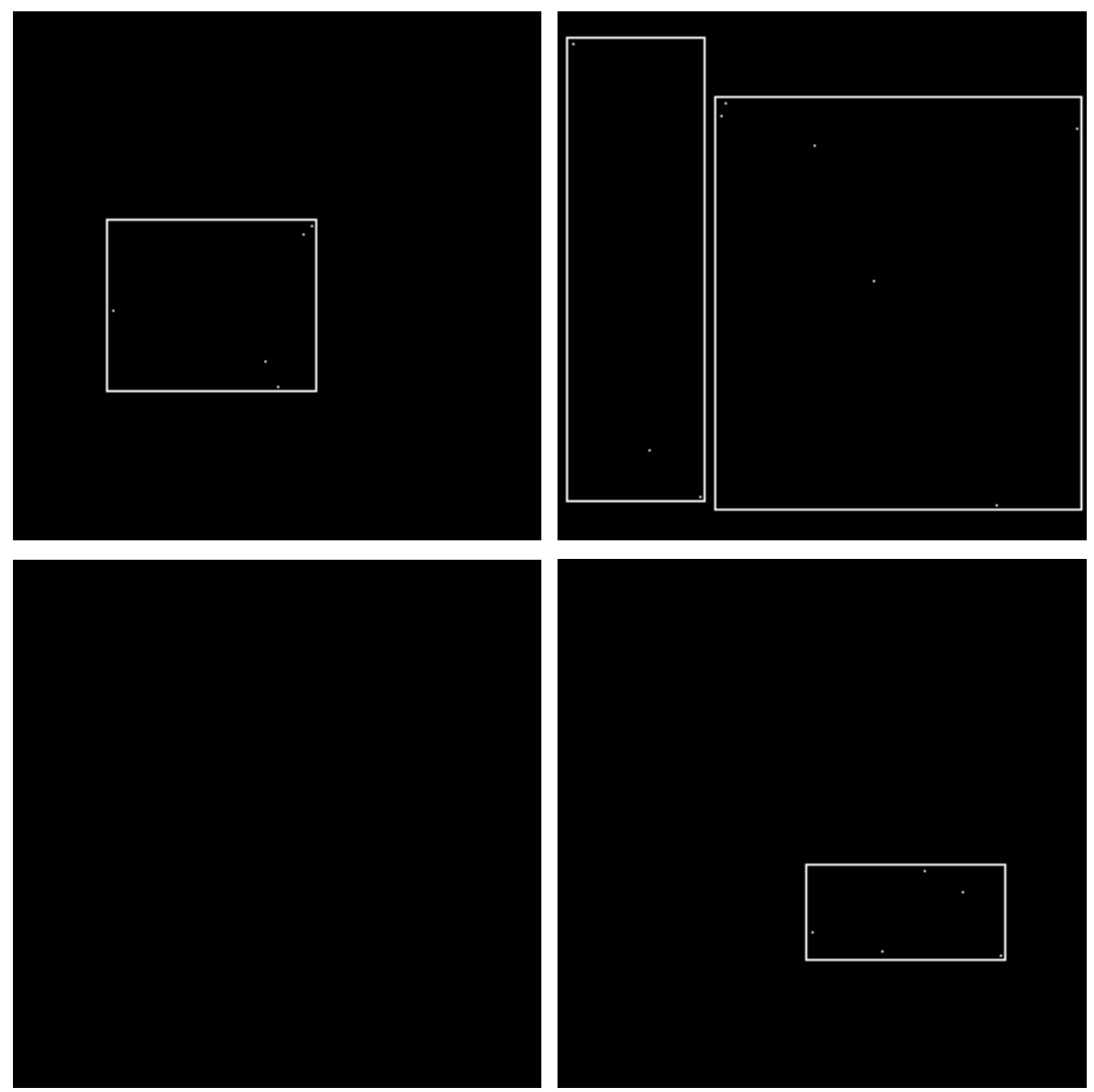

Figura 6-18 -Detecção de "clusters" pelo método de “crescimento de região".

\subsubsection{Visão geral do sistema computacional desenvolvido}

Além das funções primordiais de detecção de "clusters", alguns métodos auxiliares de tratamento de imagem, verificação de resultados e auxílio ao usuário foram implementados no sistema computacional desenvolvido. Na figura 619 é apresentada uma visualização hierárquica completa do sistema. Na tabela 6-6 há a descrição de cada uma das funções disponíveis. 


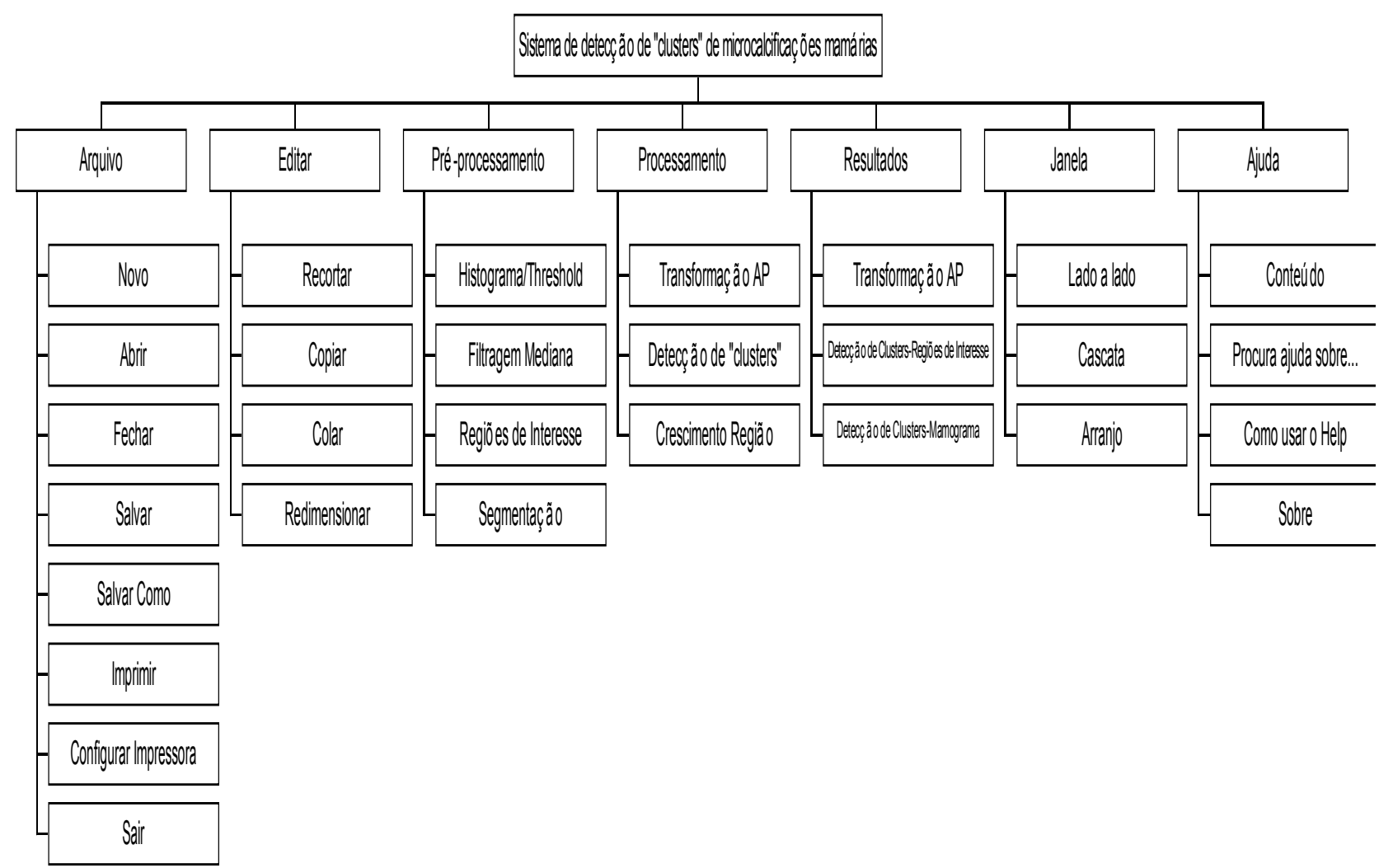

Figura 6-19 - Visão geral do sistema computacional desenvolvido.

Tabela 6-6 - Funções do sistema computacional desenvolvido.

\begin{tabular}{|c|c|c|}
\hline Menu & Função & Descrição \\
\hline \multirow[t]{8}{*}{ Arquivo } & Novo & Inicia um novo arquivo (imagem do tipo Bitmap). \\
\hline & Abrir & $\begin{array}{l}\text { Abre uma nova imagem do tipo Bitmap para } \\
\text { processar. }\end{array}$ \\
\hline & Fechar & Encerra o processamento de uma imagem aberta. \\
\hline & Salvar & Grava uma imagem aberta. \\
\hline & Salvar Como & $\begin{array}{l}\text { Grava uma imagem aberta com um nome diferente } \\
\text { do atual. }\end{array}$ \\
\hline & Imprimir & Imprime a imagem na impressora padrão. \\
\hline & Configurar Impressora & $\begin{array}{l}\text { Permite selecionar a impressora padrão e alterar as } \\
\text { suas configurações. }\end{array}$ \\
\hline & Sair & Encerra a execução do sistema. \\
\hline \multirow[t]{4}{*}{ Editar } & Recortar & Elimina trecho selecionado da imagem. \\
\hline & Copiar & $\begin{array}{l}\text { Copia trecho selecionado para a área de } \\
\text { transferência. }\end{array}$ \\
\hline & Colar & $\begin{array}{l}\text { Copia trecho da área de transferência para a janela } \\
\text { ativa. }\end{array}$ \\
\hline & Redimensionar & $\begin{array}{l}\text { Permite diminuir ou aumentar o tamanho da } \\
\text { imagem. }\end{array}$ \\
\hline
\end{tabular}


Pré-processamento Histograma/Threshold

Filtragem Mediana

Regiões de interesse

Segmentação

Crescimento de Região
Monta o histograma da imagem e possibilita a aplicação da técnica de "thresholding" (explicações adicionais nos itens 3.2.1 e 3.2.3).

Executa a filtragem mediana na imagem da janela ativa (explicações adicionais no item 3.2.8.b).

Executa o procedimento de identificação das regiões de interesse da imagem (explicações adicionais no item 6.1.1).

Executa a segmentação da imagem para destacar as estruturas de interesse (explicações adicionais no item 6.1.2).

Executa o procedimento de transformação áreaponto recursiva (explicações adicionais no item 5.4.1).

Executa a detecção de "clusters" através do método de "mascaramento" (explicações adicionais no item 6.1.4.a).

Executa a detecção de "clusters" através do método de "crescimento de região" (explicações adicionais no item 6.1.4.b).

\begin{tabular}{|c|c|c|}
\hline \multirow[t]{3}{*}{ Resultados } & Transformação AP & $\begin{array}{l}\text { Exibe os resultados obtidos com a execução da } \\
\text { transformação área-ponto. }\end{array}$ \\
\hline & $\begin{array}{l}\text { Detecção de "clusters" } \\
\text { regiões de interesse }\end{array}$ & $\begin{array}{l}\text { Exibe os resultados obtidos com a detecção de } \\
\text { "clusters" para as regiões de interesse selecionadas. }\end{array}$ \\
\hline & $\begin{array}{l}\text { Detecção de "clusters" } \\
\text { mamograma }\end{array}$ & $\begin{array}{l}\text { Exibe os resultados obtidos com a detecção de } \\
\text { "clusters" para as imagens de mamogramas } \\
\text { processados. }\end{array}$ \\
\hline \multirow[t]{3}{*}{ Janela } & Lado a lado & $\begin{array}{l}\text { Posiciona todas as janelas abertas na tela, uma ao } \\
\text { lado da outra. }\end{array}$ \\
\hline & Cascata & $\begin{array}{l}\text { Posiciona todas as janelas abertas na tela, uma sob a } \\
\text { outra outra. }\end{array}$ \\
\hline & Arranjo & Ordena os ícones minimizados na tela. \\
\hline \multirow[t]{4}{*}{ Ajuda } & Conteúdo & Exibe o conteúdo do auxílio do sistema. \\
\hline & Procura ajuda sobre & $\begin{array}{l}\text { Permite localizar um assunto para obtenção de } \\
\text { auxílio. }\end{array}$ \\
\hline & Como usar o Help & Ensina como utilizar o sistema de ajuda. \\
\hline & Sobre & Exibe tela com informações sobre o sistema. \\
\hline
\end{tabular}




\subsection{Materiais utilizados}

O sistema descrito no item anterior foi utilizado para processar imagens de "phantoms" mamográficos e de mamogramas reais, obtidos no Hospital das Clínicas de Ribeirão Preto (USP).

Foram utilizados dois tipos de "phantoms":

"Phantoms" mamográficos fabricados pelo RMI Wisconsin, contendo simulações de microcalcificações de $0,54 \mathrm{~mm}, 0,32 \mathrm{~mm}$, $0,24 \mathrm{~mm}$ e $0,20 \mathrm{~mm}$, além de simulações de nódulos e estrias ([FRÈRE-82]), que não constituem objetos de interesse nesta pesquisa. A disposição dessas estruturas pode ser visualizada na imagem da figura 6-20. As condições técnicas das exposições foram as seguintes: $25 \mathrm{kVp}, 1 \mathrm{~s}$ e distância foco-filme de $0,5 \mathrm{~m}$. O equipamento utilizado foi um "Mammodiagnost Philips", com ponto focal de $1,20 \times 0,75 \mathrm{~mm}$.

\begin{tabular}{|c|c|c|c|}
\hline \multirow{2}{*}{$\begin{array}{c}\text { Microcalcificações } \\
0,24 \mathrm{~mm}\end{array}$} & Massa & Fibra & $\begin{array}{c}\text { Fibra } \\
0,96 \mathrm{~mm}\end{array}$ \\
\hline \multirow{2}{*}{$\begin{array}{c}1,0 \mathrm{~mm} \\
\text { Microcalcificações }\end{array}$} & Massa & Fibra & Fibra \\
$0,20 \mathrm{~mm}$ & $4,0 \mathrm{~mm}$ & $0,75 \mathrm{~mm}$ & $0,45 \mathrm{~mm}$ \\
& & & Fibra \\
Microcalcificações & Massa & Fibra & $1,56 \mathrm{~mm}$ \\
$0,54 \mathrm{~mm}$ & $0,5 \mathrm{~mm}$ & $1,15 \mathrm{~mm}$ & \\
& & & Nada \\
\hline Microcalcificações & Massa & Nada & \\
$0,32 \mathrm{~mm}$ & $2,0 \mathrm{~mm}$ & & \\
\hline
\end{tabular}

Figura 6-20 - Disposição das simulações do primeiro “phantom” utilizado.

2. "Phantom" composto por partículas de mármore moído incrustradas em cera. A quantidade de partículas era bem maior que 
no primeiro "phantom", não sendo conhecida com precisão. Os tamanhos das partículas variavam de 0,2 a $0,75 \mathrm{~mm}$.

As chapas radiográficas dos "phantoms" foram digitalizadas com 256 níveis de cinza e resolução de 600 dpi, em um equipamento UMAX UC1260-Pro. Exemplos de imagens digitalizadas desses "phantoms" são mostrados na figura 6-21 e na figura 6-22.

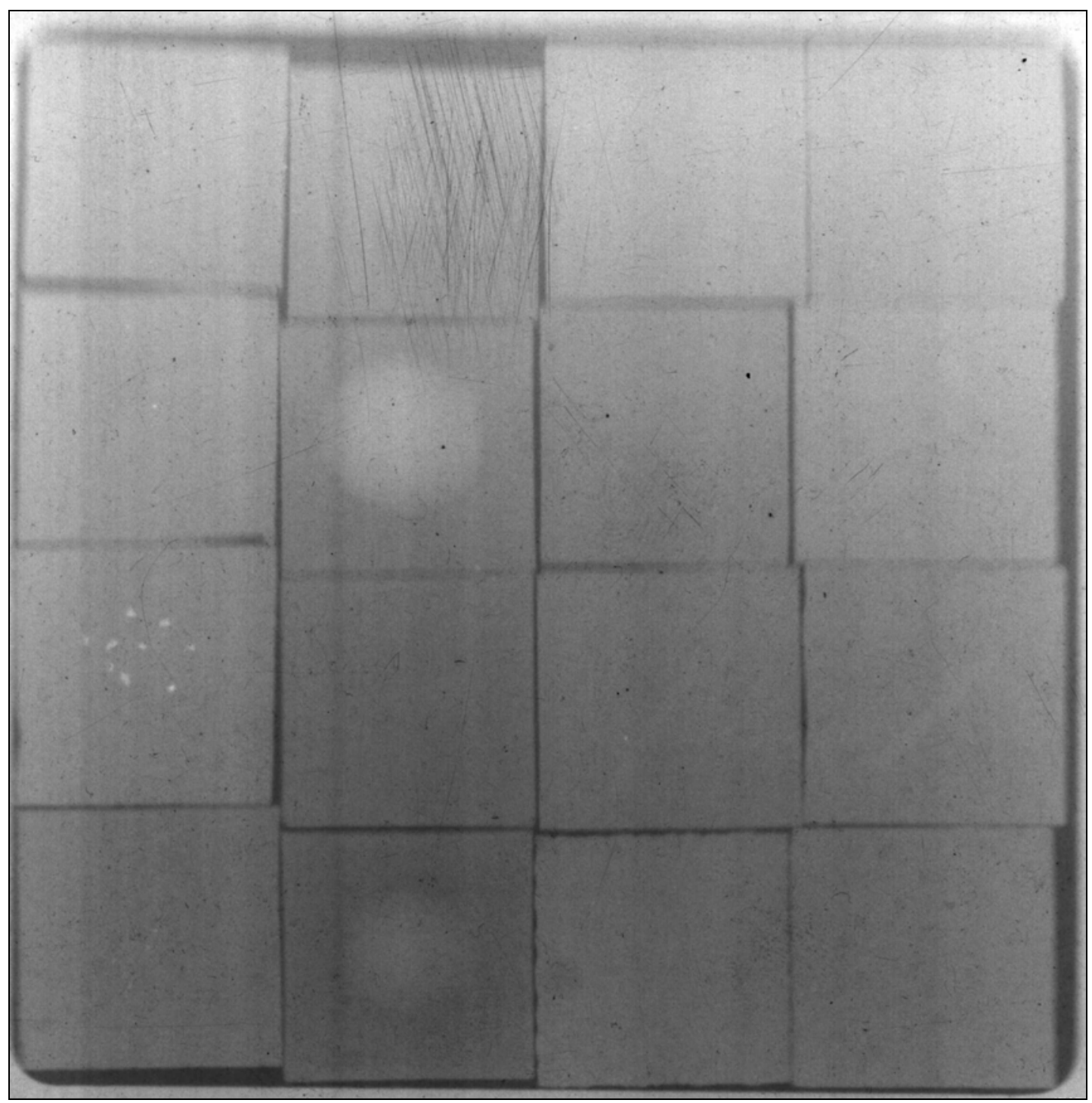

Figura 6-21 - Imagem digitalizada do primeiro "phantom": sinais de interesse estão na primeira coluna da esquerda. 


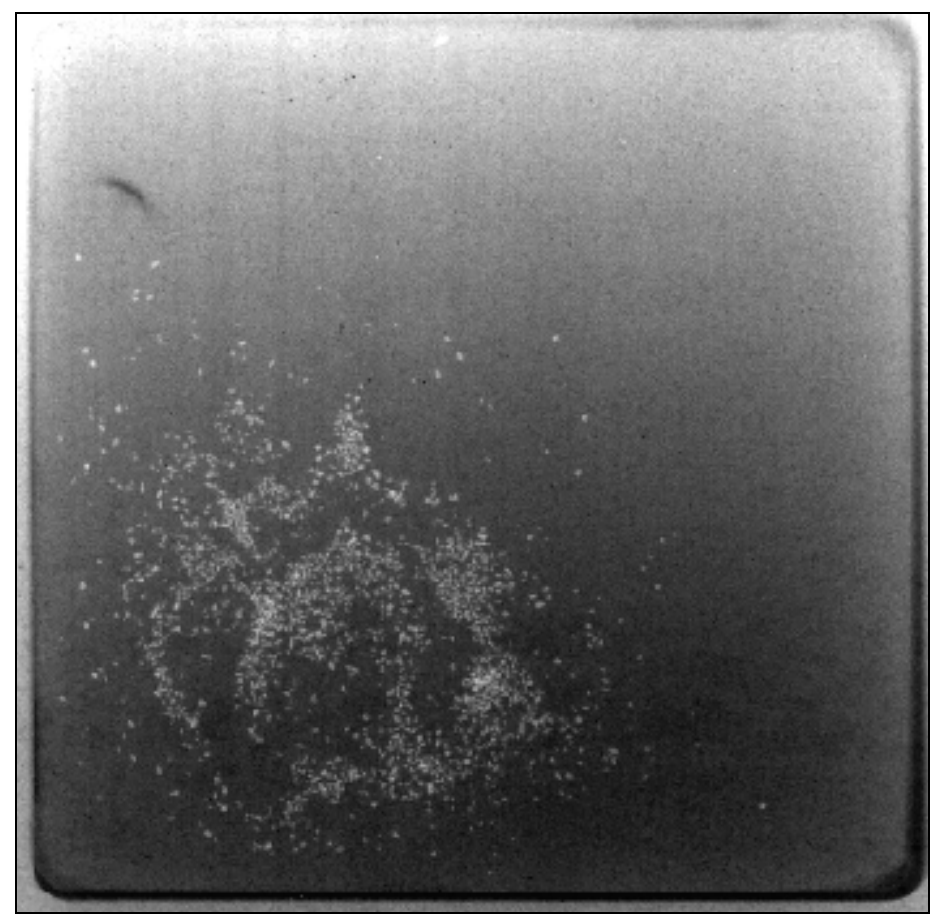

Figura 6-22 - Imagem digitalizada do segundo "phantom".

Os mamogramas reais, por sua vez, foram obtidos junto ao Hospital das Clínicas de Ribeirão Preto, devidamente acompanhados dos laudos médicos. As condições de exposição e digitalização foram as mesmas dos "phantoms". Na figura 6-23 são reproduzidos dois dos mamogramas utilizados nos testes.

O processamento das imagens foi executado em computadores do tipo IBM PC Pentium, $133 \mathrm{MHz}$, com $32 \mathrm{Mb}$ de RAM. Os resultados do processamento foram gravados em arquivos durante a execução dos programas e, posteriormente, comparados ou às informações conhecidas previamente sobre os "phantoms" ou aos laudos dos mamogramas, conforme o caso.

Essas comparações permitiram verificar a eficiência do sistema computacional desenvolvido, de acordo com o que está descrito no Capítulo 7. 


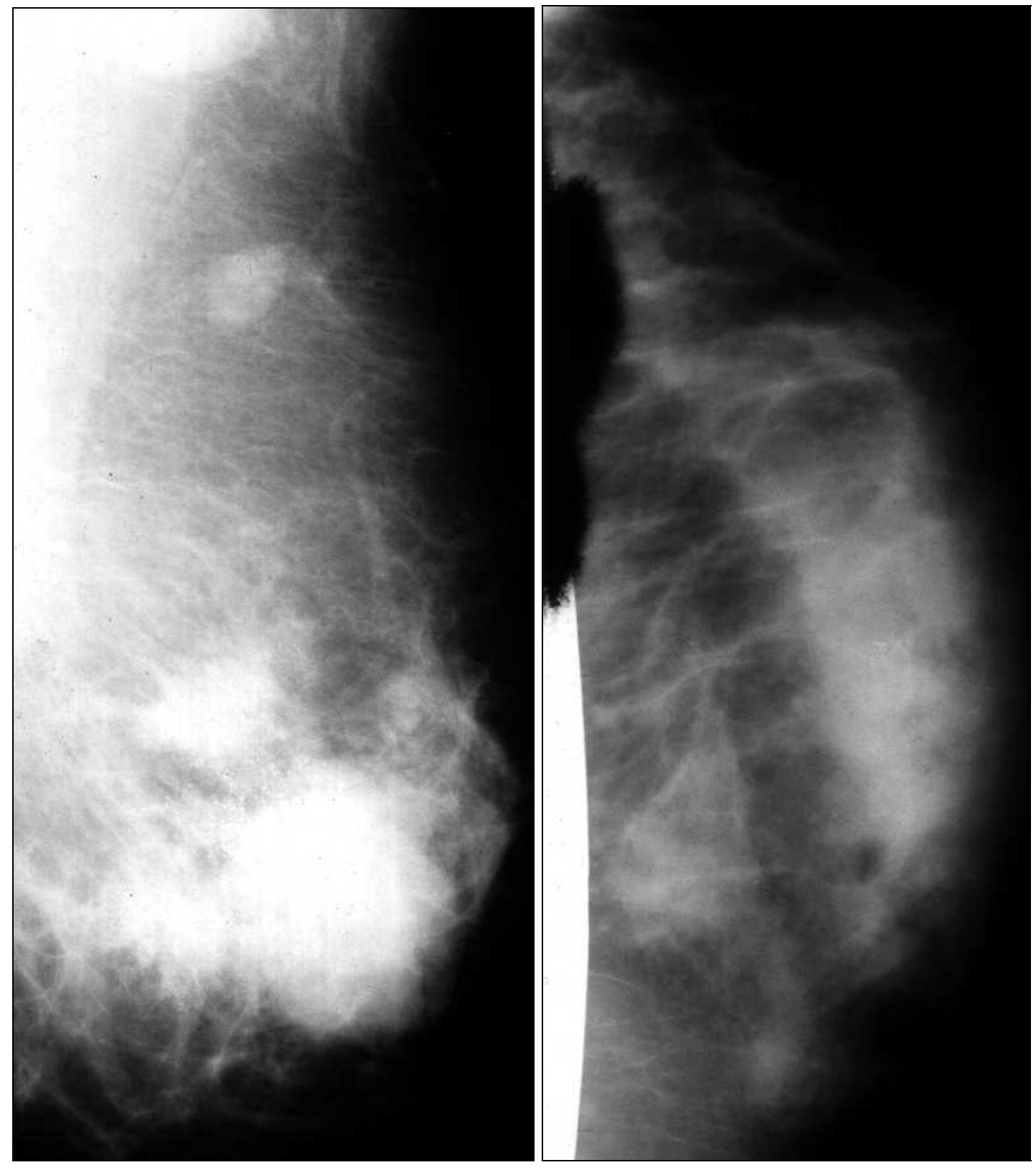

Figura 6-23 - Exemplos de mamogramas reais utilizados nos testes. 


\section{7}

\section{RESULTADOS E DISCUSSÕES}

O desenvolvimento e o teste do sistema computadorizado implementado foi estruturado em três fases:

a) testes com matrizes binárias para verificação e correção dos algoritmos utilizados;

b) testes com imagens de "phantoms";

c) testes com imagens de mamogramas reais.

\subsection{Matrizes binárias}

Essa fase consistiu em testar os programas confeccionados com matrizes pequenas, onde cada elemento podia assumir o valor "0" ou "1". Os algarismos "zeros" simulavam a não existência de sinal, e a disposição dos algarismos "uns" foi planejada de forma que cada conjunto de números simulasse uma estrutura, isto é, uma microcalcificação, como pode ser observado na figura 7-1.

Foram testados dois programas: transformação área-ponto recursiva $\mathrm{e}$ deteç̧ão de "cluster" através de "mascaramento", ambos confeccionados em linguagem $\mathrm{C}$.

O teste da transformação área-ponto recursiva teve o objetivo de definir os melhores valores para os parâmetros tamanhos de máscara, salto de linhas e salto de colunas. Basicamente, foram testadas 6 variações desses parâmetros:

Máscara 3 x 3, saltando 1 linha e 1 coluna a cada iteração;

Máscara 3 x 3, saltando 2 linhas e 2 colunas a cada iteração;

Máscara 4 x 4, saltando 1 linha e 1 coluna a cada iteração;

Máscara 4 x 4, saltando 2 linhas e 2 colunas a cada iteração;

Máscara 5 x 5, saltando 1 linha e 1 coluna a cada iteração;

Máscara 5 x 5, saltando 2 linhas e 2 colunas a cada iteração. 
$\mathrm{Na}$ figura 7-2 mostramos exemplos do resultado de duas dessas variações, após o processamento da matriz da figura 7-1. Cada algarismo "1" representa um pixel resultante da transformação de um sinal. No caso (a), foi utilizada máscara de 3 linhas x 3 colunas, salto de linha 2 e salto de coluna 2. Foram identificados 12 algarismos “1”, indicando a presença de 12 sinais (microcalcificações). No caso (b), foi utilizada máscara de 5 linhas x 5 colunas, salto de linha 2 e salto de coluna 2. Restaram 9 sinais, isto é, 9 algarismos " 1 ".

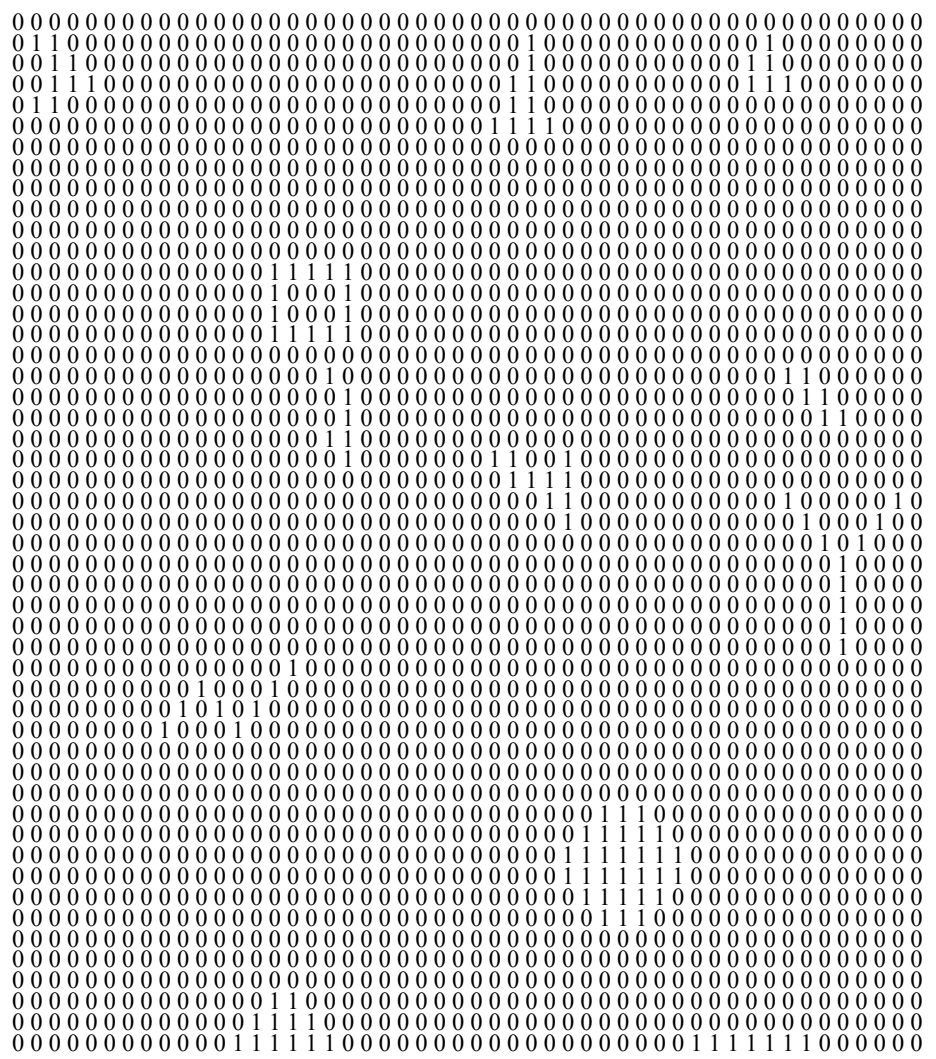

Figura 7-1 - Exemplo de matriz binária utilizada nos testes.

Algumas observações são importantes neste ponto da pesquisa:

Quanto maior o tamanho da máscara e menor o salto de linhas e colunas, maior é o tempo computacional exigido para a obtenção dos resultados do processamento.

Quanto maior o tamanho da máscara, maior é a tendência de junção de sinais próximos. Dependendo do tamanho da máscara utilizada, o programa detectava um só sinal quando deveriam ser detectadas duas estruturas distintas. 
0000000000000000000000000000000000000000000000000000 0000000000000000000000000000000000000000000000000000000

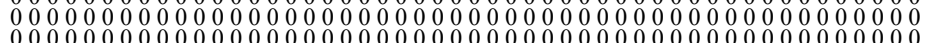

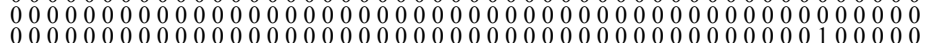

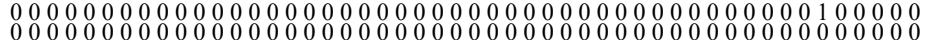

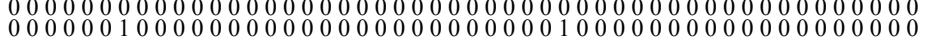

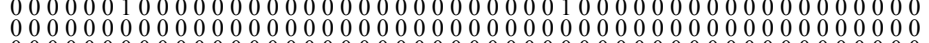

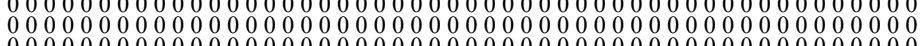

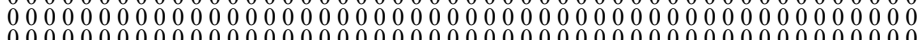

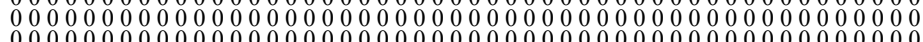

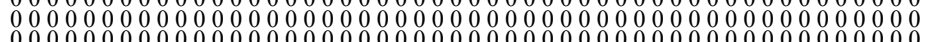
0000000000000000000000000000000000000000000000000000000000

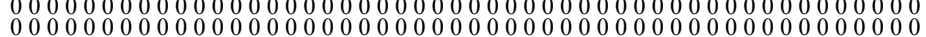
00000000000000000000000000000000000000000000000000000000000000000

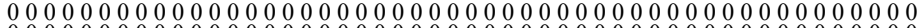
$\begin{array}{llllllllllllllllllllllllllllllllllllllllllllllllllllll}0 & 0 & 0 & 0 & 0 & 0 & 0 & 0 & 0 & 0 & 0 & 0 & 0 & 0 & 0 & 0 & 0 & 0 & 0 & 0 & 0 & 0 & 0 & 0 & 0 & 0 & 0 & 0 & 0 & 0 & 0 & 0 & 0 & 0 & 0 & 0 & 0 & 0 & 0 & 0 & 0 & 0 & 0 & 0 & 0 & 0 & 0 & 0 & 0 & 0\end{array}$

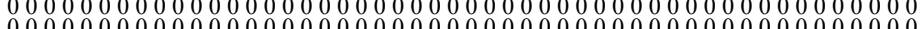

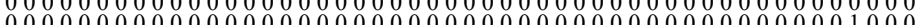
00000000000000000000000000000000000000000000000000 00000000000000000000100000000000000000000000000000

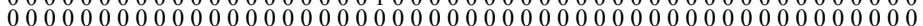
000000000000000000000000000000000000000000000000000 000000000000000000000000000000000000000000000000000000000 0000000000000000000000000000000000010000000000000000000 10000000000000000000000000000000000000000000000000000000000000 00000000000000000000000000000000000000000000000000

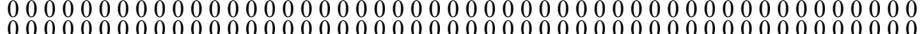

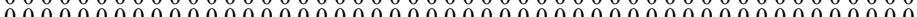

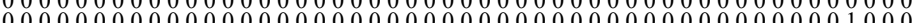
00000000000000000000000000000000000000000000000000 00000000000000001000000000000000000000000000000000 00000000010001000000000000000000000000000000000000000 000000000000000000000000000000000000000000000000000000 0000000000000000000000000000000000000000000000000000 00000000000000000000000000000000000000000000000000000000 0000000000000000000000000000000000000000000000000000 0000

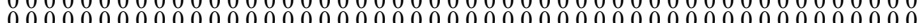
00000000000000000000000000000000000000000000000000

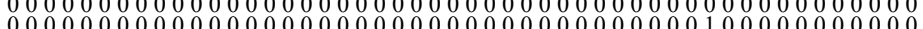
年 000000000000000000000000000000000000000000000000000000000 000000000000000000000000000000000000000000000000000000

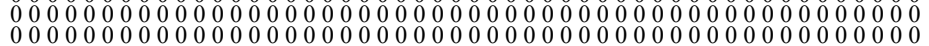

00000000000000000000000000000000000000000000000000 00000000000000000000000000000000000000000000000000000000000

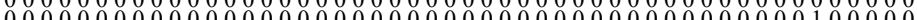

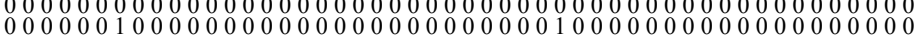
000000000000000000000000000000000000000000000000000000000 000000000000000000000000000000000000000000000000000 000000000000000000000000000000000000000000000000000000000 00000000000000000000000000000000000000000000000000 $\begin{array}{lllllllllllllllllllllllllllllllllllllllllllllllll}0 & 0 & 0 & 0 & 0 & 0 & 0 & 0 & 0 & 0 & 0 & 0 & 0 & 0 & 0 & 0 & 0 & 0 & 0 & 0 & 0 & 0 & 0 & 0 & 0 & 0 & 0 & 0 & 0 & 0 & 0 & 0 & 0 & 0 & 0 & 0 & 0 & 0 & 0 & 0 & 0 & 0 & 0 & 0\end{array}$

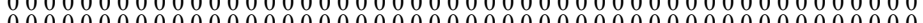
00000000000000000000000000000000000000000000000000

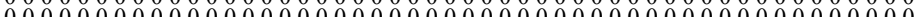
00000000000000000000000000000000000000000000000000

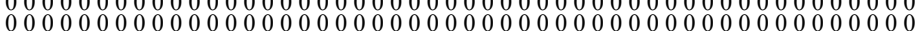
000000000000000000000000000000000000000000000000000 0000000000000000000000000000000000000000000000000000000000 00000000000000000000000000000000000000000000000000000000000 00000000000000000000100000000000000000000000000000 $\begin{array}{lllllllllllllllllllllllllllllllllllllllllllllllllll}0 & 0 & 0 & 0 & 0 & 0 & 0 & 0 & 0 & 0 & 0 & 0 & 0 & 0 & 0 & 0 & 0 & 0 & 0 & 0 & 0 & 0 & 0 & 0 & 0 & 0 & 0 & 0 & 0 & 0 & 0 & 0 & 0 & 0 & 0 & 0 & 0 & 0 & 0 & 0 & 0 & 0 & 0 & 0 & 0 & 0 & 0 & 0 & 0 & 0\end{array}$

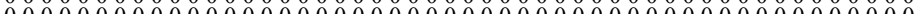

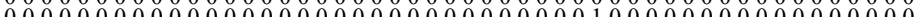
000000000000000000000000000000000000000000000000 00000000000000000000000000000000000000000000000000 00000000000000000000000000000000000000000000000000 000000000000000000000000000000000000000000000000000 0000000000000000000000000000000000000000000000000000000000000 00000000000000000000000000000000000000000000000000 100000000000000000000000000000000000000000000000000000000000000 000000000000000000000000000000000000000000000000000 $\begin{array}{lllllllllllllllllllllllllllllllllllllllllllllllllllll}0 & 0 & 0 & 0 & 0 & 0 & 0 & 0 & 0 & 1 & 0 & 0 & 0 & 0 & 0 & 0 & 0 & 0 & 0 & 0 & 0 & 0 & 0 & 0 & 0 & 0 & 0 & 0 & 0 & 0 & 0 & 0 & 0 & 0 & 0 & 0 & 0 & 0 & 0 & 0 & 0 & 0 & 0 & 0 & 0 & 0 & 0 & 0 & 0 & 0\end{array}$

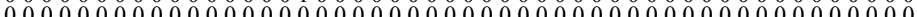

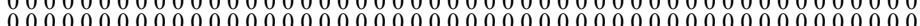
00000000000000000000000000000000000000000000000000 0000000000000000000000000000000000000000000000000000000000

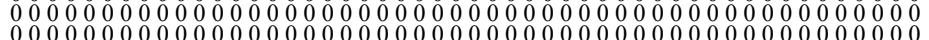

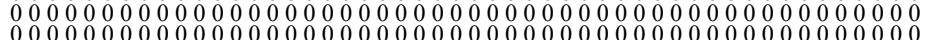

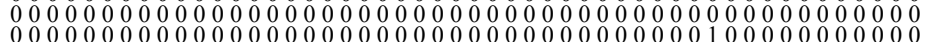

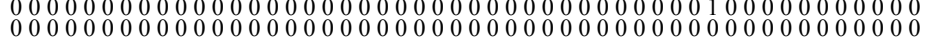

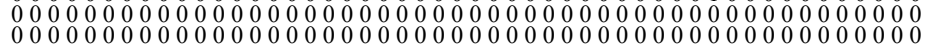
$\begin{array}{llllllllllllllllllllllllllllllllllllllllllllllllll}0 & 0 & 0 & 0 & 0 & 0 & 0 & 0 & 0 & 0 & 0 & 0 & 0 & 0 & 0 & 0 & 0 & 0 & 0 & 0 & 0 & 0 & 0 & 0 & 0 & 0 & 0 & 0 & 0 & 0 & 0 & 0 & 0 & 0 & 0 & 0 & 0 & 0 & 0 & 0 & 0 & 0 & 0 & 0 & 0 & 0 & 0 \\ 0 & 0 & 0 & 0 & 0 & 0 & 0 & 0 & 0 & 0 & 0 & 0 & 0 & 0 & 0 & 0 & 0 & 0 & 0 & 0 & 0 & 0 & 0 & 0 & 0 & 0 & 0 & 0 & 0 & 0 & 0 & 0 & 0 & 0 & 0 & 0 & 0 & 0 & 0 & 0 & 0 & 0 & 0 & 0 & 0 & 0 & 0 & 0 & 0\end{array}$ 000000000000000000000000

(b)

Figura 7-2 - Resultados obtidos no processamento de matrizes binárias - transformação áreaponto recursiva. a) Máscara $3 \times 3$, salto de linha 2 , salto de coluna 2 . b) Máscara $5 \times 5$, salto de linha 2 , salto de coluna 2 . 
3. Dependendo da forma do sinal, certas estruturas são transformadas em dois pixels, quando o algoritmo propõe a transformação em um só ponto. Este problema já havia sido exposto por Nishikawa et al. [NISHIKAWA-93a], quando salientou que, geralmente, as formas desses sinais são características de microcalcificações relacionadas a tumores malignos e, portanto, é melhor contá-los como dois sinais do que ignorá-los.

O teste do algoritmo de agrupamento de microcalcificações em "clusters" consistiu em verificar se em uma área pré-definida havia uma quantidade mínima de sinais que indicassem a presença de um "cluster". Os resultados variaram de acordo com os valores atribuídos à área e à quantidade de sinais, indicando um bom funcionamento do programa. A partir desses testes, decidiu-se utilizar o algoritmo proposto, procurando-se 3 sinais em uma área de $1 \mathrm{~cm}^{2}$, de acordo com a definição médica mais citada na literatura.

\subsection{Imagens de "phantoms"}

A segunda fase executada para a obtenção de resultados foi o teste com imagens de "phantoms". O objetivo foi verificar a exatidão do sistema computacional, para o processamento de imagens. As características dos "phantoms" utilizados foram descritas no capítulo 6. Cada uma das imagens de "phantom" (mostradas no capítulo anterior, figura 6-21 e figura 6-22) foi dividida em 16 partes, com tamanho médio de 500 linhas x 500 colunas. Foram processados 18 trechos desse porte, sendo extraída de cada um deles pelo menos uma região de interesse. Na figura 7-3 podem ser observados um exemplo de um "phantom" e as respectivas regiões de interesse dele extraídas. As regiões foram identificadas utilizando-se os seguintes parâmetros:

* Thresholding: 0,98

* $\quad$ Porcentagem da média de cinza: 0,5 


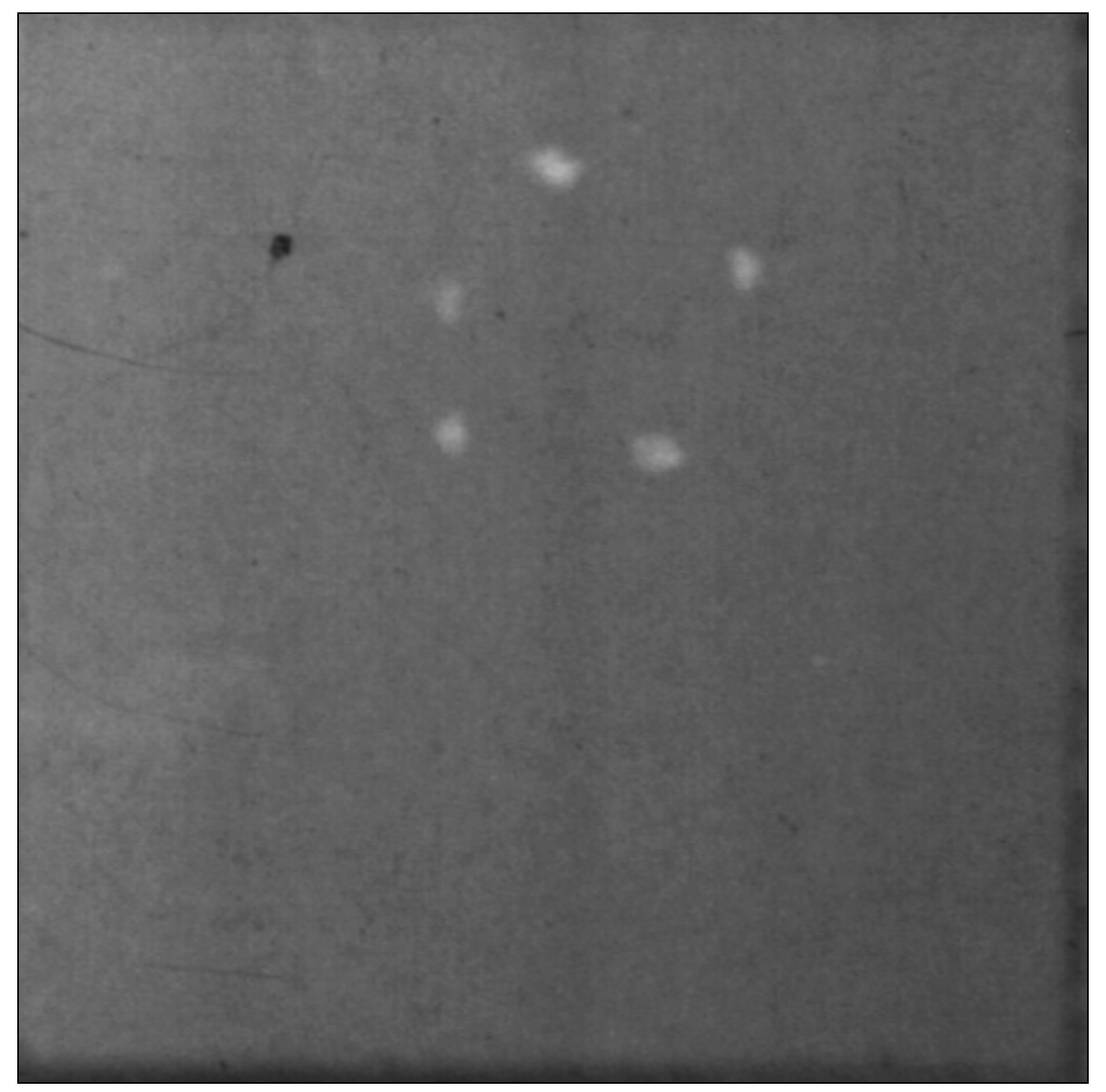

(a)

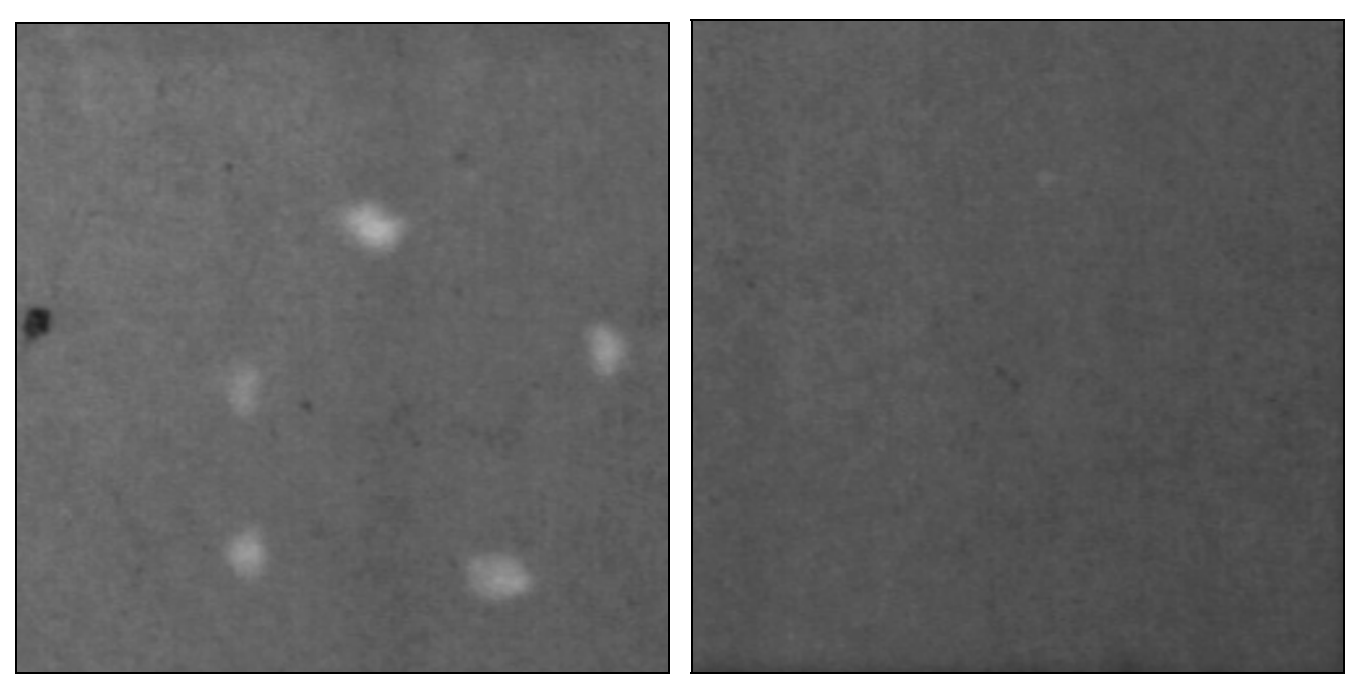

(b)

Figura 7-3 - a) Imagem de "phantom"; b) regiões de interesse. 
No total, foram processadas 31 regiões de interesse com 250 linhas $\mathrm{x}$ 250 colunas, com os parâmetros apresentados na tabela 7-1. A tabela 7-2 mostra os resultados do processamento, divididos de acordo com o valor de desvio-padrão utilizado no processo de segmentação, visto que este demonstrou exercer grande influência nos resultados dos diagnósticos proporcionados pelo programa. São mostrados o total de diagnósticos encontrados para cada categoria (verdadeiropositivo, falso-positivo, verdadeiro-negativo e falso-negativo) e a porcentagem em relação ao total de imagens processadas.

Tabela 7-1 - Parâmetros do processamento de imagens de "phantoms".

\begin{tabular}{ll}
\hline Fase & Parâmetros utilizados \\
\hline Detecção de regiões de interesse & Altura da Região: 250 linhas \\
& Largura: 250 colunas \\
& Salto de linha: 125 \\
& Salto de coluna: 125 \\
& Valor de Thresholding: 0,98 \\
& Porcentagem da média de cinza: de 0 a 1, \\
dependendo da variação de intensidade da & imagem \\
& Valor de thresholding: 0,98 \\
& Desvio Padrão: 3,00 a 4,00 \\
Segmentação & Tamanho da máscara: 3 \\
& Salto de linha: 2 \\
Transformação AP & Salto de coluna: 2 \\
& Área considerada: 236 pixels \\
Detecção de "clusters" - método & Quantidade mínima de microcalcificações: 3 \\
de "mascaramento" & Distância mínima entre clusters: 50 \\
& Salto de linha e coluna: 118 \\
\hline
\end{tabular}

Tabela 7-2 - Resultado do processamento de imagens de "phantoms".

\begin{tabular}{|c|c|c|c|c|c|c|c|c|c|}
\hline \multirow[t]{2}{*}{$\begin{array}{c}\text { Valor do } \\
\text { Desvio-padrão } \\
\text { da } \\
\text { segmentação } \\
\end{array}$} & \multirow[t]{2}{*}{$\begin{array}{l}\text { Quantidade de } \\
\text { imagens } \\
\text { processadas }\end{array}$} & \multicolumn{2}{|c|}{$\begin{array}{c}\text { Total de } \\
\text { "clusters" } \\
\text { verdadeiro- } \\
\text { positivos } \\
\end{array}$} & \multicolumn{2}{|c|}{$\begin{array}{c}\text { Total de } \\
\text { "clusters" } \\
\text { falso-positivos }\end{array}$} & \multicolumn{2}{|c|}{$\begin{array}{c}\text { Total de } \\
\text { "clusters" } \\
\text { verdadeiro- } \\
\text { negativos } \\
\end{array}$} & \multicolumn{2}{|c|}{$\begin{array}{c}\text { Total de } \\
\text { "clusters" } \\
\text { falso-negativos }\end{array}$} \\
\hline & & Quant. & $\%$ & Quant. & $\%$ & Quant. & $\%$ & Quant. & $\%$ \\
\hline 3,0 & 31 & 22 & $71 \%$ & 9 & $29 \%$ & 0 & $0 \%$ & 0 & $0 \%$ \\
\hline 3,5 & 31 & 19 & $61 \%$ & 5 & $16 \%$ & 4 & $13 \%$ & 3 & $10 \%$ \\
\hline 4,0 & 31 & 17 & $55 \%$ & 0 & $0 \%$ & 9 & $29 \%$ & 5 & $16 \%$ \\
\hline
\end{tabular}


Inicialmente, a segmentação das imagens de "phantoms" foi processada com o parâmetro "desvio padrão" com valor 3. Percebeu-se que a porcentagem de diagnósticos falso-positivos era alta e, então, foi decidido o reprocessamento do conjunto de imagens, mudando-se esse parâmetro para 3,5 e 4,0, sucessivamente. Com isso, a sensibilidade do método diminui, ocorrendo, conseqüentemente, uma diminuição da quantidade de diagnósticos falso-positivos. Em contrapartida, percebeu-se que, quanto maior este valor, maior foi o número de casos falso-negativos. Esse fato ocorre porque a segmentação considera o contraste do sinal em relação à estrutura de fundo para mantê-lo ou eliminá-lo, usando, para essa comparação, o valor estabelecido de "desvio padrão". Portanto, quanto maior este valor, menor é a quantidade de sinais remanescentes. No conjunto de imagens de "phantoms" utilizado para teste o melhor valor foi 4,0, pois forneceu a maior porcentagem de diagnósticos verdadeiros (84\%) e a menor porcentagem de diagnósticos falsos (16\%). Na figura 7-4 podemos visualizar graficamente este efeito.

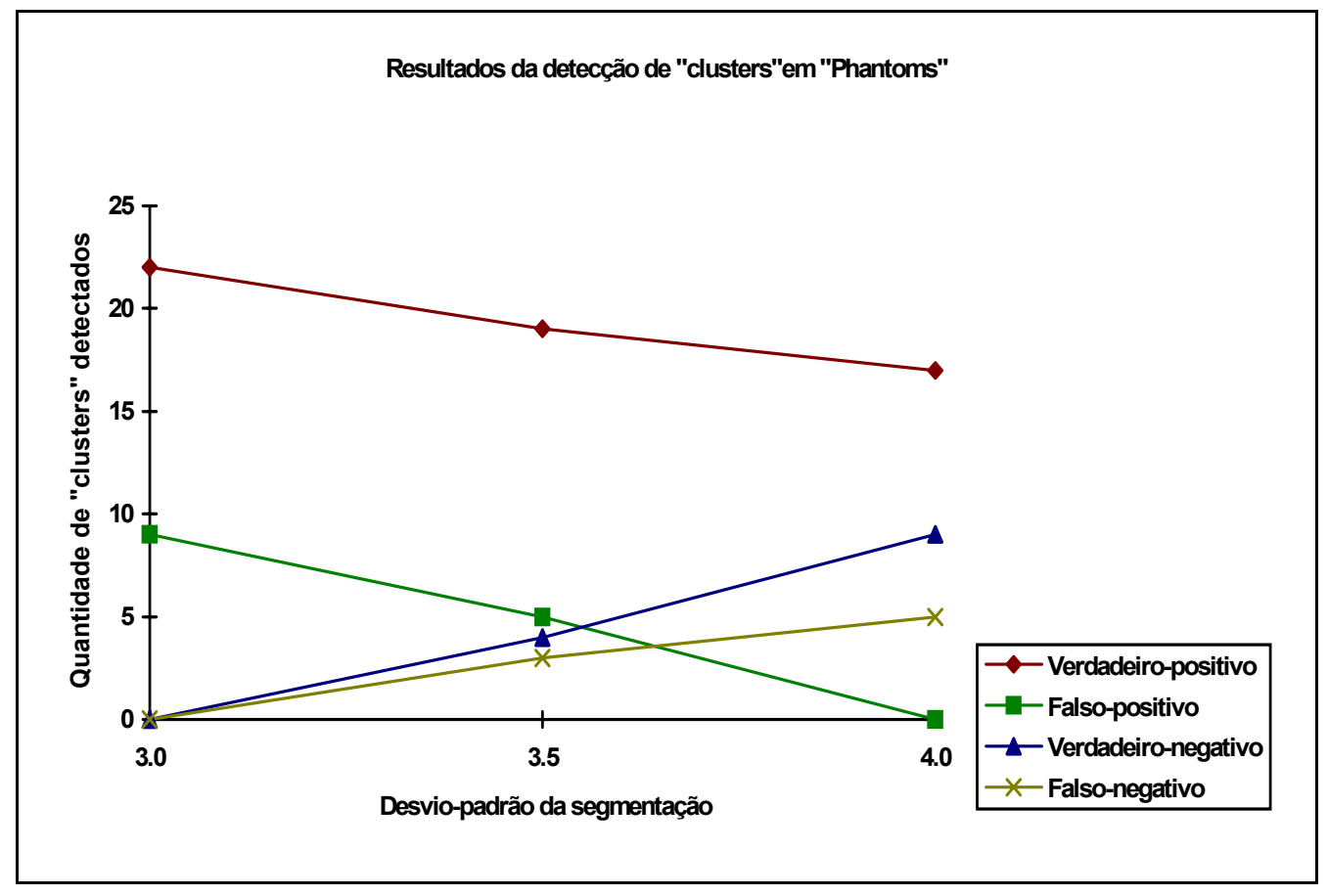

Figura 7-4 - Efeito do desvio padrão da segmentação nos resultados dos diagnósticos de imagens de "phantoms" processadas. 
O processamento das imagens de "phantoms" foi de extrema importância para a avaliação inicial e a correção do sistema. Através desse processamento foi detectada a necessidade de deixar muitos parâmetros dos programas variáveis, visto que as características de cada imagem variavam de acordo com as características de impressão no filme. Entre esses parâmetros, destacamos:

* $\quad$ porcentagem da média de nível de cinza (fase de identificação de regiões de interesse);

* tamanho da máscara (transformação área-ponto);

* distância mínima entre os “clusters" (detecção de "clusters").

Algumas dificuldades foram encontradas nessa fase de processamento:

* $\quad$ variação de intensidade - este fator é um problema que traz grandes dificuldades durante o processamento. A distribuição de intensidade que chega no filme não é uniforme em todo o campo de radiação. Isso faz com que, algumas vezes, existam porções da imagem mais claras do que as partes onde estão as microcalcificações (figura 7-5 a seguir). Na detecção semi-automática de regiões de interesse, esse dado é um fator importante, pois pode ocorrer a não identificação de uma região de interesse em decorrência do fato da média de níveis de cinza daquela porção ser menor que a média de cinza da imagem. Para minimizar este problema, tornamos variável o parâmetro "porcentagem da média de cinza", que indica qual a porcentagem da média geral deve ser utilizada para comparação e conseqüente detecção das regiões de interesse. Por exemplo, se esse parâmetro assumir o valor 0,5 , serão marcadas todas as regiões cuja média de níveis de cinza for maior ou igual a $50 \%$ da média de cinza da imagem. Dessa forma, se uma determinada região não for identificada como sendo de interesse por estar mais escura do que o restante da imagem, o usuário pode refazer o processamento, atribuindo um valor menor a esse parâmetro.

* contraste - em alguns casos, o contraste entre as estruturas de interesse e o fundo da imagem era muito pequeno (vide figura 7-6), resultando em uma baixa performance do sistema de detecção no que diz respeito à identificação das estruturas de interesse e eliminação dos ruídos. Avaliar esse fator no 
processamento de "phantoms" foi muito importante, pois proporcionou informações para melhorar os parâmetros do sistema de digitalização de imagens.

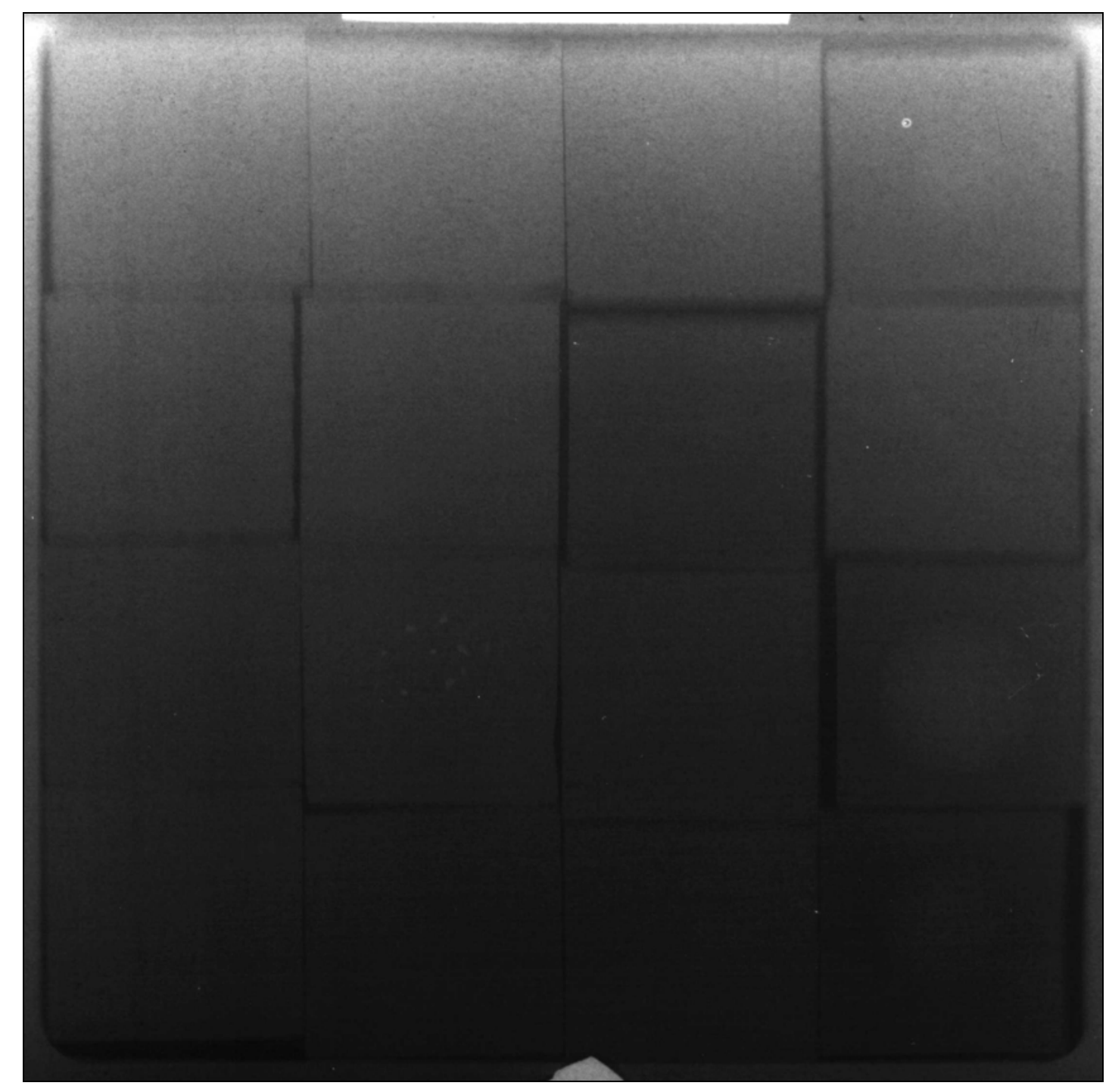

Figura 7-5 - Exemplo de imagem de "phantom" com variação de intensidade. 

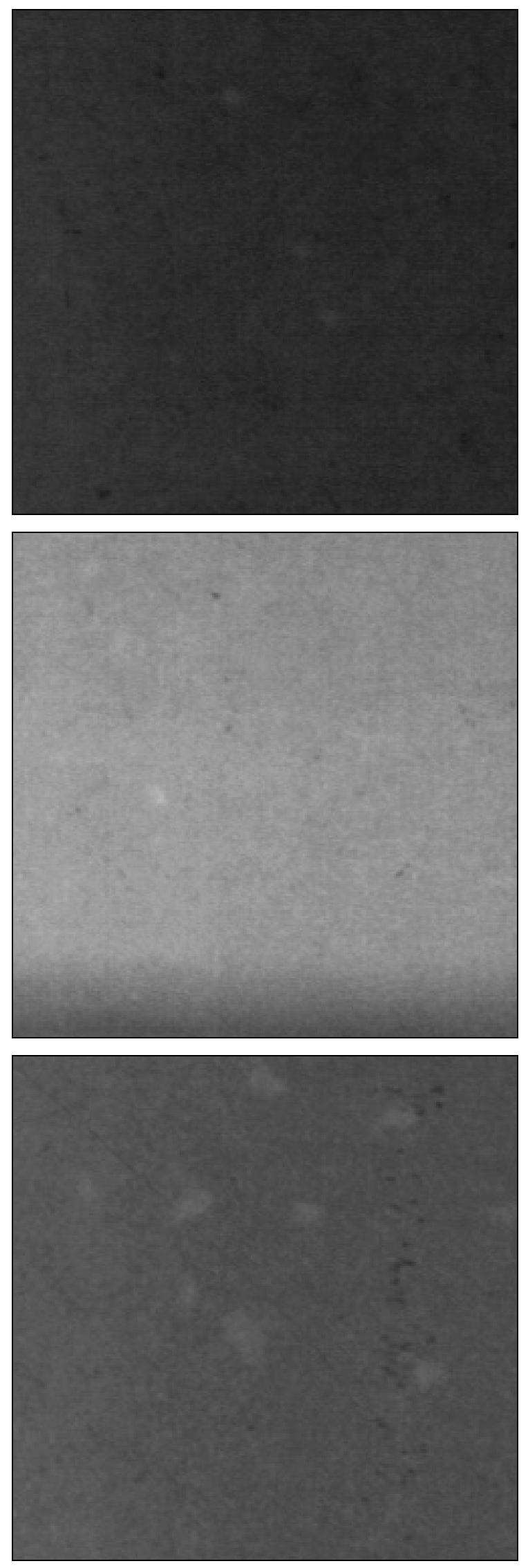

Figura 7-6 - Exemplos de imagem de trechos de "phantom" com contraste baixo. 
* resolução da imagem - visto que o tamanho das microcalcificações está geralmente abaixo de $0,7 \mathrm{~mm}$, a resolução da imagem digitalizada foi considerada como um item muito importante no processamento. Adotamos a resolução de 600 pontos por polegada, o que nos forneceu um tamanho de pixel compatível com as necessidades de processamento. No entanto, isso causou dificuldade na eliminação de alguns ruídos, pois, com um tamanho de pixel muito pequeno, os ruídos tendem a ser compostos por mais de um pixel, o que acaba impedindo a sua eliminação durante a segmentação (o processo de segmentação utilizado considerou como ruído os sinais compostos por menos de quatro pixels). $\mathrm{Na}$ figura 7-7 pode ser verificada a manutenção de ruídos após o processo de segmentação. A figura mostra que a quantidade de ruído remanescente varia com a diminuição e aumento da sensibilidade do sistema. Os valores utilizados de desviopadrão foram, respectivamente, 3,0, 3,5 e 4,0 nas imagens em (b), (c) e (d) da figura 7-7.

* transformação área-ponto - o problema encontrado durante essa fase do processamento das imagens dos "phantoms" foi quando houve transformação de um único sinal em mais de um pixel, como já citamos. Acreditamos que a principal causa desse fato é que as partículas de mármore moído utilizadas no "phantom" 2, apesar de apresentarem um tamanho muito próximo da dimensão das microcalcificações, muitas vezes apresentam formas diferentes das estruturas reais. No caso de simulação de sinais em "phantoms", não é fácil construir estruturas com formas próximas das microcalcificações no organismo humano. Por isso, houve uma contribuição desse fator para o aumento do número de diagnósticos falso-positivos. Esse problema foi minimizado nos testes com imagens de mamogramas reais. $\mathrm{Na}$ figura 7-8 até a figura 7-10 podemos observar esse efeito. Alguns sinais não foram transformados em um único pixel, originando pixels adicionais. 


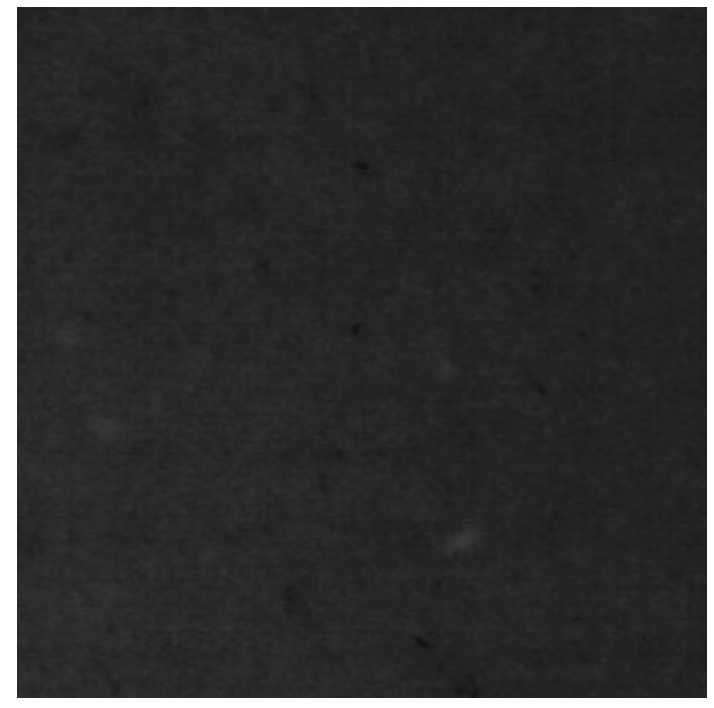

(a)

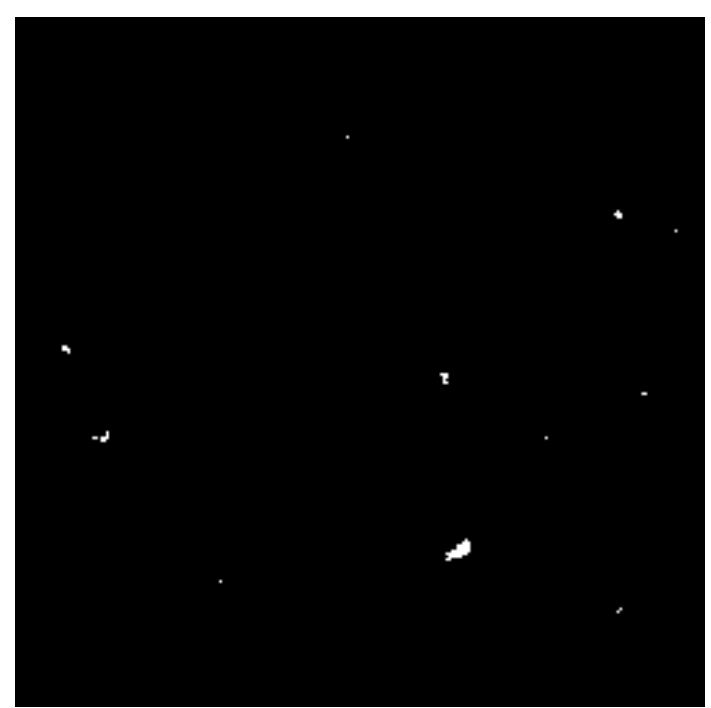

(c)

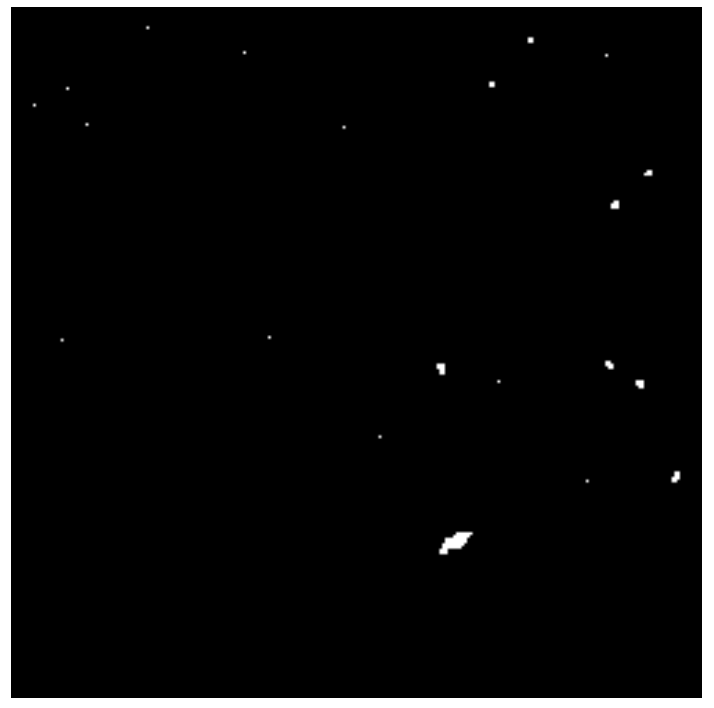

(b)

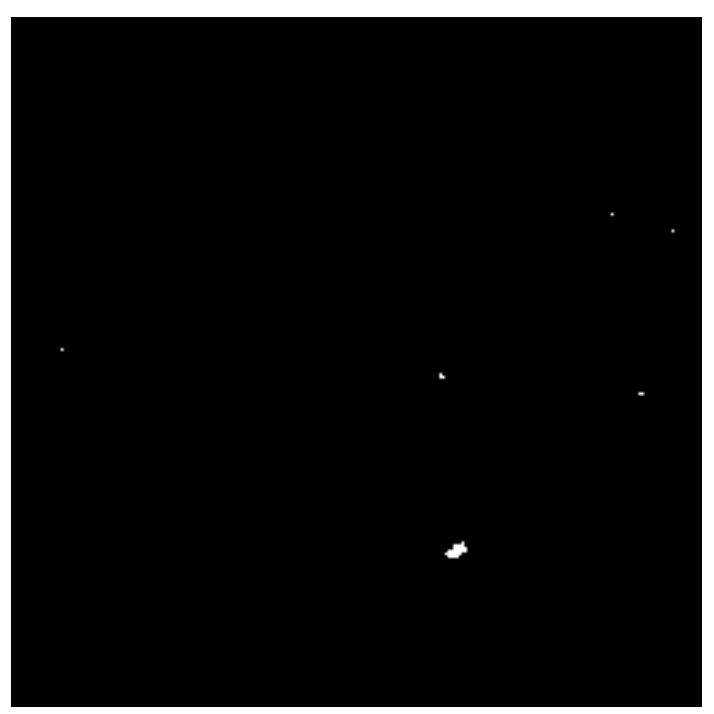

(d)

Figura 7-7 - Influência da resolução da digitalização e da sensibilidade do sistema na eliminação de ruídos. a) imagem original; b) imagem segmentada com valor de desvio padrão 3,0 ; c) imagem segmentada com valor de desvio padrão 3,5 ; d) imagem segmentada com valor de desvio padrão 4,0 . 
132
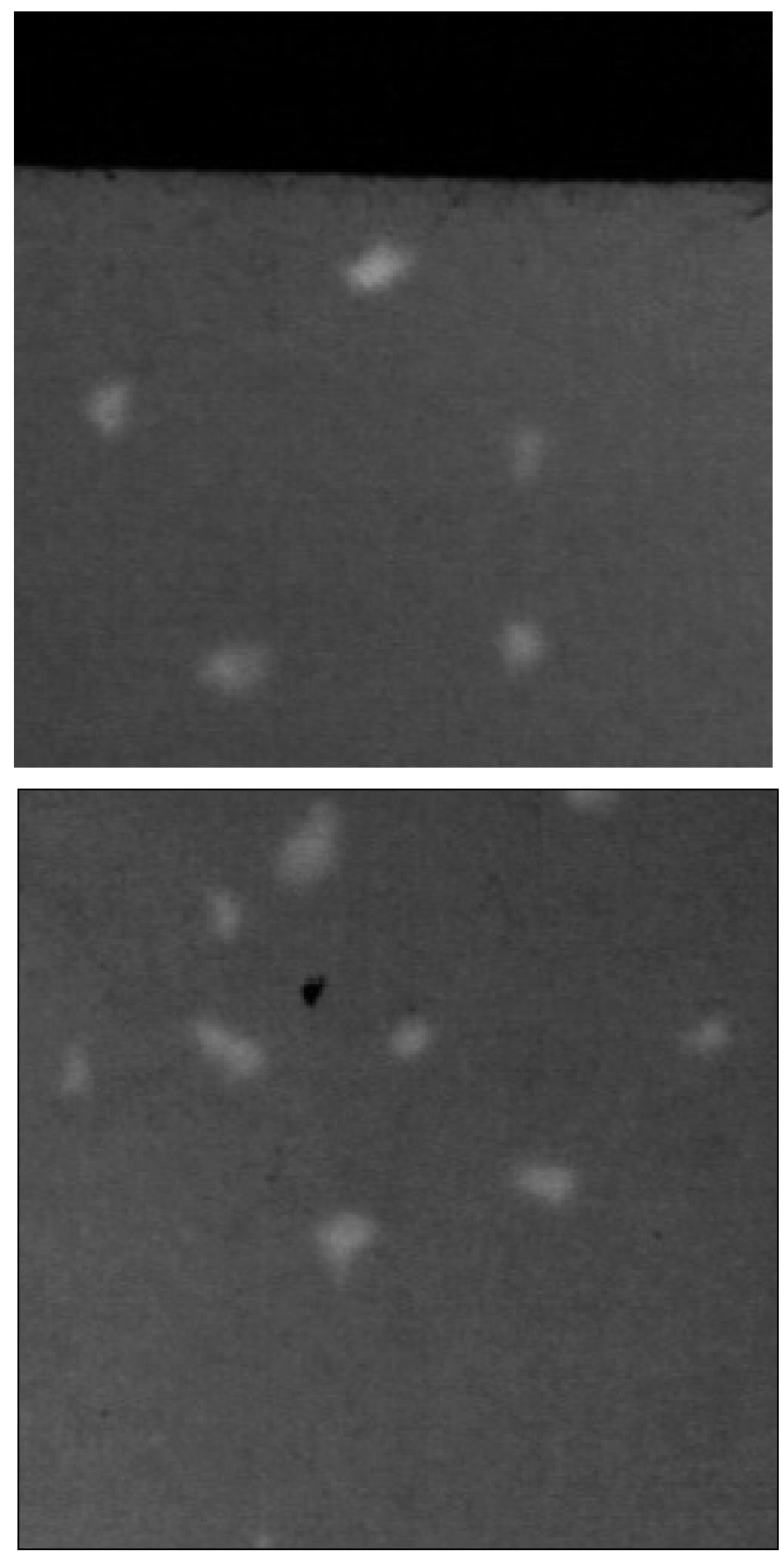

Figura 7-8 - Efeito da transformação área-ponto em imagens de "phantoms" - imagens originais. 

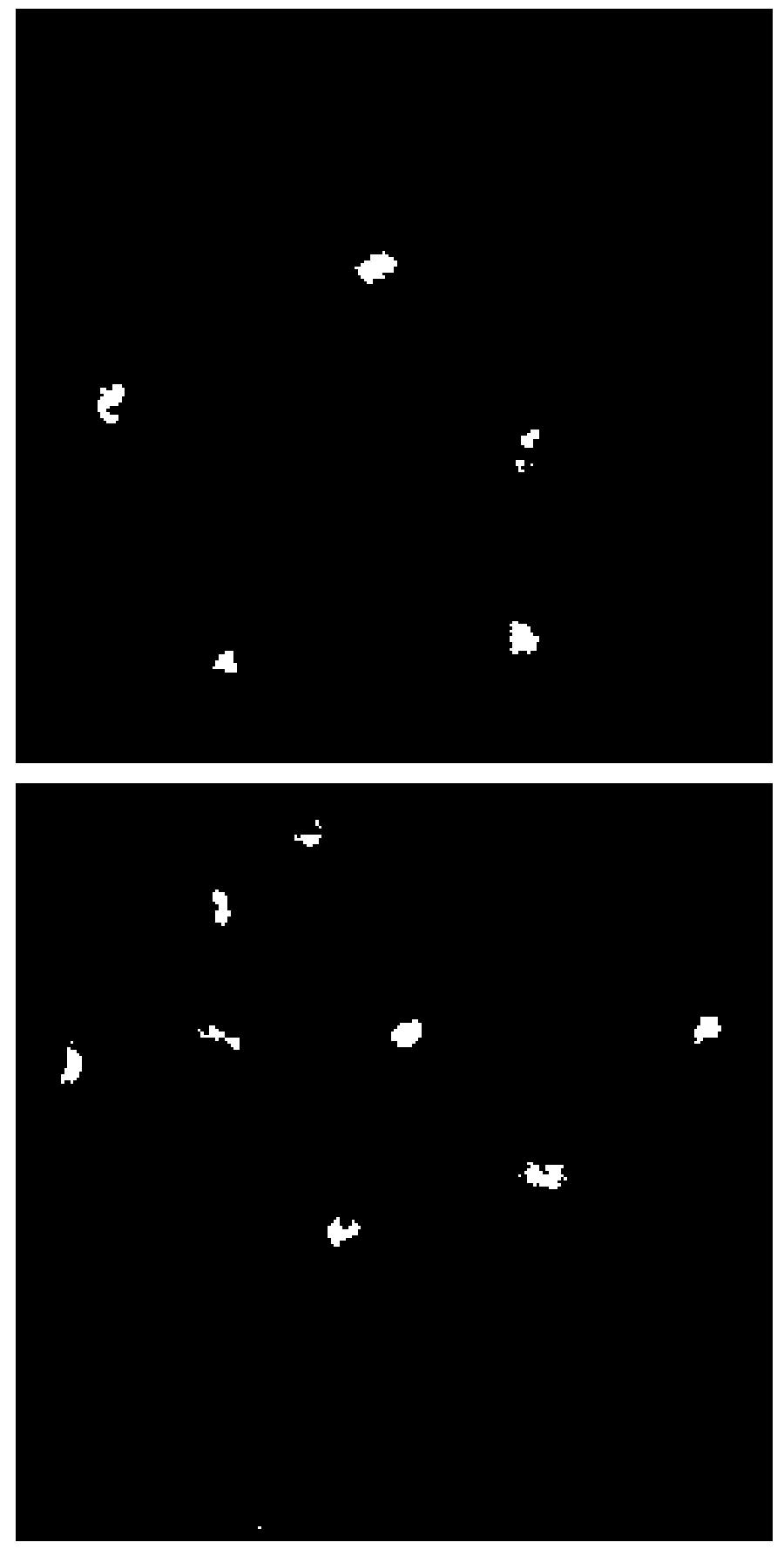

Figura 7-9 - Efeito da transformação área-ponto em imagens de "phantoms" - imagens segmentadas. 

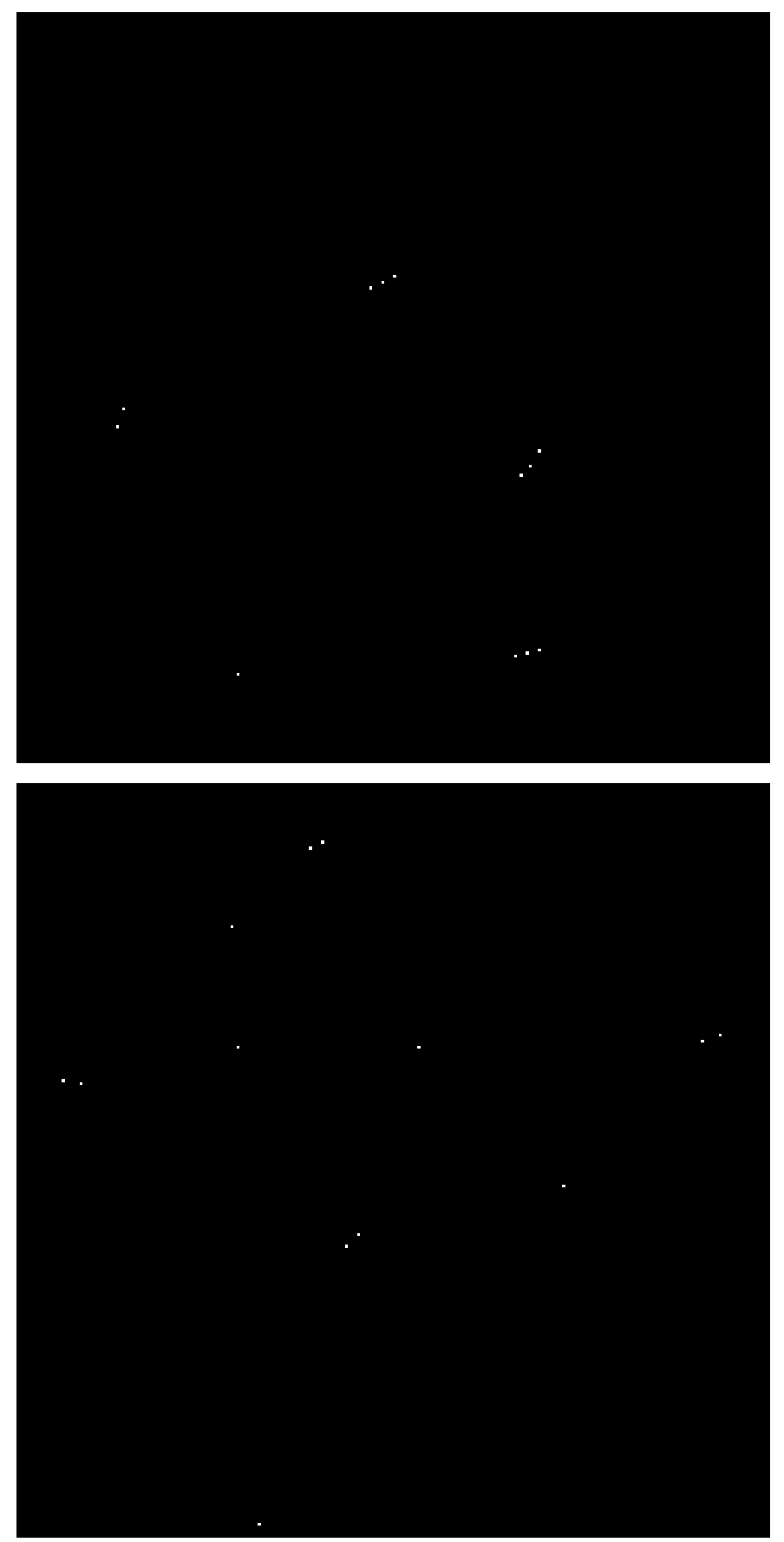

Figura 7-10 - Efeito da transformação área-ponto em imagens de "phantoms" - imagens resultantes após transformação área-ponto. Alguns sinais resultaram em mais de um pixel.

* integração de sinais isolados - durante a detecção de "clusters" através do método de "mascaramento", percebeu-se que alguns sinais não eram identificados como pertencentes a "clusters", mas, na imagem, estavam muito próximos de algum agrupamento. Isso pode ocorrer quando, em alguma iteração anterior, o "cluster" já foi identificado e, conseqüentemente, os seus sinais já foram 
eliminados. Para diminuir as ocorrências desse tipo de situação, o programa, após ter identificado todos os "clusters" da imagem, realiza um procedimento que verifica se os sinais remanescentes estão próximos de algum sinal que pertence a algum agrupamento. A distância utilizada para essa verificação é o tamanho da área considerada para a identificação das aglomerações, definido pelo usuário. Se o sinal estiver separado de algum sinal pertencente a "cluster" por uma distância menor ou igual a esse tamanho, o sinal isolado é integrado a esse "cluster".

* agrupamento de "clusters" próximos - ainda na fase de identificação de "clusters" através do método de "mascaramento", observou-se que alguns agrupamentos foram identificados como duas ou mais aglomerações separadas, dependendo do posicionamento de seus sinais. Para resolver essa questão, foi implementado um procedimento de verificação da distância existente entre todos os "clusters" identificados, dois a dois. Foram calculadas todas as distâncias dos sinais de um agrupamento em relação a todos os sinais do outro agrupamento, sendo armazenada a menor delas. Se a menor distância encontrada fosse menor ou igual a uma distância pré-determinada, os "clusters" eram considerados como um só agrupamento. A distância utilizada como parâmetro de comparação para esse teste geralmente foi um valor próximo do tamanho da área verificada.

$\mathrm{Na}$ figura 7-11 pode ser observado o processamento completo de uma imagem de "phantom", as regiões de interesse selecionadas e as diversas fases de processamento dessas regiões.

Os problemas encontrados nessa fase foram resolvidos, geralmente, através da implementação de procedimentos adicionais no sistema computacional, tais como: rotinas para junção de sinais isolados na deteç̧ão de "cluster", rotina para agrupamento de "clusters" próximos e procedimento para identificação de regiões de interesse. Com isso, o sistema tornou-se mais adequado às situações reais, cujos testes descrevemos no próximo item. 


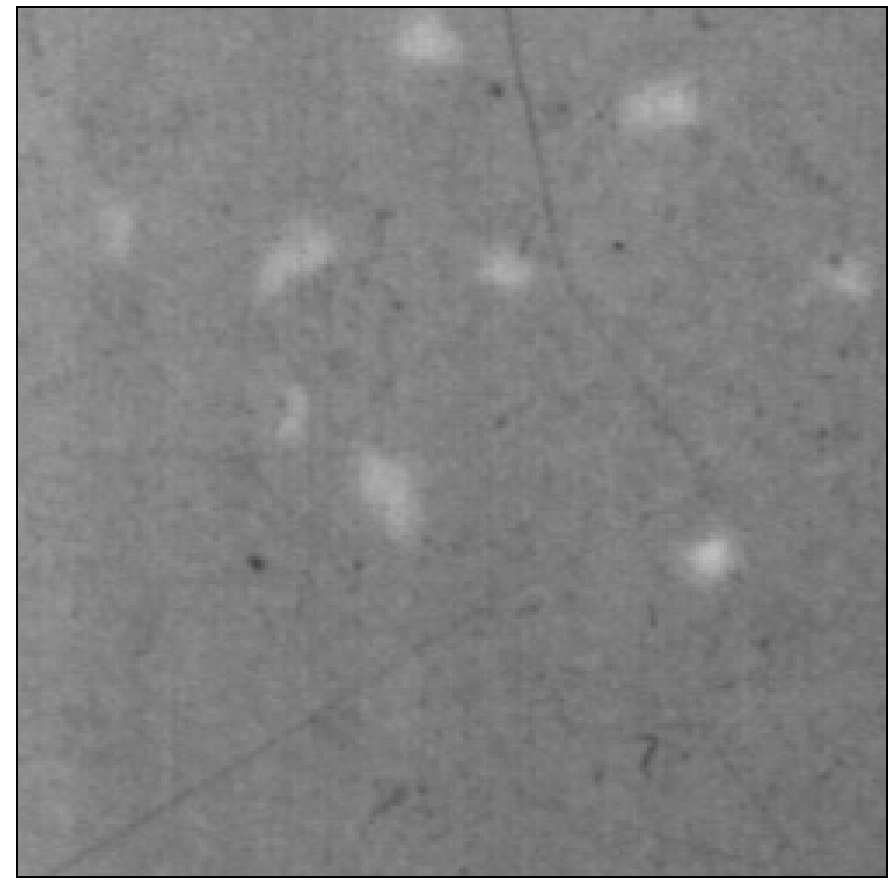

Figura 7-11 (a)

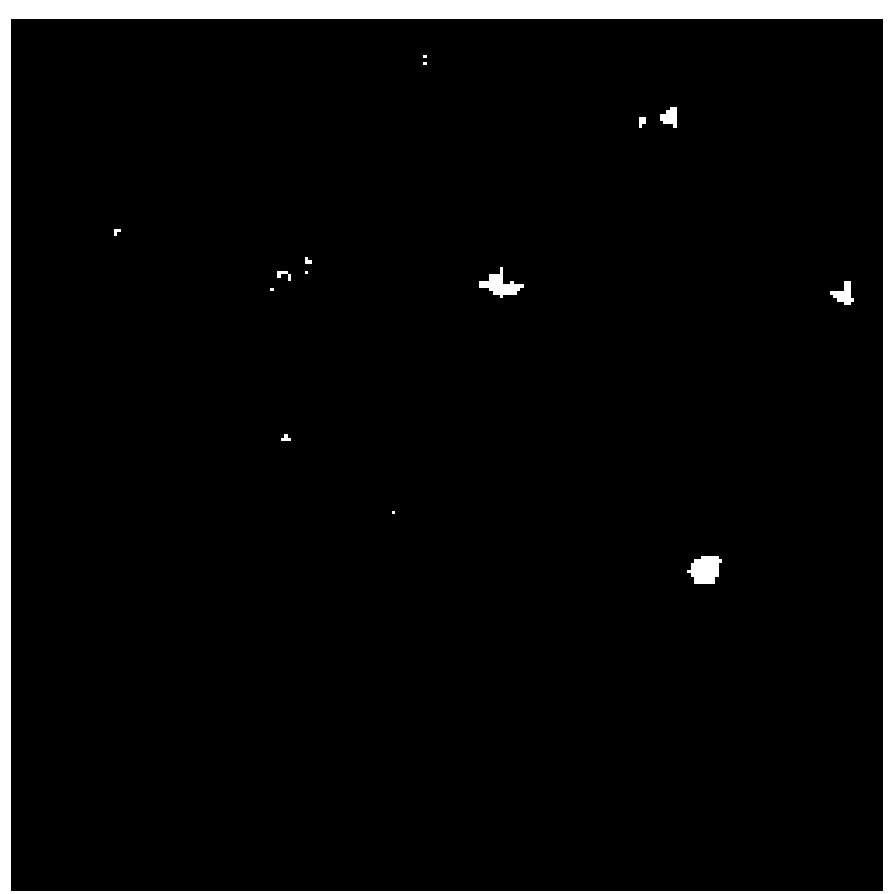

Figura 7-11 (b) 


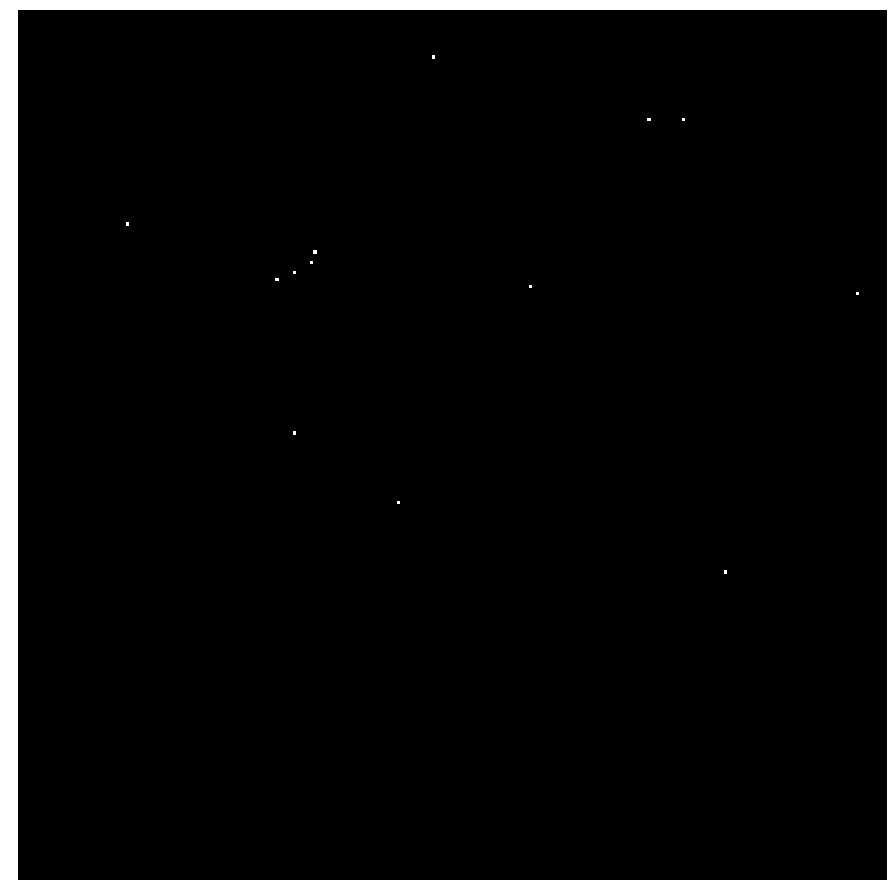

Figura 7-11 (c)

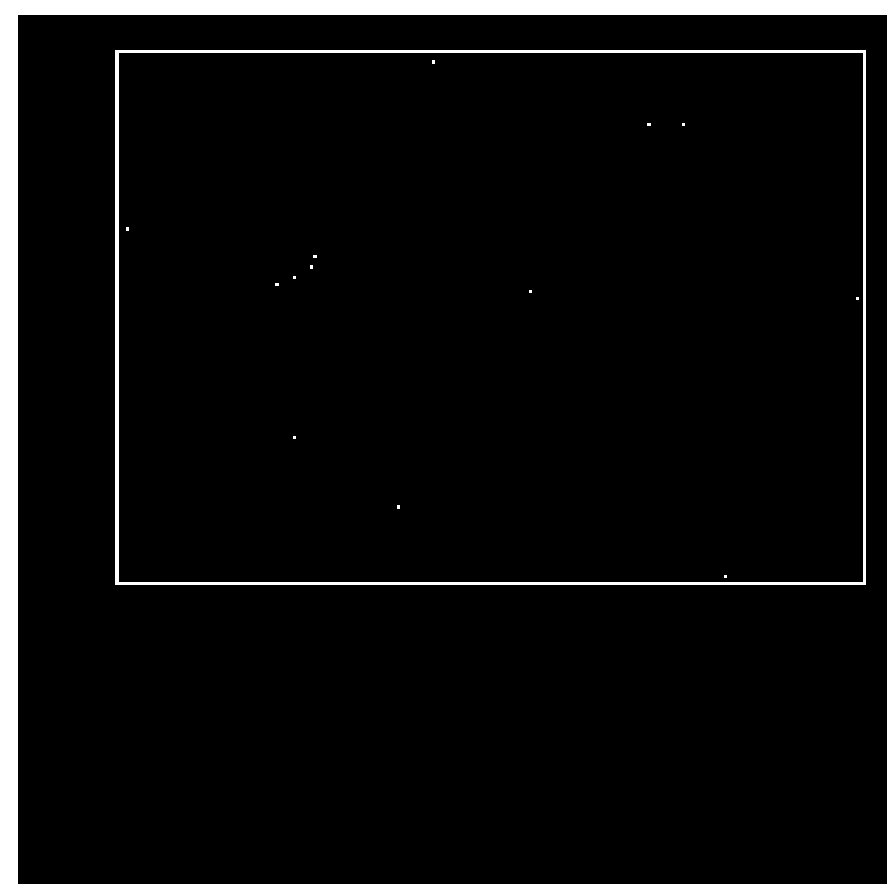

Figura 7-11 (d)

Figura 7-11 - Processamento completo de uma região de interesse de uma imagem de "phantom". a) região de interesse, b) região de interesse após segmentação, c) região de interesse após transformação área-ponto e d) região de interesse após a deteç̧ão de "clusters". 


\subsection{Imagens reais}

Nesta fase, foi verificada a performance do sistema computacional elaborado no processamento de imagens reais. Foram processados dois conjuntos de imagens de mamogramas:

1o.) 16 imagens de mamogramas obtidos no Hospital das Clínicas de Ribeirão Preto, todas com laudo médico. Os filmes foram digitalizados em um digitalizador UMAX UC1260-Pro, com resolução de 600 dpi e 256 níveis de cinza.

2o.) 16 imagens obtidas do National Expert and Training Centre for Breast Cancer Screening e Department of Radiology at the University of Nijmegen, na Holanda, através da Internet.

\subsubsection{Primeiro conjunto de imagens}

Antes do processamento das imagens, foi feita uma verificação visual das possíveis regiões de interesse. Foram selecionados trechos que poderiam conter agrupamentos de microcalcificações e trechos que provavelmente não tinham "clusters", a fim de verificar o desempenho do sistema na identificação de "clusters" verdadeiros e na não identificação de "clusters" falsos. Devido ao tamanho de alguns mamogramas e à falta de recursos computacionais, alguns mamogramas foram divididos em duas partes ou tiveram algumas partes eliminadas. No total, foram processadas 64 regiões de interesse com 250 linhas x 250 colunas, com os parâmetros apresentados na tabela 7-3.

Um exemplo de mamograma e as regiões de interesse dele extraídas foi mostrado na figura 6-5. A tabela 7-4 mostra os resultados do processamento das regiões de interesse.

Como demonstrado na tabela $7-4$, os testes do sistema foram executados variando-se o valor do parâmetro "desvio-padrão" durante a segmentação, da mesma forma como havia sido feito nos testes com "phantoms". Notou-se que, nesse caso, o aumento do valor desse parâmetro piorou a performance do sistema, aumentando o número de diagnósticos falso-negativos. 
Tabela 7-3 - Parâmetros do processamento de imagens de mamogramas reais.

\begin{tabular}{ll}
\hline Fase & Parâmetros utilizados \\
\hline Detecção de regiões de interesse & Altura da Região: 250 linhas \\
& Largura: 250 colunas \\
& Salto de linha: 125 \\
& Salto de coluna: 125 \\
& Valor de Thresholding: 0,98 \\
& Porcentagem da média de cinza: de 0 a 0,5, \\
& dependendo da variação de intensidade da \\
imagem & Valor de thresholding: 0,98 \\
& Desvio Padrão: 3,00 \\
Segmentação & Tamanho da máscara: 3 \\
& Salto de linha: 2 \\
Transformação AP & Salto de coluna: 2 \\
& Área considerada: 236 pixels \\
Deteção de "clusters" - método de & Quantidade mínima de microcalcificações: 3 \\
"mascaramento" & Distância mínima entre clusters: 118 \\
& Salto de linha e coluna: 118 \\
\hline
\end{tabular}

Tabela 7-4 - Resultado do processamento de imagens de mamogramas reais através do método de "mascaramento".

\begin{tabular}{|c|c|c|c|c|c|c|c|c|c|}
\hline \multirow[t]{2}{*}{$\begin{array}{l}\text { Desvio-padrão } \\
\text { da segmentação }\end{array}$} & \multirow[t]{2}{*}{$\begin{array}{c}\text { Total de } \\
\text { imagens } \\
\text { processadas }\end{array}$} & \multicolumn{2}{|c|}{$\begin{array}{c}\text { Total de } \\
\text { diagnósticos } \\
\text { verdadeiro- } \\
\text { positivos }\end{array}$} & \multicolumn{2}{|c|}{$\begin{array}{c}\text { Total de } \\
\text { diagnósticos } \\
\text { falso- } \\
\text { positivos }\end{array}$} & \multicolumn{2}{|c|}{$\begin{array}{c}\text { Total de } \\
\text { diagnósticos } \\
\text { verdadeiro- } \\
\text { negativos }\end{array}$} & \multicolumn{2}{|c|}{$\begin{array}{c}\text { Total de } \\
\text { diagnósticos } \\
\text { falso- } \\
\text { negativos }\end{array}$} \\
\hline & & Quant. & $\%$ & Quant. & $\%$ & Quant. & $\%$ & Quant. & $\%$ \\
\hline 3,0 & 16 & 15 & $94 \%$ & 1 & $6 \%$ & 0 & $0 \%$ & 0 & $0 \%$ \\
\hline 3,5 & 16 & 11 & $69 \%$ & 1 & $6 \%$ & 0 & $0 \%$ & 4 & $25 \%$ \\
\hline
\end{tabular}

Muitos dos problemas encontrados nas fases anteriores não existiram nesta fase, visto que, à medida que os testes evoluíam, o sistema era corrigido. No entanto, ainda permaneceram algumas questões:

* identificação das regiões de interesse - algumas vezes o posicionamento da máscara para gravação de região de interesse ocorria na metade do "cluster" ou do trecho previamente identificado; a alteração dos parâmetros tamanho da região (altura e largura) e salto de linhas e colunas resolveu esse problema; 
* diferença da distribuição de intensidade - essa questão, já levantada durante o processamento de "phantoms", continuou a existir no processamento de mamogramas. Não é um problema que pode ter um tratamento genérico, pois cada imagem possui características próprias, exigindo a utilização de parâmetros diferenciados durante a execução do programa. Como, na fase anterior, já havíamos definido como variável o parâmetro "porcentagem da média de cinza", o procedimento aqui adotado foi simplesmente alterá-lo para um valor adequado, dependendo de cada imagem. O valor desse parâmetro foi obtido, na maioria dos casos, experimentalmente. Geralmente, o valor inicial foi 0,5 e, quando a imagem apresentava variação na intensidade, esse valor era diminuído até que as regiões desejadas fossem identificadas. Exemplos de imagens de mamogramas onde a distribuição de intensidade sofre variação são apresentados na figura 7-12.

* presença de objetos - algumas vezes, no exame mamográfico, são utilizados objetos, geralmente radiopacos, com a finalidade de orientar o observador. Na maioria das vezes, a imagem desses objetos apresenta níveis de cinza maiores que no restante do filme (tendendo para o branco), o que influencia no cálculo da média geral de níveis de cinza, prejudicando a identificação das regiões de interesse. Na figura 7-13 é possível perceber a presença de "defeitos" que prejudicam o processamento dessa fase. Com isso, as regiões de interesse são identificadas somente se for utilizado o valor 0 de desvio padrão. Isto causa incômodo, pois o usuário deve desprezar as regiões seqüencialmente até ser atingida a região desejada. Uma sugestão para eliminar essa questão é discutida no item 7.4.

* contraste da imagem - esse item é outro fator inerente de cada imagem, exigindo uma solução individual de processamento no sentido de escolher os parâmetros que podem apresentar melhores resultados. O contraste corresponde à diferença dos níveis de absorção de raios-X pelos diversos tecidos que compõem a mama. A solução mais efetiva foi alterar alguns parâmetros durante o processo de digitalização, como, por exemplo, o nível de contraste e brilho, o que permitiu a obtenção de imagens digitalizadas em condições melhores do que as condições originais de observação dos filmes mamográficos. 


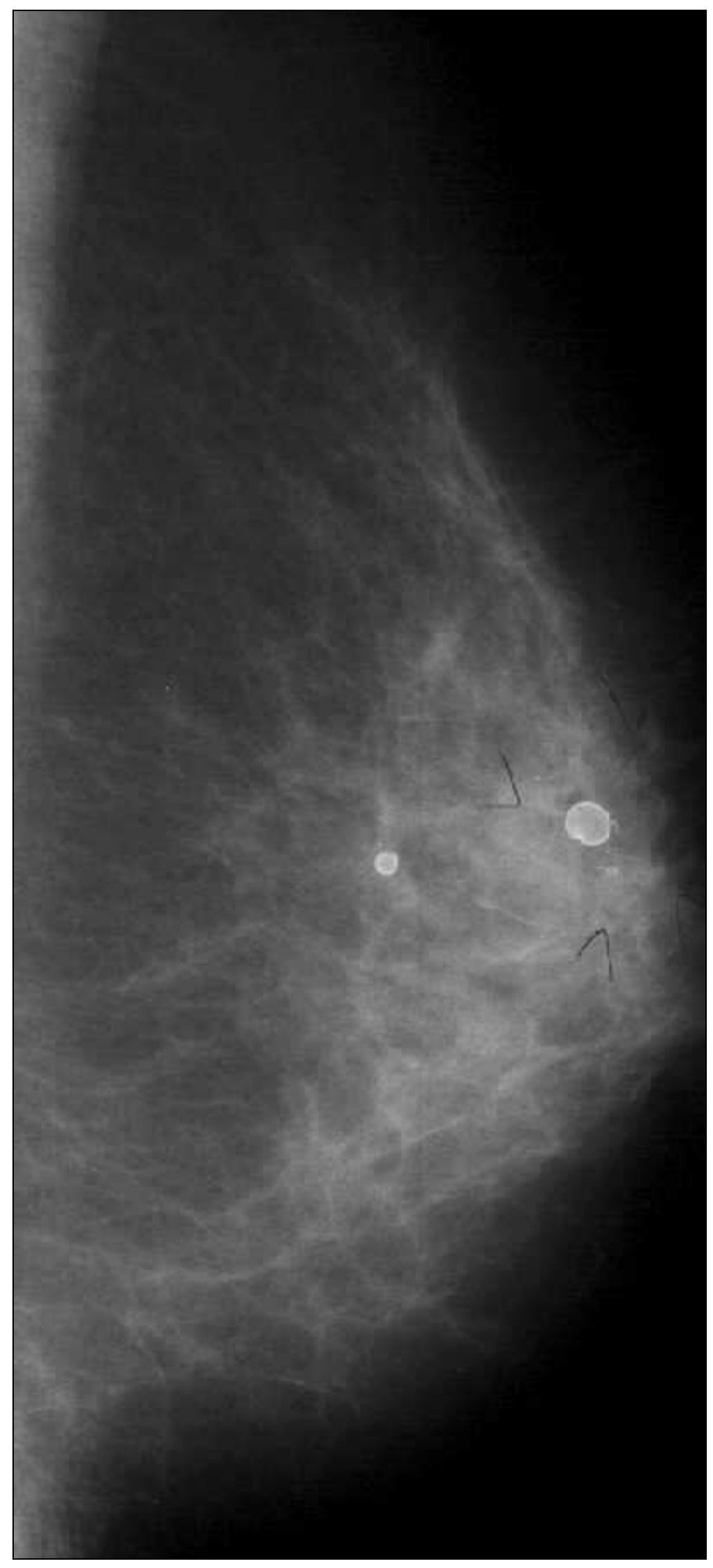

Figura 7-12 (a) 


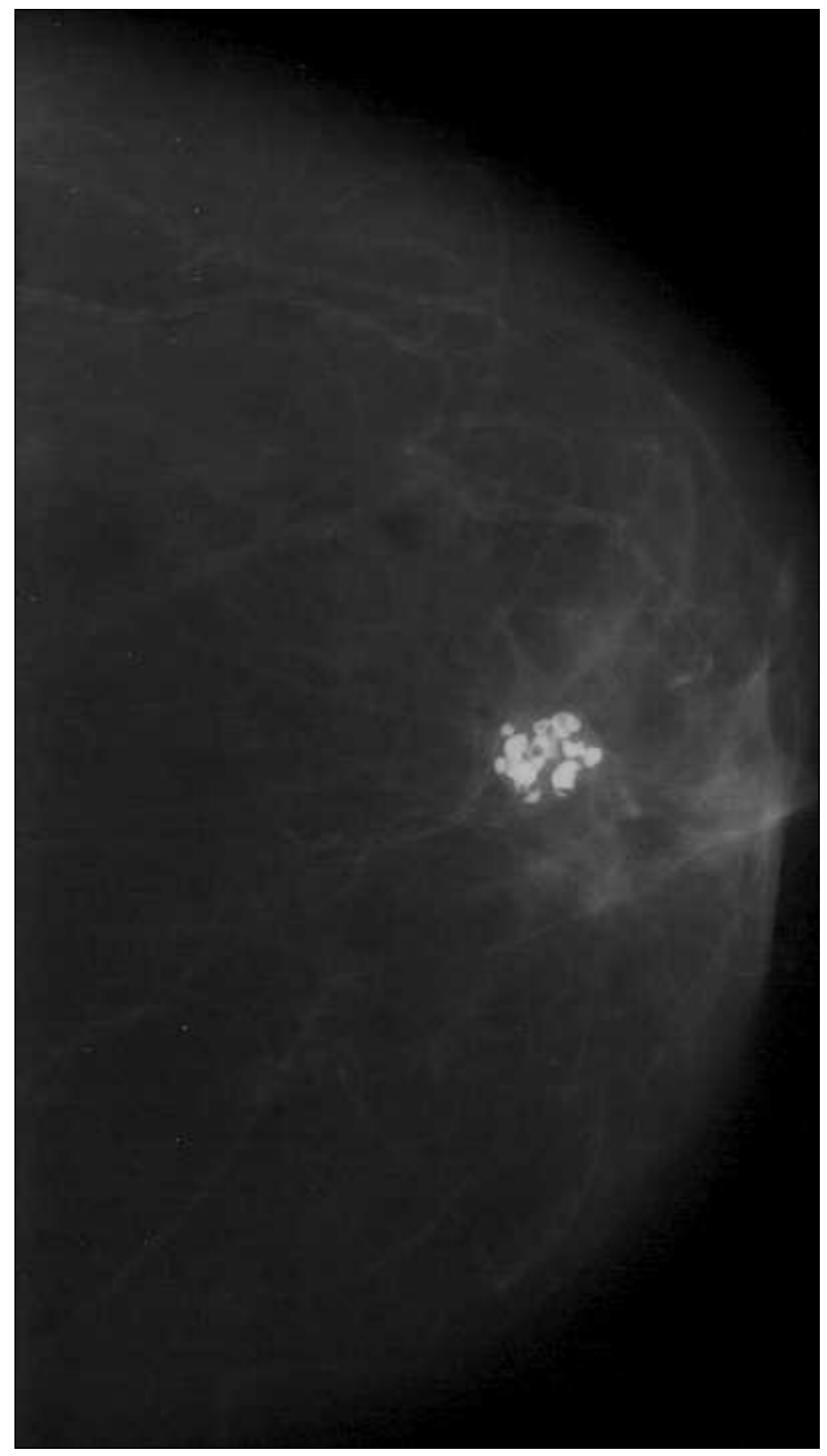

Figura 7-12 (b)

Figura 7-12 - Exemplos de imagem de mamograma com variação na distribuição de intensidade. 

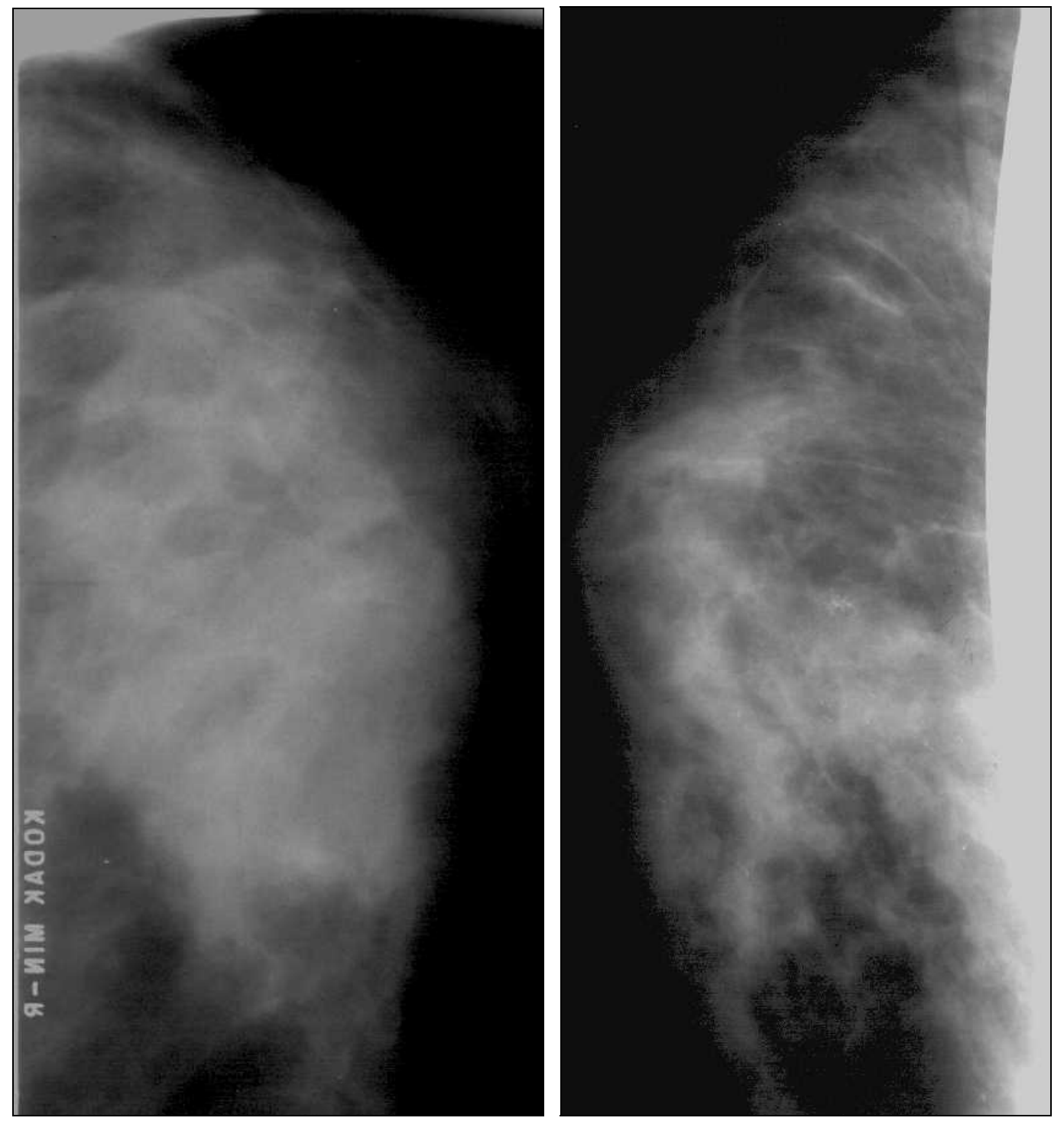

Figura 7-13 (a)

Figura 7-13 (b) 


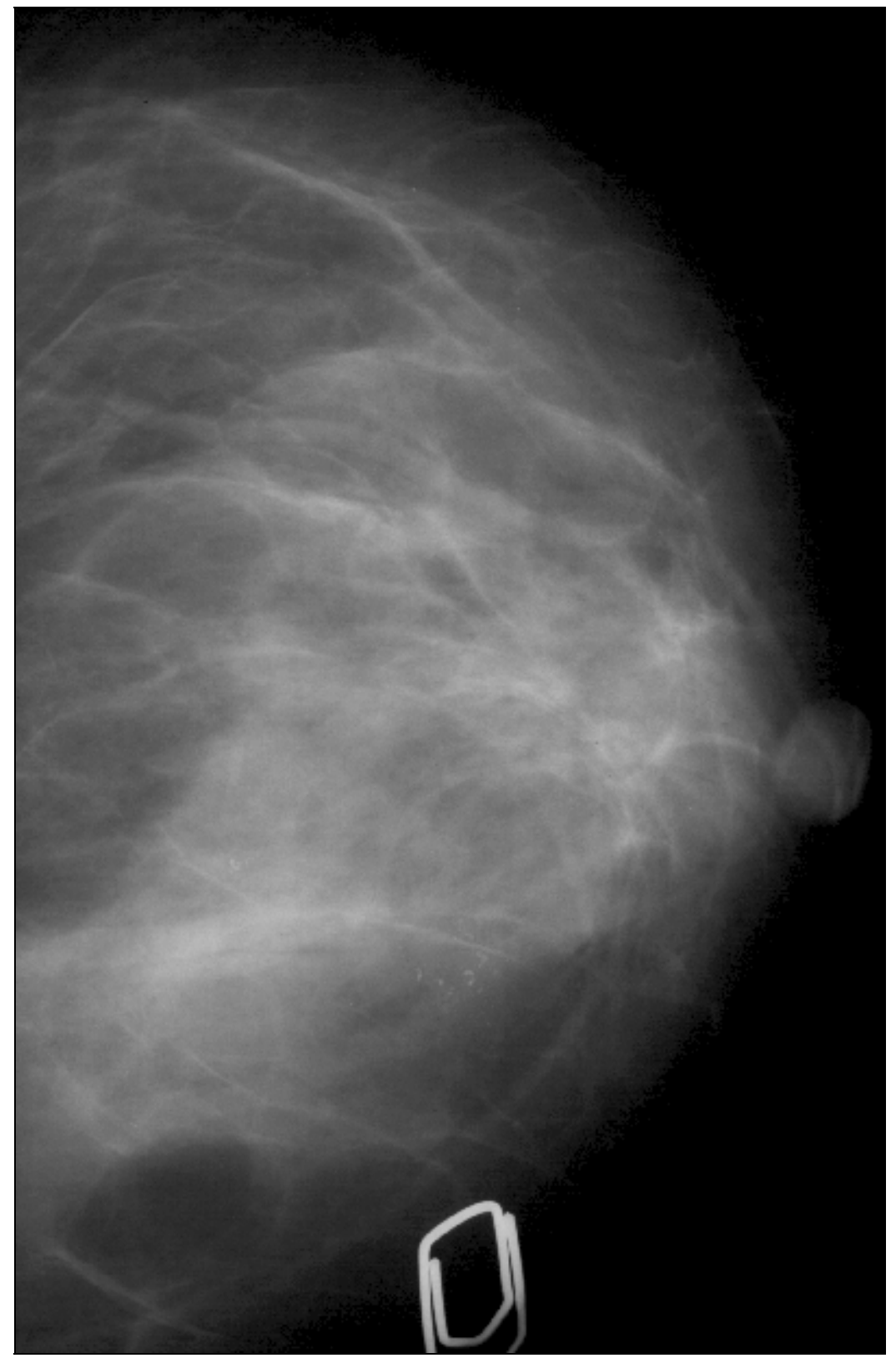

Figura 7-13 (c)

Figura 7-13 - Exemplos de imagens de mamogramas com objetos que atrapalham a identificação das regiões de interesse. a) identificação do filme na parte inferior esquerda; b) faixa branca na parte lateral direita; c) objeto na parte inferior.

- tempo de execução - observou-se que o tempo de processamento para a detecção de "clusters" aumenta consideravelmente com o aumento do tamanho das regiões de interesse, sendo que o processo de segmentação é o que mais contribui para este fato. Para diminuir este problema, procuramos trabalhar com as menores regiões de interesse possíveis. No gráfico da figura 7-14 podemos visualizar a relação entre o tempo de processamento e algumas dimensões de regiões de 
interesse analisadas. É possível observar o aumento não linear do tempo de processamento à medida que aumenta o número de linhas e colunas da imagem. As regiões submetidas ao teste procuraram englobar o mesmo trecho da imagem original, para que as características da imagem não exercessem influência no tempo de processamento. Na figura 7-15 até a figura 7-18 são mostradas as regiões de interesse utilizadas no teste e o correspondente resultado, assim como os tempos envolvidos em cada fase do processamento. Ainda para efeito de verificação de tempo de processamento, testes foram realizados processando-se imagens inteiras e comparando-se o tempo dispendido com o processamento de regiões de interesse da imagem. Em alguns casos, o tempo gasto para o processamento de toda a imagem chega a ser 6 ou mais vezes maior que o tempo total gasto para o processamento de regiões de interesse.

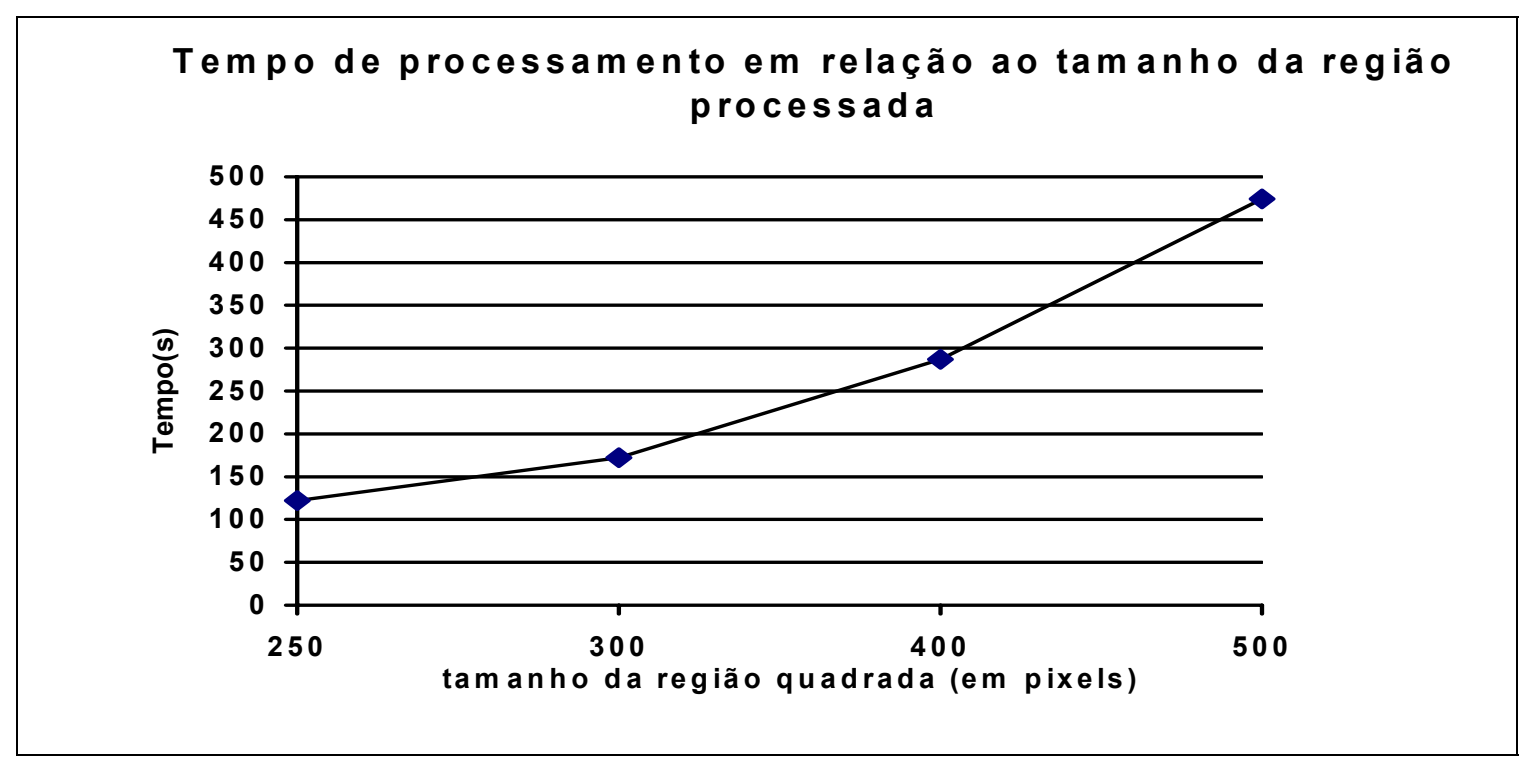

Figura 7-14 - Relação entre tamanho da região de interesse e tempo de processamento para deteç̧ão de "clusters".

- transformação área-ponto - o problema da transformação de um sinal em mais de um pixel continuou existindo durante os testes com mamogramas reais, mas em grau bem menor que aquele percebido no processamento de "phantoms", ao menos para as imagens utilizadas. Como já foi comentado, as formas e tamanhos das estruturas reais, fazem com que o algoritmo de transformação áreaponto funcione de forma mais efetiva para imagens de mamogramas. Exemplos da 
transformação área-ponto em um mamograma são mostrados na figura 7-19, onde é possível perceber que o algoritmo é eficiente para microcalcificação real, transformando-a em um único ponto.
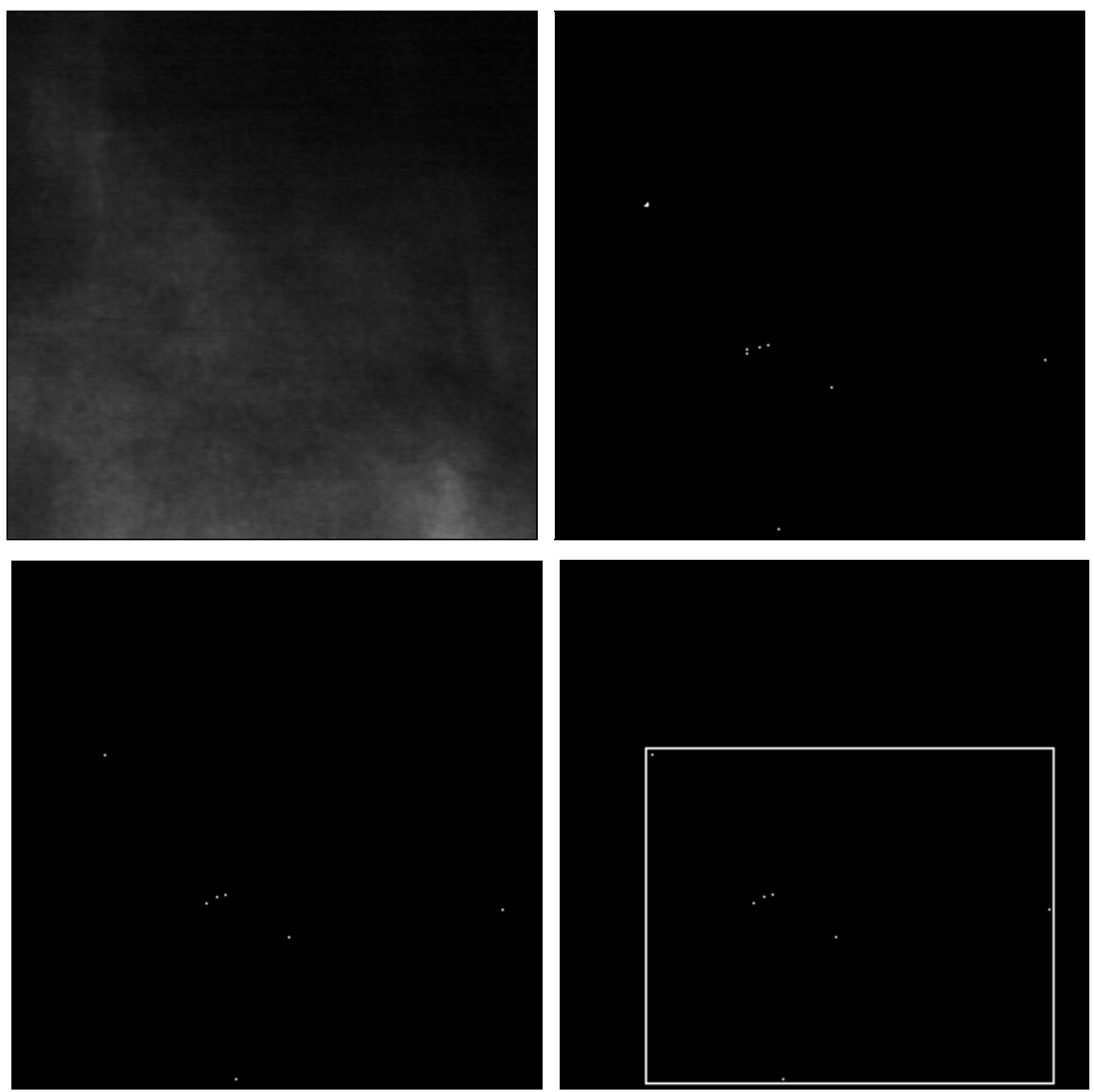

Figura 7-15 - Processamento de regiões de interesse com tamanhos diferentes e tempos de execução computacional dispendidos. Imagem com tamanho $250 \times 250$ - tempo de processamento: 122. 


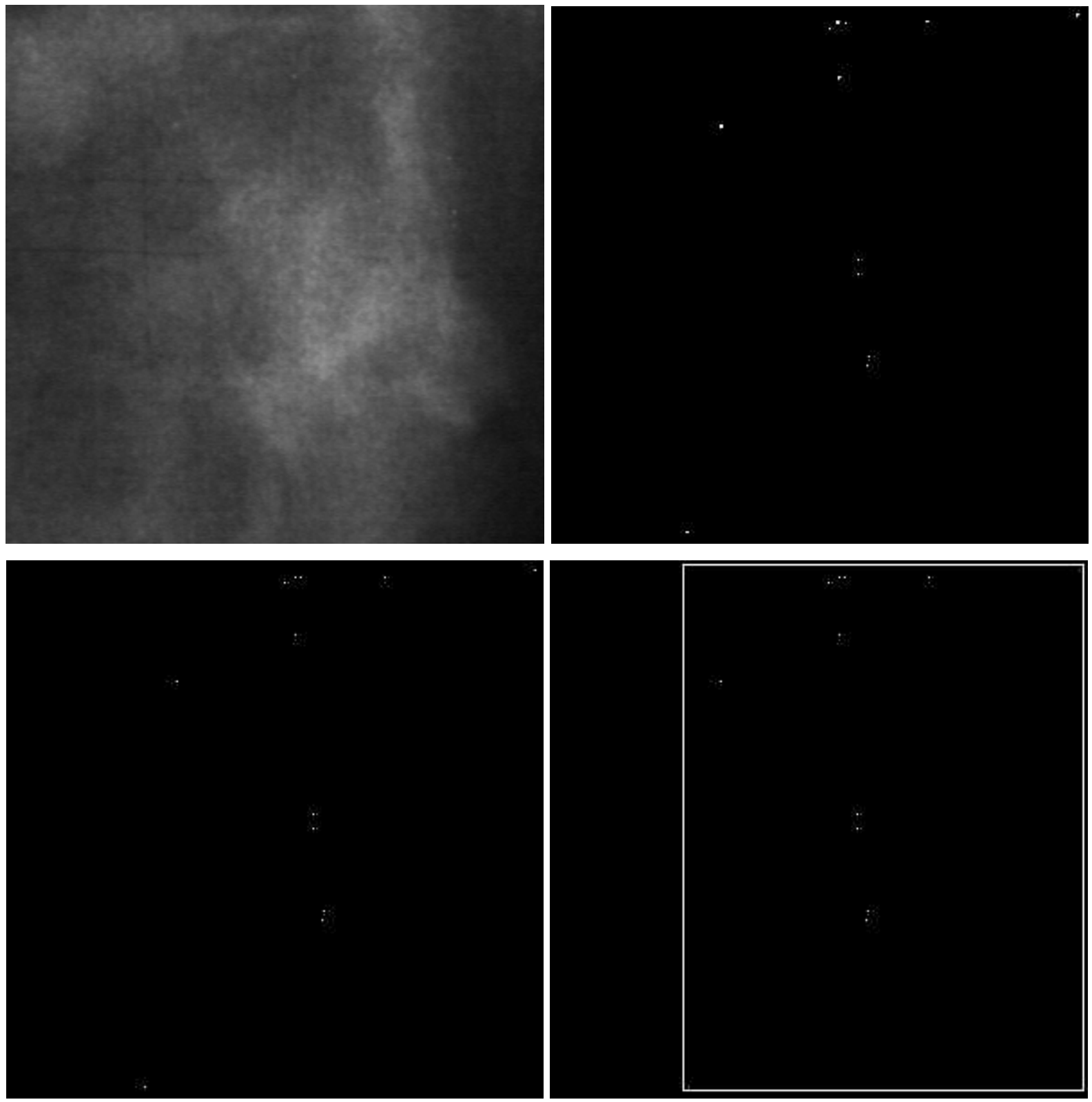

Figura 7-16 - Processamento de regióes de interesse com tamanhos diferentes e tempos de execução computacional dispendidos. Imagem com tamanho 300x300 - tempo de processamento: 172. 


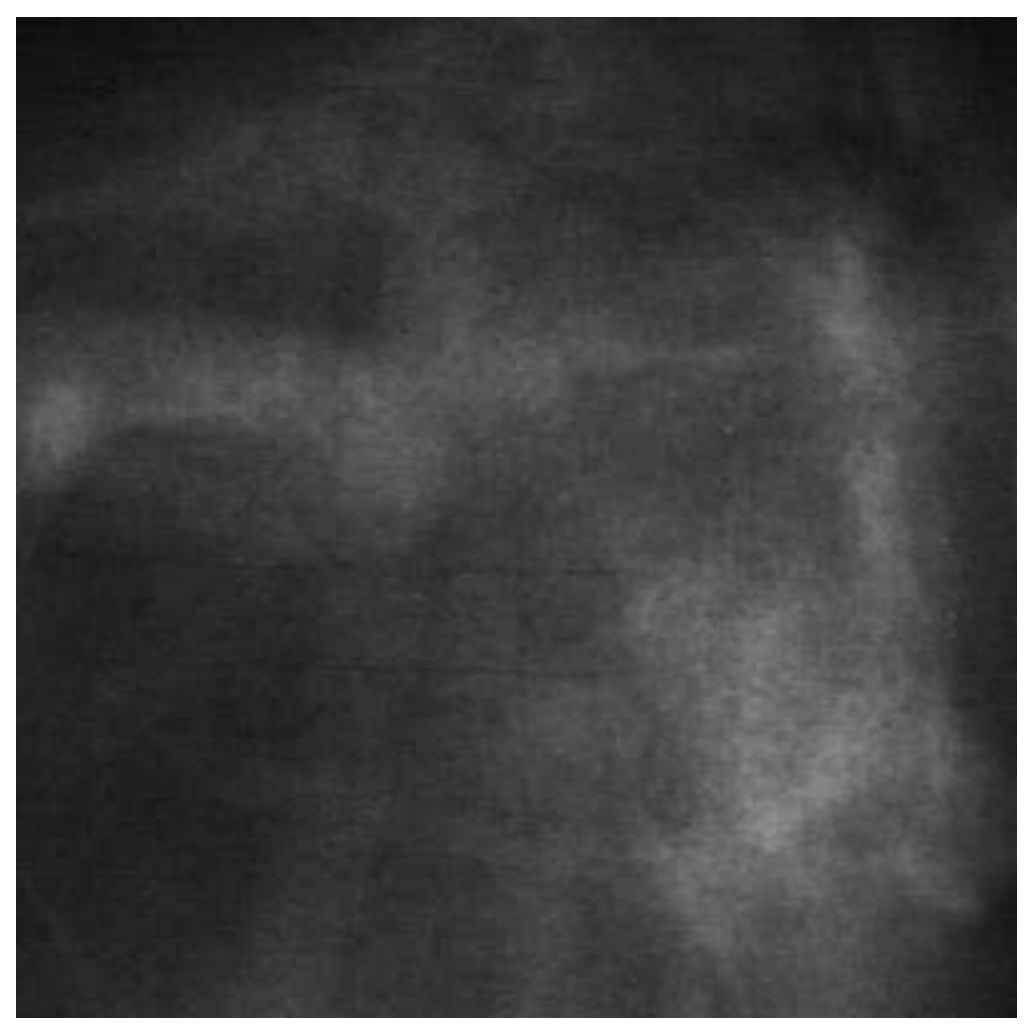

Figura 7-17 (a)

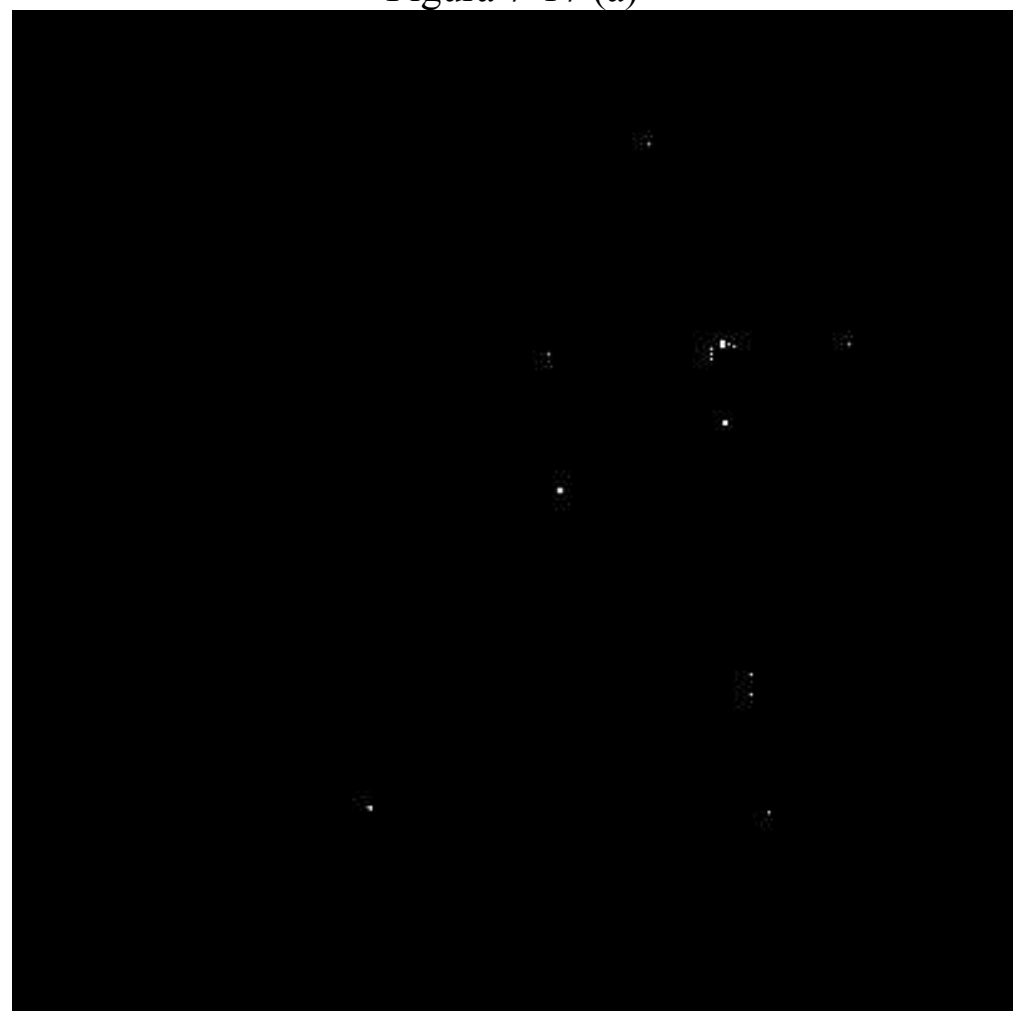

Figura 7-17 (b) 


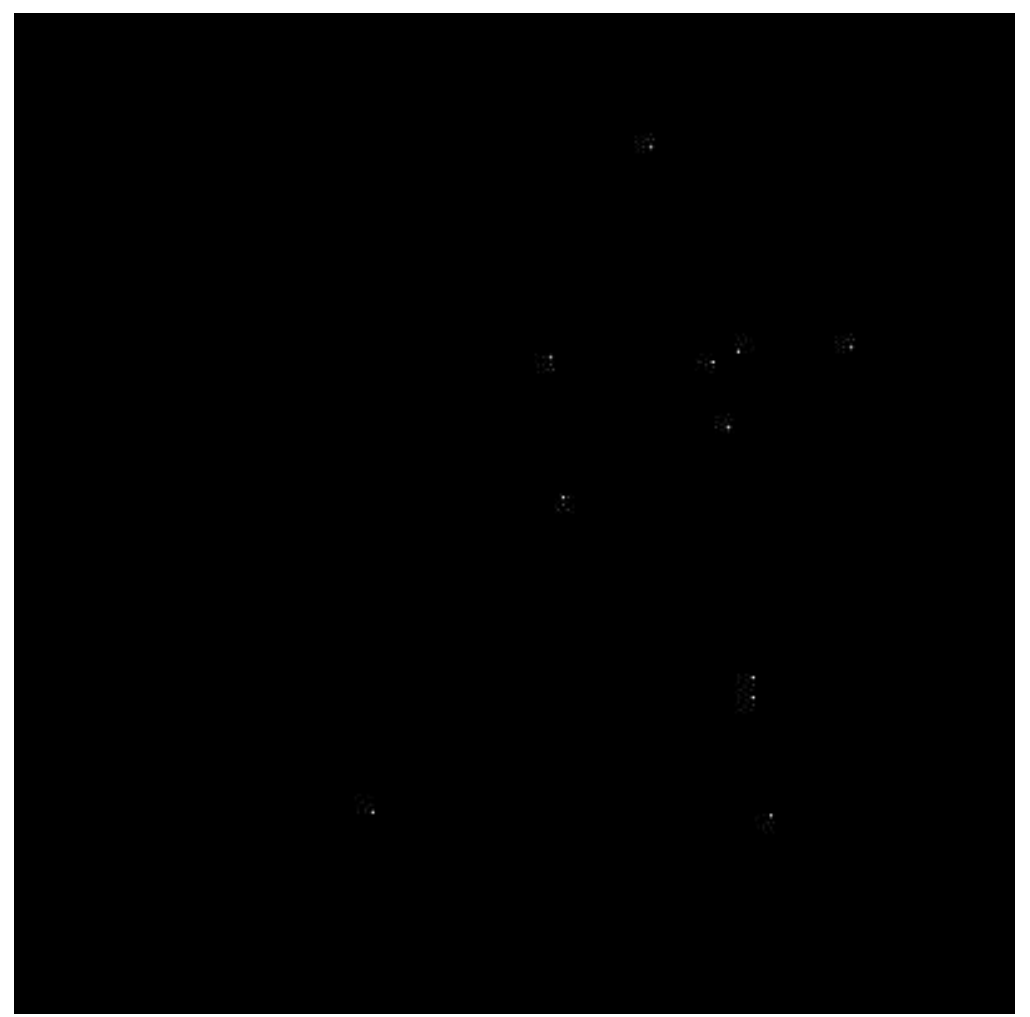

Figura 7-17 (c)

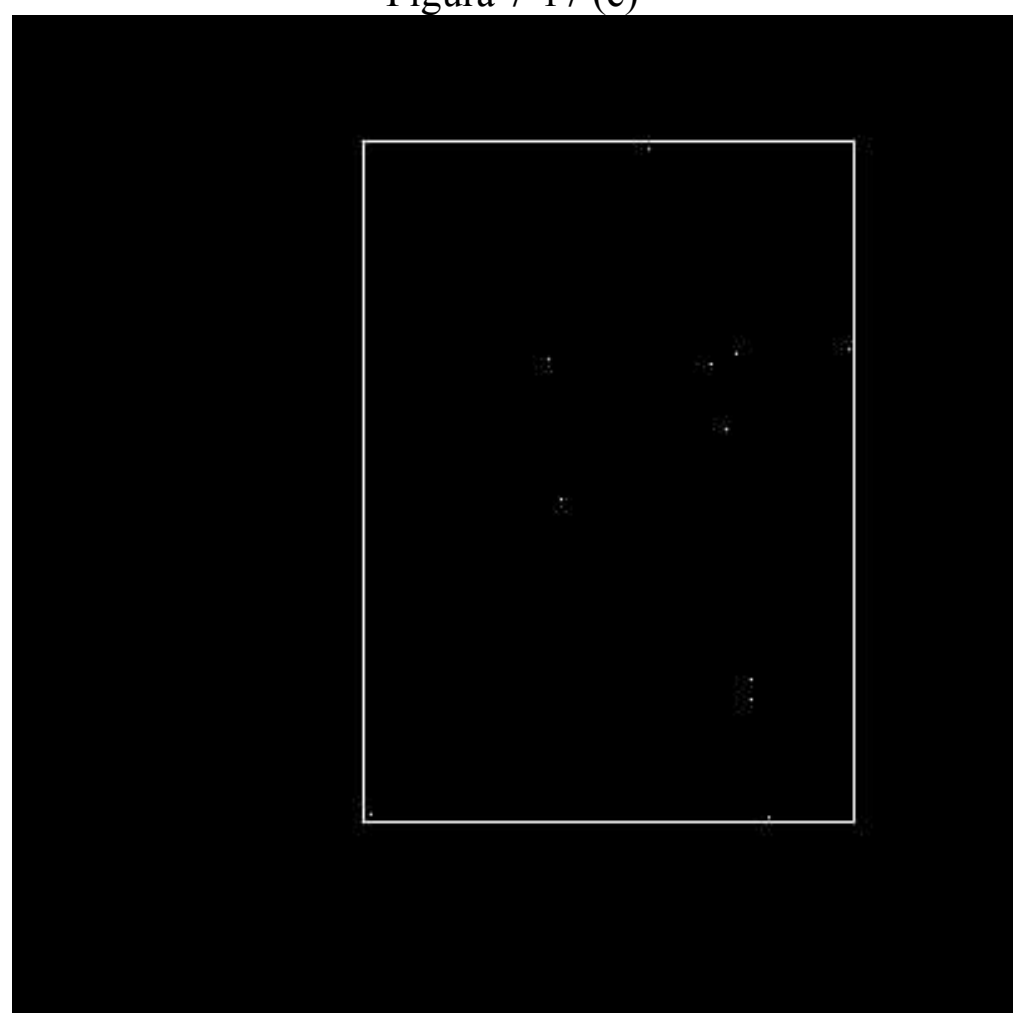

Figura 7-17 (d)

Figura 7-17 - Processamento de regiões de interesse com tamanhos diferentes e tempos de execução computacional dispendidos. c) imagem com tamanho 450x450 - tempo de processamento: 287 . 


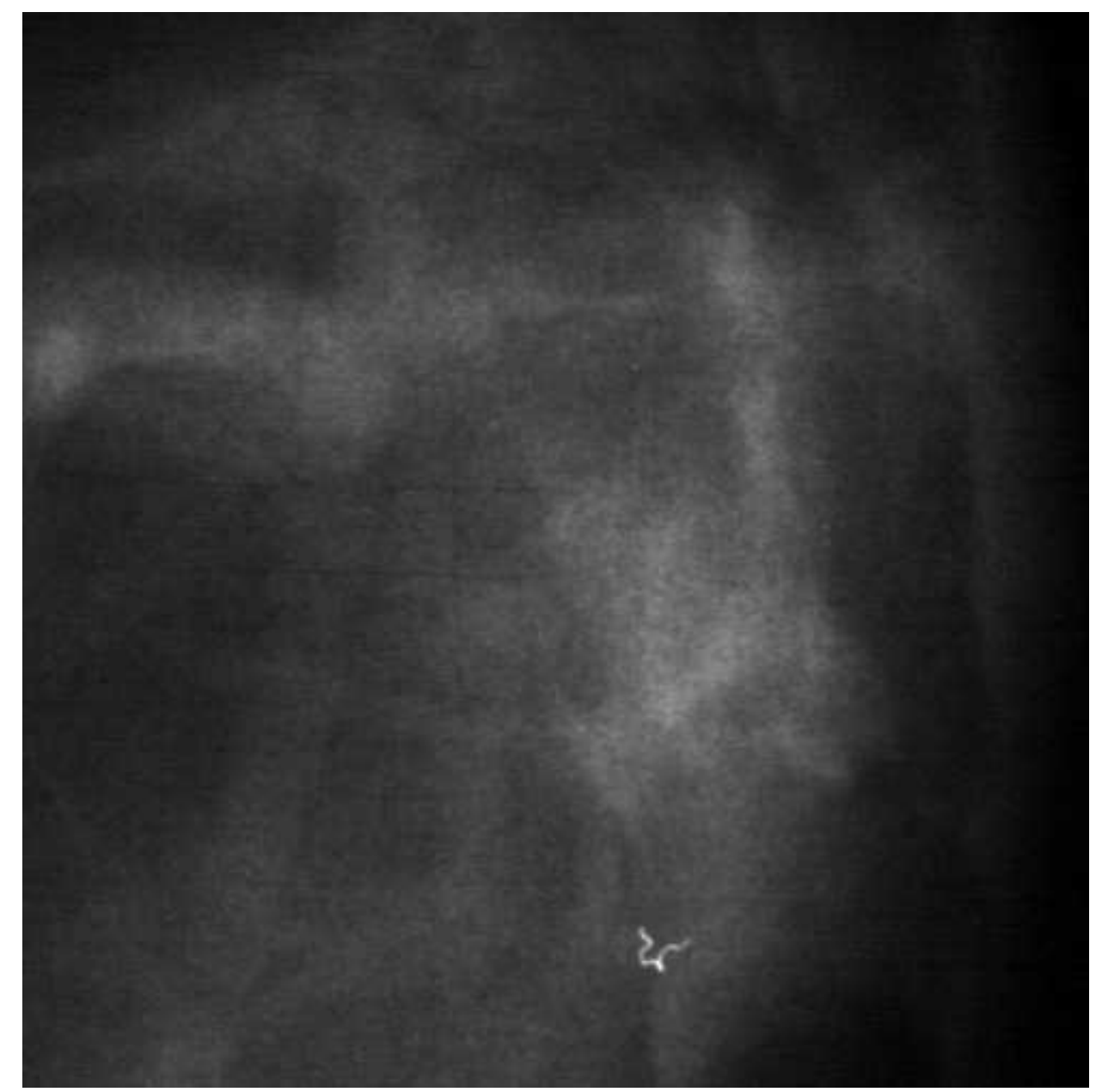

Figura 7-18 (a) 


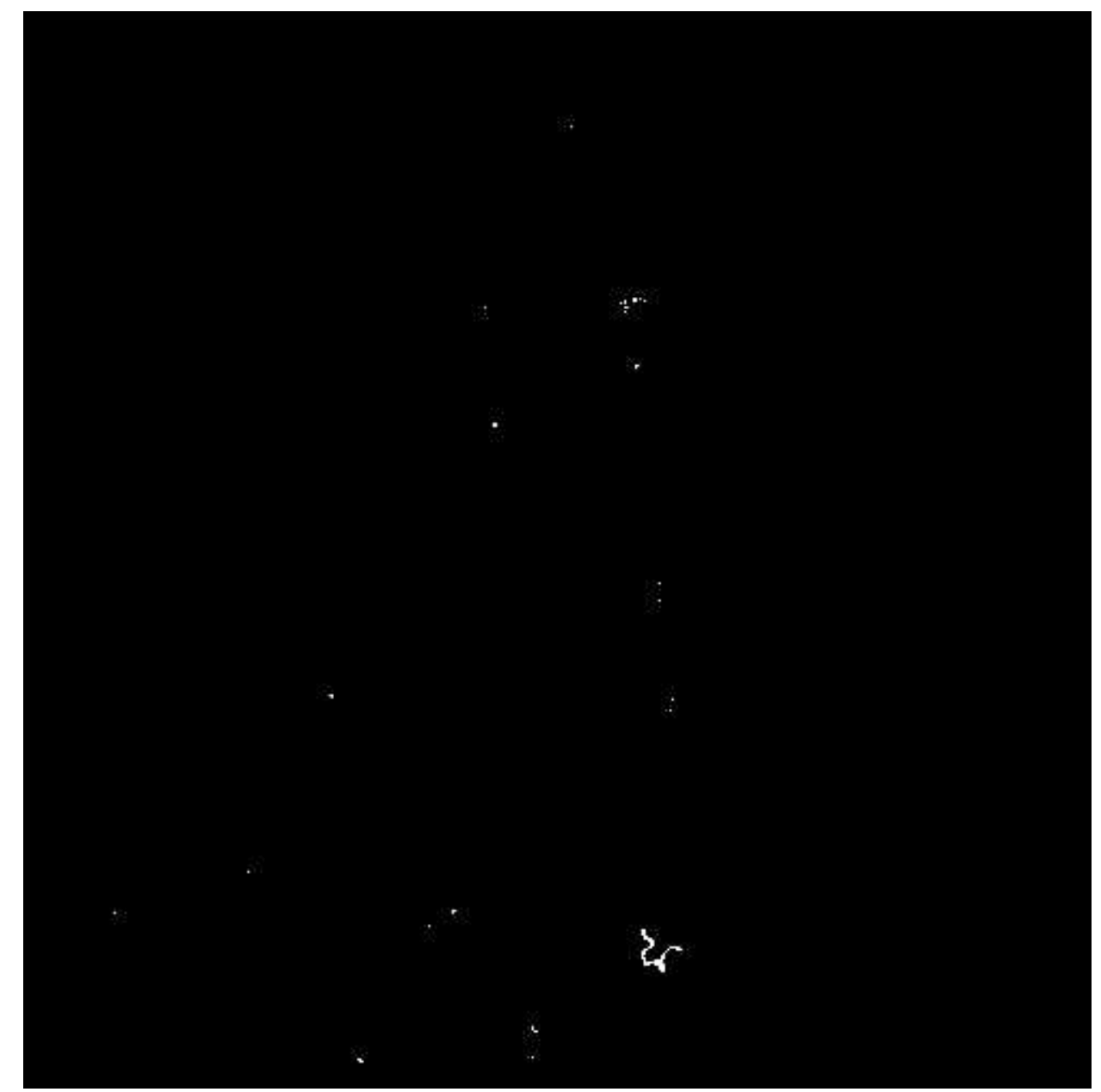

Figura 7-18 (b) 


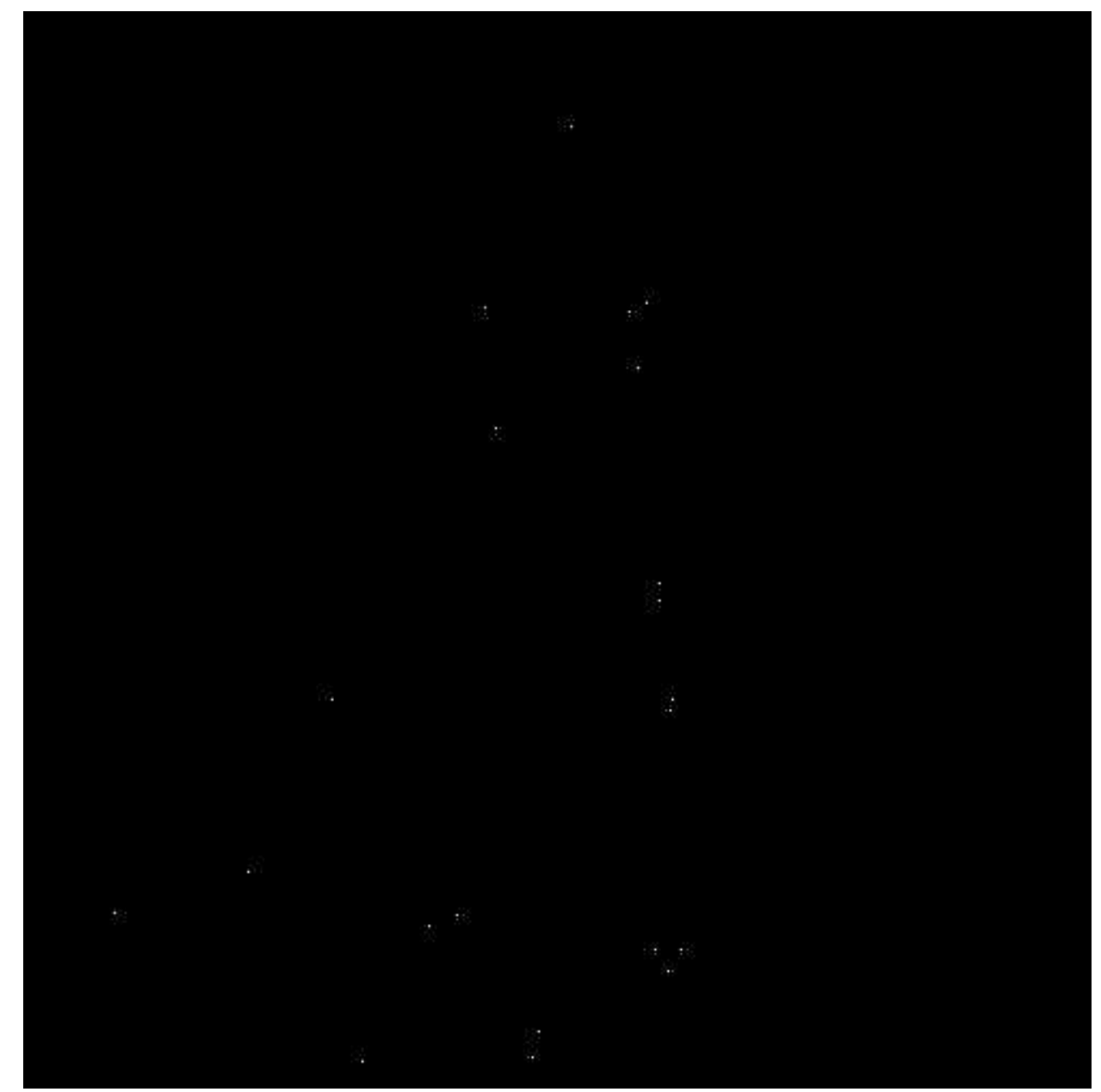

Figura 7-18 (c) 


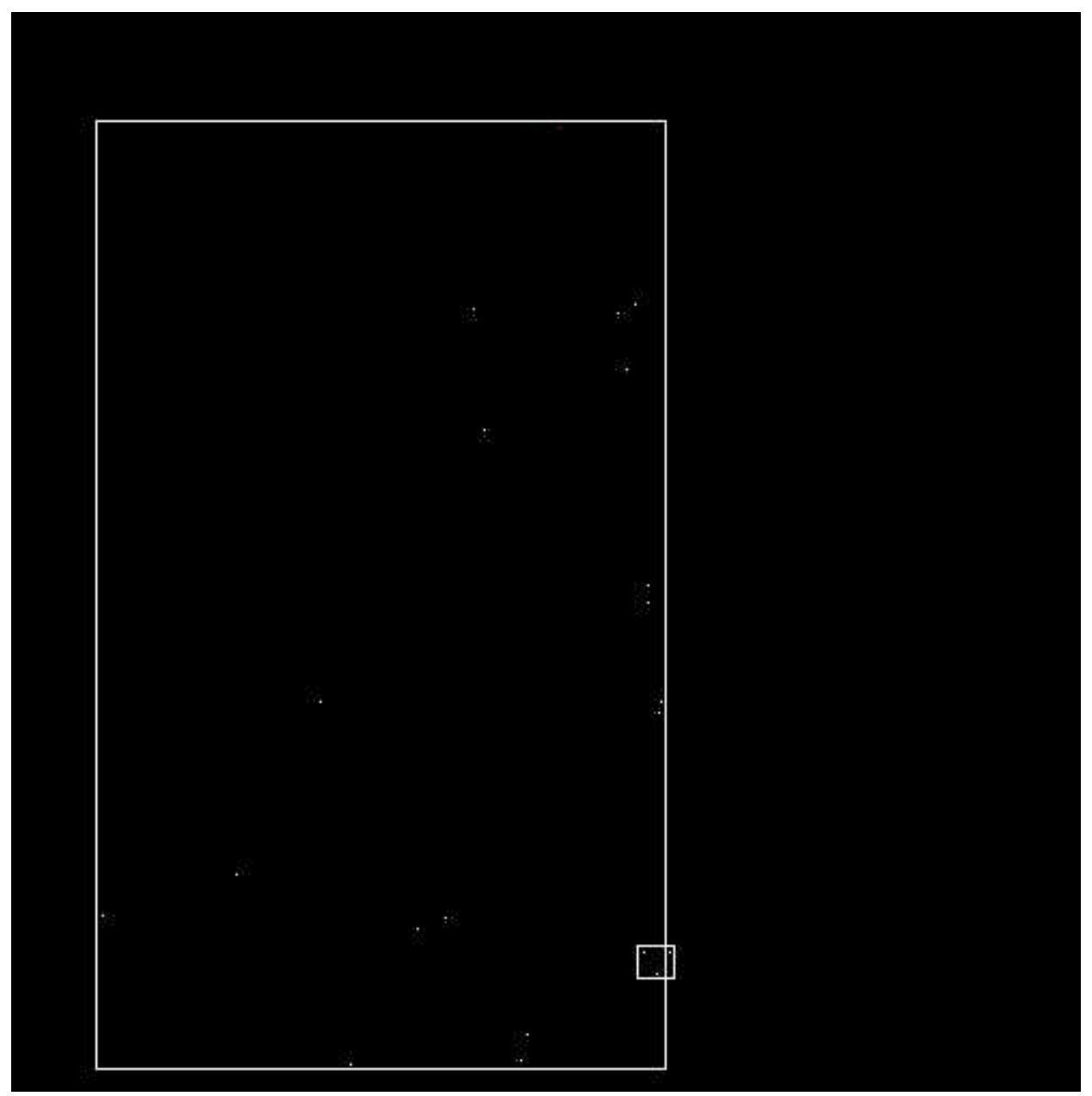

Figura 7-18 (d)

Figura 7-18 - Processamento de regiões de interesse com tamanhos diferentes e tempos de execução computacional dispendidos. Imagem com tamanho 500x500 - tempo de processamento: 474 .

Além dos procedimentos executados durante o teste com "phantoms", foi implementado o método de detecção de "clusters" através de crescimento de região, técnica de processamento muito citada na literatura. Na tabela 7-5 são mostrados os resultados da identificação de "clusters" através desse método, para as imagens reais.

Considerando-se o total de diagnósticos do mamograma como um todo, percebemos que a performance dos dois métodos de identificação de "clusters" foi idêntica. No entanto, o algoritmo de "crescimento de região" apresentou uma tendência maior em dividir um "cluster" em dois ou mais, dependendo do posicionamento dos sinais. Em conseqüência disso, em algumas regiões de interesse houve a detecção de dois "clusters" através do método de "crescimento de região", 
enquanto o método de "mascaramento" detectou apenas uma aglomeração. Na figura 7-20 apresentamos a quantidade de "clusters" detectados por imagem nos dois métodos, utilizando-se o valor de desvio-padrão 3 na segmentação. É possível observar o aumento da quantidade de agrupamentos detectados em algumas imagens.

Tabela 7-5 - Resultado do processamento de imagens de mamogramas através do método de "crescimento de região".

\begin{tabular}{|c|c|c|c|c|c|c|c|c|c|}
\hline \multirow[t]{2}{*}{$\begin{array}{c}\text { Desvio- } \\
\text { padrão da } \\
\text { segmentação }\end{array}$} & \multirow[t]{2}{*}{$\begin{array}{c}\text { Total de } \\
\text { imagens } \\
\text { processadas }\end{array}$} & \multicolumn{2}{|c|}{$\begin{array}{c}\text { Total de } \\
\text { diagnósticos } \\
\text { verdadeiro- } \\
\text { positivos }\end{array}$} & \multicolumn{2}{|c|}{$\begin{array}{c}\text { Total de } \\
\text { diagnósticos } \\
\text { falso- } \\
\text { positivos }\end{array}$} & \multicolumn{2}{|c|}{$\begin{array}{c}\text { Total de } \\
\text { diagnósticos } \\
\text { verdadeiro- } \\
\text { negativos }\end{array}$} & \multicolumn{2}{|c|}{$\begin{array}{c}\text { Total de } \\
\text { diagnósticos } \\
\text { falso- } \\
\text { negativos }\end{array}$} \\
\hline & & Quant. & $\%$ & Quant. & $\%$ & Quant. & $\%$ & Quant. & $\%$ \\
\hline 3,0 & 16 & 15 & $94 \%$ & 1 & $6 \%$ & 0 & $0 \%$ & 0 & $0 \%$ \\
\hline 3,5 & 16 & 11 & $69 \%$ & 1 & $6 \%$ & 0 & $0 \%$ & 4 & $25 \%$ \\
\hline
\end{tabular}

Na figura 7-21 até a figura 7-38 são apresentados alguns mamogramas e a detecção de "clusters" pelos dois métodos nas respectivas regiões de interesse. O primeiro exemplo corresponde às Figuras 7-21 a 7-26; o segundo exemplo é mostrado nas Figuras 7-27 a 7-32 e o terceiro exemplo é apresentado nas Figuras 733 a 7-38. O método de "mascaramento" realiza a identificação de agrupamentos verificando se em uma determinada área está presente uma quantidade mínima de sinais. A máscara utilizada percorre a imagem horizontalmente e, ao chegar no final de cada trecho de linhas, executa um salto verticalmente, reiniciando a verificação em um novo trecho de linhas. A cada posicionamento da máscara, os sinais detectados são eliminados da imagem para que não sejam contabilizados repetidamente. Estes procedimentos explicam a tendência desse método em detectar, de uma só vez, o "cluster": como o tamanho das regiões de interesse (250 linhas X 250 colunas) é próximo ao tamanho das áreas verificadas (236 linhas x 236 colunas), geralmente o "cluster" é detectado na primeira iteração; como todos os sinais identificados como participantes do "cluster" são eliminados, pode acontecer que, devido ao tamanho da área, na próxima iteração não existam sinais suficientes para compor o "cluster". 

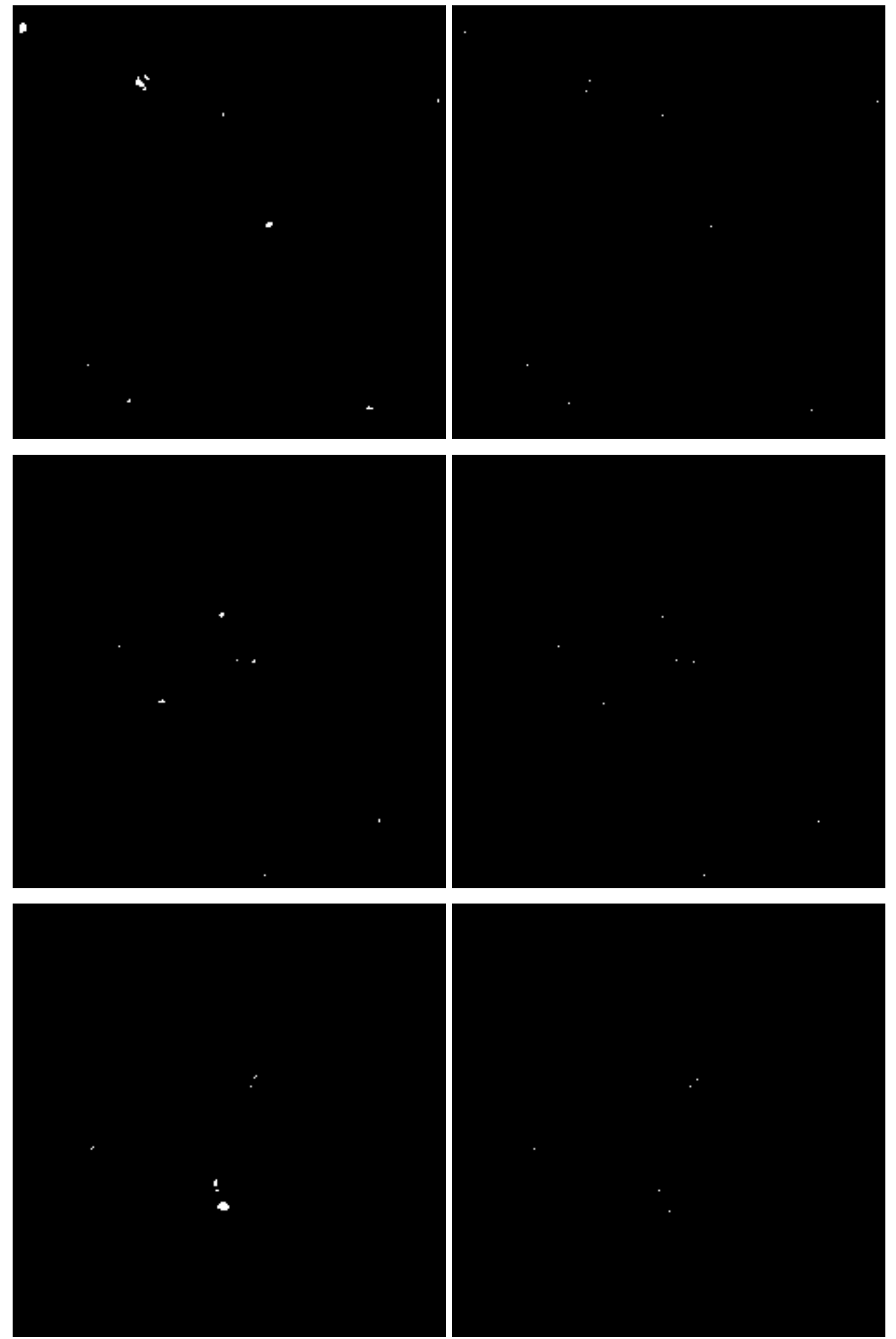

Figura 7-19 - Exemplos da transformação área-ponto em regiões de interesse de mamogramas. São mostradas imagens segmentadas e as mesmas imagens após a transformação área ponto. 


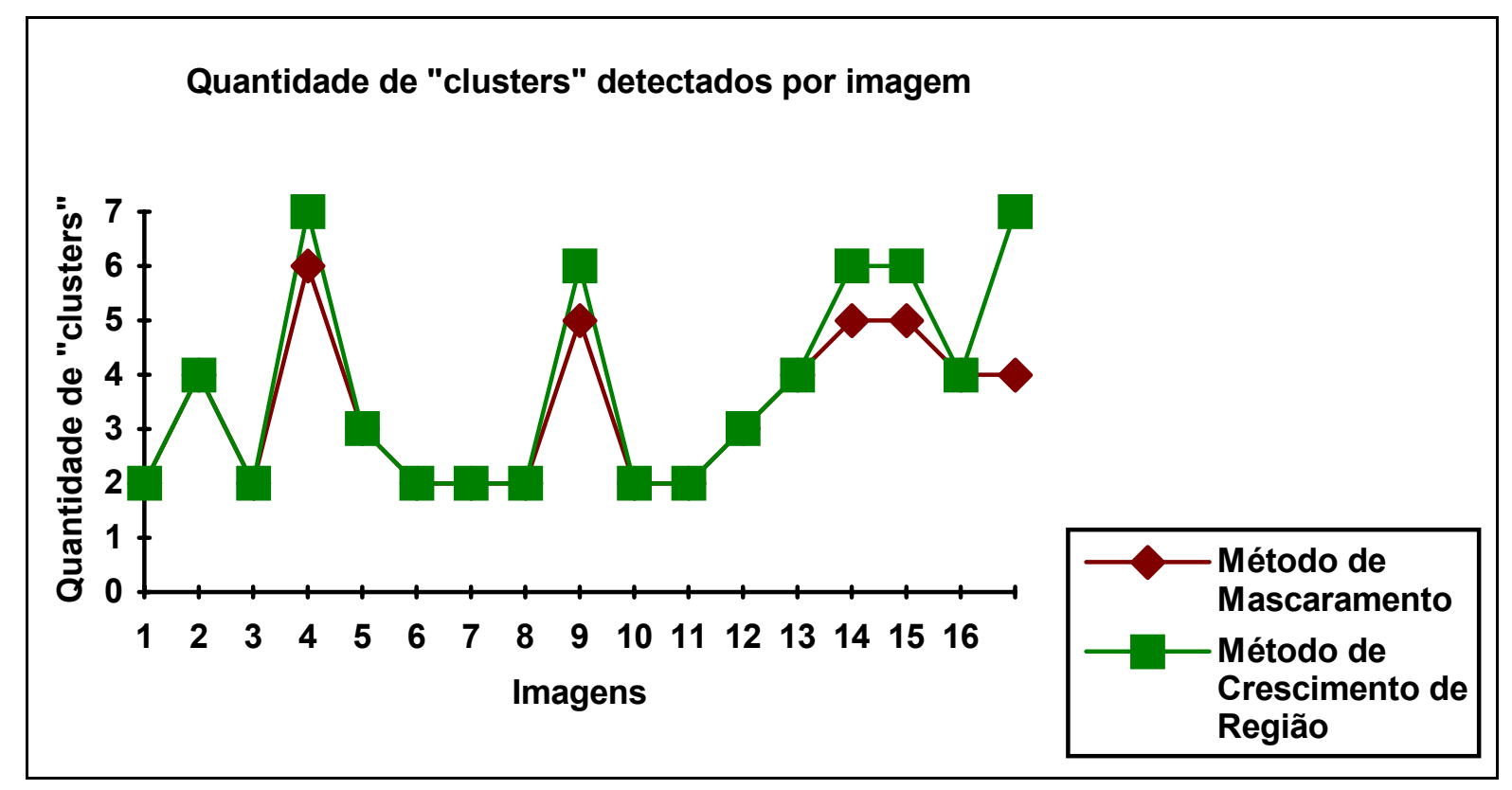

Figura 7-20 - Quantidade de "clusters" detectados pelos dois métodos utilizados.

O método de crescimento de região percorre a imagem fazendo verificações para cada sinal de forma individual. Para cada um dos pixels existentes, verifica quais sinais estão localizados a uma distância máxima dele, englobando-os como participantes do mesmo agrupamento. A implementação do programa estabeleceu a fórmula da distância "City Block" para essa verificação. Somente após a verificação da distância de todos os sinais a um determinado pixel e a eliminação dos pixels que atendem o critério de distância máxima, é que se parte para a próxima iteração, verificando-se o próximo sinal remanescente na imagem. Esse algoritmo faz com que sejam agrupados aqueles sinais mais próximos de um sinal considerado, no sentido diagonal. Os demais sinais são desprezados e poderão ser considerados como parte de outros "clusters" nas iterações posteriores. Com isso pode ocorrer de dois sinais estarem bem próximos, mas serem alocados em "clusters" diferentes, simplesmente pela ordem de execução do algoritmo.

A diferença na forma de agrupamento dos sinais é o que produz resultados diferentes na identificação de "clusters", fazendo com que eles variem de acordo com o posicionamento dos sinais. Na Figura 7-18 são observados casos cujos resultados do processamento são idênticos e outros onde os resultados são diferentes. Nessas imagens é possível observar em quais casos os métodos apresentaram diagnósticos diferentes. 


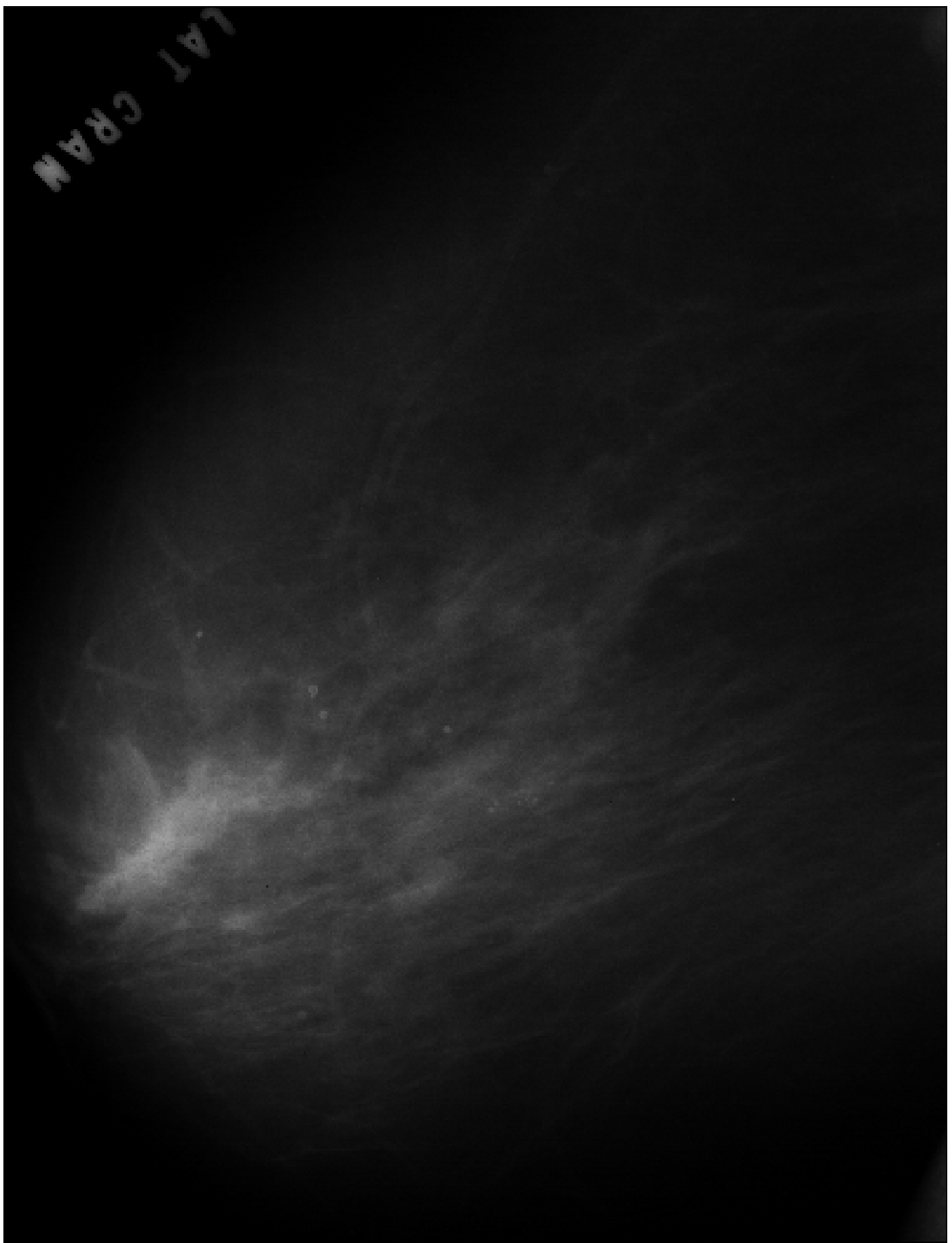

Figura 7-21 - Detecção de "clusters" em mamograma através dos dois métodos de agrupamento de sinais - mamograma original. 

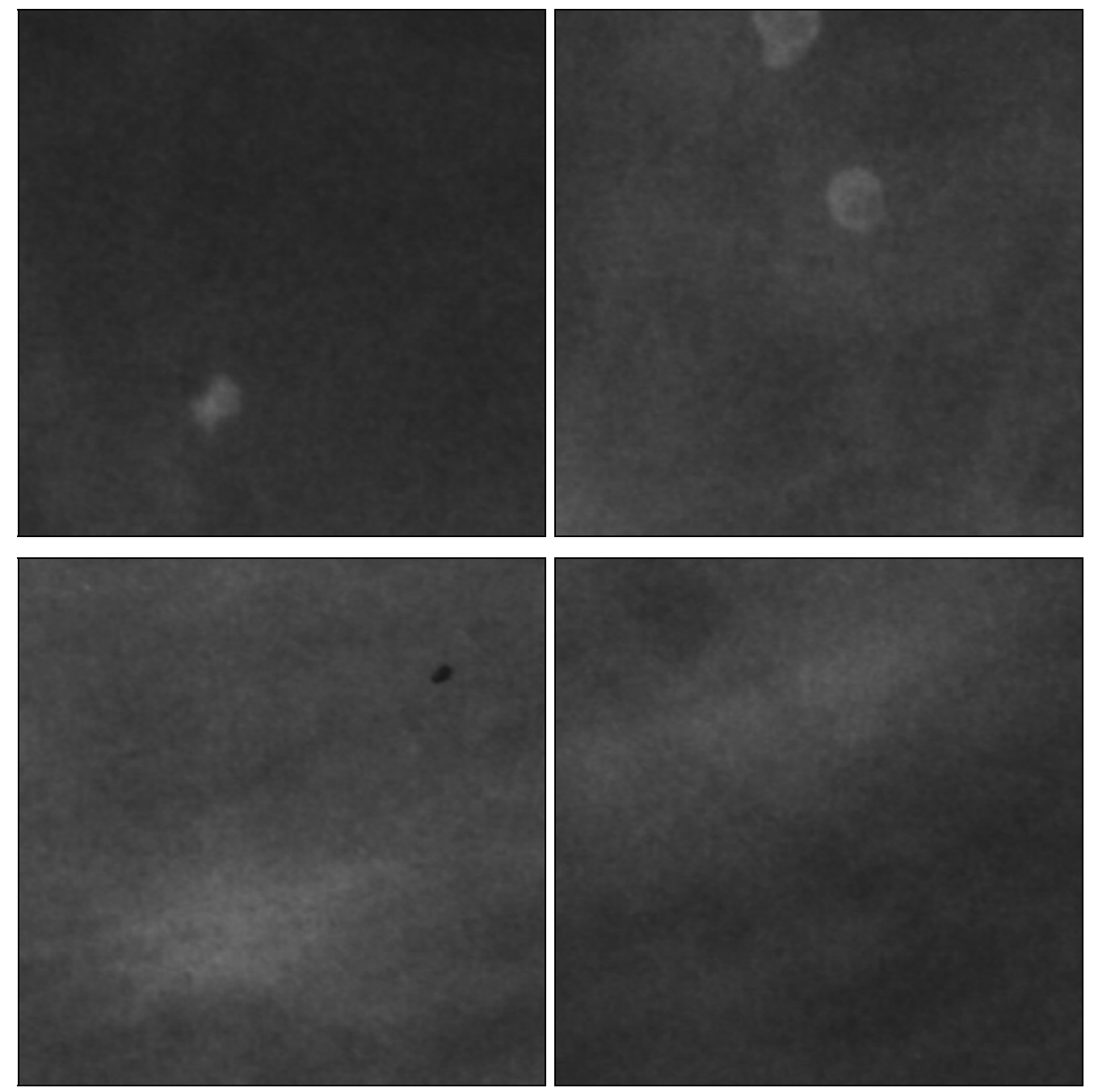

Figura 7-22 - Detecção de "clusters" em mamograma através dos dois métodos de agrupamento de sinais - regiões de interesse selecionadas. 

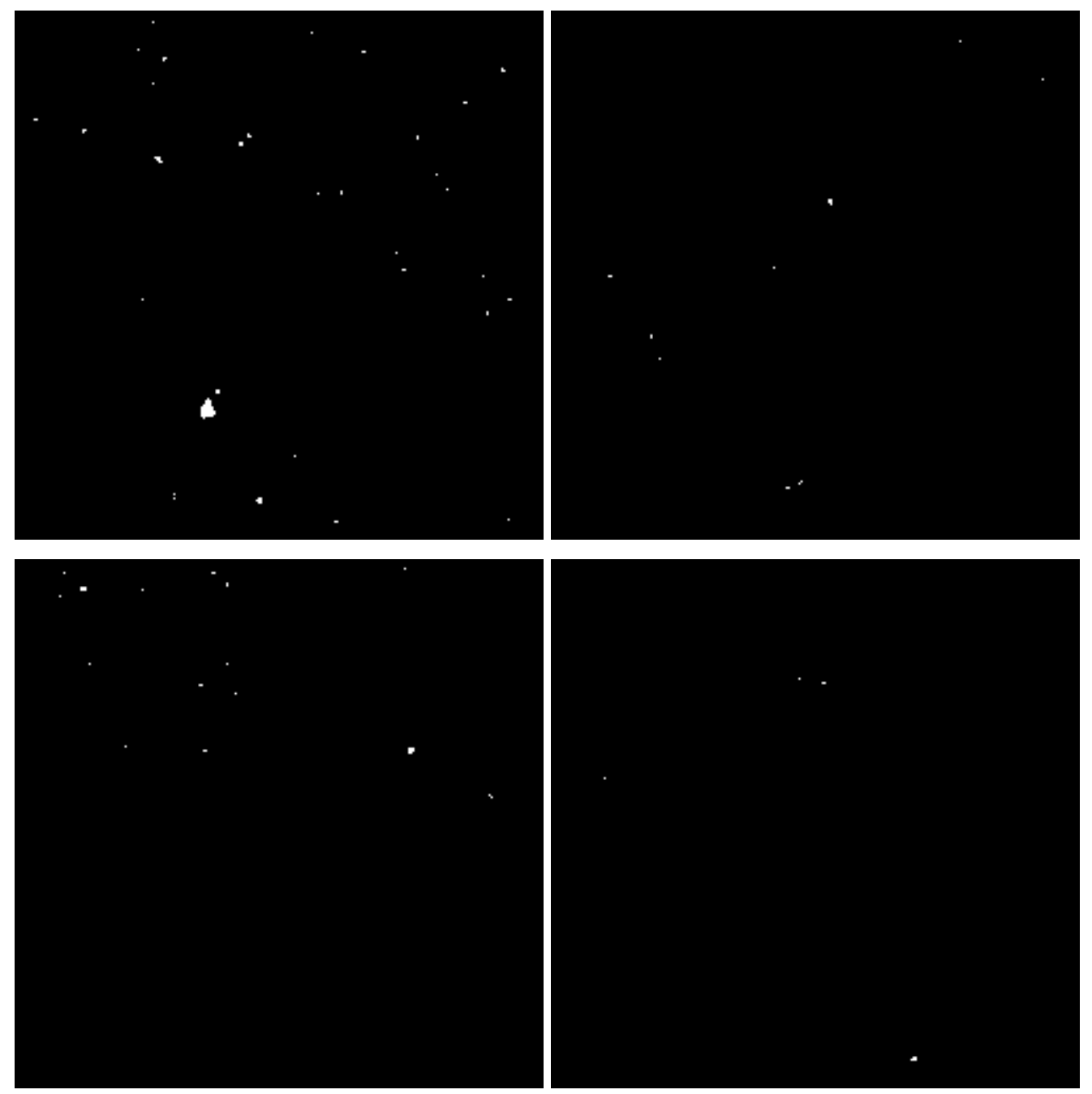

Figura 7-23 - Detecção de "clusters" em mamograma através dos dois métodos de agrupamento de sinais - regiões de interesse após segmentação. 


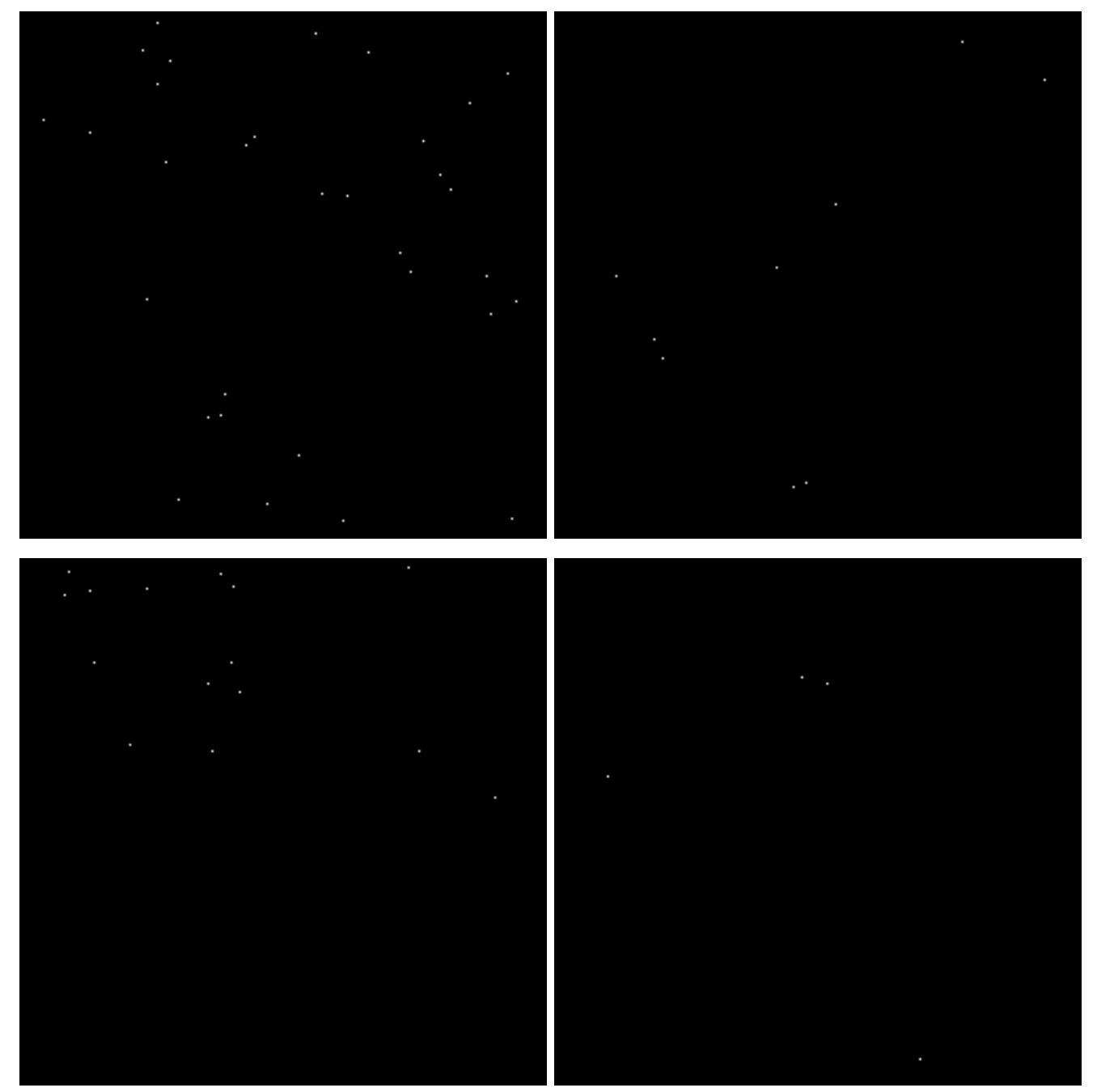

Figura 7-24 - Detecção de "clusters" em mamograma através dos dois métodos de agrupamento de sinais - regiões de interesse após transformação área-ponto. 

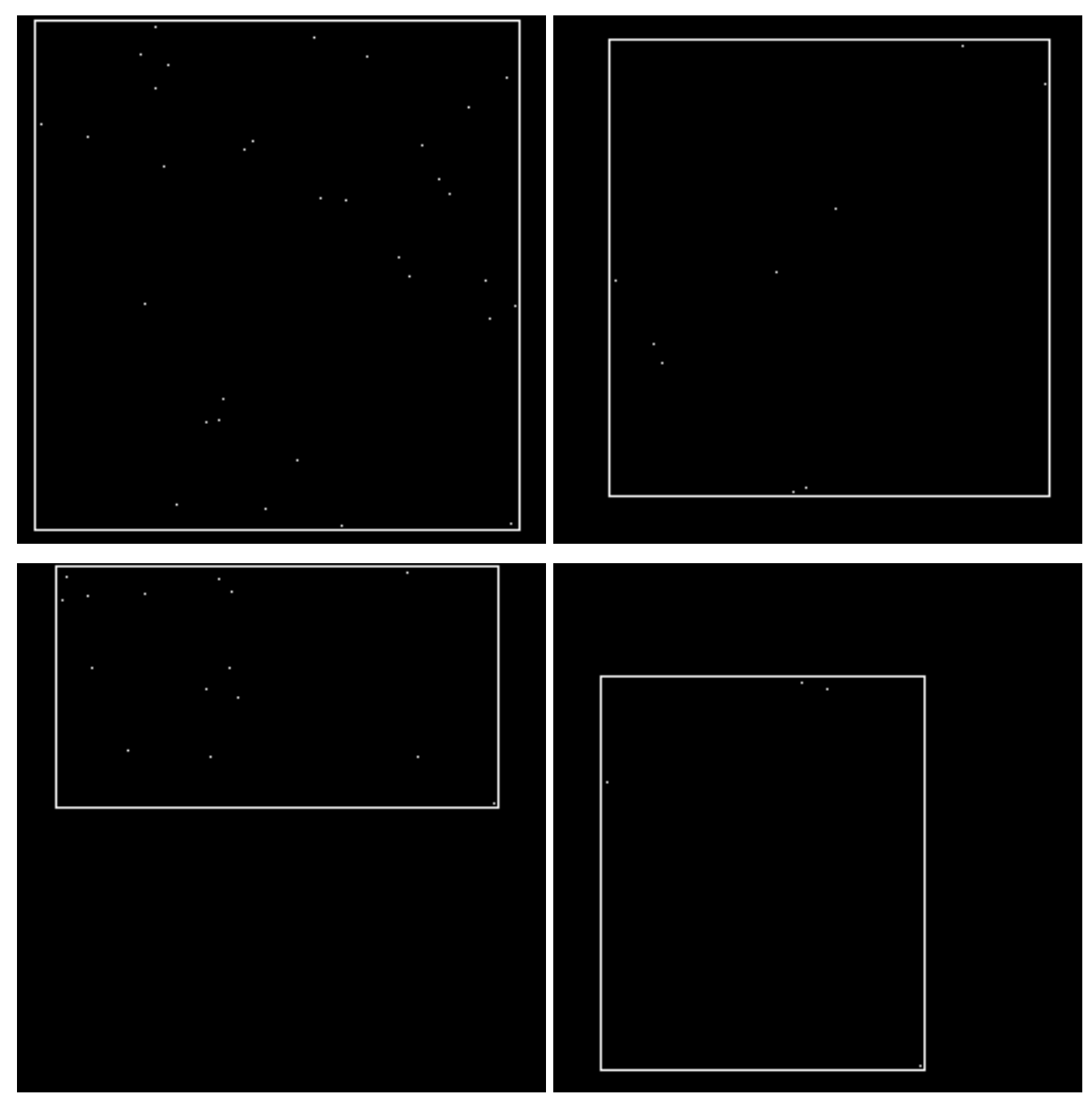

Figura 7-25 - Deteç̧ão de "clusters" em mamograma através dos dois métodos de agrupamento de sinais - regiões de interesse após detecção de "clusters" através do método de "mascaramento". 

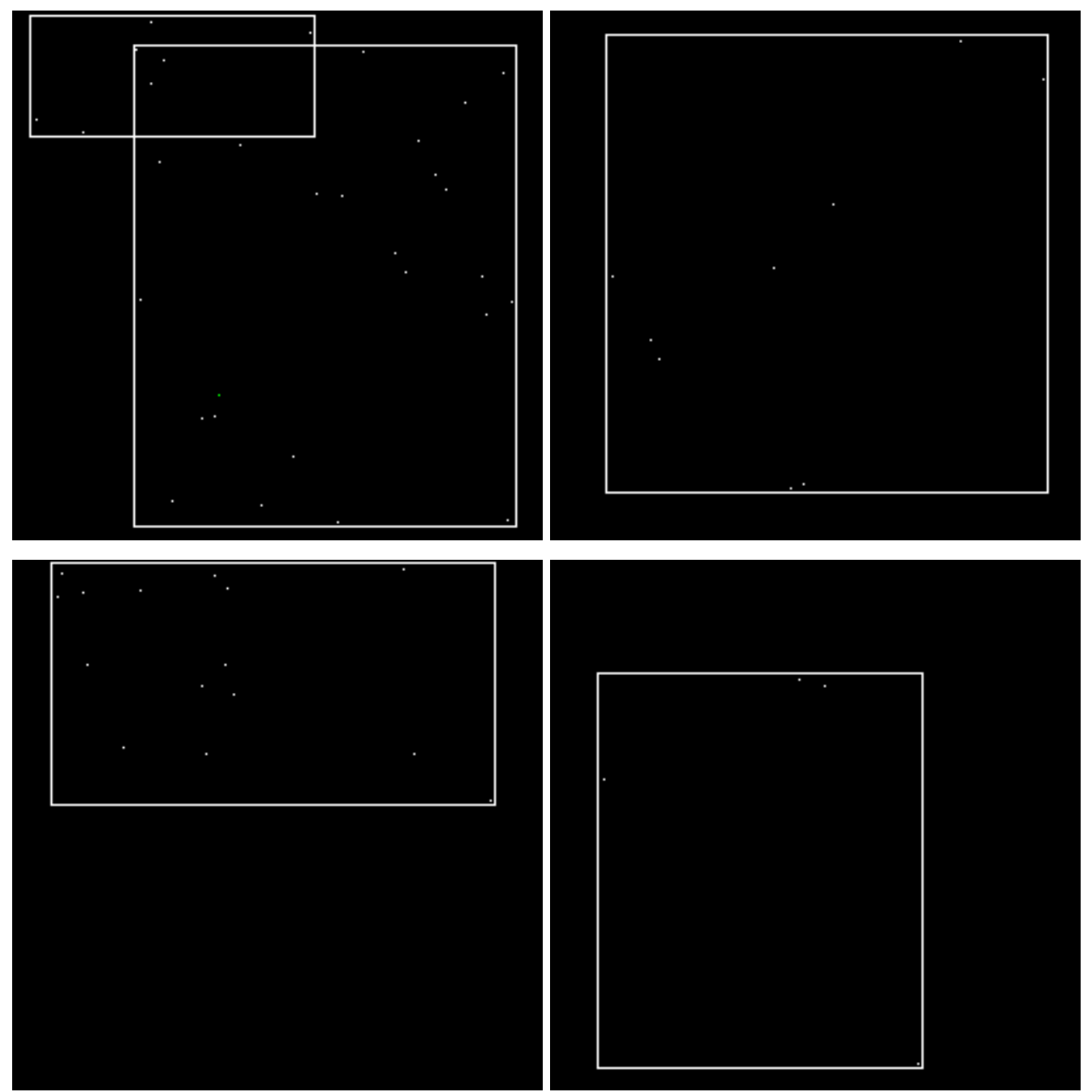

Figura 7-26 - Deteç̧ão de "clusters" em mamograma através dos dois métodos de agrupamento de sinais - regiões de interesse após detecção de "clusters" através do método de "crescimento de região". 


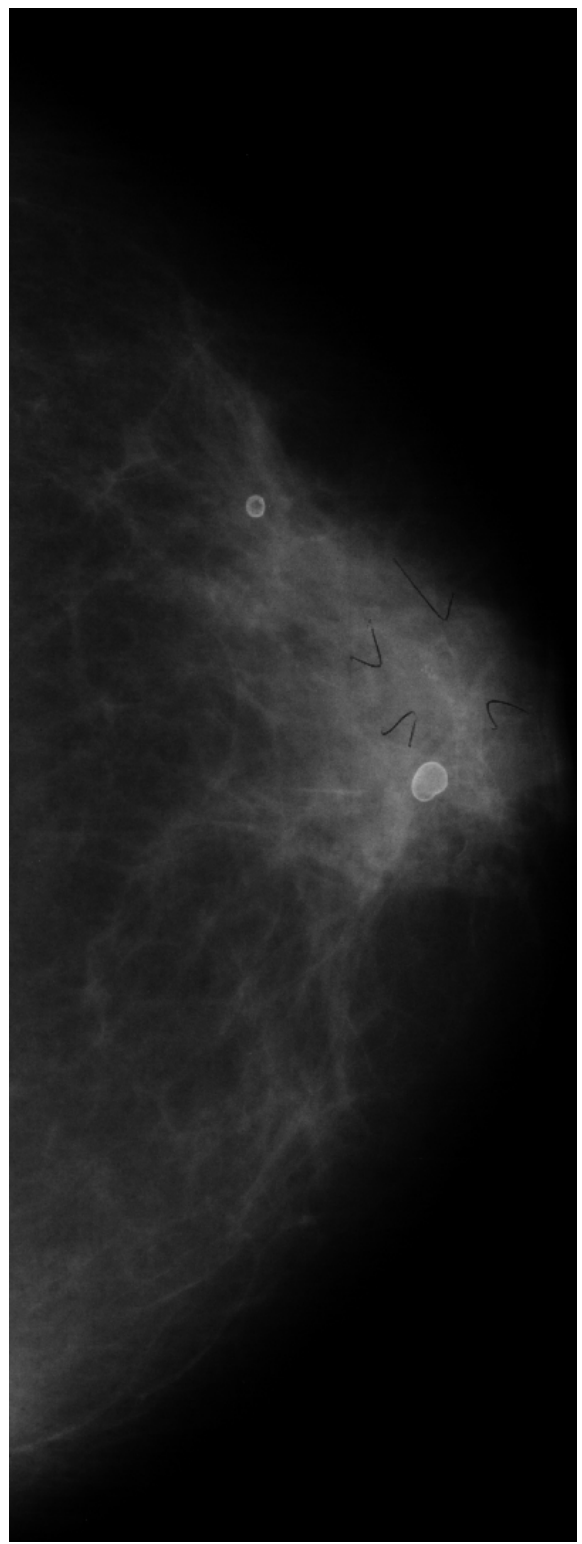

Figura 7-27 - Detecção de "clusters" em mamograma através dos dois métodos de agrupamento de sinais - mamograma original.
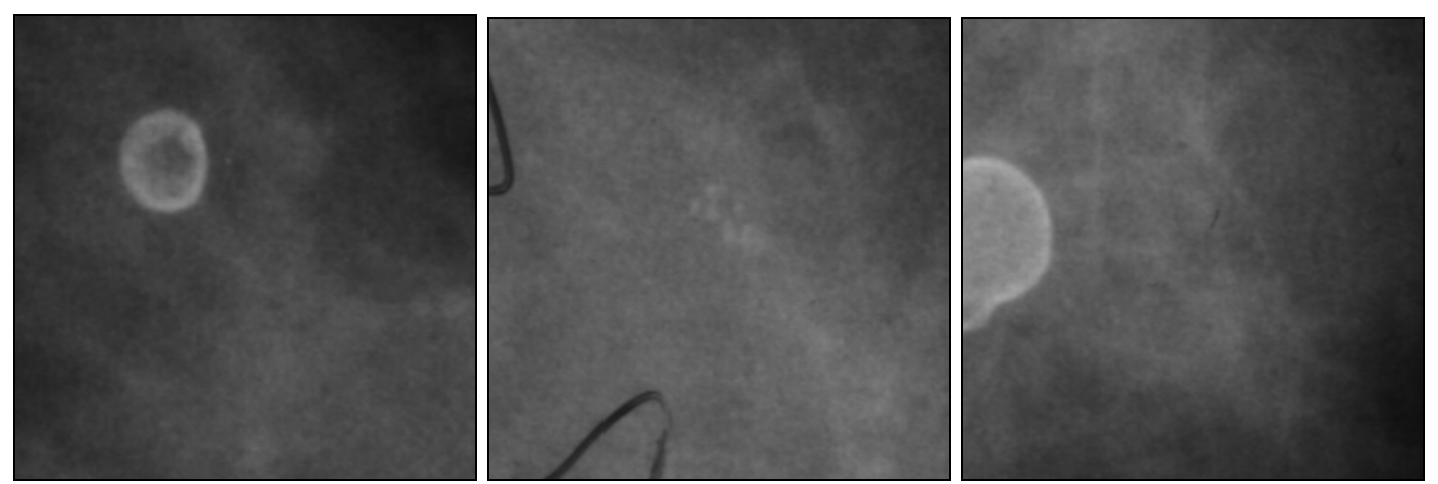

Figura 7-28 - Detecção de "clusters" em mamograma através dos dois métodos de agrupamento de sinais - regiões de interesse selecionadas. 

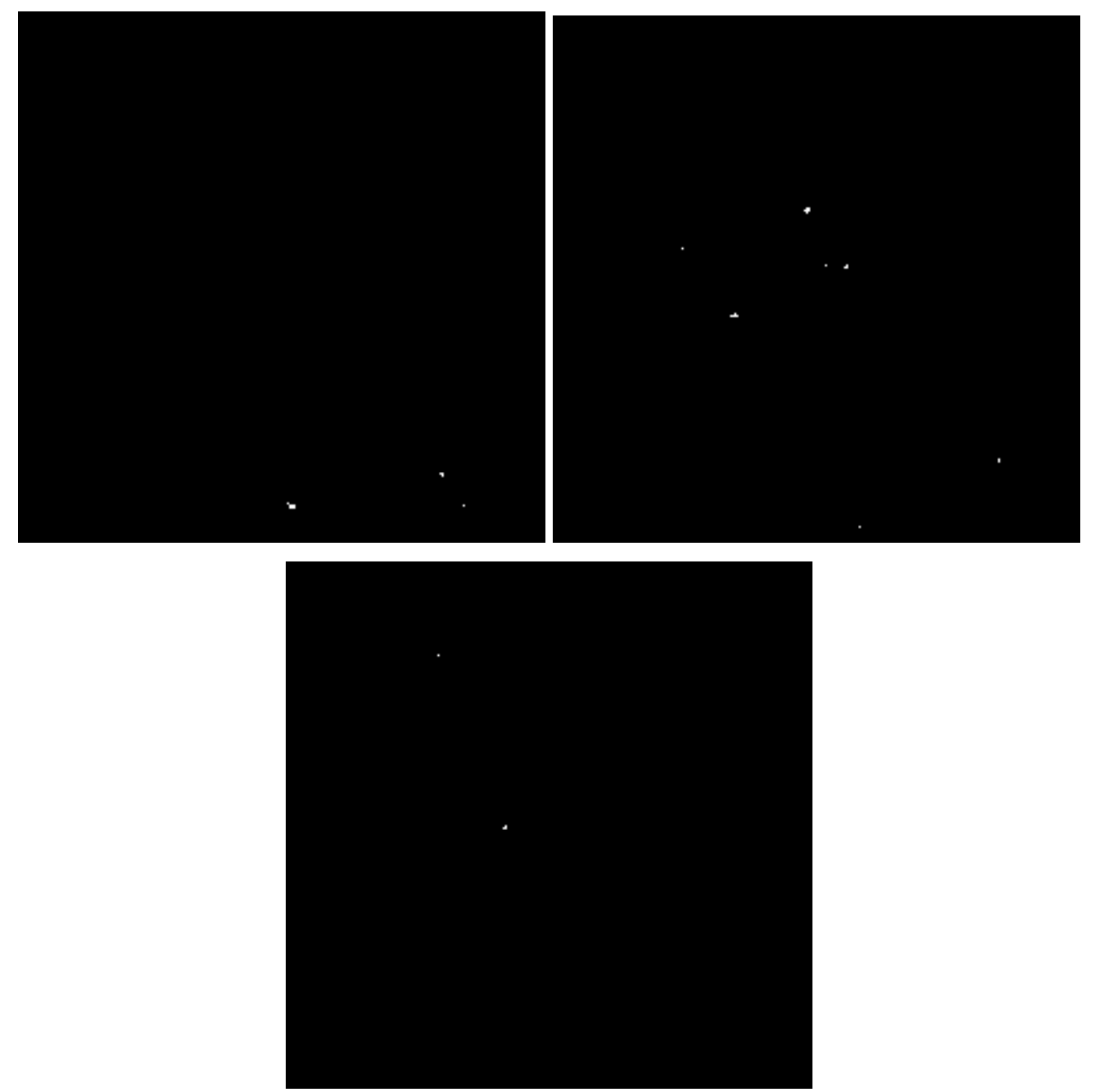

Figura 7-29 - Detecção de "clusters" em mamograma através dos dois métodos de agrupamento de sinais - regiões de interesse após segmentação.

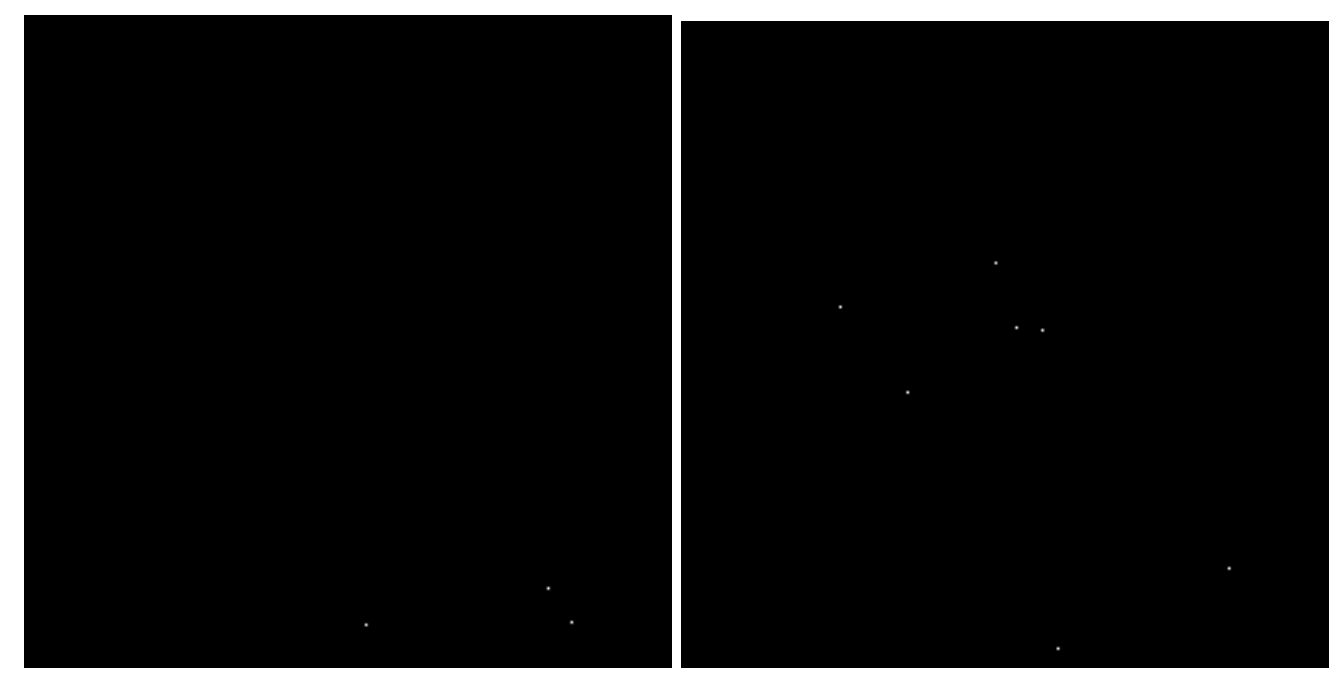




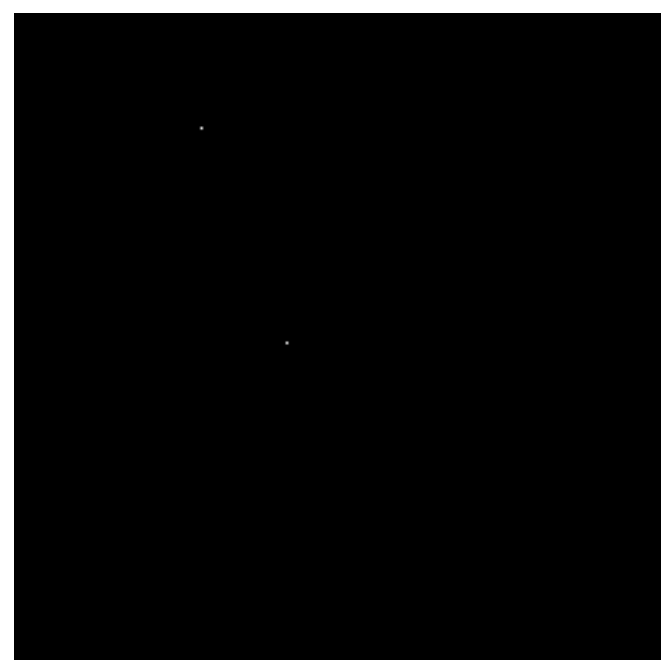

Figura 7-30 Deteç̧ão de "clusters" em mamograma através dos dois métodos de agrupamento de sinais - regiões de interesse após transformação área-ponto.

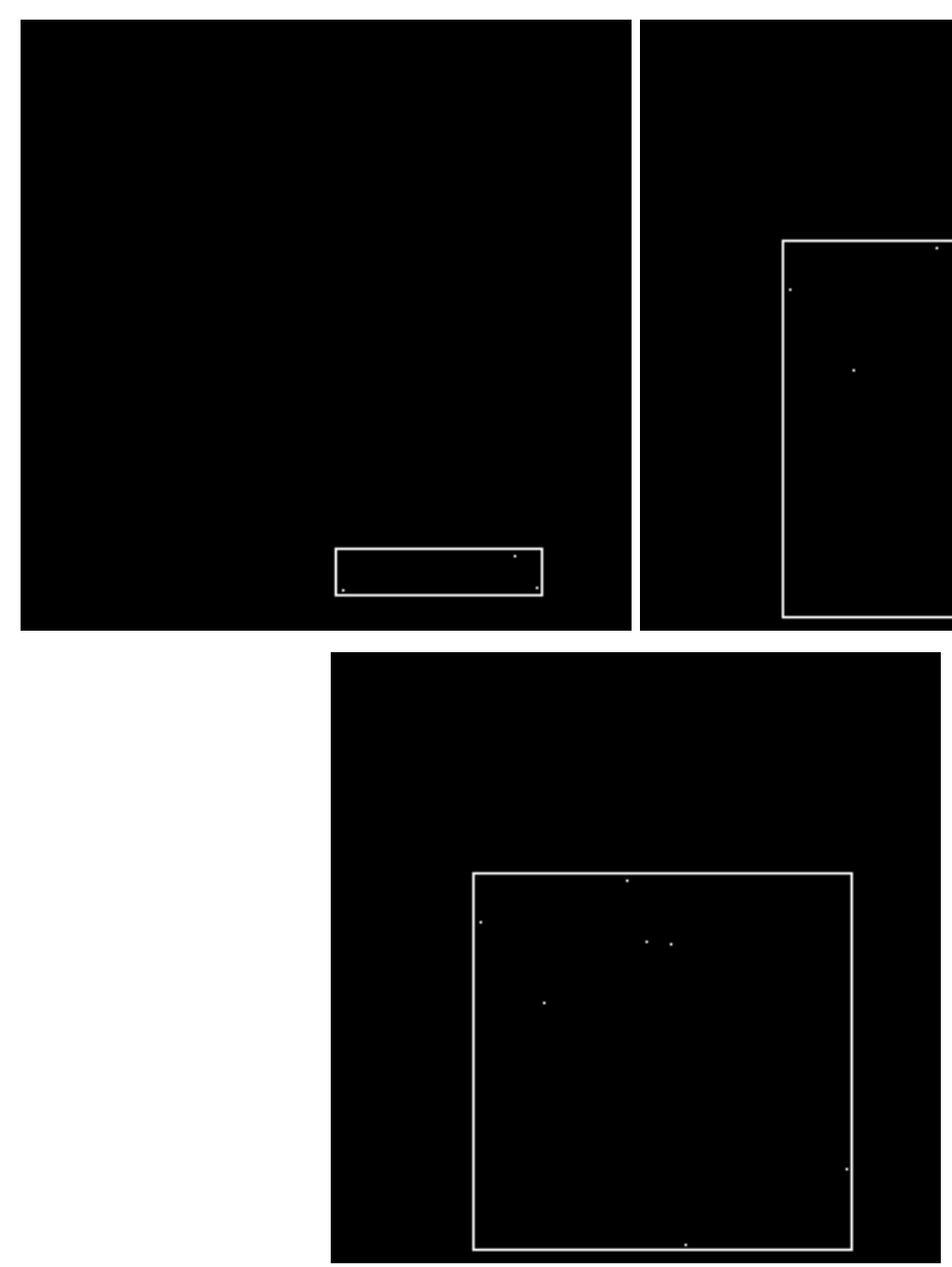

Figura 7-31 - Detecção de "clusters" em mamograma através dos dois métodos de agrupamento de sinais - regiões de interesse após detecção de "clusters" através do método de "mascaramento". 

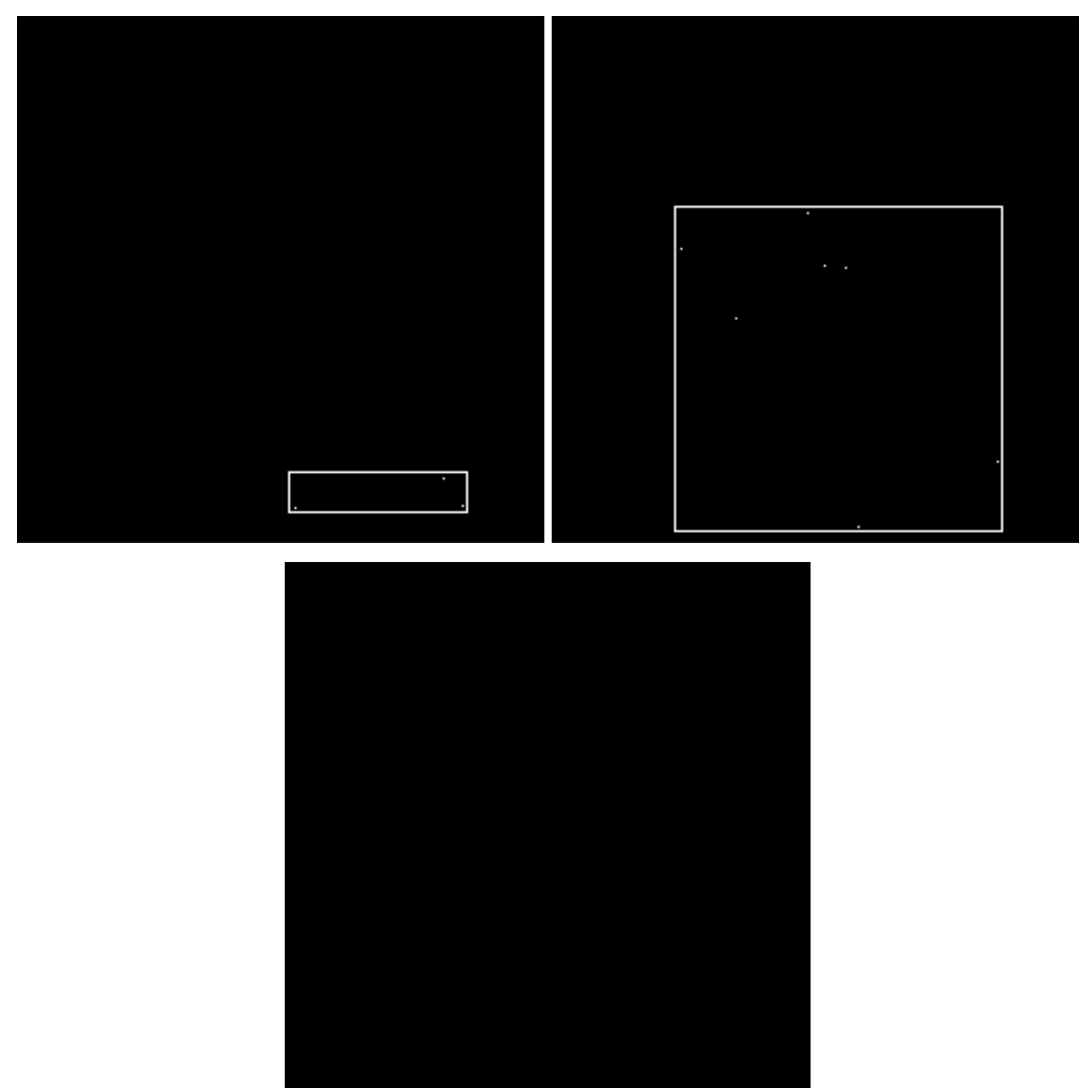

Figura 7-32 - Detecção de "clusters" em mamograma através dos dois métodos de agrupamento de sinais - regiões de interesse após detecção de "clusters" através do método de "crescimento de região". 


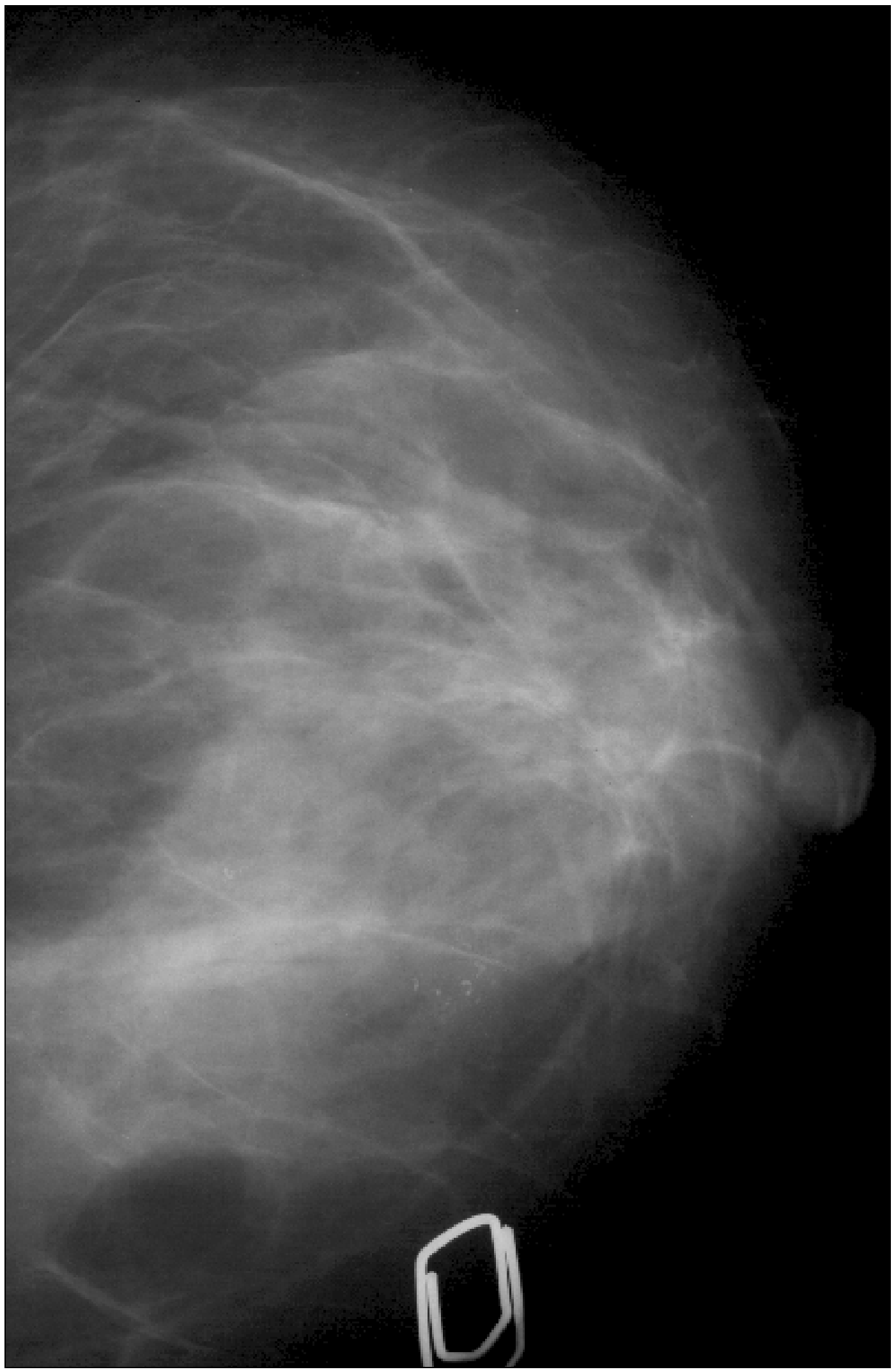

Figura 7-33 - Detecção de "clusters" em mamograma através dos dois métodos de agrupamento de sinais - mamograma original. 

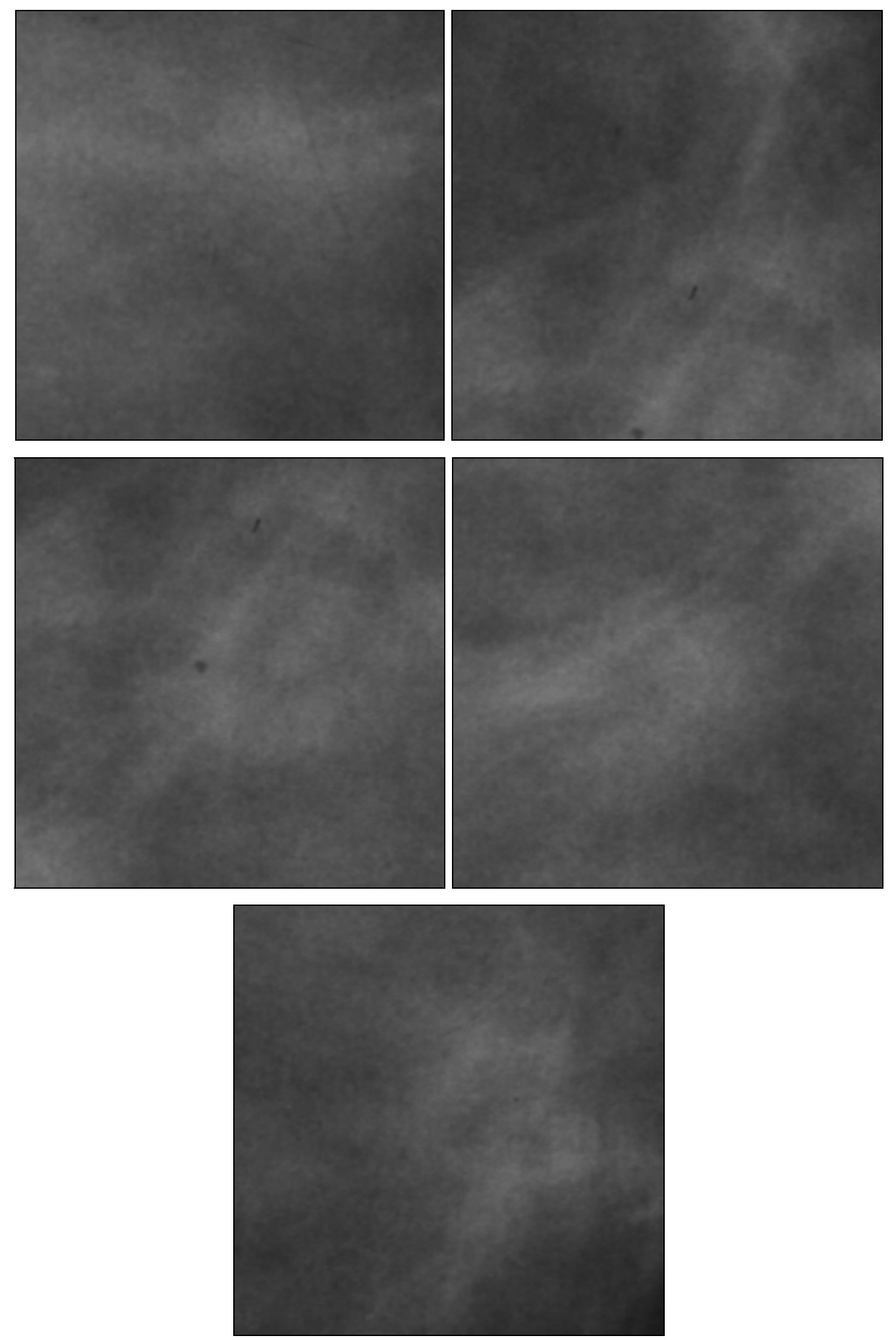

Figura 7-34 - Detecção de "clusters" em mamograma através dos dois métodos de agrupamento de sinais - regiões de interesse selecionadas. 


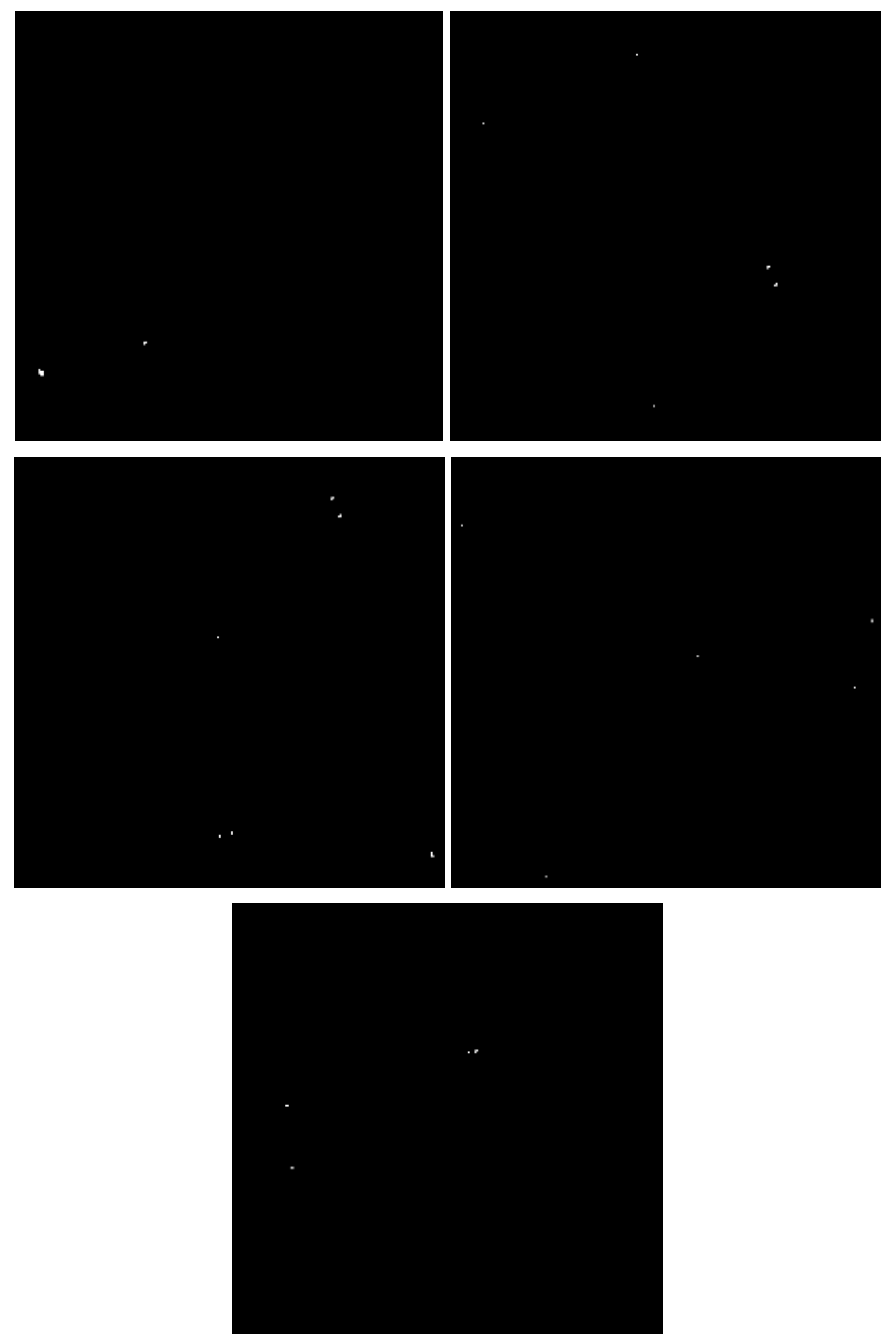

Figura 7-35 - Detecção de "clusters" em mamograma através dos dois métodos de agrupamento de sinais - regiões de interesse após segmentação. 


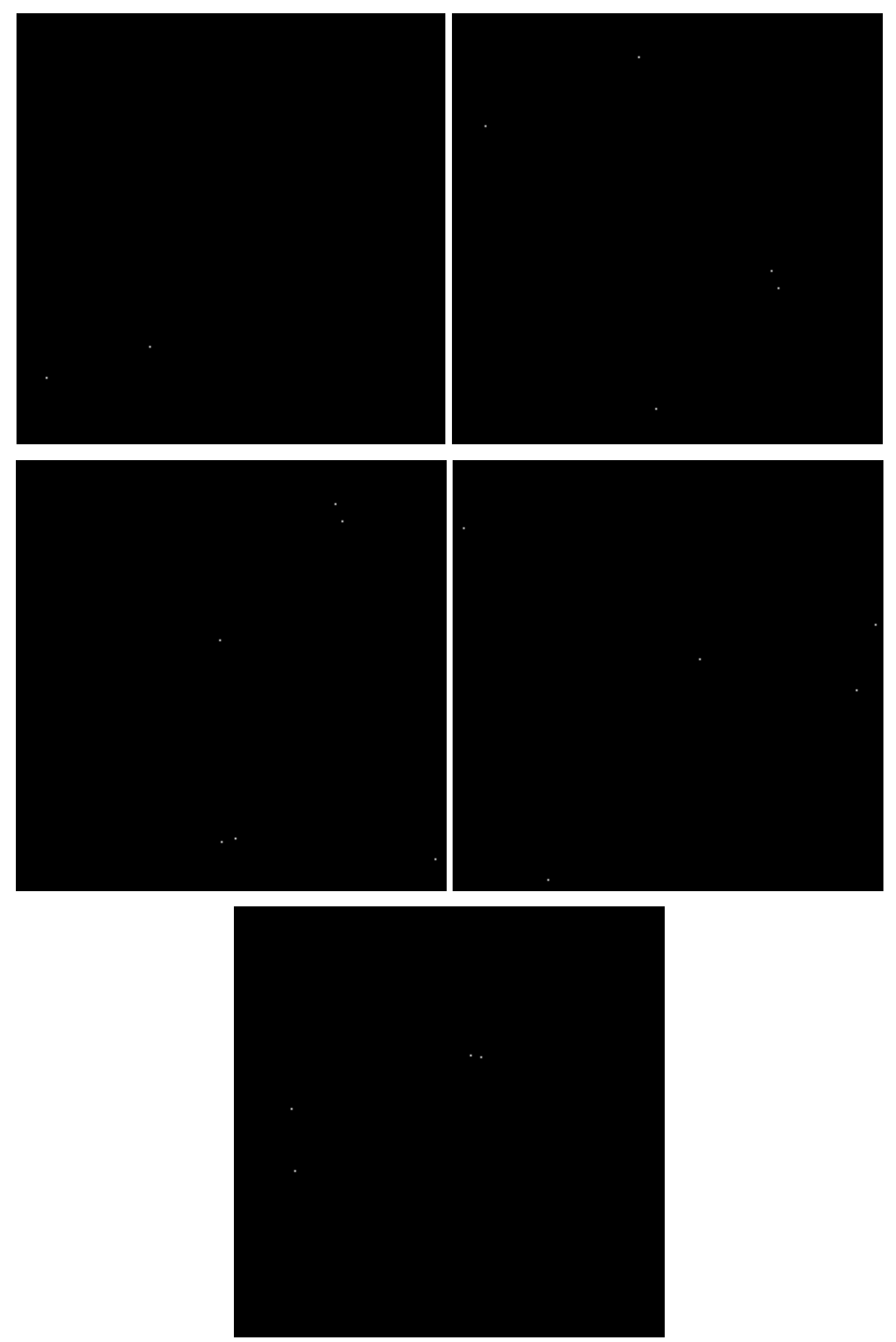

Figura 7-36 - Detecção de "clusters" em mamograma através dos dois métodos de agrupamento de sinais - regiões de interesse após transformação área-ponto. 

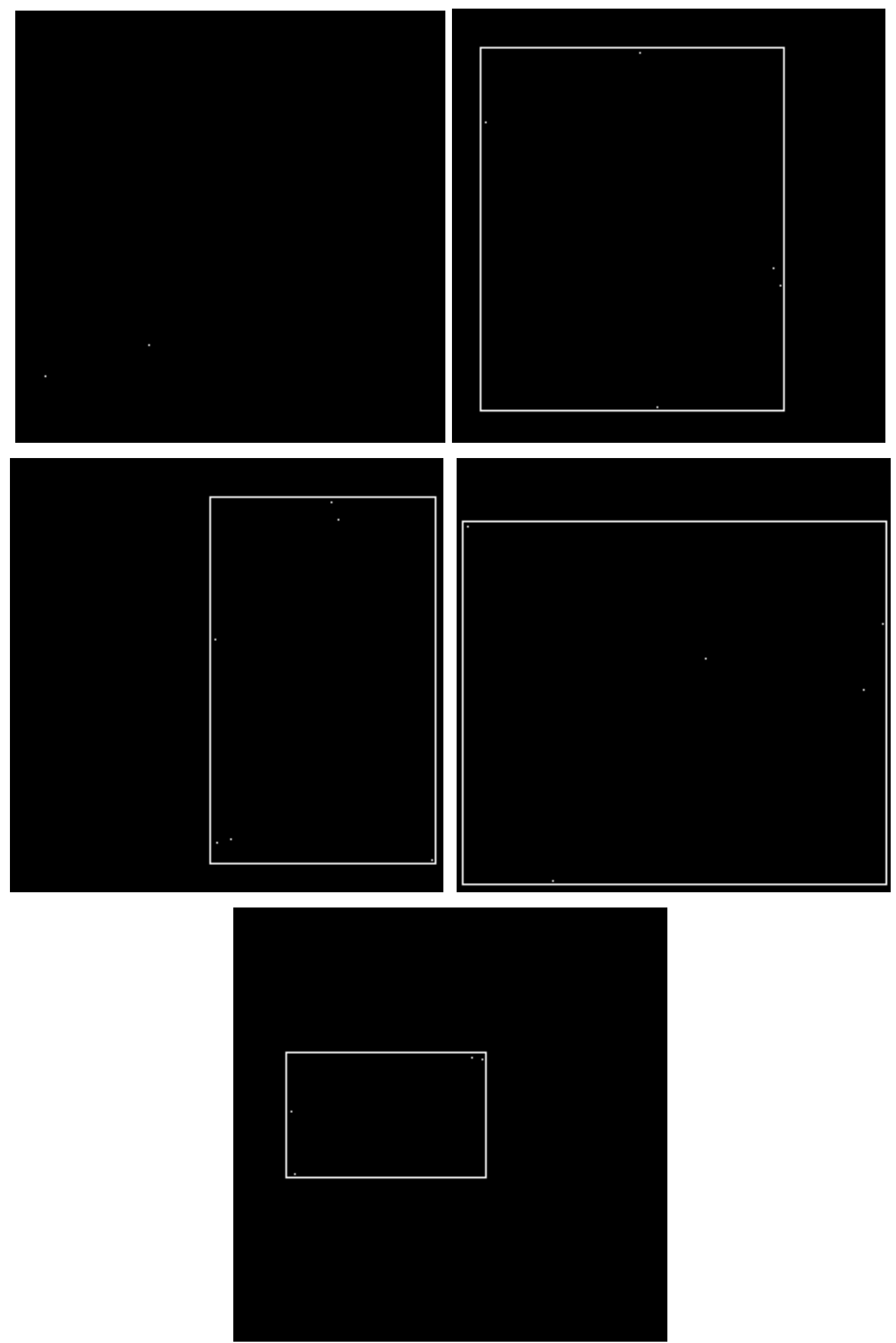

Figura 7-37 - Detecção de "clusters" em mamograma através dos dois métodos de agrupamento de sinais - regiões de interesse após deteç̧ão de "clusters" através do método de "mascaramento". 

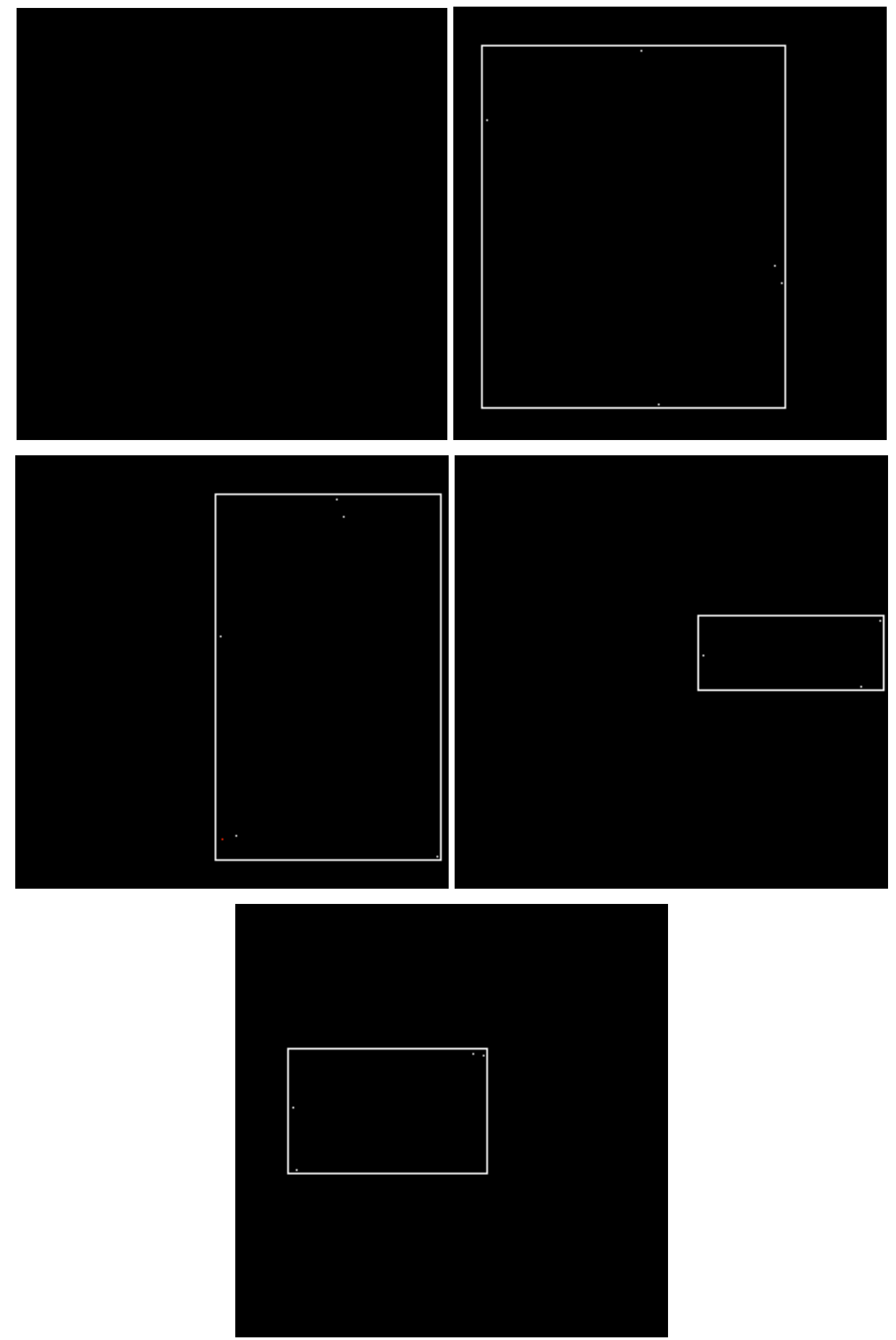

Figura 7-38 - Detecção de "clusters" em mamograma através dos dois métodos de agrupamento de sinais. - regiões de interesse após deteç̧ão de "clusters" através do método de "crescimento de região". 
Devido a essa tendência do algoritmo de "crescimento de região", concluímos que o método de "mascaramento" é mais eficiente, visto que a quantidade de "clusters" detectados na imagem pode exercer influência na decisão do médico para indicação do tratamento adequado a cada caso.

\subsubsection{Segundo conjunto de imagens}

O processamento do segundo conjunto de mamogramas teve o objetivo de estudar a influência da resolução da imagem nos diagnósticos do programa e confirmar a eficiência do sistema desenvolvido. As imagens desse conjunto foram obtidas através da utilização de vários tipos de equipamentos e combinação écran-tela Kodak MIN-R/S0177. Todas as imagens possuíam pelo menos um "cluster" de microcalcificações, cujas localizações eram conhecidas precisamente. Durante a identificação das regiões de interesse foram selecionadas regiões com e sem "clusters". Foi empregado o valor 0,5 para a porcentagem de média de níveis de cinza nessa fase. No total foram processadas 50 regiões de interesse extraídas de 16 mamogramas.

O processo de segmentação foi executado primeiramente com o valor 3,5 e depois com o valor 3,3 para o desvio-padrão. Os demais parâmetros dessa fase e das fases seguintes (transformação área-ponto e identificação de "clusters") foram idênticos aos valores utilizados para o primeiro conjunto de imagens. A identificação de "clusters" foi realizada com o método de "mascaramento".

Os resultados obtidos são apresentados na tabela 7-6. Com o valor 3,5 o sistema atingiu $82 \%$ de eficiência, fornecendo diagnóstico correto em 41 regiões de interesse. Com o valor 3,3 para o desvio-padrão, em 45 regiões o resultado foi correto, correspondendo a $90 \%$ do total de regiões testadas. Neste último caso houve uma diminuição nos diagnósticos falso-negativos. Através da tabela 7-6 é possível perceber que a performance do sistema diminuiu para esse conjunto de imagens. Isso ocorreu devido a dois fatores: o contraste baixo das imagens em geral e a resolução da digitalização. Os dois fatores exigiram a diminuição do valor de desviopadrão. Como o desvio-padrão é um parâmetro de verificação do contraste do sinal em relação ao fundo da imagem em torno dele, esse valor deve ser diminuído em imagens com baixo contraste para que sinais sejam reconhecidos. Os diagnósticos 
também sofreram influência da resolução da digitalização. Considerando que a resolução nessas imagens era menor que a resolução do primeiro conjunto de imagens, possivelmente alguns ruídos já devem ter sido eliminados durante o processo de digitalização, aumentando a probabilidade de sinais pequenos presentes nas imagens corresponderem a microcalcificações verdadeiras. Para que esses pequenos sinais fossem detectados, houve a necessidade de aumentar a sensibilidade do sistema, através da diminuição do valor de desvio-padrão.

Tabela 7-6 - Resultado do processamento do segundo conjunto de imagens de mamogramas reais através do método de "mascaramento".

\begin{tabular}{|c|c|c|c|c|c|c|c|c|c|}
\hline \multirow[t]{2}{*}{$\begin{array}{c}\text { Desvio- } \\
\text { padrão da } \\
\text { segmentação }\end{array}$} & \multirow[t]{2}{*}{$\begin{array}{c}\text { Total de } \\
\text { regiões } \\
\text { processadas }\end{array}$} & \multicolumn{2}{|c|}{$\begin{array}{c}\text { Total de } \\
\text { diagnósticos } \\
\text { verdadeiro- } \\
\text { positivos }\end{array}$} & \multicolumn{2}{|c|}{$\begin{array}{c}\text { Total de } \\
\text { diagnósticos } \\
\text { falso- } \\
\text { positivos }\end{array}$} & \multicolumn{2}{|c|}{$\begin{array}{c}\text { Total de } \\
\text { diagnósticos } \\
\text { verdadeiro- } \\
\text { negativos }\end{array}$} & \multicolumn{2}{|c|}{$\begin{array}{c}\text { Total de } \\
\text { diagnósticos } \\
\text { falso- } \\
\text { negativos }\end{array}$} \\
\hline & & Quant. & $\%$ & Quant. & $\%$ & Quant. & $\%$ & Quant. & $\%$ \\
\hline 3,5 & 50 & 30 & $60 \%$ & 5 & $10 \%$ & 11 & $22 \%$ & 4 & $8 \%$ \\
\hline 3,3 & 50 & 36 & $72 \%$ & 5 & $10 \%$ & 9 & $18 \%$ & 0 & $0 \%$ \\
\hline
\end{tabular}

Nas Figuras 7-39 a 7-43 é apresentado um exemplo de mamograma desse conjunto de imagens e o seu respectivo processamento. Nesse caso foram processadas 6 regiões de interesse, sendo que a última delas não possuía “cluster”.

Processar imagens com características diferentes foi um passo muito importante para confirmar a variação dos resultados de sistemas computadorizados de diagnósticos, citada na literatura. Verificamos dessa forma que, para cada conjunto de imagens, é necessário estudar as suas características e estabelecer os melhores valores para os parâmetros nas diferentes fases de processamento. 


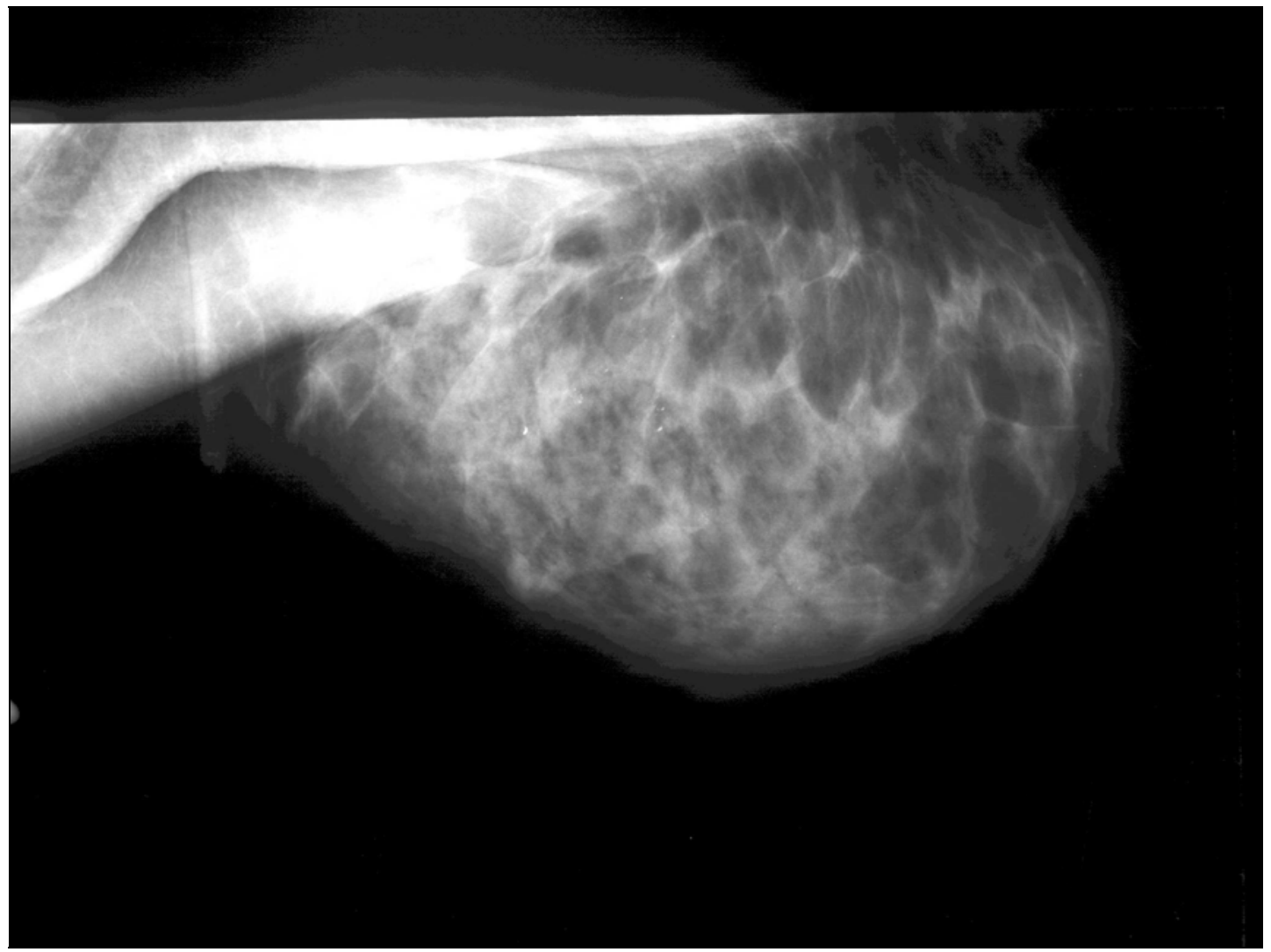

Figura 7-39 - Exemplo de processamento de um mamograma do segundo conjunto de imagens de teste - mamograma original. 


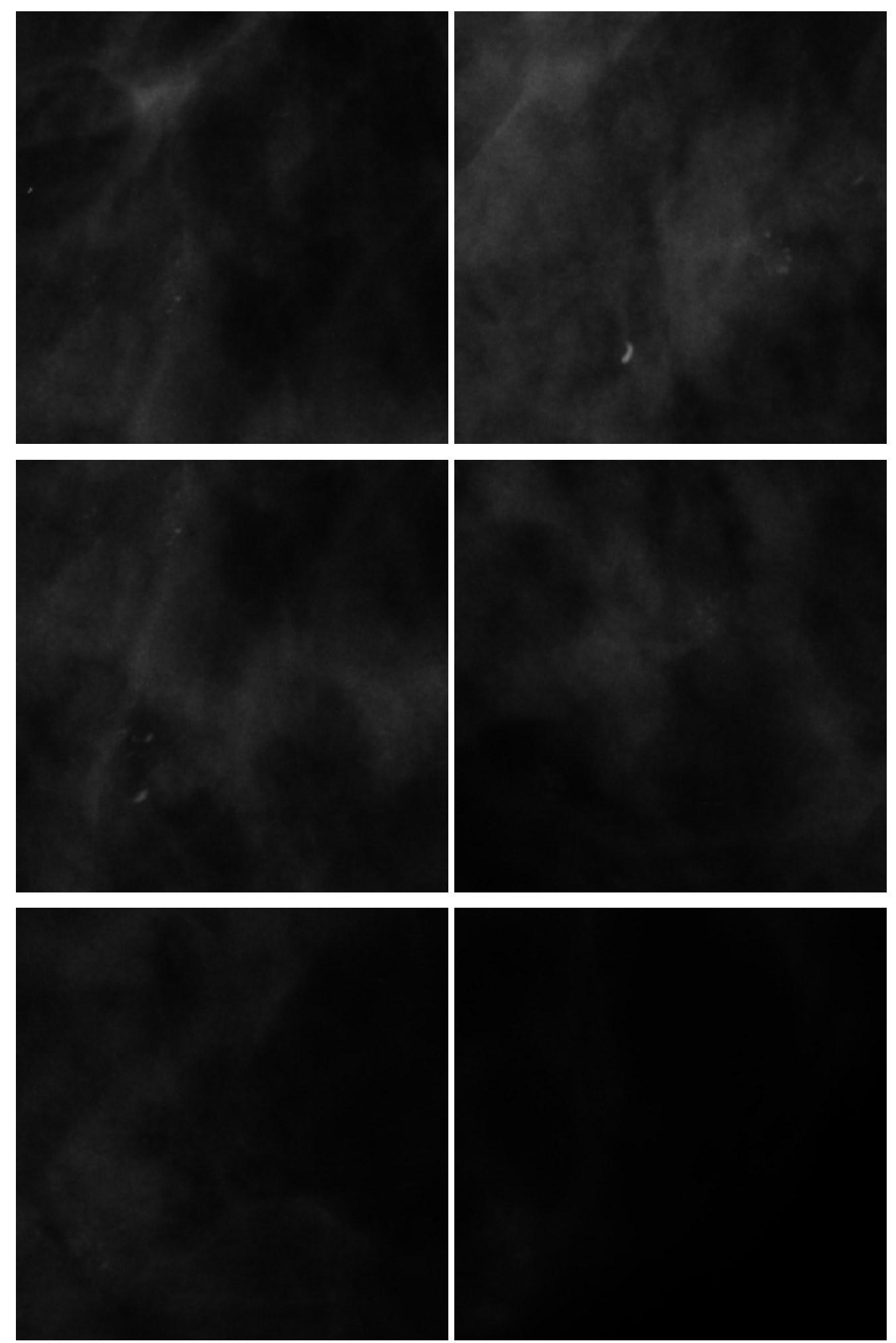

Figura 7-40 - Exemplo de processamento de um mamograma do segundo conjunto de imagens de teste - regiões de interesse selecionadas. 


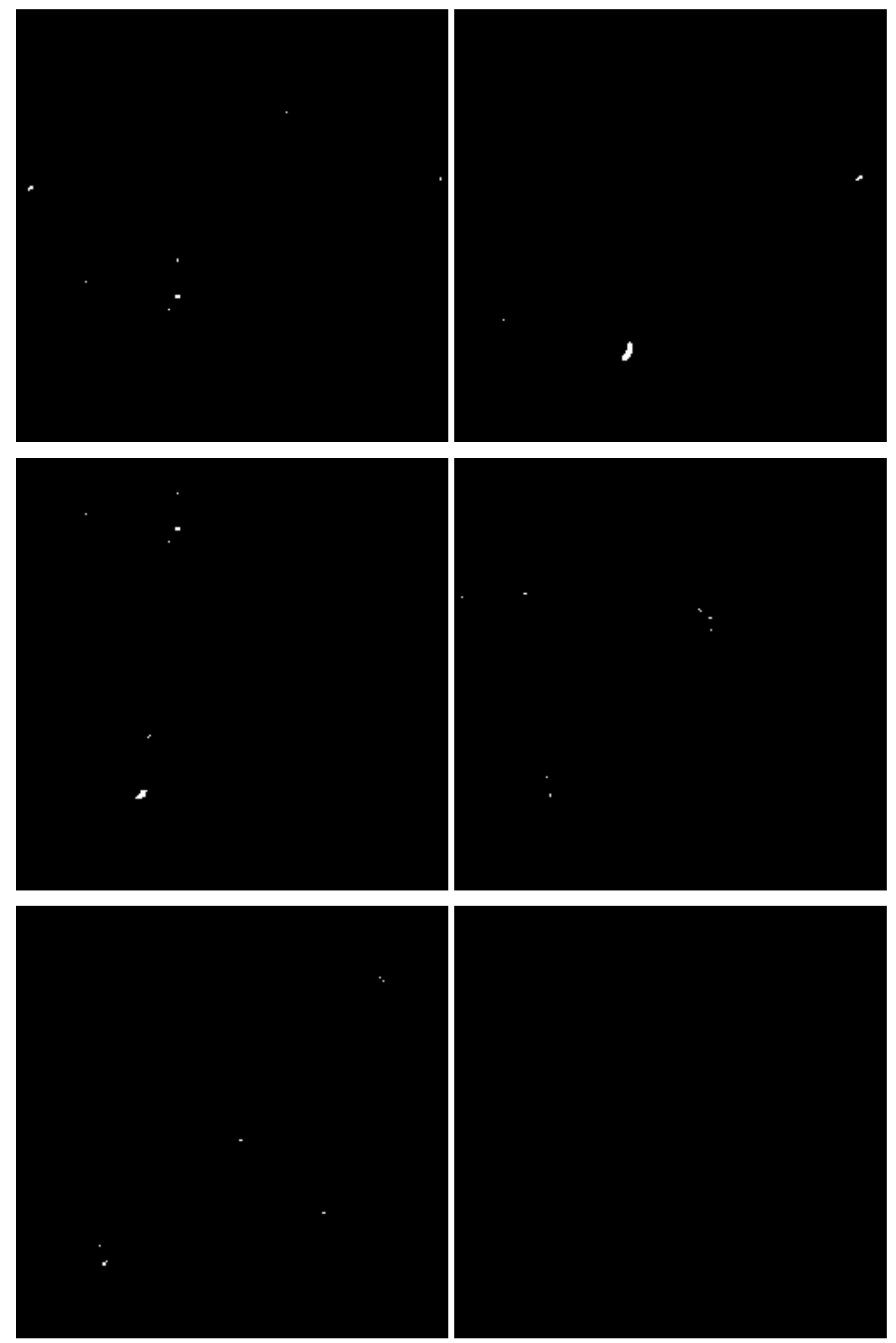

Figura 7-41 - Exemplo de processamento de um mamograma do segundo conjunto de imagens de teste - regiões de interesse após a segmentação. 


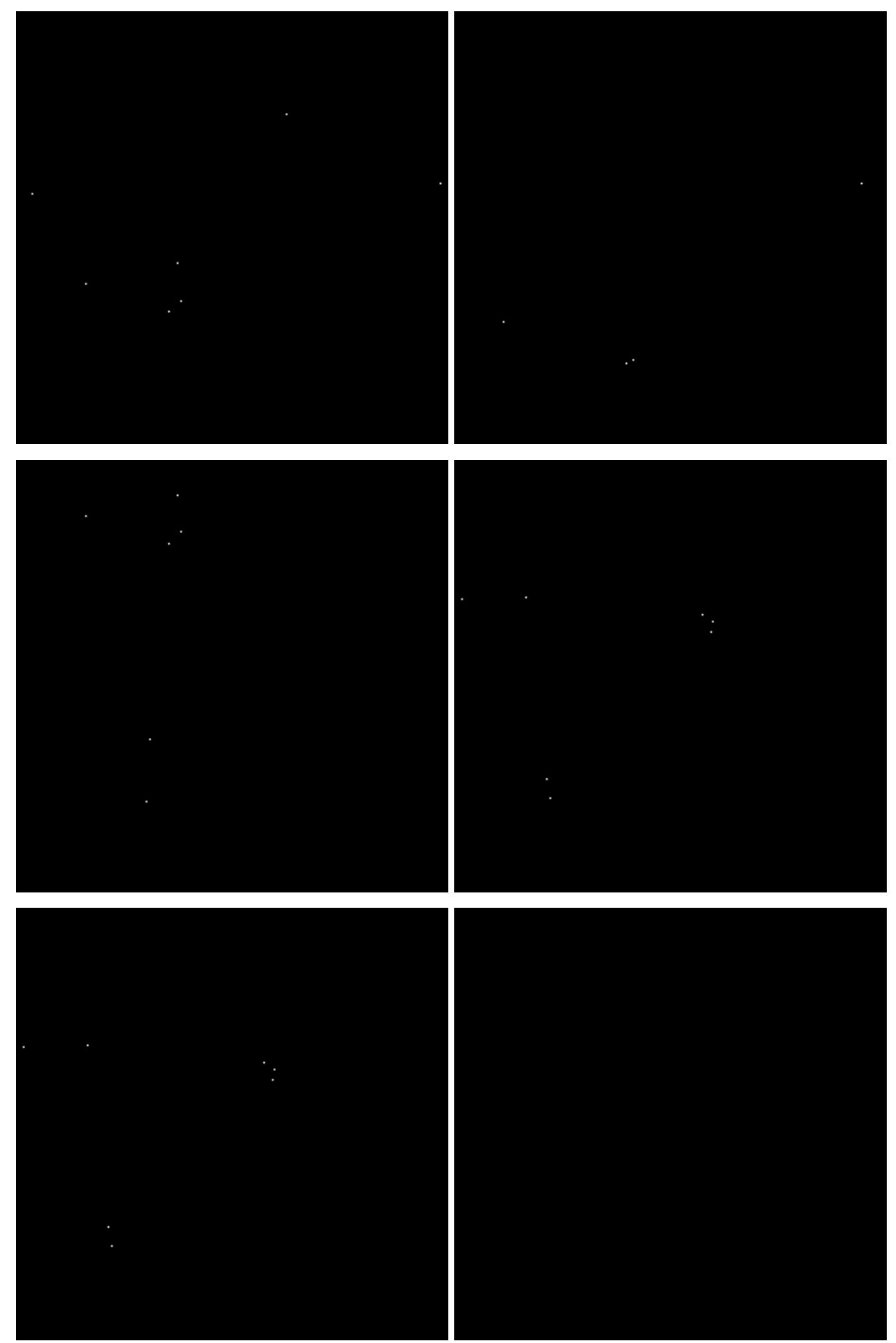

Figura 7-42 - Exemplo de processamento de um mamograma do segundo conjunto de imagens de teste - regiões de interesse após a transformação área-ponto. 

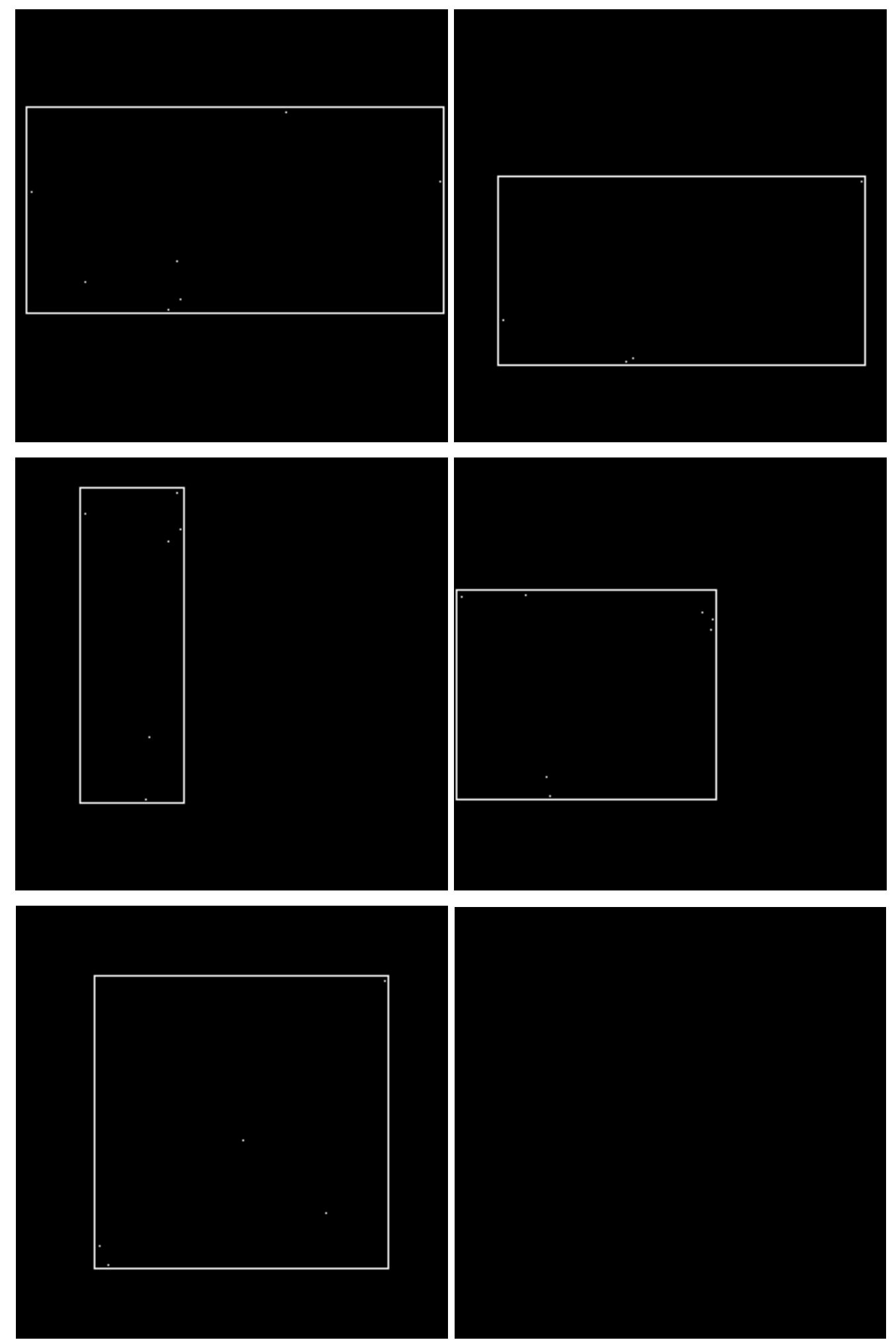

Figura 7-43 - Exemplo de processamento de um mamograma do segundo conjunto de imagens de teste - detecção de "clusters" através do método de "mascaramento". 


\subsection{Variação na deteç̧ão das regiões de interesse}

Durante a fase de detecção das regiões de interesse nas imagens de mamogramas, dois fatores chamaram a atenção: a influência de estruturas que não fazem parte da mama e o tempo de processamento exigido.

Algumas imagens contêm áreas fora da mama onde foram incluídos objetos para identificação da paciente ou localização de informações na chapa radiográfica. Como na imagem digitalizada geralmente os níveis de cinza desses objetos estão próximos do "branco", isso faz com que aumente a média geral de nível de cinza da imagem, distorcendo as informações do processamento. Em alguns casos foi possível reconhecer as regiões de interesse somente com a utilização do valor “0” (zero) no parâmetro "porcentagem da média de cinza”, o que é ruim pela necessidade de percorrer-se toda a imagem até ser atingido o trecho de interesse.

Para diminuir o efeito desse problema, em algumas imagens essas regiões foram excluídas utilizando-se um procedimento manual. Através do programa Photoshop 2.5, foi recortada somente a região da mama, fazendo com que o seu fundo assumisse o valor constante "zero" (preto) de nível de cinza. Na figura 744 são apresentados, para exemplificação, dois mamogramas antes e após esse procedimento. Em ambos os casos essa medida foi empregada a fim de eliminar as estruturas mais claras que não faziam parte da mama. Na primeira imagem (1a) foi eliminada a estrutura da parte inferior esquerda (próxima à parede toráxica), resultando na Figura (1b). Da segunda imagem (2a) foram eliminados o trecho mais claro da parte superior esquerda (região axilar) e inferior esquerda (indicando a identificação do filme), resultando na imagem (2b). A melhoria durante o reconhecimento das regiões de interesse foi grande, pois, mesmo aumentando-se o parâmetro "porcentagem da média de cinza", foram identificadas como sendo de interesse somente as áreas mais claras da imagem que estavam dentro dos limites da mama. Antes do processamento, era necessário manter esse parâmetro com o valor zero para que as devidas regiões fossem reconhecidas. 


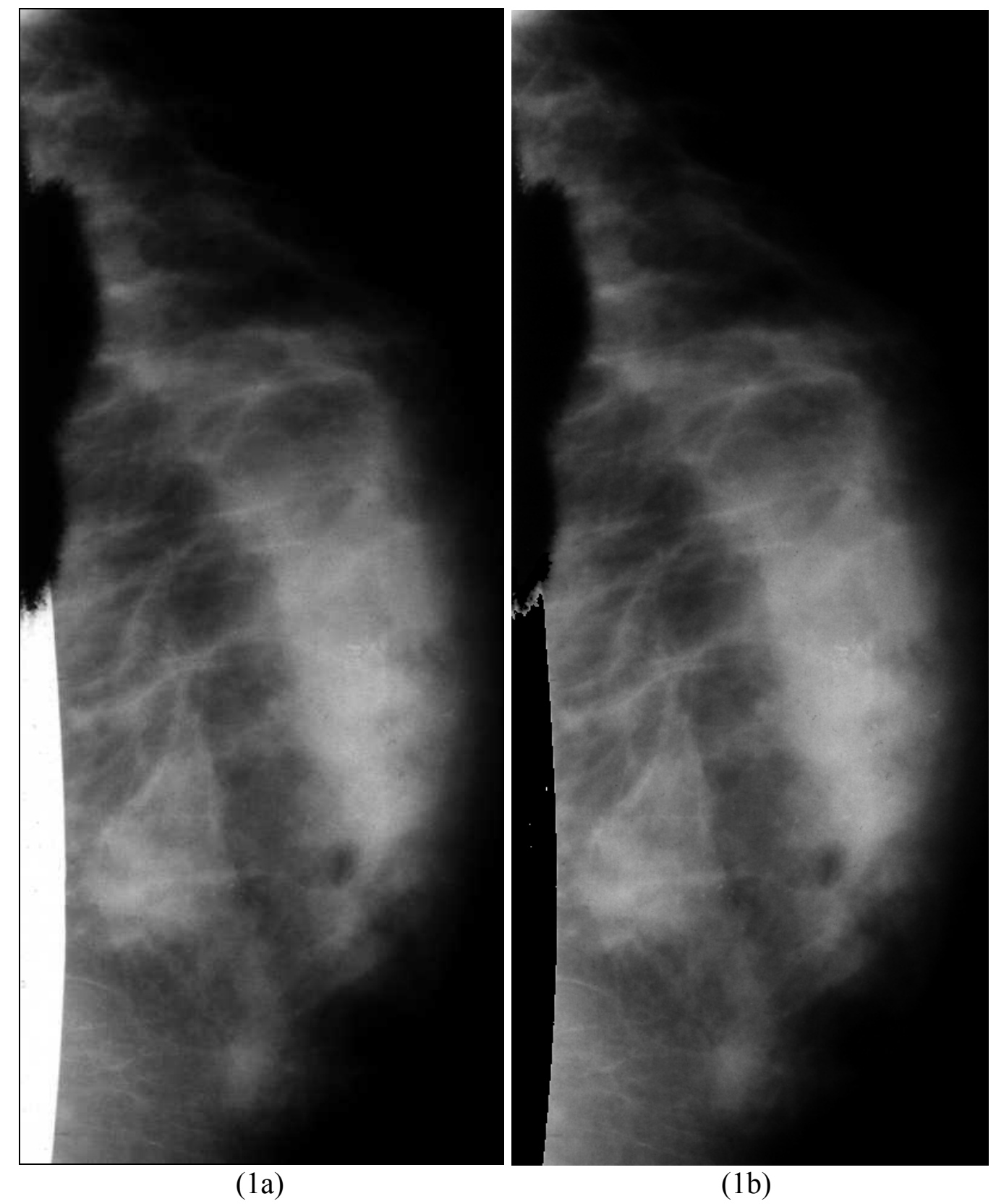




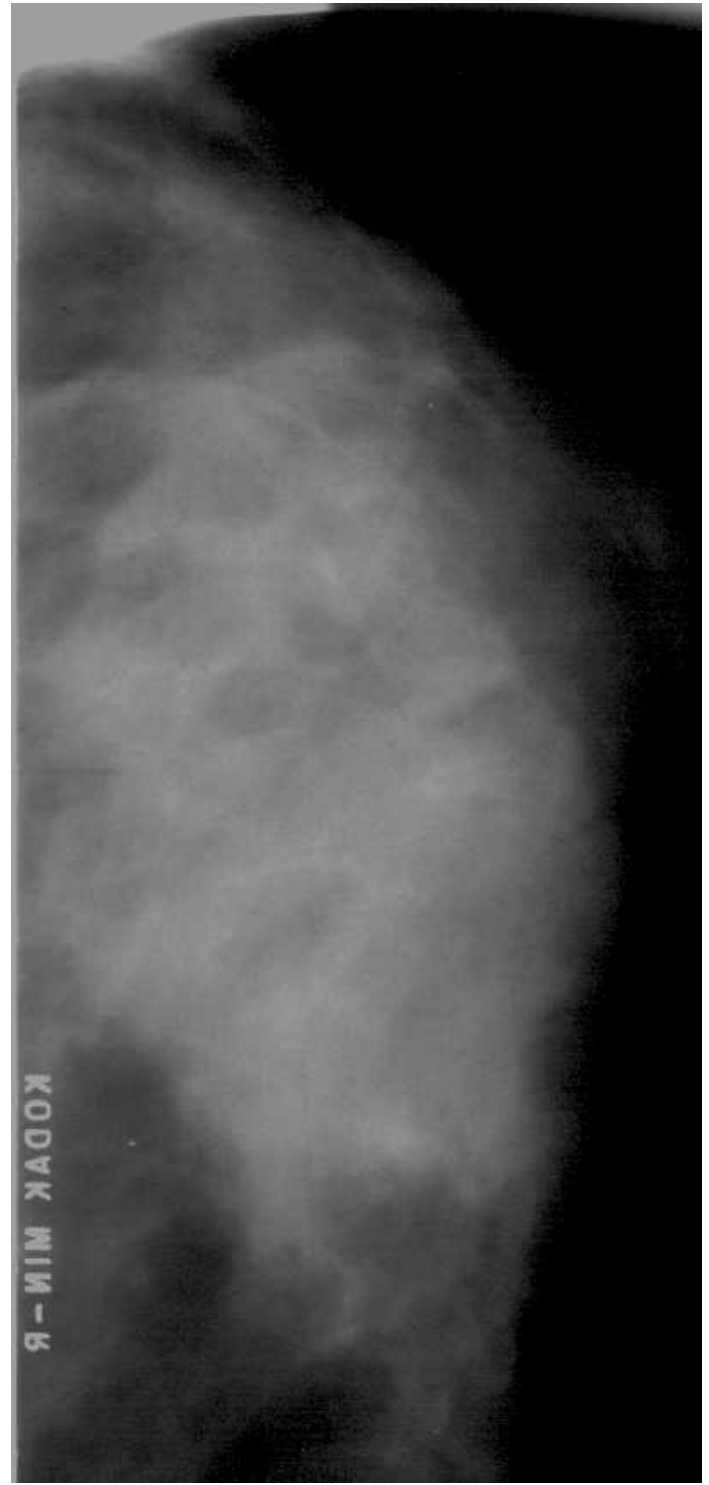

(2a)

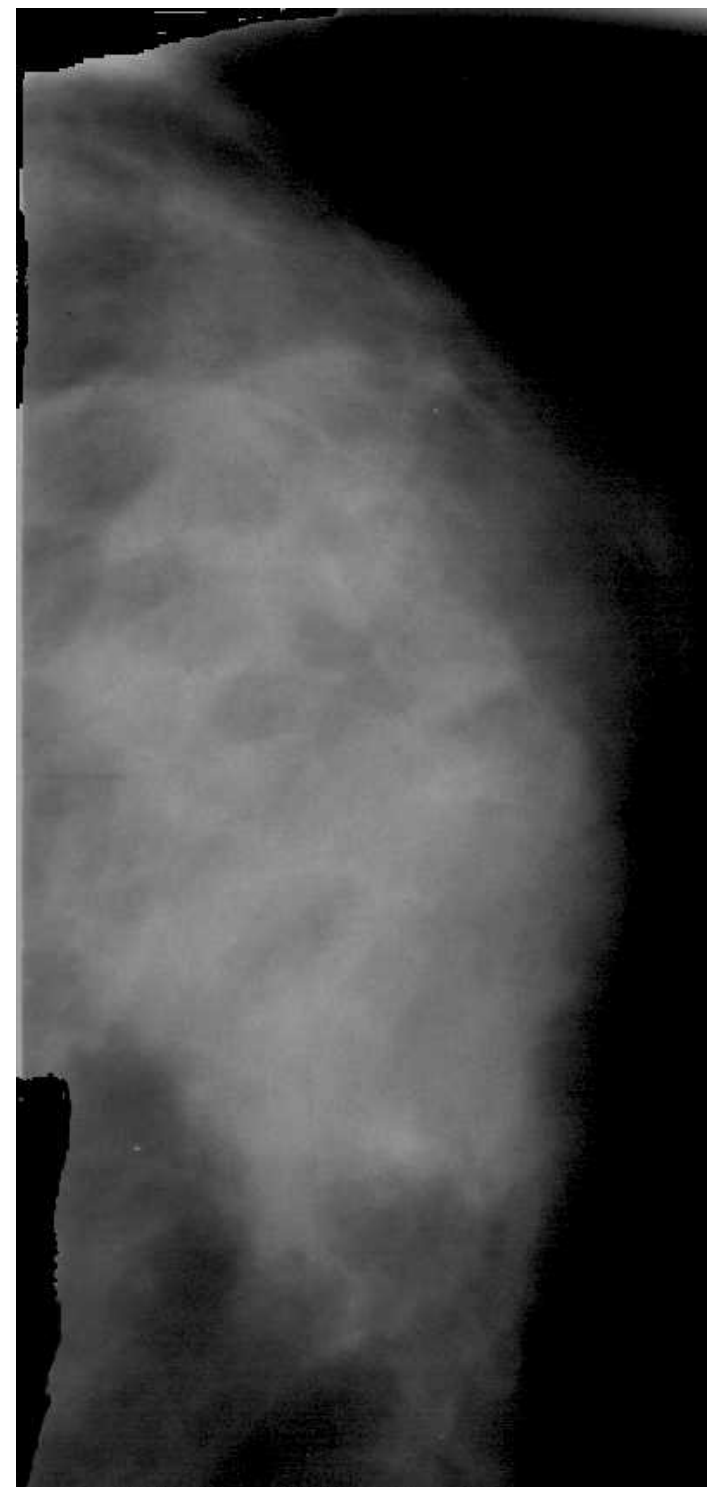

(2b)

Figura 7-44 - Imagem de mamogramas antes (1a e 2a) e após (1b e 2b) a eliminação da região em torno das fronteiras da mama.

\subsection{Considerações finais}

A avaliação da performance dos métodos de detecção de "clusters" para o primeiro conjunto de imagens de mamogramas foi realizada considerando-se o mamograma como um todo. O método de "mascaramento" atingiu 94\% de eficiência no diagnóstico de "clusters" verdadeiro-positivos para os 16 mamogramas desse conjunto de imagens. A eficiência do método de "crescimento de região" foi igual ao índice do primeiro método; porém, neste caso houve a tendência de divisão 
de "clusters", dependendo do posicionamento dos sinais dentro da região de interesse.

Para o segundo conjunto de imagens o sistema detectou $90 \%$ dos "clusters" corretamente, com o valor de desvio-padrão 3,3. A tendência na eliminação de ruídos durante os testes com as imagens desse conjunto ocorreu devido à diferença da resolução da imagem. Como o tamanho de pixel do segundo conjunto era o dobro do primeiro, sinais muito pequenos podem ter sido eliminados já durante o processo de digitalização. Outro fato importante é que, no segundo conjunto, a região externa à fronteira da mama apresentava um nível constante de cinza, bem menor que o restante da imagem. Essa característica facilitou muito a identificação das regiões de interesse.

A performance do sistema desenvolvido atingiu índices próximos dos sistemas citados na literatura. Em [CHAN-88a] o sistema apresentado para detecção de "clusters" obteve uma performance de 90\% de detecções corretas. Em [NISHIKAWA-92] e [NISHIKAWA-93a], os sistemas atingiram índices entre 90 a 95\%, dependendo do conjunto de imagens de testes e dos parâmetros utilizados. Em [DAVIES-90] a eficiência do sistema testado atingiu 92\%. Consideramos, dessa forma, que obtivemos bons resultados de processamento. 


\section{8}

\section{CONCLUSÕES}

A necessidade do diagnóstico precoce do câncer de mama a fim de aumentar as chances de cura leva muitos grupos de pesquisadores ao desenvolvimento de sistemas de "hardware" e "software" que visam, ora à melhoria nos equipamentos físicos de aquisição de imagem, ora à determinação de melhores posições e regiões para a realização da mamografia, ou levam ainda à implementação de programas de processamento de imagem que procurem índicios da presença do câncer.

O esquema desenvolvido nesta pesquisa tem o objetivo de identificar uma das estruturas de grande interesse no diagnóstico do câncer de mama: os “clusters" de microcalcificações. Através de técnicas de processamento de imagens, vários procedimentos foram implementados com essa finalidade, tendo como fonte de dados imagens digitalizadas de mamogramas.

A utilização de técnicas de processamento de imagens para identificar agrupamentos de microcalcificações não se limita à aplicação de técnicas básicas. Ao contrário, exige adaptações específicas do processo e adequação individual em cada imagem processada. Fatores como contraste baixo, não uniformidade na distribuição de intensidade da imagem e pequeno tamanho dos sinais são itens que dificultam o diagnóstico, exigindo grande atenção durante o desenvolvimento. Além disso, é difícil saber de antemão os melhores valores para os parâmetros ideais para cada imagem a ser processada, uma vez que as características variam enormemente.

Percebemos que a performance do sistema depende muito do conjunto de imagens de teste, como já havia observado Nishikawa et al. em [NISHIKAWA-93a]. No primeiro conjunto de imagens de mamogramas reais, o sistema atingiu 94\% de eficiência, enquanto que no segundo conjunto a eficiência alcançou o índice de 90\%. Na média foram obtidos bons resultados de processamento com o sistema aqui proposto, o qual atingiu $92 \%$ de eficiência, índice compatível com a eficiência alcançada até hoje pelos melhores sistemas citados na 
literatura. Salientamos que no segundo banco de dados as posições dos "clusters" eram conhecidas precisamente. Isso comprova a precisão do sistema na detecção de "clusters".

É importante que um sistema para auxílio no diagnóstico precoce do câncer de mama forneça um baixo índice de diagnósticos falso-positivos e falsonegativos. O primeiro pode levar a biópsias desnecessárias e o segundo pode induzir o médico a não dedicar a devida atenção a uma área onde pode existir um início de câncer. Neste sentido, o sistema aqui proposto teve uma boa performance, visto que o tamanho do pixel (42 microns) permite identificar estruturas de até $0,13 \mathrm{~mm}$ (estruturas com tamanhos menores são eliminadas durante a segmentação, que exclui da imagem sinais com 3 ou menos pixels), que podem não ser percebidas a olho nu no mamograma, particularmente se se tratar de mama densa.

Por outro lado, a resolução utilizada, além de tornar o tempo de processamento elevado, em alguns casos, pode permitir que ruídos permaneçam nas imagens. Concluímos, então, que, para a detecção de "clusters", essa resolução pode ser diminuída, considerando-se que, para o nosso caso, o formato do sinal não é importante. Para casos de classificação dos sinais com a finalidade de relacioná-los a tumores malignos e benignos, resolução mais alta torna-se importante, a fim de que as formas sejam preservadas e possam ser reconhecidas e classificadas.

Como principais vantagens do sistema desenvolvido, podemos inferir:

* diminuição do tempo de processamento através da detecção semi-automática de regiões de interesse - nos sistemas apresentados na literatura, geralmente as regiões de interesse são identificadas manualmente, sendo que o usuário deve saber manusear programas comerciais para extraí-las dos mamogramas. A detecção semi-automática que desenvolvemos permite que o usuário escolha o tamanho da região desejada e confirme sua opção em armazenar ou desprezar trechos da imagem que foram identificados como sendo de interesse. Percebemos que o tempo de processamento de regiões de interesse individuais é muito menor que o tempo de processamento do mamograma como um todo (da ordem de 6:1, dependendo da quantidade de regiões selecionadas).

* plataforma de alta usabilidade - o sistema foi desenvolvido em plataforma Windows, que, além de ser mundialmente conhecida, oferece manuseio 
fácil para o usuário. Isto torna o sistema mais fácil de ser utilizado por leigos em computação.

* parâmetros variáveis - o desenvolvimento do sistema procurou manter muitos parâmetros variáveis a fim de que o processamento seja adeqüado a cada imagem individualmente.

* portabilidade - a utilização de computadores pessoais no desenvolvimento possibilita o uso da aplicação por qualquer pessoa que possua equipamentos desse tipo, não exigindo, assim, grandes investimentos para a implantação do sistema. A maioria dos sistemas citados na literatura foram desenvolvidos em estações gráficas ou computadores de grande porte, tornando difícil a utilização desses programas em locais que não possuam o tipo de equipamento utilizado no desenvolvimento.

As desvantagens que pudemos registrar foram essencialmente as seguintes:

* necessidade de conhecimento sobre o assunto para utilizar o sistema, considerando a grande quantidade de parâmetros variáveis - essa desvantagem desaparece à medida que o usuário compreende o significado dos parâmetros utilizados. O sistema possui um esquema de ajuda instantânea que facilita a compreensão dos parâmetros.

* dificuldade em processar imagens muito grandes - é necessário equipamentos com grande capacidade de armazenamento em disco rígido e memória RAM de 32 Kbytes ou superior, para o processamento das imagens, em virtude do tamanho das mesmas. Essa característica pode deixar de constituir uma desvantagem à medida que a tecnologia permitir a aquisição de equipamentos com maiores capacidades, por preços mais baixos.

Desenvolver um sistema que forneça um diagnóstico seguro e preciso para a detecção precoce do câncer de mama não é tarefa simples. As grandes variações nas características de cada imagem impedem o emprego de parâmetros genéricos. Esse fato faz com que os sistemas desenvolvidos para a área sejam complexos e, em muitos casos, de difícil manuseio. A solução, nesta pesquisa, foi o desenvolvimento de um sistema em que boa parte dos valores utilizados no processamento de imagens pode ser modificada, possibilitando a alteração dos 
parâmetros para cada imagem submetida ao processamento. $\mathrm{O}$ fato de deixar valores passíveis de alterações pelo usuário não torna difícil a sua utilização, uma vez que todos os parâmetros apresentam valores iniciais já estabelecidos com estudos prévios.

Avaliamos que a performance do sistema desenvolvido foi bastante satisfatória, pois apresentou um nível de eficiência em torno de $94 \%$ para o processamento de mamogramas reais. Além de fornecer informações que auxiliem os médicos na formação da opinião sobre a possível existência do câncer de mama no paciente, o sistema tem a vantagem de permitir, através dos registros dos processamentos realizados, um acompanhamento de cada caso, quantificando os sinais identificados. Acreditamos, dessa forma, estar contribuindo de modo efetivo para a detecção precoce do câncer de mama. 


\section{Sugestões para pesquisas futuras}

* Processamento automatizado para a identificação da fronteira da região da mama pesquisada - isso pode eliminar a estrutura de fundo da imagem do mamograma, que influencia na identificação das regiões de interesse e, conseqüentemente, nos resultados da detecção. Além disso, pode proporcionar uma diminuição do tempo de processamento.

* Desenvolvimento de técnicas para melhoria de contraste - a melhoria do contraste é um fator determinante na performance de um sistema computadorizado que visa auxiliar diagnósticos médicos. As estruturas de interesse são diferenciadas do restante da imagem através do nível de cinza dos seus pixels. Por isso, é necessário um estudo dedicado a esse tópico, visando incrementar o contraste, sem, contudo, aumentar o nível de ruído na imagem.

* Desenvolvimento de sistemas que, além de quantificar os sinais, os qualifiquem, informando a possibilidade de estarem relacionados a tumores malignos ou benignos.

* Desenvolvimento de algoritmos que, através de análise prévia das características de cada imagem, façam sugestões de melhores parâmetros para o seu processamento.

* Utilização das técnicas aqui desenvolvidas para melhoria de contraste e detecção/classificação de microcalcificações em imagens de mamas jovens, cuja densidade é consideravelmente maior, além de sofrerem do problema de evolução mais rápida do câncer do estágio não detectável até o estágio cirúrgico. 


\section{9}

\section{REFERÊNCIAS BIBLIOGRÁFICAS}

[BALLARD-82]

BALLARD, D.H; BROWN, C.M. Computer Vision. Prentice-Hall Inc, Englewood Cliffs, New Jersey, 1982.

[BRETTLE-94]

BRETTLE, D.S.; WARD, S.C.; PARKIN, G.J.S.; COWEN, A.R.; SUMSION, H.J. A clinical comparison between conventional and digital mammography utilizing computed radiography. The British Journal of Radiology, v. 67, p. 464-468, 1994.

[BYUNG-94]

BYUNG, J.W.; BOYD, N.F.; FISHELL, E.; JONG, R.A.; YAFFE, M.J. The quantitative analysis of mammographic densities. Physics in Medicine and Biology, v. 39, p. 1629-1638, 1994.

[CHAN-87]

CHAN, H.-P.; DOI, K.; GALHOTRA, S.; VYBORNY, C.J.; MacMAHON, H.; JOKICH, P.M. Image feature analysis and computer-aided diagnosis in digital radiography. I.Automated detection of microcalcifications in mammography. Medical Physics, v. 14(4), p. 538-548, 1987.

[CHAN-88a]

CHAN, H.-P.; DOI, K.; LAM, K.-L.; VYBORNY, C.J.; SCHMIDT, R.A.; METZ, C.E. Digital characterization of clinical mammographic microcalcifications p. applications in computer-aided detection. SPIE Med. Imaging II p. Image Formations Detection Processing and Interpretation, v. 914, p. 591-593, 1988.

\section{[CHAN-88b]}

CHAN, H-P.; DOI, K.; VYBORNY, C. J.; LAM, K-L.; SCHMIDT, R. A. Computeraided detection of microcalcifications in mammograms. Methodology and preliminary clinical study. Original Investigations, 1988.

\section{[CHAN-90]}

CHAN, H.-P.; DOI, K.; VYBORNY, C.J.; SCHMIDT, R.A.; METZ, C.E.; LAM, K.L.; OGURA, T.; WU, Y.; MacMAHON, H. Improvement in radiologists' detection of clustered microcalcifications on mammograms: the potential of computer-aided diagnosis. Investigative Radiology, v. 25(10), p.1102-1110, 1990. 
[CHAN-94]

CHAN H.-P.; NIKLADSON L.T.; IKEDA D.M.; LAM, K.L.; ADLER, D.D. Digitization requirements in mammography: effects on computer-aided detection of microcalcifications. Medical Physics, v. 21(7), p. 1203-1211, 1994.

[CURRY III-90]

CURRY III, T.S.; DOWDEY, J.E.; MURRY JR., R.C. Christensen's Physics of Diagnostic Radiology. Lea \& Febiger, Philadelphia, 4th Edition, 1990.

[DAVIES-90]

DAVIES, D.H.; DANCE, D. R. Automatic computer detection of clustered calcification in digital mammograms. Physics in Medicine and Biology, v. 35 (8), p. 1111-1118, 1990.

[DENGLER-93]

DENGLER, J.; BEHRENS, S.; DESAGA, J.F. Segmentation of microcalcifications in mammograms. IEEE MI, v. 12(4), p. 634-642, 1993.

[DHAWAN-86]

DHAWAN, A.P.; BUELLONI, G.; GORDON, R. Enhancement of mammographic features by optimal adaptive neighborhood image processing. IEEE Transactions on Medical Imaging, v. MI-5(1), p. 8-15, 1986.

[DHAWAN-88]

DHAWAN, A.P.; ROYER, E.L. Mammographic feature echancement by computerized image processing. Computer Methods and Programs in Biomedicine, v. 27, p. 23-35, 1988.

[DOI-96]

DOI, K. Perspectives on digital image analysis in medical image. Potencial usefulness of computer-aided diagnosis. Anais do III Fórum Nacional de Ciência e Tecnologia em Saúde, v. 2, p. 795-796, 1996.

[EGAN-80]

EGAN, R.L.; McSWEENEY, M.B.; SEWELL, C.W. Intramammary calcifications without an associated mass in benign and malignant diseases. Radiology, v. 137(1), p. 1-7, 1980.

[FAHRIG-94]

FAHRIG, R.; YAFFE, M.J. A model for optimization of spectral shape in digital mammography. Medical Physics, v. 21(9), p. 1463-1471, 1994. 
[FAM-88]

FAM, B.W.; OLSON, S.L.; WINTER, P.F.; SCHOLZ, F.J. Algorithm for the detection of fine clustered calcification on film mammograms. Radiology, v. 169, p. 333-337, 1988.

[FITZGERALD-81]

FITZGERALD, M.; WHITE, D.R.; WHITE, E.; YOUNG, J. Mammographic practice and dosimetry in Britain. Br. J. Radiol., v. 54, p. 212-220, 1981.

[FRÈRE-82]

FRÉRE, A. F. Investigações de qualidade de imagens radiológicas com um sistema densitométrico computadorizado. São Carlos, IFSC/USP, 1982. Tese (doutoramento).

[GONZALEZ-87]

GONZALEZ, R.C.; WINTZ, P. Digital Image Processing. Addison-Wesley Publishing Company, United States of America, 1987.

[GRAPS-95]

GRAPS, A. An Introduction to Wavelets. IEEE Computational Science and Engineering, Summer 1995, v. 2(2), 1995.

[HAUS-78]

HAUS, A.G.; COWART, R.W.; DODD G.D.; BENCOMO, J. A method of evaluating and minimizing geometric unsharpness for mammographic X-ray units. Radiology, v. 128 , p. $775-778,1978$.

[ISHIDA-83]

ISHIDA, M; FRANK, P.H.; DOI, K.; LEHR, J.L. High quality digital radiographic images: improved detection of low-contrast objects and preliminary clinical studies. RadioGraphics, v. 3(2), p. 325-338, 1983.

[ISHIDA-84]

ISHIDA, M.; DOI, K.; LOO, L-N.; METZ, C.E.; LEHR, J.L. Digital image processing: effect on detectability of simulated low-contrast radiographic patterns. Radiology, v. 150 , p. $569-575,1984$.

\section{[JACKSON-93]}

JACKSON, V.P; HENDRICK, E.; FEIG, S.A.; KOPANS, D.B. Imaging of the radiographically dense breast. Radiology, v. 188, p. 297-301, 1993. 
[JIANG-92]

JIANG, Y.; NISHIKAWA, R.M.; GIGER, M.L.; DOI, K.; SCHMIDT, R.A.; VYBORNY,C.J. Method of extracting signal area and signal thickness of microcalcifications from digital mammograms. Proceedings of SPIE: Imaging Technologies and Applications, v. 1778, p. 28-36, 1992.

[JIN-93]

JIN, H-R.; KOBATAKE, H. Extraction of microcalcifications from mammograms using morphological filter with multiple structuring elements. Systems and Computers in Japan, v. 24(11), p. 66-74, 1993.

\section{[KALLERGI-92]}

KALLERGI, M.; WOODS, K.; CLARKE, L.; QIAN, W.; CLARK. R.A. Image segmentation in digital mammography: comparison of local thresholding and region growing algorithms. Computerized Medical Imaging and Graphics, v. 16(5), p. 323-331, 1992.

\section{[KILDAY-93]}

KILDAY, J.; PALMIERI, F.; FOX, M.D. Classifying mammographic lesions using computerized image analysis. IEEE TMI, v. 12(4), p. 664-669, 1993.

\section{[LAINE-95]}

LAINE, A.; FAN, J.; YANG, W. Wavelets for contrast enhancement of digital mammography. IEEE Engineering in Medicine and Biology, v. 14(5), p. 536-550, 1995.

[LE GAL-84]

LE GAL, M.; CHAVANNE, G.; PELlIER, D. Valeur diagnostique des microcalcifications groupées découvertes par mammographies. BULL Cancer, v. 71, p. 57-64, 1984.

\section{[LEFEBVRE-94]}

LEFEBVRE, F.; BENALI, H.; GILLES, R.; DI PAOLA, R. A simulation model of clustered breast microcalcifications. Medical Physics, v. 21(12), p. 1865-1874, 1994.

[LOW-91]

LOW, A. Introductory Computer Vision and Image Processing. McGraw-Hill Bood Company, London, 1991.

[MARQUES-90]

MARQUES, P.M.A. Desenvolvimento de um sistema de radiografia digital. São Carlos, EESC/USP, 1990. Tese (doutoramento). 
[MORROW-92]

MORROW, W.M.; PARANJAPE, R.B.; RANGAYYAN, R.M.; DESAUTELS, J.E.L.

Region-based contrast enhancement of mammograms. IEEE Transactions on Medical Imaging , v. 11(3), p. 392-405, 1992.

[NISHIKAWA-87]

NISHIKAWA, R.M.; MAWDSLEY, G.E.; FENSTER, A.; YAFFE, M.J. Scannedprojection digital mammography. Medical Physics, v. 14(5), p. 717-727-, 1987.

[NISHIKAWA-92]

NISHIKAWA, R.M.; JIANG, Y.; GIGER, M.L.; DOI, K.; VYBORNY, C.J.; SCHMIDT, R.A. Computer-aided detection of clustered microcalcifications. Proceedings of IEEE International Conference on Systems, Man and Cybernetics (Chicago),p. 1375-1378, 1992.

[NISHIKAWA-93a]

NISHIKAWA, R.M.; GIGER, M.L.; DOI, K.; VYBORNY, C.J.; SCHMIDT, R.A. Computer-aided detection and diagnosis of masses and clustered microcalcifications from digital mammograms. State of the Art in Digital Mammographic Image Analysis World Scientific Publishing Co. , 1993.

[NISHIKAWA-93b]

NISHIKAWA, R.M.; GIGER, M.L.; DOI, K.; VYBORNY, C.J.; SCHMIDT, R.A. Computer-aided detection of clustered microcalfications: an improved method for grouping detected signals. Medical Physics, v. 20(6), p. 1661-1666, 1993.

[NISHIKAWA-94]

NISHIKAWA,. R.M.; GIGER, M.L.; DOI, K.; METZ, C.E.; YIN, F-F.; VYBORNY, C.L.; SCHMIDT, R.A. Effect of case selection on the performance of computeraided detection schemes. Medical Physics, v. 21(2), p. 265-269, 1994.

[OLSON-88]

OLSON, S.L.; FAM, B.W.; WINTER, P.F.; SCHOLZ, F.J.; LEE, A.K.; GORDON, S.E. Breast calcifications: analysis of imaging properties. Radiology, v. 169(2), p. 329-332, 1988.

[PEREIRA-95]

PEREIRA, A.S. Processamento de Imagens Médicas utilizando a transformada de Hough. São Carlos, EESC/USP, 1995. Tese (doutoramento).

\section{[PLEWES-95]}

PLEWES, D.B.; SABOL, J.M.; SOUTAR, I.; CHEVRIER, A.; SHUMAK, R. Role of equalisation mammography of dense breasts. Medical \& Biological Engineering \& Computing, v. 33, p. 167-173, 1995. 
[QIAN-94]

QIAN, W.; CLARKE, L.P.; KALLERGI, M.; CLARK, R. A. Tree-structered nonlinear filters in digital mamography. IEEE Transactions on Medical Imaging, v. 13(1), p. 25-36, 1994.

[QIAN-95]

QIAN, W,; CLARKE, L.P.; ZHENG, B.; KALLERGI, M.; CLARK, R. Computer assisted diagnosis for digital mammography. IEEE Engineering in Medicine and Biology, v. 14(5), p. 561-569, 1995.

[RANGAYYAN-96]

RANGAYYAN, R.M. Digital image processing techniques for computer-aided diagnosis of breast cancer. Anais do III Fórum Nacional de Ciência e Tecnologia em Saúde, v. 2, p. 831-843, 1996.

[RICHARDSON-95]

RICHARDSON JR.; W. B. Applying wavelets to mammograms. IEEE Engineering in Medicine and Biology, v. 14(5), p. 551-560, 1995.

\section{[SABOL-93]}

SABOL, J.M.; SOUTAR, I.C.; PLEWES, D.B. Mammographic scanning equalization radiography. Medical Physics, v. 20(5), p. 1505-1515, 1993.

\section{[SAIPETCH-95]}

SAIPETCH, P.; HO, B.K.T.; PANWAR, R.; MA, M.; WEI, J. Applying wavelet transforms with arithmetic coding to radiological image compression. IEEE Engineering in Medicine and Biology, v. 14(5), p. 587-593, 1995.

[SCAFF-79]

SCAFF, L.A.M. Bases Físicas da Radiologia. Diagnóstico e terapia. Sarvier S/A Editora de Livros Médicos, São Paulo, 1979.

[SCHIABEL-94]

SCHIABEL, H.; VENTURA, A.; FRÈRE, A.F. Formal study of lateral magnification and its effect on mammographic image sharpness. Medical Physics, v. 21(2), p. 271-276, 1994.

[SHEN-93]

SHEN, L.; RANGAYYAN, R.M.; DESAUTELS, J.E.L. Detection and classification of mammographic calcifications. International Journal of Pattern Recognition and Artificial Intelligence, v. 7(6), p. 1403-1416, 1993. 
[SHEN-94]

SHEN, L.; RANGAYYAN, R.M.; DESAUTELS , J.E. L. Application of shape analysis to mammographic calcifications. IEEE Transactions on Medical Imaging, v. 13(2), p. 263-274. 1994.

[SICKLES-82]

SICKLES, E.A. Mammographic detectability of breast microcalcifications. Am. J. Radiol. v. 139, p. 913-918, 1982.

[SICKLES-86]

SICKLES, E. A. Breast calcifications: mammographic evaluation. Radiology, v. 160, p. 289-293, 1986.

[VILLELA-96]

VILLELA, R.L. Estudo comparativo das técnicas de segmentação de microcalcificações em imagens mamográficas. Anais do III Fórum Nacional de Ciência e Tecnologia em Saúde, v. 2, p. 575-576, 1996.

[WEE-75]

WEE, W.G.; MOSKOWITZ, M.; CHANG, N.-C.; TING, Y.-C.; PEMMERAJU S. Evaluation of mammographic calcifications using a computer program. Radiology, v. 116, p. $717-720,1975$.

[WEI-95]

WEI, D.; CHAN, H-P.; HELVIE, M.A.; SAHINER, B.; PETRICK, N.; ADLER, D.D.; GOODSITT, M.M. Classification of mass and normal breast tissue on digital mammograms: multiresolution texture analysis. Medical Physics, v. 22(9), p.1501$1513,1995$.

[WILKS-87]

WILKS, R.J. Principles of Radiological Physics. New York, Churchill Livingstone, 1987.

[WINSBERG-67]

WINSBERG, F.; ELKIN, M.; MACY JR.; J.; BORDAZ, V.; WEYMOUTH, W. Detection of radiographic abnormalities in mammograms by means of optical scanning and computer analysis. Radiology, v. 89, p. 211-215, 1967.

[XIONG-93]

XIONG, Y.; LAM, C.F.; FREY, G.D.; CROLEY, M.R. Contrast enhancement of mammogram by image processing. SPIE Image Processing, v. 1898, p. 852-858, 1993. 
[YABASHI-89]

YABASHI, S.; HATA, M.; KUBO, K.; ISHIKAWA, T. Extraction and Computational estimation of malignant microcalcification on mammography. Systems and Computers in Japan, v. 20(12), p. 67-75, 1989.

[YANG-95]

YANG, Z.; KALLERGI, M.; DEVORE, R.A.L LUCIER, B.J.; QIAN, W.; CLARK, R.A.; CLARKE, L.P. Effect of wavelet bases on compressing digital mammograms. IEEE Engineering in Medicine and Biology, v. 14(5), p. 570-577, 1995. 